Portland State University

PDXScholar

\title{
Classroom Engagement as a Proximal Lever for Student Success in Higher Education: What a Self- Determination Framework within a Multi-Level Developmental System Tells Us
}

Una Ji Chi

Portland State University

Follow this and additional works at: https://pdxscholar.library.pdx.edu/open_access_etds

Part of the Higher Education Commons

Let us know how access to this document benefits you.

Recommended Citation

Chi, Una Ji, "Classroom Engagement as a Proximal Lever for Student Success in Higher Education: What a Self-Determination Framework within a Multi-Level Developmental System Tells Us" (2014). Dissertations and Theses. Paper 1666.

https://doi.org/10.15760/etd.1665

This Dissertation is brought to you for free and open access. It has been accepted for inclusion in Dissertations and Theses by an authorized administrator of PDXScholar. Please contact us if we can make this document more accessible: pdxscholar@pdx.edu. 
Classroom Engagement as a Proximal Lever for Student Success in Higher Education: What a Self-Determination Framework within a Multi-Level Developmental System Tells Us

by

Una J. Chi

A dissertation submitted in partial fulfillment of the requirements for the degree of

Doctor of Philsophy

in

Applied Psychology

Dissertation Committee: Ellen A. Skinner, Chair Thomas A. Kindermann

Yves Labissiere Joel Steele

Portland State University 2014 
(C) 2013 Una J. Chi 
College success and student engagement / i

\begin{abstract}
This study examined the role of course engagement in college student success, especially for students who have multiple life commitments and few social supports. Building on previous measurement work and based in self-determination theory, the study was organized in five steps. Relying on information provided by 860 undergraduates from 12 upper and lower division Psychology classes, the first step was to improve the measurement of course engagement, by mapping the increased complexity found in self-reports of college students (by incorporating items capturing engagement in "out-of-classroom" activities and general orientation, to standard items tapping classroom engaged and disaffected behavior and emotion). 12 items were selected to create a brief assessment covering the conceptual scope of this multidimensional construct; its performance was compared to the full scale and found to be nearly identical.

Second, the assessment was validated by examining the functioning of course engagement within the classroom model: As predicted, engagement was linked to proposed contextual and personal antecedents as well as course performance, and fully or partially mediated the effects of both context and self-perceptions on actual class grades; findings also indicated the importance of including a marker of perceived course difficulty. Third, the university level model was examined, which postulated key predictors of students' overall academic performance and persistence toward graduation. Unexpectedly, academic identity was found to be the primary driver of persistence and the sole predictor of GPA; moreover, it mediated the effects of learning experiences and course engagement on both outcomes.
\end{abstract}


College success and student engagement / ii

The fourth and most important step was to integrate the classroom and university models through course engagement, to examine whether students' daily engagement predicted their overall performance and persistence at the university level. As expected, course engagement indeed showed a significant indirect effect (through academic identity) on both success outcomes, and these effects were maintained, even when controlling for the effects of university supports. Finally, student circumstances were added to the integrated model, specifically focusing on whether course engagement buffered cumulative non-academic demands on performance and persistence. Although unexpected, most interesting was the marginal interaction revealing that students whose lives were higher in non-academic demands showed the highest levels of persistence when their course engagement was high (and were the least likely to return next term when their engagement was low). Future measurement work and longitudinal studies are suggested to examine how course engagement cumulatively shapes academic identity, especially for students with differentiated profiles of non-academic demands and supports. Implications of findings are discussed for improving student engagement and success, and for using the brief assessment of course engagement as a tool for instructor professional development, and as part of threshold scores that serve as early warning signs for drop-out and trigger timely and targeted interventions. 
College success and student engagement / iii

\section{Dedication}

Grow that beard Daddy! ๑ 
College success and student engagement / iv

\section{Acknowledgements}

This journey was made possible through the support, encouragement, challenges and wisdom of many wonderful people who chose to remain part of my life. Foremost, my patient and flexible advisors - Dr. Ellen Skinner and Dr. Thomas Kindermann whose dialectics perfectly balance each other out in many areas, creating an environment full of autonomy support, warmth, and structure. My respect and gratitude are boundless. To my committee members - Dr. Yves Labissiere and Dr. Joel Steele - you are both amazing people, I am so thankful for the opportunity to learn from such interesting and intelligent experts, and am honored that you accepted the responsibility of evaluating my work and ideas.

Without my non-academic social support, no matter that quality and quantity of academic support, I would not be here to write this. Love, like trust, only grows with the giving, and is inexhaustible, yet without pain and sorry, they could not exist. I love you all. To my partners in the academic journey, cheers and 'onward and upward!' - Sarah Hoague, Jennifer Pitzer, Cynthia Taylor, and Hyuny Clark-Shim - oh what we will accomplish. To my strength and inspiration, you guys, there are no words - Vickie Chung (Wendlick), Chen Huang, Joseph Martorella, Ganchimeg Yadam, and, forever a Moose (from a Flea), John Bruse. For those new in my life, but no less loved and valued, our journey is just beginning - Damaris Garcia, Paul Wendlick, Vanessa and April. 


\section{Table of Contents}

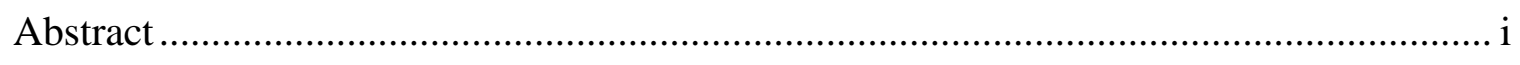

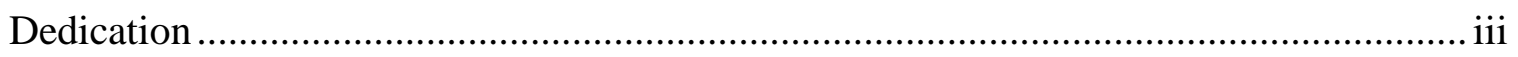

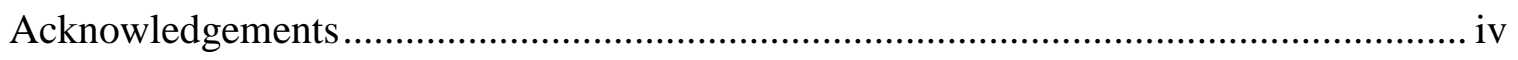

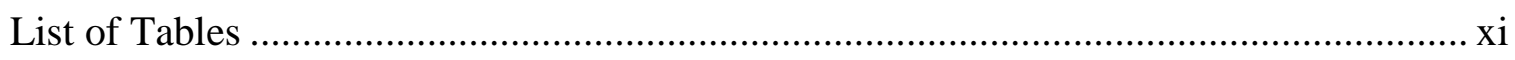

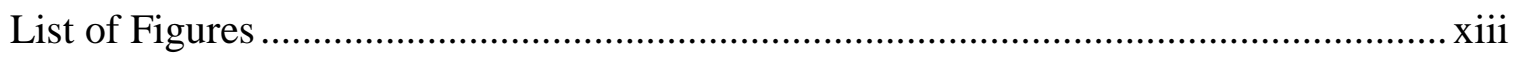

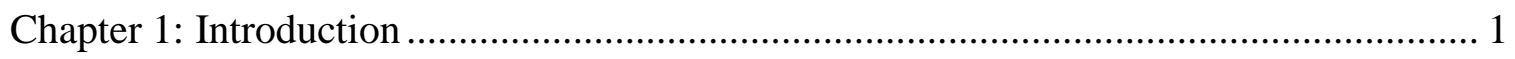

Chapter 2: Student Success at the University (Macro) and Classroom (Micro) Level..... 10

Self-determination Theory and the Self-System Model of Motivational

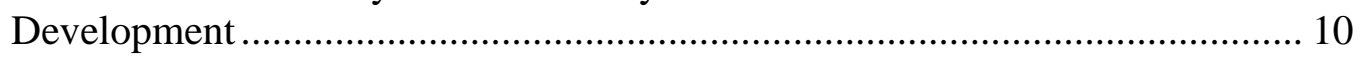

Macro-Model of Student Success at the University Level ................................... 13

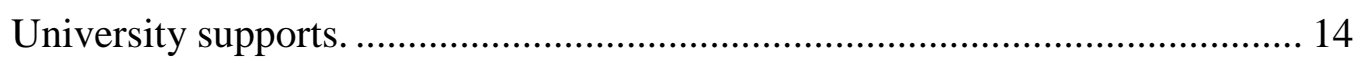

Academic identity and university learning experiences. .............................. 15

Macro-model processes. .................................................................... 17

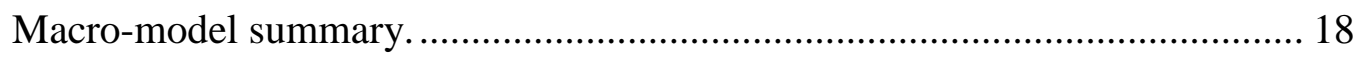

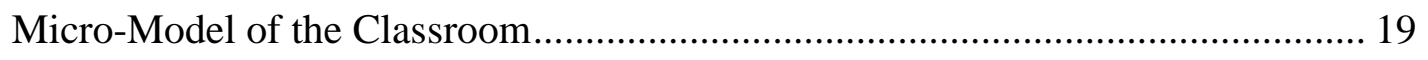

Engagement in Elementary and Secondary Education .................................... 21

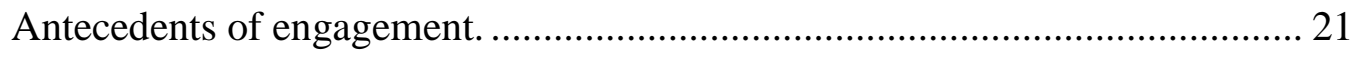

Buffering effect and development of engagement.................................... 24

Developmental pathways of engagement. ................................................. 24

Summary of engagement in elementary and secondary education.................. 25

Engagement in Post-Secondary Education .................................................... 26

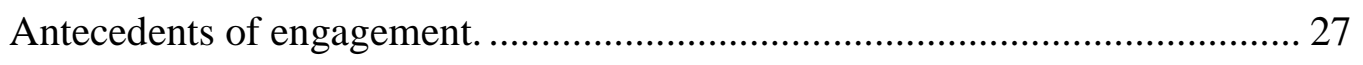

Buffering effects and development of engagement. .................................. 28 
College success and student engagement / vi

Summary of engagement in post-secondary education. .............................. 30

Summary of Micro-model................................................................... 31

Chapter 3: Conceptualization and Measurement of Engagement as a Predictor and a

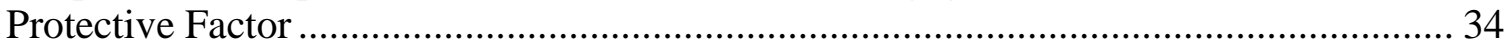

Conceptualization and Measurement of Engagement......................................... 34

Measurement of College Course Engagement.................................................. 36

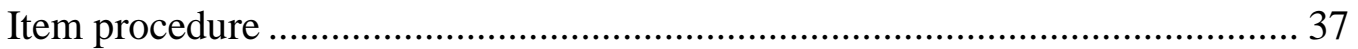

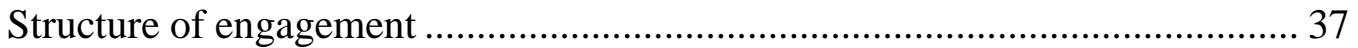

Links to academic performance ............................................................. 39

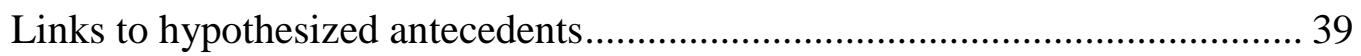

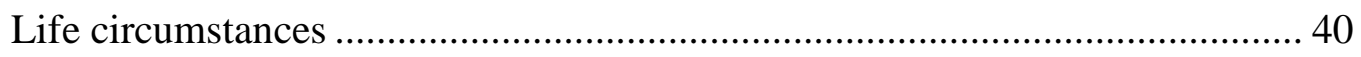

Summary of course engagement measurement........................................ 41

The Integrated Model: Course Engagement and the Macro-Model ...................... 42

Summary of the integrated model................................................................. 44

Course Engagement and Student Circumstances in the Integrated Model ............. 45

Global social support for academics. .................................................. 47

Demands: Student commitments requiring internal \& external resources. ............ 48

Summary of student circumstances. ........................................................ 49

Summary of course engagement as predictor and protective factor. ............... 50

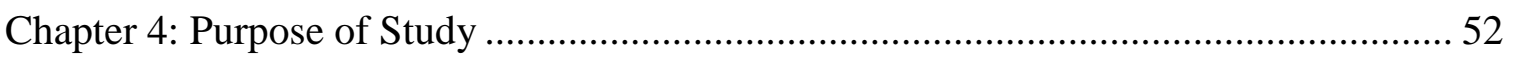

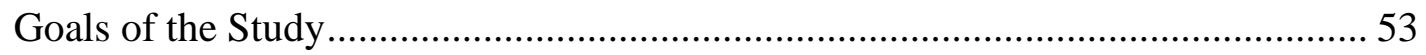

1. Improved measurement of college course engagement. ............................. 54

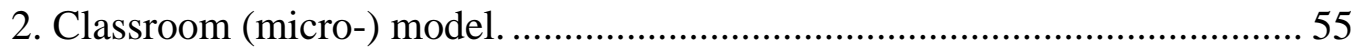

3. University (macro-) model............................................................. 55 
College success and student engagement / vii

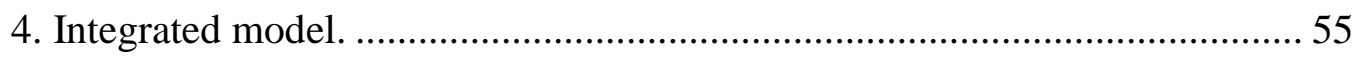

5. Student circumstances in the integrated model, demands highlight ............. 56

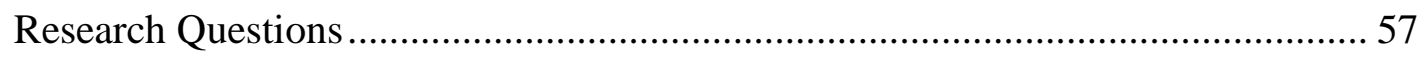

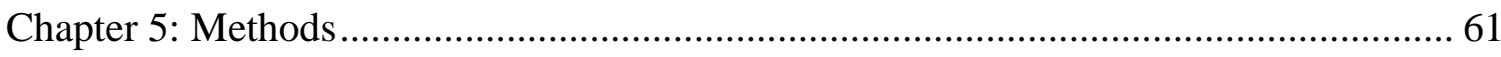

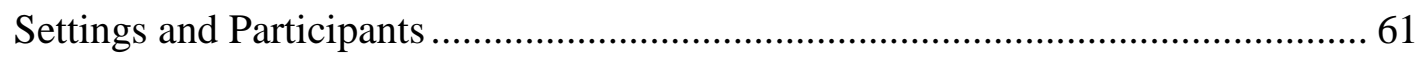

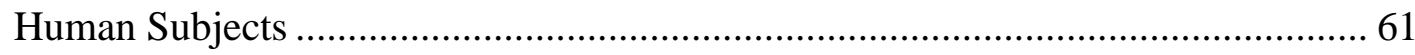

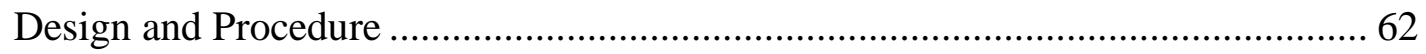

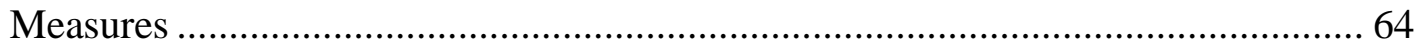

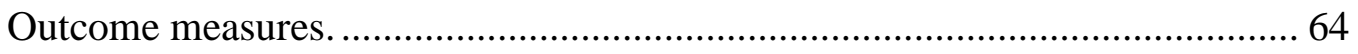

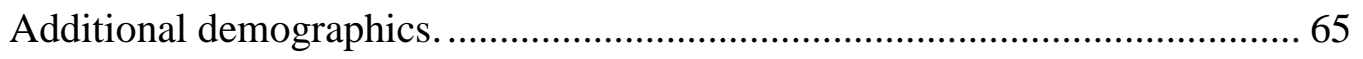

Classroom model measures...................................................................... 65

University model measures............................................................. 70

Student circumstance measures. .......................................................... 73

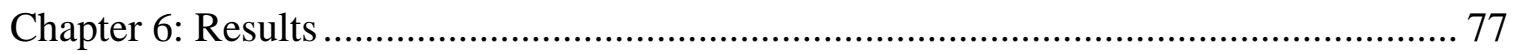

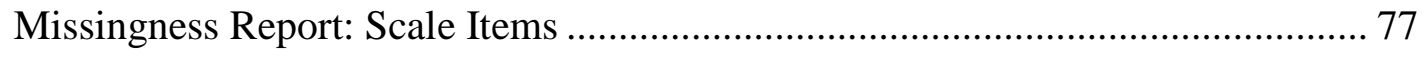

Missingness Report: Demographic and Categorical Items ................................. 78

Non-Engagement Scale Psychometrics ....................................................... 80

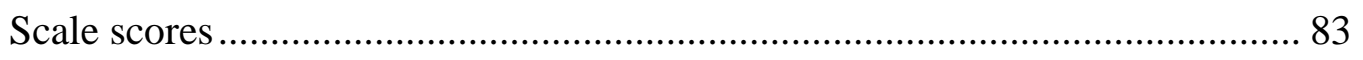

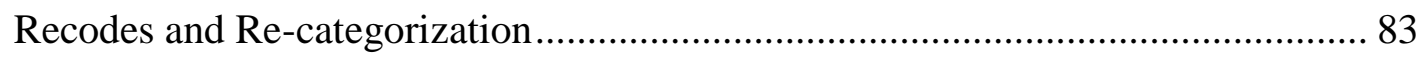

Grade re-categorization and imputation................................................. 83

Demands re-code and re-categorization................................................. 84

RQ1: Improved Measurement of Course Engagement....................................... 90

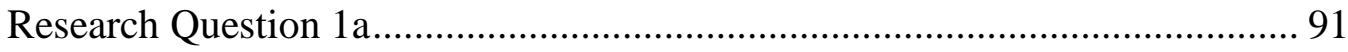

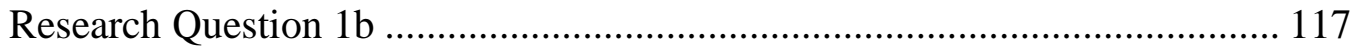


College success and student engagement / viii

Research Question 1c........................................................................ 119

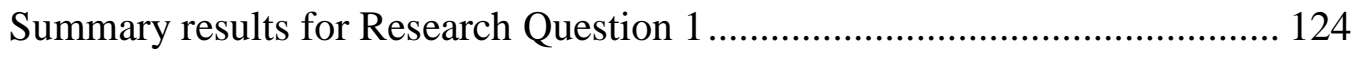

RQ2: Classroom (micro) model.................................................................... 126

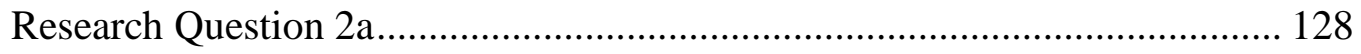

Research Question 2b ................................................................... 130

Research Question 2c.................................................................. 131

Summary results for Research Question 2 ............................................. 133

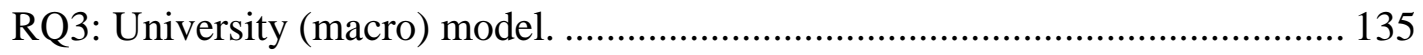

Research Question 3a...................................................................... 136

Research Question 3b .................................................................... 137

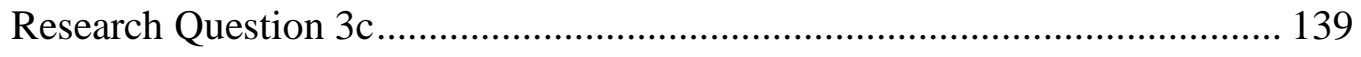

Summary results for Research Question 3 ............................................. 141

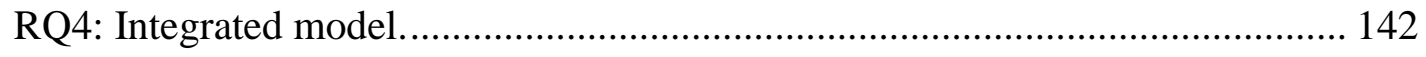

Research Question 4a...................................................................... 143

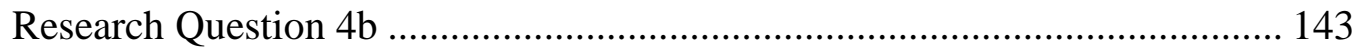

Research Question 4c ................................................................... 145

Research Question 4d ................................................................... 147

Summary results for Research Question 4 ............................................ 149

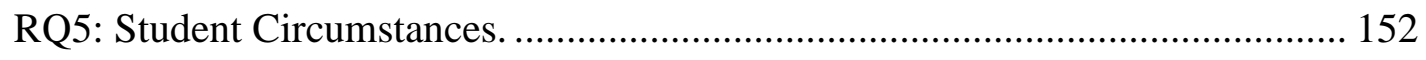

Research Question 5a................................................................ 153

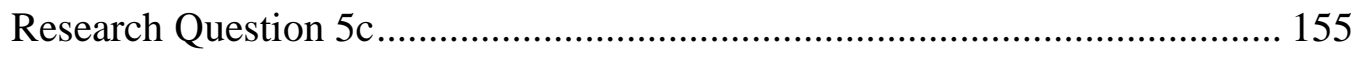

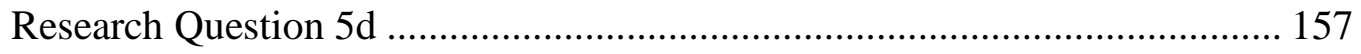

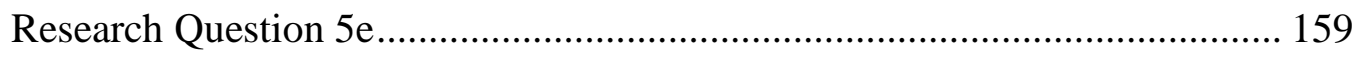

Summary results for Research Question 5 ............................................ 163 


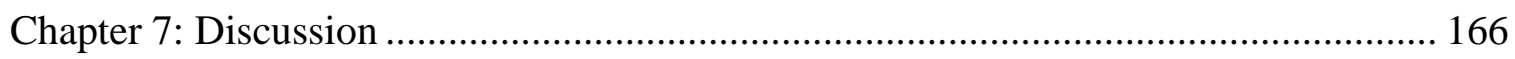

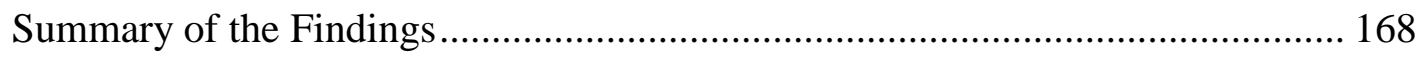

The students and the constructs. ............................................................ 168

Research Question 2: Micro- (Classroom) model. .................................... 171

Research Question 3: Macro- (University) model..................................... 174

Research Question 4: Integrated model. ............................................... 177

Research Question 5: Circumstances and Course Engagement in the Integrated model........................................................................................ 180

Strengths and Limitations of the Current Study ............................................. 184

Measurement....................................................................................... 185

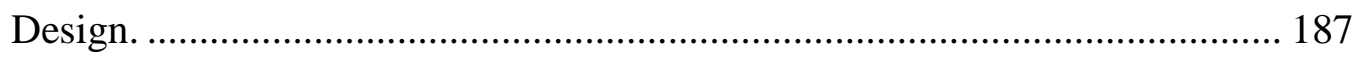

Micro-model: Examining the functioning of engagement at the classroom level. 190

Macro-model of student success at the university level............................. 191

Integrated model and circumstances in the integrated model....................... 192

Implications and Future Directions ......................................................... 194

Course engagement and the classroom.................................................... 196

Complexity of course engagement........................................................ 196

The course engagement measure. ............................................................ 197

Further examination of functioning: Direct effects in the models................. 199

Longitudinal study of classroom model.................................................... 202

The role of class difficulty and course engagement................................... 203

University level processes and success................................................. 204

Integration and circumstances process model........................................... 205

Course engagement in the integrated model .............................................. 207 
College success and student engagement / $\mathrm{x}$

The surprising strength of academic identity in predicting overall student success and channeling the effects of course engagement........................... 207

Role of student circumstances. ................................................................. 210

Fuller model application - reciprocity and instructors. .................................. 215

Instructor course engagement. ....................................................... 216

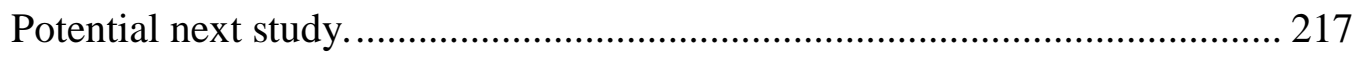

Real World Application. ........................................................................... 220

Uses of course engagement to address student circumstances for universities

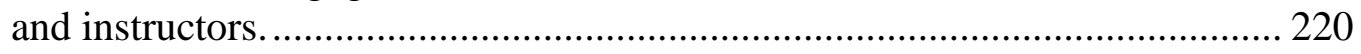

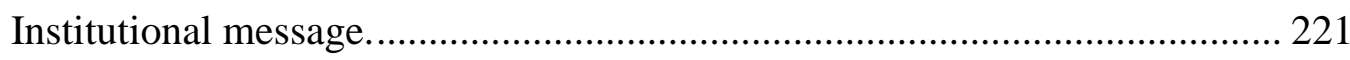

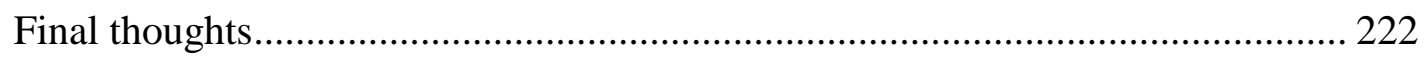

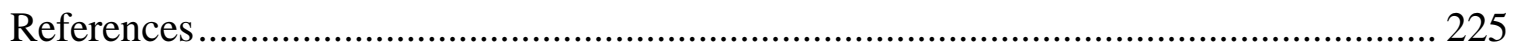

Appendix A. IRB submission and approval ...................................................... 249

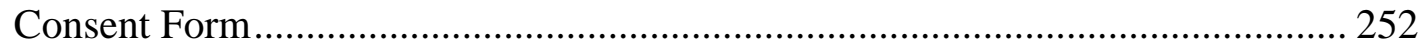

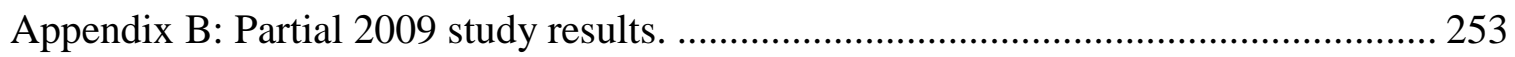

Table A.1. Descriptive and model fit statistics for Final Thesis (Chi, 2009) scales

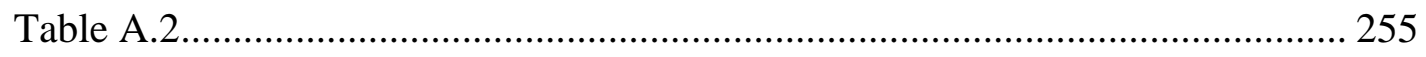

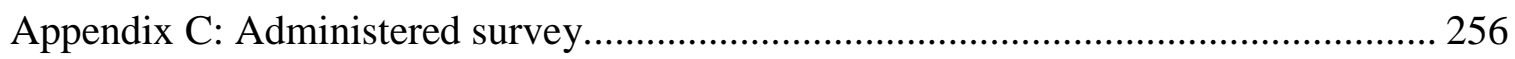

Appendix D. All items, all measures, by model/construct codebook.......................... 262

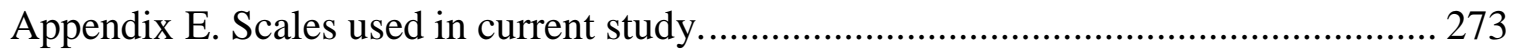

Summary of measures/constructs by model. ............................................. 273 


\section{List of Tables}

Table 1. Non Engagement Scale Statistics ……………………………………..... 81

Table 2. Correlations of GPA, expected course grade, and actual grade......................... 84

Table 3. Response frequencies for Non-academic circumstances ................................... 85

Table 4. Structural and Psychometric analyses for the four, single-factor scales - all items.

Table 5. Psychometrics for the four dimensions - 36 items (reduced full scale)........... 100

Table 6. (a-g) Bi-polar model fit comparisons,(h) four-factor model intercorrelations. 110

Table 7. Four-factor problem item covariances........................................................ 116

Table 8. Psychometrics for Full Engagement, Context and Self-perception scales. ...... 118

Table 9. Relations between the full course engagement measure and the classroom constructs.

Table 10. 12-item Course Engagement Scale ................................................................ 121

Table 11. Comparison of relations between the reduced course engagement measure and the full 36-item measure with the classroom constructs.

Table 12. The four hierarchical structured dimensions: Comparing relations between the reduced course engagement measure (12-items) and the full measure (36items) with

Table 13. Context and Self coefficients on Course Engagement.................................... 129

Table 14. Comparison of relations between the classroom constructs........................... 129

Table 15. Course engagement coefficients on actual grade........................................... 131

Table 16. Relations of class constructs to outcome and confound. ............................... 132

Table 17. Mediation of Context \& Self variables on Actual grades by Course engagement, controlling for class difficulty..................................................... 133

Table 18. Descriptive and psychometric statistics for University model constructs. ..... 136

Table 19. University support and academic identity relations to University Learning Experiences 
College success and student engagement / xii

Table 20. Comparison of relations between the University constructs. 138

Table 21. University learning experiences and academic identity as predictors of Persistence and Performance. 138

Table 22. Mediation of University support and academic identity on Persistence and Performance by University Learning Experiences. 140

Table 23. Correlations between course engagement and the macro model constructs... 144

Table 24. Mediation of Course Engagement effects on Persistence and GPA by academic identity and university learning experiences. 146

Table 25. Mediation of Course Engagement effects on Persistence and GPA by academic identity and university learning experiences, controlling for university supports

Table 26. Response frequencies for Non-academic circumstances. 154

Table 27. Correlations between student success outcomes and student non-academic circumstances.

Table 28. Mediation of Global Social Support for Academics effects on Persistence and GPA by Course Engagement.

Table 29. Mediation of Global social supports for academics effects on Persistence by course engagement, controlling for university supports 158

Table 30. Moderation of Cumulative Demand effects on Persistence and GPA by Course both cumulative demands and for course engagement on persistence. At the average Engagement (grand mean centered variables).

Table 31. Interactions of course engagement and cumulative demand on intentions to persist. 
College success and student engagement / xiii

\section{List of Figures}

Figure 1. Theory of universal human needs (self-determination theory; SDT) in a dynamic, reciprocal process model (self-system model of motivational development; SSMMD).

Figure 2. University (Macro) model: Distal model of student cumulative experience. ... 13

Figure 3. Classroom (Micro) model: Proximal model of student experiences.................. 20

Figure 4. Structural relations among the four components of Engagement. ..................... 38

Figure 5. Integrated model: Course engagement over time and its contribution to performance and persistence...................................................................... 43

Figure 6. Circumstances in the Integrated model. .......................................................... 46

Figure 7. Moderation of relationship between cumulative demands and persistence by course engagement.

Figure 8. Structure and internal relations of 36-item course engagement. 170

Figure 9. Course engagement as mediator of classroom constructs, controlling for class difficulty

Figure 10. University learning experience as mediator of (A) university support and (B) academic identity effects on persistence (with relations of university constructs.

Figure 11. Relations of course engagement to the macro model constructs, and academic identities full mediation of course engagements direct effect on GPA. ....... 177

Figure 12. Direct and indirect effects of course engagement on persistence mediated by (A) university learning experiences and (B) academic identity, when controlling for university support.

Figure 13. Relations of global social support for academics and cumulative demand to the macro constructs of university support and GPA, and the micro construct of course engagement, along with partial mediation by course engagement of global social support for academics effect on GPA.

Figure 14. Course engagement as mediator of global social support for academics on persistence, controlling for university supports (indirect effect is significant at $.01^{*}$ without the control in the model) 
College success and student engagement / xiv

Figure 15. Full systems model of the university and classroom process of student success based on the theory of universal human needs (self-determination theory; SDT) and dynamic, reciprocal process of motivation (self-system model of motivational development; SSMMD), visibly manifested by engagement. 1 through 4 indicates pathways of interest............................................. 218 
College success and student engagement / 1

\section{Chapter 1: Introduction}

Drop-out among college students is a growing national concern (ACT, 2010; Aud \& Hannes, 2011). At the individual level, there is generally little argument about the benefits of a college degree. The more education an individual has, the higher his or her economic earning potential. These two variables - education level and income - also act as parental/familial protective factors against undesirable developmental trajectories for subsequent generations of infants, children, and adolescents, as shown in numerous areas of research. Equally important as outcomes of education for the individual are those psycho-social aspects that also feed into income earning abilities, such as self-esteem, responsibility, and cognitive strategies (e.g., Kapitanoff, 2009; Maeda, Thoma, \& Bebeau, 2009). Society also gains from the continued education of its citizens. An educated population makes more informed decisions and greater contributions to the running and maintenance of human society through critical thinking, innovation, and learned skills (Livingston, 2008; Symonds et al., 2011; Task Force on Latina/o Student Success, 2010).

However, according to the 2011 annual Condition of Education report, the number of students who graduate from US high schools or get a GED are but a fraction of secondary students (75.5\%), even with all the supports for their success at earlier stages of the educational pipeline, from pre-kindergarten to high-school and all the transitions in between (US Dept. of Educaton, 2011). Among these graduating secondary students, only a subset (68.1\%) then apply to and attend higher education institutes (Aud, et al., 2012; Rampey, Dion, \& Donahue, 2009; Symonds et al., 2011). Out of this smaller 
College success and student engagement / 2

group, only approximately $58 \%$ attain a degree within six years, indicating a high percentage who subsequently drop out of college (Symonds et al., 2011; US Dept. Educaton, 2011; Rampey, Dion, \& Donahue, 2009). Understanding the factors that underlie student success in higher education is vital for both the welfare of individuals and the maintenance and development of our society.

Even though a college education is not the only road to success, and there are legitimate reasons an individual may decide to discontinue the student role, drop-out from higher education should be prevented when possible, and there is a growing body of research focusing on this issue. However, given today's political, economic, accountability, and social climate, the task of higher education institutions has become more complex in at least three ways. First, the composition of the student body is changing. American public universities and colleges today not only have the longstanding issues around diversity and first-generation students, but also have the added complexity of an increasing percentage of their undergraduate enrollment consisting of non-traditional students, such as women and students who both work and have families (Aud \& Hannes, The condition of education 2011 in brief (NCES 2011-034), 2011). Second, not only is the student body more complex, but the expected level and variety of student learning experiences are also more complex (e.g., community engagement, multimedia, non-academic activities; Quimby \& O'Brien, 2006; Oregon GEAR UP, 2009). Third, the political and historical contexts within which these institutions function are more complex, for example, they face increased and mandated accountability, lowered 
College success and student engagement / 3

levels of state funding, and less flexibility in resource allocation (Kanter, Khurana, \& Nohria, 2007; National Research Council, 2009).

Colleges and universities are keenly aware of the challenges involved in helping their students graduate (Fitzgerald \& Zimmerman, 2005), and provide a host of curricular initiatives, programs, and activities designed to support student success (university supports; Glogowska, Young, \& Lockyer, 2007). Such programs as advising, childcare, financial aid, non-traditional support, and cultural centers are widespread. In addition to the supports and programs offered by universities, research has identified two general factors that show links to student success for broad representations of the student body: (1) academic identity and (2) university learning experiences. Academic identity refers to how students perceive themselves around their choice to be in college, their ability to succeed there, and whether their ideas and success are important to the institution. These facets of identity have been shown to predict student learning and progress through the education system (Hausmann, Schofield, \& Woods, 2007; Torres, Susan, \& Renn, 2009). Academic identity is, in turn, related to students' perceptions of what they have gained by being at their institution, or university learning experiences. University learning experiences refer to students' perceptions about whether their academic learning and skills have been augmented by their participation at the institution (Kuh, 2004; Hausmann et al., 2007; Van Etten, Pressley, McInerney, \& Liem, 2008). Academic identity and university learning experiences are global, or university level, student perceptions about their scholarship and student role. 
College success and student engagement / 4

The same research that addresses these three areas, however, points to a fourth area - students' repeated experiences within and across classes, experiences that may shape and support identity, learning, and success. This critical factor is highly malleable, and a potential intervention lever. Students' experiences of their university are key, the core of which is their cumulative experiences in their courses: experiences of participation and learning on a regular basis. At the classroom level, a student's course grade and decision to persist in pursuing their educational goals can be shaped by these proximal, daily, repeated interactions. Central to these experiences is their engagement. Engagement in the learning process, as used here, does not refer to either community or civic engagement, or to extra-curricular or enrichment activities (Smith, Sheppard, Johnson, \& Johnson, 2005; Wolf-Wendel, Ward, \& Kinzie, 2009; Fredricks, Blumenfeld, \& Paris, 2004). Instead, it refers to behaviors and emotions related to participation in learning activities, and is seen as a manifestation of student motivation. These behaviors and emotions are shaped by interactions between the student and whatever is encountered during the overall endeavor of taking a class, be it another person (e.g., instructor, peers), the format (e.g., on campus, online), or the tasks (e.g., textbook, exam, lecture). When you are a student, by definition, you go to classes - repeated meetings of a class within a term and new classes across the terms. By having opportunities to succeed, clear structure in instruction, and supportive experiences, what goes on in a classroom can boost students' perceptions of themselves as competent, valid students who believe in the efficacy and goals of their college. These perceptions can increase the depth and 
College success and student engagement / 5

frequency of students' engagement in the learning process and in tasks needed for student success.

Classroom engagement - that is, enthusiastic constructive participation in academic activities - is a construct in educational research that has the potential to span the divide between research focusing on student circumstances and university supports, and that focusing on individual learning and development (Skinner, Marchand, \& Kindermann, 2008). Not only do levels of classroom engagement have important academic consequences (e.g., Carini, Kuh, \& Klein, 2006; Jang, Reeve, \& Deci, 2010), but this motivational state is malleable and thus open to external intervention not only at the school level but, even more deeply, at the classroom level. In research examining elementary, middle, and high school students, engagement in classes has emerged as a predictor of positive academic outcomes such as retention, performance, and completion, as a protective factor against negative academic outcomes, and as a buffer between students and their life circumstances (Janosz, Archambault, Morizot, \& Pagani, 2008). However, fewer studies have explored how academic engagement operates for college students (Martin, 2009b; Symonds et al., 2011).

Moreover, it does not seem clear that the large corpus of research about younger students should be directly applicable to college students. Prior research on classroom engagement with college students demonstrated that engagement with the daily processes of classroom-based learning may be more complex than that found with younger students (Chi, 2009). The different developmental life situations of older students may play a more pronounced role in their class engagement (Rosenbaum \& Rochford, 2008). Along 
College success and student engagement / 6

with cognitive and biological developments, older students also experience increased complexity and external demands (both material and in interpersonal relationships) in their private lives - at home, at work, in their communities, - as well as greater reliance on the self in regards to future direction (e.g., course selection, major selection), regulation (e.g., whether to attend a lecture, do the reading), encouragement, and motivation. In general, post-secondary students do not live in the same academic and social worlds as elementary and secondary students. School offers a regimented, consistent environment for children (e.g., same teachers, same classmates who are also of similar age, same amount of time spent each day at school). College, however, involves a complex self-motivated scheduling of time, various amounts of time spent in class, classmates covering a wide age range who change with each class, new instructors every few months, and complex social structures within class, within the post-secondary institution, and within the greater world of work and independent living which often accompanies attending college.

Along with these differences, there is the high diversity of roles and responsibilities in today's university student populations that are beyond just those of a student (The College Board, 2011; Livingston, 2008; US Dept. of Educaton, 2011). Returning students, working students, students with families, and students from all corners of the globe are now a common, and growing, percentage of new enrollees. Postsecondary students also differ from younger students in their level of cognitive development, stable self-perceptions (Baltes, Lindenberger, \& Staudinger, 2006), cumulative academic and life experiences, self-selection into the context, and outside 
College success and student engagement / 7

forces which place demands on time and energy or provide financial and emotional support (Wapner \& Demick, 2005). The demands an individual feels in their life is an incredibly complex and intrapersonal thing, resulting from lifelong experiences, biology, etcetera. As scientists, we strive to somehow capture and quantify what might be construed as a demand - something external and/or internal to the self that requires allocation of some limited resource. This is necessary to model and understand the processes and interactions of systems, if we want to include demands in our research. In this respect, many definitions of 'demand' are appropriate, as long as they are justified, backed up, and explained in context to the problem under research (including research into demands themselves). The literature on higher education student success has begun to include the effects that multiple commitments (such as work and family; Butler, 2007) and available supports (such as resources and social academic supports; Lee, Hamman, \& Lee, 2007) can have on success and completion of college. All these factors interact (Bronfenbrenner \& Morris, 1998), potentially creating conflicting demands, and could affect the way engagement is structured for post-secondary students, how it functions, or which areas are most in need of support (Baltes, 1987).

Research on classroom engagement, the marker of the quality of classroom experiences (including teaching, peers, and the nature of the academic work) can seem far removed from the university's concerns with higher-order constructs such as university support and university learning experiences, especially when designing an intervention tool aimed at improving the higher education system as it is today. The contention here is that classroom engagement, separated from its antecedents and 
College success and student engagement / 8

outcomes, can be considered an accessible and malleable intervention lever for improving student development and overall success. Engagement potentially crosses the individual and university level realms of student perceptions (e.g., Weaver \& Qi, 2005; Schaufeli, Martinez, Pinto, Salanova, \& Bakker, 2002), which might allow small adjustments to the classroom context (e.g., teachers, instruction, etc.) to affect students' long term overall development and success.

Except for the increased complexity of actual engagement, findings from studies which do look at the aspects of engagement that shape academic achievement for postsecondary students seem generally consistent with results found at the earlier levels of education - despite the differences in life situations between elementary/secondary students and post-secondary students (Carini et al., 2006; Glanville \& Wildhagen, 2007; Symonds et al., 2011). Engagement may even act as a buffer for those non-academic demands that tend to derail student progress. If a measure of classroom engagement could be developed that is conceptually equivalent to that used with primary and secondary students but developmentally appropriate for college students, institutions of higher education would have one more tool to counteract forces that prevent student success, including those circumstances outside the institution's realm of influence.

In order to examine the role(s) of classroom engagement across levels of the higher education system, and make clear the antecedents and processes which foster this engagement, this study relied on a theoretical framework based on self-determination theory (SDT). Applying SDT to the classroom context, a model was used which separates the research on academic engagement into categories of antecedents to, outcomes of, and 
College success and student engagement / 9 actual classroom engagement (Connell \& Wellborn, 1991; Kindermann, 2007; Niemiec \& Ryan, 2009; Ryan \& Connell, 1989; Skinner \& Belmont, 1993; Skinner et al., 2008; Skinner, Wellborn, \& Connell, 1990; Wellborn \& Connell, 1991; Wang \& Eccles, 2011), to illuminate the process of student success at the micro-level. While the picture available from cross-sectional data is a static one, SDT itself posits continual development of individuals that both affects and is affected by who and what they interact with (Connell, 1990; Connell \& Wellborn, 1991; Deci \& Ryan, 2000). By applying SDT at the macro level, to the development of academic identity and university learning experiences, links between class experiences of engagement, the university system, and overall student success were examined. The goal of the study was to complete the construction of a measure of engagement for college students and to examine its role in student success both in the classroom and at the university more generally, while accounting for general levels of non-academic student circumstances. Accountability to many stakeholders has institutions looking for ways to show others why and how they are doing their jobs. Student engagement is being tossed back and forth in conversations, mission statements, ranking systems, and initiative programs and proposals. When claims related to student engagement are made the use of this measure - a theoretically-based, psychometrically sound, face valid component - can provide hard statistical numbers to test and support such assertions. 
College success and student engagement / 10

\section{Chapter 2: Student Success at the University (Macro) and Classroom (Micro) Level}

This dissertation was motivated by interest in the role of classroom engagement in college student success, especially for students who have multiple life commitments (e.g., who are working and/or have families) and few social supports (e.g., first generation students). Universities with high proportions of such students have initiatives focused on student success and retention, typically defined in terms of academic performance and persistence until graduation (e.g., Task Force, 2010). In service of these initiatives, universities offer a range of student supports, such as advising, tutoring, centers for returning women or Latino students, and so on. Without disputing the importance of such supports, the central argument of this dissertation is that the core element that allows students to succeed in college is the quality of their learning experiences, with a special emphasis on learning experiences organized around the classes they take.

\section{Self-determination Theory and the Self-System Model of Motivational Development}

To examine the role of proximal learning experiences in college student success, the framework of a motivational model derived from self-determination theory was applied (SDT; Deci \& Ryan, 2000; Skinner et al., 1990; Vansteenkiste, Niemiec, \& Soenens, 2010). This framework creates a living picture of student academic experience grounded in established theory and research (Skinner et al., 1990; White, 1974; ZimmerGembeck, Chipuer, Hanisch, Creed, \& McGregor, 2006). Self-determination theory postulates that there are innate psychological needs within all humans, and that our motivation to engage or to 'act' (in the sense of action theory, where action incorporates behavioral, emotional, and cognitive aspects) is based on the fulfillment of these needs 
College success and student engagement / 11

within the context of the activity (Connell, 1990; Pintrich, 2003). These needs must be supported in order for people to develop and/or maintain a healthy life. The three needs posited by SDT are (1) autonomy - the need to authentically endorse one's own actions or goals; (2) relatedness - the need to belong, be part of and accepted by others; and (3) competence - the need to experience oneself as effective in producing desired and preventing undesired outcomes (Deci \& Ryan, 2000).

The self-system model of motivational development (SSMMD; Connell, 1990; Connell \& Wellborn, 1991; Ryan \& Connell, 1989) posits that individuals perceive (consciously or not) these needs as being met (or not met) by the context and social partners of any enterprise. Individual self-system processes (SSPs) are based on the interactions between the context and the individuals' needs, and motivate engagement (thoughts, feelings, and behaviors) within that context. The result of this engagement is individual development and goal achievement. If needs are thwarted or simply not met, less positive outcomes occur. These can include removal of self from the context, lowered achievement or productivity within the context, and disaffection from the goals of the context (Assor, Kaplan, \& Roth, 2002; Katz \& Assor, 2007; Skinner et al., 1990; Vallerand, 1997; Vansteenkiste, Lens, \& Deci, 2006).

The context and the social others in the context can provide for the needs through autonomy support for individuals, structure within the context which allows for opportunities to be competent, and involvement/warmth which allows for a sense of relatedness to the context (Chirkov, 2009; Kindermann, 2011; Pelletier \& Sharp, 2009). At the same time, these provisions can be elicited from the context based on how the 
individual is perceived by those contextual social others, who have their own needs.

There is, overall, a continuous series of feedback loops (e.g., Roth, Assor, Kanat-

Maymon, \& Kaplan, 2007; Skinner et al., 2008; Trouilloud, Sarrazin, Bressoux, \& Bois, 2006). Figure 1 presents SDT in the SSMMD.

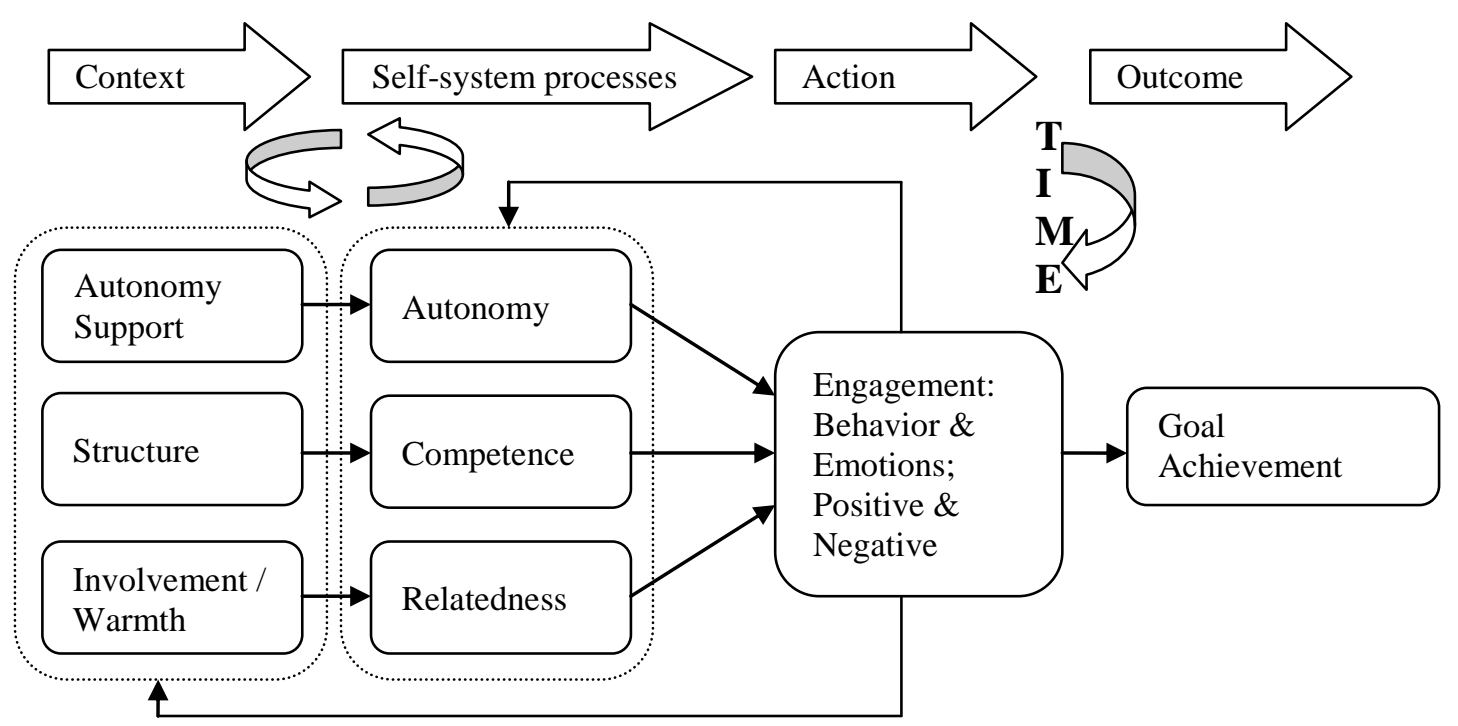

Figure 1. Theory of universal human needs (self-determination theory; SDT) in a dynamic, reciprocal process model (self-system model of motivational development; SSMMD).

Applying this model and framework to an endeavor such as education allows us to take snapshots of this continual reciprocal process at different levels in a system, examine outcomes at all levels, investigate the relations between levels, and pinpoint possible areas of effective interventions for improvement. By modeling the process of overall university success and the process of classroom success using SDT, the connection between these two levels can be clarified at a psychological level, not just through performance markers. The general assumption governing the current study was that the resource carried cumulatively upward from the classroom is the development of 
College success and student engagement / 13

student engagement in learning. In order to justify this contention, the following sections of this chapter describe (1) a model of general overall student success at the university level, referred to as the macro-model, and (2) a model of student success at the classroom level, referred to as the micro-model. Subsequent chapters depict the conceptualization and measurement of college student engagement, and the evidence of it as a predictor of student success and as a potential protective factor for students with highly demanding life circumstances and few resources.

\section{Macro-Model of Student Success at the University Level}

The macro-model used to organize the current study is presented in Figure 2. The target outcome is college student success. When colleges and universities attempt to measure student success they typically use GPA, graduation and retention rates as population-based, administratively useful quantitative indices of assessing performance.

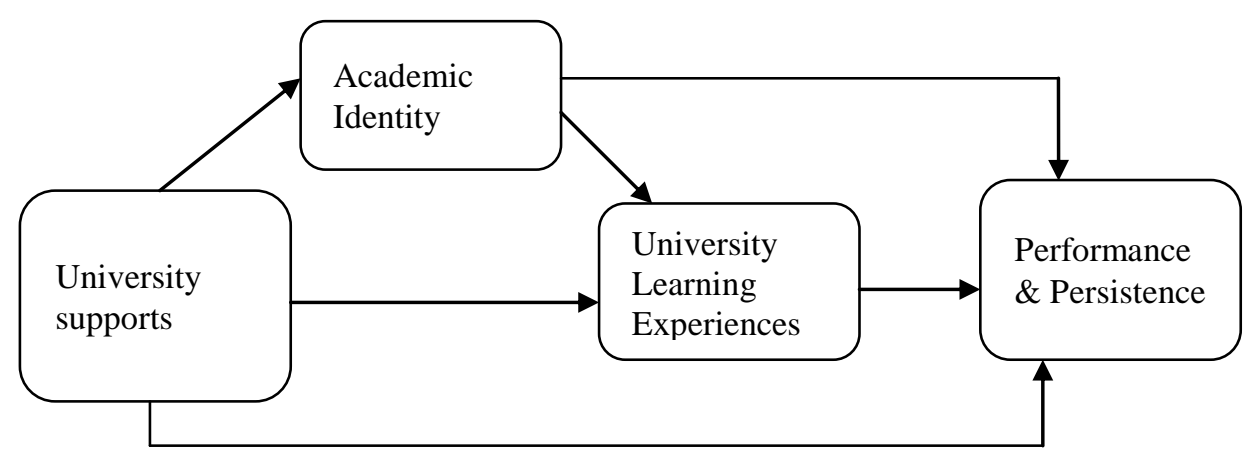

Figure 2. University (Macro) model: Distal model of student cumulative experience.

It is easy to think of student success in this way (i.e., at the demographic level). However, it is also important to keep in mind that it is actually the individual student learning that these indices should represent, and that such learning should be the true marker for the 
College success and student engagement / 14

performance of post-secondary education institutions. It is the development of critical thinking, experiences with diversity of all natures, self-knowledge, and competence in practical skills that should emerge in an individual from their experiences at an institute of higher learning, as well as a diploma and a specific career path (e.g., Laird, Shoup, \& Kuh, 2005; Fitzgerald \& Zimmerman, 2005). With that said, persistence (retention rates) and grade point averages (GPAs) were the targeted outcomes of this macro-model because they are commonly accepted markers of student success, and cumulatively, of an institute's performance (Donaldson \& Townsend, 2007; The National Center for Public Policy and Higher Education, 2008; US Dept. of Educaton, 2011).

University supports. Most higher education institutions have put supports into place to address many of the issues faced by incoming students. Four broad areas of institutional supports that have demonstrated their value in contributing to student success are (1) academic supports, such as tutoring, disability centers, writing labs, access to quality advising, financial aid, and career advising (e.g., Barlow \& Villarejo, 2004); (2) support for diversity in student experiences and interrelations, such as multi-cultural centers and events, cultural and minority programs (e.g., Task Force, 2010); (3) aids to students with multiple responsibilities, such as child-care centers and class scheduling friendly to working students (e.g., Carney-Crompton \& Tan, 2002; Sweet \& Moen, 2007); and (4) encouraging social life and development, such as recreation centers, planned outings, student health and counseling services (e.g., Fowler \& Zimitat, 2008). Together, these university supports not only assist a broad student body, but also can be instrumental in the success for targeted student groups. These supports are vital and are 
key players in any model of post-secondary student success, and are seen as supportive and direct in their influence on GPA and persistence in the model presented here.

Academic identity and university learning experiences. Two equally important factors that have been studied as predictors of student performance and persistence in college are students' development of a positive student identity and perceptions of their university learning experiences. Academic identity - how students perceives themselves in relation to the university and their student role (Jackson et al., 2011; Kasworm, 2005); and university learning experiences - perceptions of the development of knowledge, skills, and personal growth that were fostered by their institution (e.g., Lee \& Tsai, 2011) were the two other main constructs included in the macro-model.

Students' perceptions of personal 'fit' to both the idea of and experiences with the university constitute an important promotive or limiting factor to student success and persistence (Luyckx, Schwartz, Soenens, Vansteenkiste, \& Goossens, 2010). Academic identity, in line with self-determination theory, was conceptualized as student selfperceptions around being a student: (1) autonomy - personal endorsement of the contention that college is what one wants to be doing right now); (2) competence confidence that one can do what is required; and (3) relatedness - feelings of connection to the university and the sense that it matters to the university that one succeeds (Niemiec et al., 2006). Academic identity is the second construct in the model of university student success.

The internal assessment of how learning (i.e., student action) is supported by university actions and ideals (Anctil, Ishikawa, \& Scott, 2008) was the third construct of 
College success and student engagement / 16

the university model. University learning experiences were conceptualized as student self-perceptions of the extent to which their institutions have contributed to their academic success (Vignoles, Camilo, Manzi, Golledge, \& Scabini, 2006; Van Etten et al., 2008; NSSE, 2010). The positive effect of constructive student actions (such as study time, course and event attendance, and participation in academic activities) on grades is well accepted. A portion of this success is supported or fostered by university climate and actions, such as class offerings, quality of instruction, advising and mentoring, and other university context experiences. It is the student's overall perceptions of these contributions by their institution to their success that was hypothesized as being reflected in university learning experiences.

The National Survey of Student Engagement (NSSE). To illustrate the construct of student assessment of overall university contributions to their development and success, one set of items from the National Survey of Student Engagement (NSSE, 2009b) was selected for use in the current study. The NSSE is a well-researched survey of student higher education experiences, the results of which are used by students, institution administrators, parents, and governments to aid in decision making and as a marker of institution quality (NSSE, 2009; NSSE, 2011b). Prior research on the NSSE (2009b) question "To what extent has your experience at this institution contributed to your knowledge, skills, and personal development in the following areas?" has shown 1that the 14 response items map onto three areas considered central to the goals of higher education when speaking of 'learning': (1) Growth in general education, such as writing, speaking, and critical thinking; (2) growth in practical competencies, such as quantitative 
analysis, and job/work related skills; and (3) personal/social development, such as understanding others of diverse backgrounds and developing a personal code/ethics (Laird et al., 2005; NSSE, 2010). Rather than just measuring how often student actions were performed, such as writing papers or presenting in class, or how much a concept was emphasized in coursework (e.g., critical thinking), this set of questions captures student perceptions of what an institution has contributed overall to their development and academic success.

Macro-model processes. Looking at these three components of student success academic identity, university learning experiences, and university supports - a working system began to take shape, as shown in Figure 2. University supports and academic identity were considered to be contributors to student perceptions of their overall university learning experiences: Help and support from the institution is there when and if you need it; being a student has relevance, acceptance, and purpose. Overall university learning experiences were expected to cumulatively incorporate and reflect the specific experiences which supported or undermined student success in regards to these overall perceptions.

At the same time that academic identity and university supports contribute to university learning experiences, overall experiences also shape identity and the need or willingness to utilize institutional supports. A series of undesirable academic experiences or challenging circumstances may be the thing that prompts students to seek support. Positive or negative experiences may take root and be incorporated into a student's academic identity and his or her beliefs regarding the genuineness and efficacy of 
College success and student engagement / 18

institutional supports. University learning experiences, which incorporated all perceptions of post-secondary institutional academic life, was expected to add to the effects that academic identity and university supports have on student success.

As can be seen in Figure 2, academic identity, university supports and university learning experiences were expected to directly relate to overall student success. University supports are in place for this very reason - to help targeted student groups succeed. High academic identity was theorized to increase performance by promoting the investment of more time and energy in academic tasks. By understanding how to succeed as a student, feeling capable, respected, and cared for by the institution and its representatives, a student should be more likely to persist in pursuing their educational goals, even when under demanding circumstances outside the academic realm. When student success is associated with institutional effectiveness in promoting student development and learning (university learning experiences), it seems more likely that a student would continue at that institution and succeed in their educational goals.

Macro-model summary. The macro-model targets overall college success, which refers to student intentions to persist in college and academic performance (GPA, as a marker for the development of self-determined learning). Three predictors of these measures of student success are overall university learning experiences (e.g., institutionally fostered community, critical thinking, instruction and skills), academic identity (views of self in relation to academics and the institution; e.g., NSSE, 2011b; Taniguchi \& Kaufman, 2005; Jackson, Miller, Frew, \& Gilbreath, 2011), and the availabiliy and adequacy of university provided supports. According to this proposed 
College success and student engagement / 19

macro-level model, university learning experiences, academic identity and university supports directly and indirectly influence students' trajectories of university success. This picture as it stands has only one direct lever for universities to use in order to promote student success and help students in demanding life circumstances, namely university supports. Moreover, at this level measurement draws on generalized thoughts, feelings, and behaviors of students and their overall experiences rather than on concrete, lived, proximal experiences that have the potential to become integrated, ongoing, long-term, and effective targets for change. For proximal predictors of student success, we must look to the students' experiences in college classrooms.

\section{Micro-Model of the Classroom}

The micro-model of student success at the classroom level, presented in Figure 3, was organized around student achievement and engagement in their college courses. The link between class grades and educational completion is built into our school systems. Graduation is predicated on acceptable GPA which is predicated on acceptable individual class performance in the form of grades, regardless of elementary, secondary, or postsecondary educational context. A fairly straightforward equation for success appears to be: Show up, put in time and effort, graduate. However, it is clear that this is not how the real world always plays out. The myriad of internal and external states, circumstances, historical context, and their intermingling matters tremendously (Bronfenbrenner \& Morris, 1998), resulting in a vast platform of research focusing on the factors that affect student success. 
College success and student engagement / 20

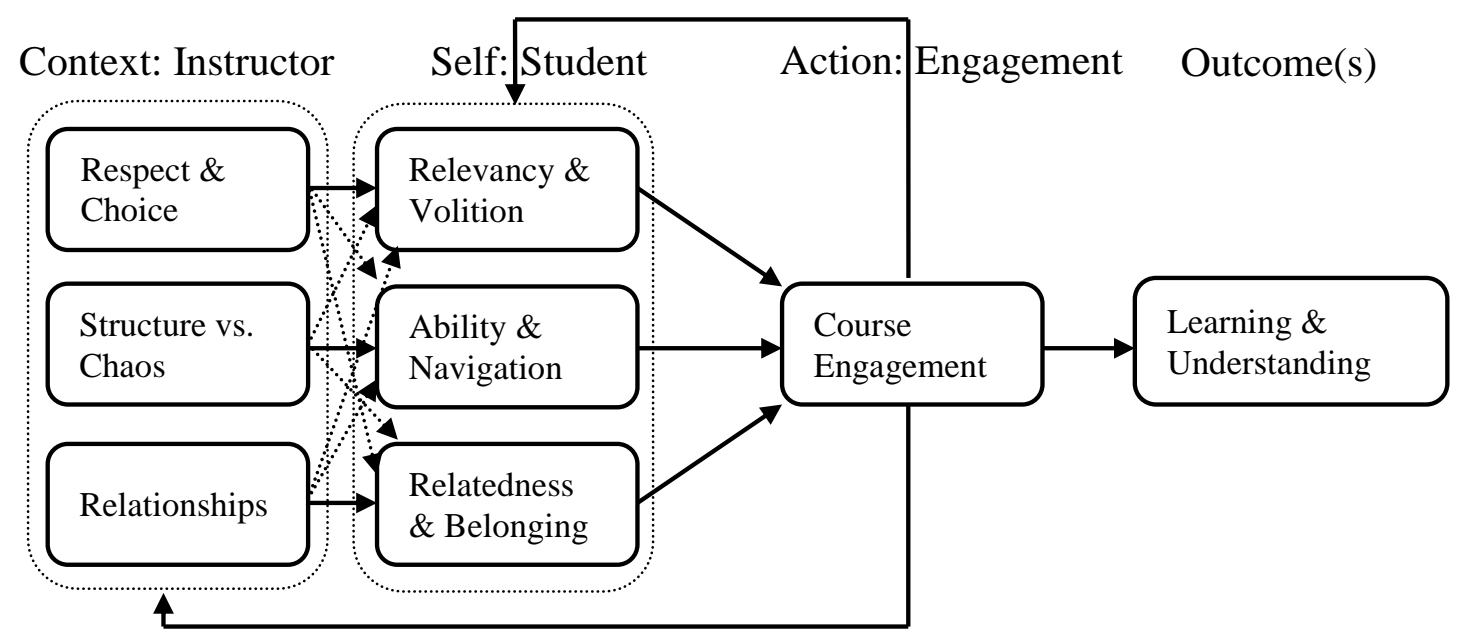

Figure 3. Classroom (Micro) model: Proximal model of student experiences. Classroom engagement in a model of self-system reciprocal processes as a predictor of academic outcomes.

Among these factors, engagement has emerged as a highly studied aspect for predicting student achievement that attempts to account for the real world of the student (Appleton, Christenson, Kim, \& Reschly, 2006; Fredricks et al., 2004; Furlong et al., 2003; Glanville \& Wildhagen, 2007; Janosz et al. 2008; Shernoff \& Schmidt, 2008;

Skinner et al., 1990). There are many definitions of engagement in school, each with its own links to student success (Jimerson, Campos, \& Greif, 2003; Robbins, Allen, Casillas, Peterson, \& Le, 2006; Wolf-Wendel et al., 2009). In the current study, engagement refers to students' enthusiastic, constructive participation in the academic work in a class. This kind of engagement has been shown over decades of research to promote student learning, grades, achievement, retention, and graduation (Fredricks et al., 2004).

Knowing the factors that contribute to success is critical but does not serve the goal of understanding how student success is achieved, and how success develops and can be supported. It is the contention here that use of the dynamic process SSMMD based 
College success and student engagement / 21

on SDT is an informative and useful way to clarify how success happens (see Figure 3). This model incorporates engagement research constructs yet distinguishes among antecedents, consequences, and actual engagement when looking at student success. In applying this model, it is important to consider the research base that provides evidence for the inclusion of the constructs as depicted. This research base is presented in the following sections, with a more detailed discussion of the construct of engagement itself in the subsequent chapter.

\section{Engagement in Elementary and Secondary Education}

Antecedents of engagement. In educational research, a variety of personal (student self-perceptions) and contextual (perceptions of teacher behavior) factors have been found to predict success and persistence in school prior to the post-secondary level. How teachers behave and are perceived affect students' beliefs about themselves. These student self-perceptions can determine how fully students engage in academics. Students' experiences with teachers and perceptions about the self, though sometimes referred to in research as part of engagement, are actually antecedents to engagement proper - which refers to what students feel and do when participating in academic tasks. Based on SDT, three kinds of self-perceptions and contextual supports are critical to engagement, namely, those organized around the needs for relatedness, competence, and autonomy.

Student relatedness and teacher involvement in the classroom. Relatedness, that is, feeling that others in school like you, that people around you care if you are okay or not, that you are relevant and belong in school, lead to greater time and energy engaging in the academic activities and with teachers and classmates (Gambone, Klem, \& Connell, 
College success and student engagement / 22 2002; Huebner, Antaramian, Hills, Lewis, \& Saha, 2011; Karcher, 2005; O'Farrell \& Morrison, 2003; Reschly, Huebner, Appleton, \& Antaramian, 2008; Wentzel, 2009). Identifying with classmates and/or with the school (relatedness) has consistently shown a positive relationship with academic performance (Burton, Lydon, D'Allesandro, and Koestner, 2006; Jennings, 2003). Moreover, feeling left out can decrease achievement (Guay, Bovin, \& Hodges, 1999; Pekrun, Elliot, \& Markus, 2009). When the teacher is perceived as emotionally supportive or involved around the student's well-being and academic success, this sense of relatedness can be increased (Tatar \& Yahav, 1999; Wentzel, 1997; Weinstein, 1989). When elementary students feel their teachers or parents are there for them and can be relied on (involvement), their school performance is higher than if they feel no support around school (Cooper \& Crosnoe, 2007; Hughes, Luo, Kwok, \& Loyd, 2008; Ryan, Stiller, \& Lynch, 1994; Woolley \& Bowen, 2007).

Student competence and teacher structure in the classroom. Not only do classmates and other context social partners influence how well the student feels they belong and are accepted (relatedness), they also exert a strong influence on a student's sense of competence around academics and being a student, which in turn affects achievement (Elliot \& Dweck, 2005; McMillan, Simonetta, \& Singh, 1994; Tapola \& Niemivirta, 2008; Wang \& Reeves, 2007). When students have a sense of control over success or failure at school, when they feel efficacious, confident, and competent, they spend more time and effort to accomplish the tasks required to succeed (Smart, Ethington, \& Umbach, 2009). Performance is enhanced when students know what is being asked of them, and know they have ability to do what is asked (Hardre \& Reeve, 
College success and student engagement / 23

2003; Murayama \& Elliot, 2009). Teachers create structure in the learning environment by being consistent, with clear contingencies, and providing explanations. Thus teachers can provide scaffolding for student competence by being flexible and supportive in structuring the class, adapting their teaching to students' learning, and by giving clear instructions and explanations around assignments (Elliot \& Dweck, 2005). This can significantly improve a student's self-competence around their class work (Skinner et al., 2008; Urdan \& Turner, 2005).

Student autonomy and teacher autonomy support in the classroom. It is not just who likes you and how good you are, it is also who you are (Valle et al., 2008). Feeling that what you are doing and learning is relevant to something about or within you increases both the time and effort students dedicate to academics (Reeve \& Jang, 2006). At some point, a choice (not necessarily conscious) is made to conform to the requirements of learning and doing in academics (McGregor \& Elliot, 2002). Authentic instruction (interesting, discussions with social others, application to real life) can boost this sense of autonomy (Fulmer \& Frijters, 2011; Reeve, Jang, Carrell, Jeon, \& Barch, 2004). When the teacher is perceived as promotive of mutual respect among peers and encourages interaction among them (autonomy support), student autonomy is fostered. Autonomy supportive teachers provide choice, allow students to follow their own interests, and provide rationales for the activities requested. Disruptive behaviors decrease, positive motivation around school increases, and higher achievement is attained (Grolnick, Farkas, Sohmer, Michaels, \& Valsiner, 2007; Ryan \& Patrick, 2001; Patrick, Ryan, \& Kaplan, 2007). 
College success and student engagement / 24

Buffering effect and development of engagement. These personal and contextual factors not only promote student success, but also can be protective against negative academic outcomes. When looking at the prevention of negative outcomes (versus the fostering of positive outcomes), academic engagement can be protective for those in potentially at-risk demographic groups (Archambault, Janosz, Morizot, \& Pagani, 2009; Brewster \& Bowen, 2004; Finn \& Rock, 1997; Glanville \& Wildhagen, 2007; Martin, 2007). All student and teacher antecedents discussed above are involved autonomy and autonomy support, competence and structure, and relatedness and involvement (e.g., Salmela-Aro, Kiuru, Leskinen, \& Nurmi, 2009). When any of these factors are bolstered, rates of delinquency, drop-out, anti-social behaviors, and other undesirable school related outcomes (e.g., teen pregnancy) decrease (Morrison, Robertson, Laurie, \& Kelly, 2002; Schwartz, Gorman, Nakmoto, \& McKay, 2006). In some studies, a greater effect on student success is shown for students in demographically at-risk populations (e.g., Coll, et al., 1996; Fall \& Roberts, 2012). Strong student academic self perceptions (autonomy, competence, and relatedness) and high qualtiy teacher contexts (autonomy support, structure, and relatedness) appear to serve as a buffer against difficult non-academic circumstances.

Developmental pathways of engagement. To complicate matters (and part of the motivation for this study), engagement displays trajectories in growth and decline associated with developmental age and gender, not just with the individual and contextual factors outlined above. Overall, there is a documented downward trend in students' academic engagement (Wigfield, Eccles, Schiefele, Roeser, \& Davis-Kean, 2006). 
College success and student engagement / 25

Engagement in school drops from elementary to middle school, and again from middle school to high school as they progress through school. Hence it is often the condition of 'no change', or the maintenance of engagement, that is considered a positive outcome. Autonomy seems to become more important with increased age and grade, and engagement appears more stable for females than for males (Archambault et al., 2009; de Bruyn, 2005; H. M. Marks, 2000; Martin, 2009; Gottfried, Marcoulides, Gottfried, Oliver, \& Guerin, 2007; Grouzet, Otis, \& Pelletier, 2006; Hughes et al., 2008; Janosz et al., 2008; Kenney-Benson, Pomerantz, Ryan, \& Patrick, 2006; Shim, Ryan, \& Anderson, 2008; Wang \& Eccles, 2011).

Summary of engagement in elementary and secondary education. There is clear evidence at the elementary and secondary levels that being emotionally interested in school, cognitively effortful and related to school goals and/or social partners, and being involved in the behavioral actions associated with school and learning all combine into a motivational force that not only propels a student towards positive outcomes, but can also buffer them from circumstances that might lead to negative outcomes. Unfortunately, a trend of overall decreases in engagement is apparent across grades, and particular factors seem to be more important in maintaining engagement at different grades.

Regardless of how constructs are labeled, from the perspective of the student, predictors of the kinds of student actions that lead to academic success include: (1) Relating to, connecting with, or having a sense of belonging to school; (2) understanding what is required and feeling competent to do the tasks required; and (3) understanding the whys of tasks, taking ownership, identifying with the goals of school and how it is 
College success and student engagement / 26

relevant or useful for personal goals and success. These predictors can be supported or thwarted by how the school context operates and by how that context is perceived by the student. Thus: (1) Feeling that the school or teacher cares about your success can improve security in the student role or comfort in school; (2) receiving good teaching and clear instructions on how to accomplish academic tasks can increase the sense of competence; and (3) knowing why those tasks are required and how they relate to the students' interests can increase the ownership or positive acceptance for doing the tasks.

\section{Engagement in Post-Secondary Education}

Although empirical support for the importance of classroom engagement for younger students is firmly established, the corresponding effects for students in postsecondary education have only recently begun to be explored. As with younger students, the way student engagement has been conceptualized is diverse (e.g., see Pike, Smart, \& Ethington, 2012 and Krause, 2005). There are good reasons to suspect that conceptualizations and models need to be adapted for use with college students. In general, post-secondary students do not live in the same academic and social world as elementary and secondary students. The variety of post-secondary student variables (mixed ages, mixed educational levels, mixed living situations, mixed life responsibilities, etc.) may affect the motivational processes and how needs are expressed within the SSMMD (Bronfenbrenner \& Morris, 1998; Connell, 1990). Early indications from research, however, do point to many processes and mechanisms operating at the post-secondary level that are similar to those found with younger students. 
College success and student engagement / 27

Antecedents of engagement. As with younger students, positive classroom interactions, strong identification with the student role, and positive student perceptions of the campus environment lead to more engaged post-secondary students. The antecedents of autonomy and autonomy support, competence and structure, and relatedness and involvement still matter to student success, even though post-secondary students live in a different cognitive, circumstantial, and institutional world (Bembenutty, 2010; Boatright-Horowitz, Langley, \& Gunnip, 2009; Chi, 2009; Harackiewicz, Durik, Barron, Linnenbrink-Garcia, \& Tauer, 2008; Hu \& Kuh, 2002; Kuh, Cruce, Shoup, Kinzie, \& Gonyea, 2008; McClenney, 2007; McMilan, 2010; Niemiec et al., 2006; NSSE, 2011; Steele \& Fullagar, 2009).

Student actions, such as amounts of time and effort expended on classwork, are well recognized key factors contributing to success and are often included in assessemnt instruments, such as the Benchmarks of Education put forth by the NSSE (NSSE, 2011b). Even so, perceived institutional emphasis on learning, or institutional climate, along with high quality relationships, and practical, relevant instruction, all show links to success for a broad range of students (Coll \& Eames, 2008; Muller \& Louw, 2004; Pascarella, Salisbury, \& Blaich, 2011; Shell \& Husman, 2008). Overall, having good instructors, who are autonomy supportive, involved, and offer flexible yet consistent class structure, is related to students' academic achievement (Ahlfeldt, Mehta, \& Sellnow, 2005; Black \& Deci, 2000; Reeve \& Jang, 2006; Smart et al., 2009; Roeser \& Peck, 2009). Informational feedback from instructors, real-life relevancy of topics, and teaching methods that respect, support and scaffold student interest and learning all increase 
College success and student engagement / 28

satisfaction and performance for college students. Student self-regulation, academic selfefficacy beliefs, and internalized stereotypes and student social norms can also aid or detract from eventual student success (Elliot \& Murayama, 2008; Filak \& Sheldon, 2003; Gore Jr., 2006; Hackett, 1985; Jang, 2008; Kim, Chang, \& Park, 2009; Nonis, Philhours, \& Hudson, 2006; Ratelle, Guay, Vallerand, Larose, \& Senecal, 2007; Tessier, Sarrazin, \& Ntoumanis, 2008; Zimmerman \& Kitsantas, 2007).

Beyond academic life, students with higher well-being (including creating a balance between responsibilities), enabled by personal social support around multiple roles, also tend to show higher achievement (Horstmanshof \& Zimitat, 2007; Jansen \& Bruinsma, 2005; Le, Casillas, Robbins, \& Langley, 2005; McCarthy \& Kuh, 2006; Munro, 1981; Oregon GEAR UP, 2009b). Studies show that this social support remains a predictor of academic success even when common pre-entry characteristics are accounted for, such as parental education and income. These relations of internal and contextual antecedents to student success, in general, seem to be invariant across cultures and gender, although, as in earlier grades, women are less disaffected overall with their schooling (Conger \& Long, 2010; Jang, Reeve, Ryan, \& Kim, 2009; Kuh, 2009; Lynch, La Guardia, \& Ryan, 2009; Morrison, Cosden, O'Farrell, \& Campos, 2003; Rodgers \& Summers, 2008).

Buffering effects and development of engagement. As with younger students, academic engagement has been found to serve as a protective factor. Negative academic outcomes (Munro, 1981; Svanum \& Bigatti, 2009), maladjustment (Nes, Evans, \& Segerstrom, 2009), and effects of at-risk status (Campos, et al., 2009) can all decrease 
College success and student engagement / 29

with increases in authentic instruction, opportunities to experience competence, and perceptions of the care and commitment to student success by institutions. This buffering effect seems to be differentially effective for different groups, as seen with younger students. For example, gains in engagement and critical thinking leading to higher GPA seem most beneficial to students with the lowest levels of performance, who are at-risk based on demographic status, and who belong to non-traditional groups (Hausmann et al.2007; F. Wang, 2008). Research on the intersections of work, family, and school indicates that engagement can act as a buffer against the multiple role demands faced by most students in the $21^{\text {st }}$ century (Butler, 2007).

Moreover, there is support for developmental changes in college engagement, although some are in the opposite direction as those of younger students. In higher education, these changes are linked to college level (Freshman to Senior), life-stage (dependent, independent, married, parent, or working), and extent of experience with the U.S. administrative and instructional system and norms (Cantwell et al., 2001; Clark, 2005; Harackiewicz, Barron, Tauer, \& Elliot, 2002; Sinclair, Christenson, Lehr, \& Anderson, 2003; Zhang, Gan, \& Cham, 2007). For example, first year students rate different aspects of engagement as more important to their academic efforts than do seniors, as do returning students versus traditional students, and overall disaffection with schooling in general declines from freshmen to seniors (Carini et al., 2006; Chi, 2009; Padilla, 2009). The research is not clear on these developmental changes happening within undergraduate students due in part to the circumstantial differences that interact with these demographics. Disaffection may decrease due to basic selection effects - the 
College success and student engagement / 30

most highly disaffected students, as adults with greater autonomy around life choices, may simply drop out of college. Or, in line with the concept of emerging adulthood, it is possible that the approach to learning (and non-academic circumstances) shifts as students get closer to leaving the academic system - new students may hold the surface learning orientation to pass a course that, with increased investment of time and resources, changes to an orientation of understanding and serious application of learning to their future, post-educational life.

Summary of engagement in post-secondary education. Post-secondary students are diverse in age; they may be living on their own, living with a significant other, have their own children, or even be taking care of their parents. Some will be working to support themselves and their dependents; others will work for pocket change, while others will attend classes as their only responsibility. They may be fresh out of high school, or returning to school now that their own children are adults. Even with these clear differences between being a student in elementary or secondary school and being a student in a post-secondary institution, there is evidence that similar processes may be operating based on the similarity in antecedents to and buffering effects of student behavior and affect.

Supportive and engaged instructors and institutions who recognize and respect student contributions while providing informational feedback in a consistent manner increase student engagement in learning and subsequent success. While women are less disaffected than men, all students gain by role balance and social support around and across roles. These supports can be differentially important for different groups, with 
College success and student engagement / 31

highest effects for certain marginalized groups (e.g., lowest performance level, nontraditional status). While different aspects of engagement seem to hold greater or lesser importance based on where in the process of higher education a student is located, and for how long they have been attending college, there still is a decline in overall disaffection from freshmen to seniors, based largely on the loss of disaffected students in their college careers or, possibly, on a shift in the purpose of learning associated with emerging adulthood and leaving academia. Nonetheless, it seems there are consistent factors and processes in the motivation to persist and succeed at academics regardless of where you are in the educational system (elementary, secondary, post-secondary). Results of research in the area are promising in suggesting that engagement may be an important factor in college student success. At the same time, the landscape is still very confused as to what academic engagement really is and research on how to support it is still scarce; these two themes are visited in the next chapter.

Summary of Micro-model. Research specifically into classroom engagement, whether pre- or post-secondary, reveals clear links to higher grades, higher classroom attendance and on-task behaviors, and higher likelihood of progressing to the next grade. These links appear robust across diverse student social economic status or ethnic groups, although the strength of the effects may vary by culture (e.g., Chirkov, 2009; de Bilde, Vansteenkiste, \& Lens, 2011; Lynch et al., 2009). Knowledge of these important contributors to student success allows the creation of a classroom model designed to differentiate the effects on success of classroom engagement from those of the context of the class (instructors, peers, nature of tasks) and of the students perceptions of themselves 
College success and student engagement / 32

as a student (Furrer \& Skinner, 2003; Skinner et al., 1990; Tsai, Kunter, Ludtke, Trautwein, \& Ryan, 2008).

The classroom model (as seen in Figure 3) targets student success in specific courses, which refers to completing the course and getting a good grade (a proxy for good understanding and individual development). The proximal predictor of course success is student behaviors and emotions in the academic work of the class, or classroom engagement (e.g., Skinner, Kindermann, \& Furrer, 2009). Personal predictors of student engagement are an individual's sense of autonomy, competence, and relatedness within the context (Connell, 1985; Pierson \& Connell, 1992; White, 1959). These selfperceptions encompass: (1) Student knowledge and ability to address challenges in the class (competence), (2) student self-determination and personally valuing the class experiences (autonomy); and (3) a sense of belonging in the class, where instructors have an investment in knowing individual students and supporting their success (relatedness) (Kindermann \& Skinner, 1992; Skinner \& Belmont, 1993; Skinner et al., 2008).

Included in the classroom level model is the course's ability to meet students' needs. Proximal predictors of these self-perceptions are instructors' provision of autonomy support, structure, and involvement (Connell, Halpem-Felsher, Clifford, Crichlow, \& Usinger, 1995; Klem \& Connell, 2004; Lubbers, Van Der Werf, Snijders, Creemers, \& Kuyper, 2006; Vansteenkiste, Soenens, Verstuyf, \& Lens, 2009; White, 1974). The classroom context, provided by the class instructor, encompasses: (1) respect, flexibility, and recognition of student interest (autonomy support); (2) clarity, consistency, and quality of instruction (structure); and (3) evidence of instructor 
College success and student engagement / 33

investment in both knowing individual students and believing in their capacity to succeed (involvement). Student engagement can in turn aid, detract from or deter instructors in providing their supports (Assor, Kaplan, Feinberg, \& Tal, 2009). This is a continual dynamic loop, which, when moving in a positive direction, fosters student behaviors and emotions that are in line with school demands and characteristics. Over the course of a class, and across academic terms, these interactions can be mutually reinforcing and affect students' trajectories of academic success. In this manner, classroom engagement student behaviors and emotions - is energized by self-perceptions which are fostered or thwarted by class experiences. But what makes up these behaviors and emotions? How do we measure them and how do they matter to overall post-secondary student success? The specific definition and measurement of classroom engagement is addressed in the next chapter, along with a model of how it can help to integrate what happens in classes with what happens cumulatively at the university level, and how it might carry upward potential buffering effects against difficult life circumstances. 
College success and student engagement / 34

\section{Chapter 3: Conceptualization and Measurement of Engagement as a Predictor and \\ a Protective Factor}

In order to empirically examine the role of engagement in student success at the college level, it is necessary to specify the conceptualization of engagement, and to create a measure of it that is valid for use with college students. Moreover, a model must be constructed which specifies how engagement can rise up from the classroom to the university level (referred to as the "integrated model"), and shows how student circumstances may shape the role of engagement at this level. Each of these issues is addressed in the following sections.

\section{Conceptualization and Measurement of Engagement}

Classroom engagement, which refers to students' effortful, active, constructive, enthusiastic participation in learning activities within the classroom (Skinner \& Belmont, 1993: Skinner et al., 1990) is considered a multidimensional construct (Hughes et al., 2008; Skinner et al., 2008; Skinner et al., 1990). Measurement of classroom engagement distinguishes among four components which compose its overall expression by the students in class. These components are behavioral engagement, emotional engagement, behavioral disaffection, and emotional disaffection. Engagement involves a behavioral component - trying hard, keeping up with class readings, active attention and participation in class discussions - and an emotional component - interest in the material covered in class, enjoyment while in class, and enthusiasm for being in class.

Disaffection entails passivity, lack of effort, disruption, and withdrawal from learning activities, and encompasses student reactions of boredom, helplessness, exclusion and 
College success and student engagement / 35

coercion. This is beyond simply a lack of engagement, or amotivation. Here too, there is both a behavioral component - absences, tardiness, inattention, and little or no effort expended on class assignments or discussions - and an emotional component - boredom, anxiety, frustration, rebellion, or anger.

Prior measurement work with third through sixth grade students and their teachers supports this multidimensional conceptualization of engagement (Skinner et al., 2009). This study confirmed four factors, found behavioral and emotional components were positively correlated, and that engaged and disaffected components were negatively correlated, though emotional disaffection showed additional sub-dimensions around type of emotion, such as anxious, bored, or frustrated. This four factor model was a better fit to the data than models which distinguished between two factors - one that distinguished behavior from emotions, and one that distinguished between engagement and disaffection. Both student and teacher assessments of student engagement showed this structure, and there was modest agreement between ratings by the teacher and ratings by the student (average $r=.30$ ). This agreement between raters was higher around the behavioral dimensions (average $r=.36$ ), and even higher when aggregates of the components were examined. Analyses of the four components of engagement found that they were generally uni-dimensional and internally consistent (alpha coefficients ranging from .61 to .83).

Over the school year, the components of engagement were moderately stable (average for student ratings $r=.62$, average for teacher ratings $r=.74$ ), although, as found in other research, mean levels of engagement decreased. Students tended to report 
College success and student engagement / 36

higher levels of behavioral engagement and higher levels of emotional disaffection than did teachers. Comparison of classroom engagement observations with the student and teacher reports of engagement showed a modest relation between teacher reports and ontask/off-task observations (ranging from .35 to .40), with students rated as more engaged (versus disaffected) showing more on-task behaviors and less off-task behaviors.

Relations between engagement and its potential facilitators was positive and stable over the school year, facilitators such as high sense of control, identified and intrinsic motivation, and relatedness to their teacher and classmates. Relations to areas which might undermine engagement (and foster disaffection) were negative and stable, factors such as low control beliefs around success, external motivation, and hostile, chaotic and controlling relations with teachers. These general strategies for examining the structural, psychometric, and functional properties of the engagement measure were used in constructing a measure for college students.

\section{Measurement of College Course Engagement}

This multidimensional construct of classroom engagement has been reliably used in primary and secondary classes with demonstrated links to student success. The question arises, "Can an analogous conceptualization and measure of engagement be developed for use with post-secondary students?". If so, the new measure could be used to evaluate classroom contexts and target potential areas of intervention to increase college student success. This dissertation builds on prior research (Chi, 2009), which aimed to develop a measure of adult classroom engagement, and examine whether the structure and function of classroom engagement was similar to that found with younger 
College success and student engagement / 37

students. To assess construct theoretical validity, links were examined between the new measure and two key aspects of college classes proposed by the SSMMD to shape engagement and disaffection. These aspects are: (1) Student self-reports of whether their motivational needs are met in the college class - competence, autonomy, and relatedness, and (2) student perceptions of the motivationally supportive behaviors provided by their class instructor - structure, autonomy support, and involvement. Student self-reports of their expected grade in the course, their overall GPA, and actual course grades were considered measures of academic achievement.

Item procedure. To create the college measurement tool of classroom engagement in the previous study (Chi, 2009), a set of items were adapted from existing elementary, middle, and secondary school measures (Patrick, Skinner, \& Connell, 1993; Skinner \& Belmont, 1993; Skinner et al., 2009; Skinner et al., 1990). Attention was paid to possible differences arising from the developmentally dissimilar life tasks faced by college students, such as work and family. Using data from 405 college students from four 300 level human development (psychology) classes, this study made four contributions to research on college student motivation and achievement.

Structure of engagement. First, the structure of engagement was examined. Structural equation modeling analyses supported the notion of engagement as marked by four distinguishable but closely related components. Contrary to predictions, however, the subscales were not unidimensional: In both behavioral engagement and behavioral disaffection, multi-dimensionality was indicated. Behaviors seemed to be grouped around three different aspects of class engagement and disaffection: (1) behaviors that took place 
College success and student engagement / 38

while sitting in a class (e.g., "In-class"); (2) behaviors that took place outside the classroom but were related to the class (e.g., "Out-of-class"); and (3), the students' overall motivational goal levels for the class (e.g., "Above and beyond" and "Care less"). For the emotional components, weak support for unidimensionality was found, but further exploration was limited by the item pool. For post-secondary students, class engagement appeared to be behaviorally more complex in structure, though the existence of four main components was supported and remained distinguishable. Internal consistencies for these four components ranged from 0.85 to 0.90 . See Figure 4 for the hypothesized structure of this class engagement.

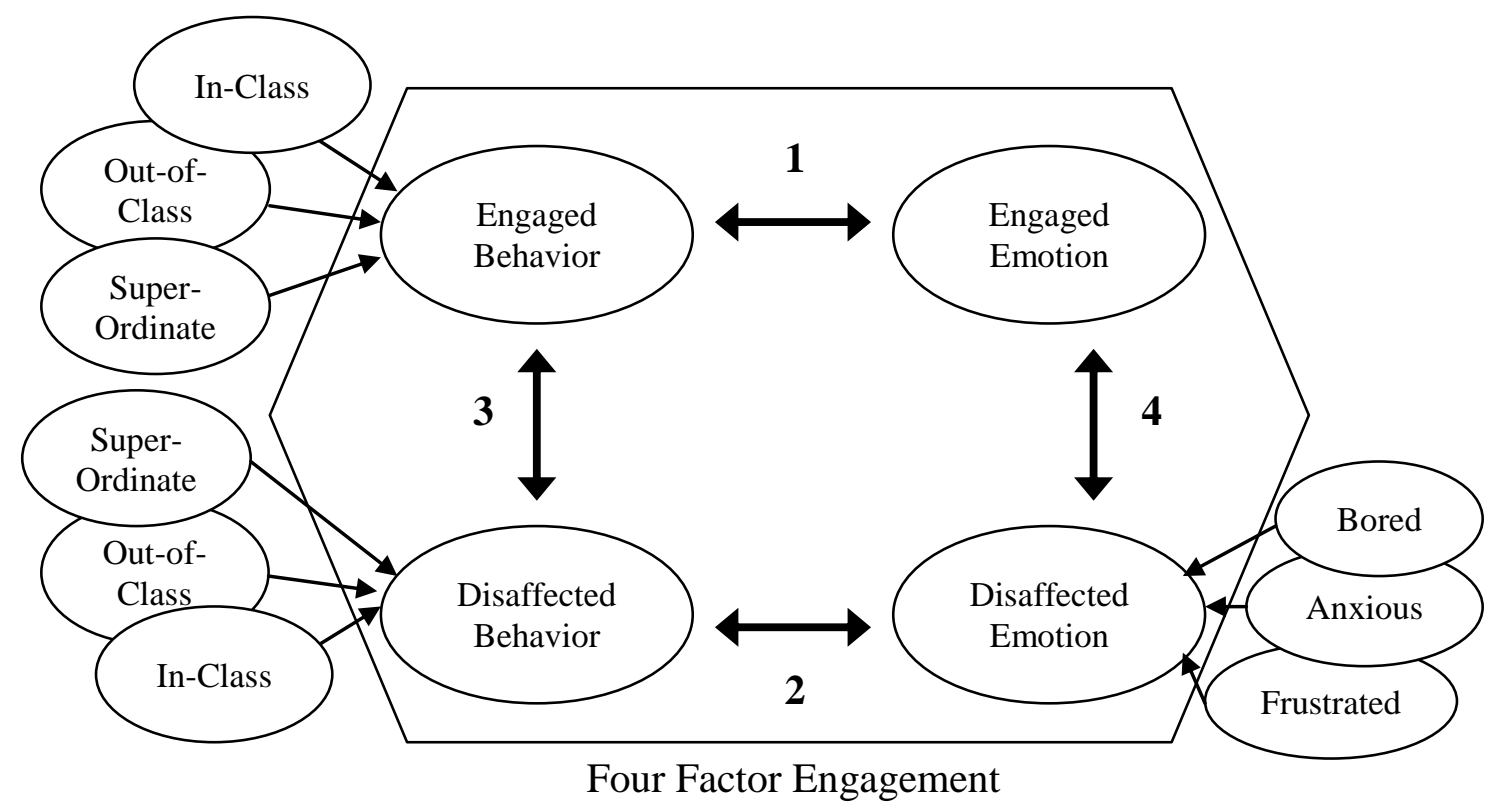

Figure 4. Structural relations among the four components of Engagement. Arrows 1 and 2 reflect a two dimensional model of engagement and disaffection that distinguishes between behavior and emotion to be a better fit than a model that does not make this distinction. Arrows 3 and 4 reflect a two dimensional model of behavior and emotion that distinguishes between engaged features and disaffected features to be a better fit than a model that does not. 
College success and student engagement / 39

Links to academic performance. Second, the effects of the components of engagement on academic performance were investigated. All components were correlated with students' expected grades in the class as predicted by theory: Engaged behaviors and emotions related to higher performance and disaffected behaviors and emotions related to lower performance. However, only behavioral engagement and emotional disaffection were unique predictors. In general, levels of class engagement do predictably relate to levels of class performance for adult students.

Links to hypothesized antecedents. Third, the study examined connections between class engagement and the SSMMD antecedents. In general, the expected links between aspects of instructor context, students' self beliefs, and student classroom engagement were supported: High contextual supports were related to high self beliefs, and high self beliefs were positively related to engagement aspects and negatively related to disaffection aspects. However, two of the self beliefs showed unexpected relations to separate components of classroom engagement. Student relatedness did not show a significant relationship to emotional engagement. Unfortunately, there was a validity issue with the classroom relatedness scale. Items for this scale were incorrectly worded to assess overall relatedness to college versus a specific class. Because these are different but related constructs, the class model of relatedness still needs to be tested. The second surprise was that student perceptions of competence were unrelated to either behavioral aspect. This may indicate that, for older students, although competence affects how a student feels about a course, it is these emotions that affect the behaviors, and not competence directly. Adults may still do what is required, at least minimally, in spite of 
College success and student engagement / 40

how well they think they can do it. Nonetheless, the SSMMD generally appears to validly model classroom processes for college students.

Life circumstances. Fourth, the study examined mean level differences in engagement and the SSMMD components as a function of students' life and demographic situations. Students with two life situations and three demographic factors showed significant differences - having children, having a scholarship, being female, being older, and length of college attendance. Students living with children reported lower levels of both behavioral and emotional engagement, higher levels of behavioral disaffection, and higher levels of perceived instructor structure. Interestingly, receiving scholarship money was related to lower levels of competence and lower levels of provided instructor structure. It may be that the receipt of such aid is more a marker of other demographics which may affect a students' sense of competence. Females reported higher levels of behavioral engagement and lower levels of behavioral disaffection than males, but no differences were found in the emotional components of classroom engagement. This gender differential is in line with previous classroom engagement research with younger students. Differences in engagement components were also found for students over the age of 23. Older students were more engaged both emotionally and behaviorally, less emotionally disaffected, and reported higher perceptions of instructor involvement than younger students. Finally, students who had attended college longer than 3.5 years saw instructors as providing more structure than students with less time invested in their higher education endeavor. Overall, these results support the notion of possible 
College success and student engagement / 41

developmental differences in classroom engagement that continue beyond the developmental level of high school students.

Summary of course engagement measurement. In university classes, a four component construct of classroom engagement did relate to class performance in expected ways. Behavioral components, both engaged and disaffected, seem more complex than those seen with younger students. Because of the multidimensionality found in college student classroom engagement, which pointed to the importance of actions and feelings beyond just those in the physical classroom, this construct is here renamed course engagement. Course engagement related to its proposed antecedents, and the antecedents with each other, in line with the processes outlined in the SSMMD. Some differences were apparent, however, based on the life circumstances of the student. These findings highlight the importance of incorporating family status and responsibility levels into models of student success. Although this study was a step towards understanding course engagement at the developmental level of post-secondary students, additional issues were also revealed.

An important next step is further clarification of the multidimensionality in the behavioral components of engagement. Second, better assessment of students' life situations would also be beneficial in examining the potentially important effects of circumstances on course engagement. Because the 2009 sample came from multiple sections of one 300 level psychology undergraduate course whose student population consisted mainly of Juniors, this would include broadening the representativeness and generalizability of the sample across all levels of undergraduates. More detailed 
College success and student engagement / 42

situational items that clarify the work, school, and family roles and responsibilities may shed light on relations between course engagement and student success, details such as part- or full-time student status, college generational status, and in-state/out-of-state status. Most importantly, in order to facilitate discussion and use of course engagement in policy and administrative decision making, two tasks must be accomplished: (1) a measurement tool must be constructed that is short, valid, reliable, and easily administered, and (2) a model must be specified that explains the links between this proximal course experience and student success at the university level. The first task was one goal of this study, as discussed in the next chapter. The integrated model is discussed in the next section.

\section{The Integrated Model: Course Engagement and the Macro-Model}

Research on course engagement in a single class may seem far removed from student graduation, especially when thinking in terms of intervention targets at the university level, such as the success of students from certain demographic and at-risk categories. However, overall student persistence and success are likely fueled by proximal experiences - in particular, it is argued, by course engagement. Course engagement unfolds over time in any given class, and cumulatively progresses with repeated experiences that are encountered in new classes each term. The development of course engagement starts on day one in the first course of the first term. The key idea is that students' experiences in all of their classes in a term form a base for the construction of their perceptions of themselves in their student role (academic identity). Social comparisons, self-reflection, and socially delivered messages in classes likely contribute 
College success and student engagement / 43

to overall student perceptions about whether their academic learning and skills have been augmented by their participation at the institution (university learning experiences).

At the macro level, these university learning experiences, shaped in tandem with academic identity and aided by university supports, were hypothesized to affect performance and intentions to persist at university or college. The effect of course engagement on performance and persistence should then be (a) direct, as well as (b) indirect through contributions to university learning experiences and academic identity, and (c) should supplement any effects of university supports. At the micro level, course engagement is the result of proximal, daily, repeated interactions with the learning enterprise. These interactions build with time and experience in and across courses. Thus where a student is in their college career and in their life-course (primacy of school, and work, family, school, and finances balance) should make a difference to course engagement's influence on overall performance as well as students' ongoing perceptions of their academic identity and university learning experiences. This integrated model is presented in Figure 5.

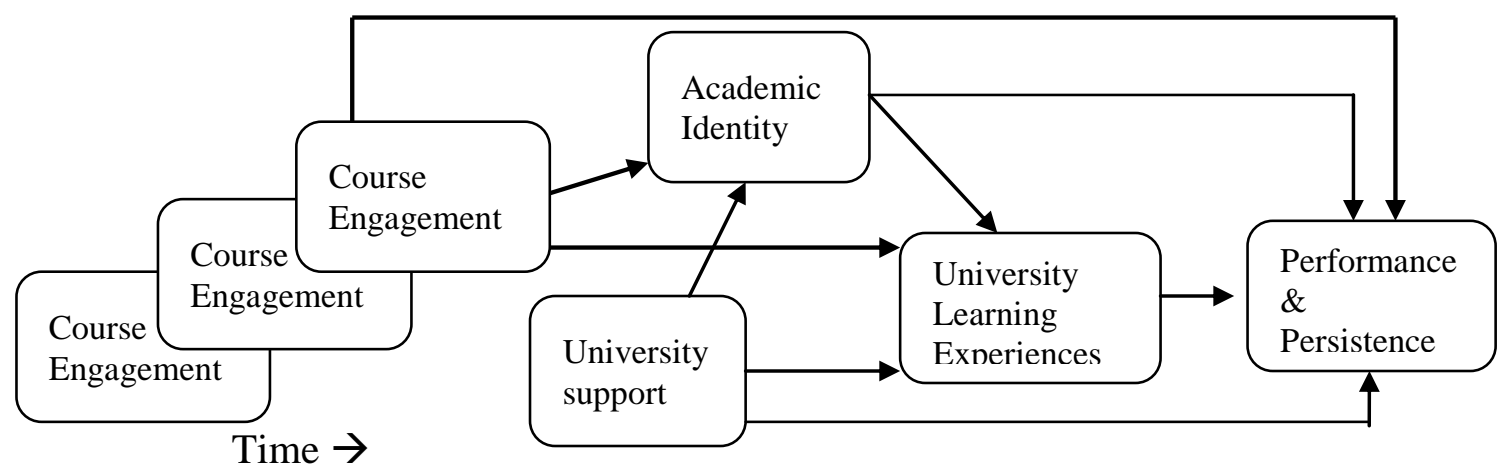

Figure 5. Integrated model: Course engagement over time and its contribution to performance and persistence. 
College success and student engagement / 44

Course engagement in this integrated model has the benefit of adding psychological profiles to the current outcome assessment commonly seen at the macrolevel. Improving classroom level measurement based on sound theory, integrating the theory into the university level, and examining the models empirically may reveal a new target for improving student success. A short measurement tool of this malleable construct, course engagement, could have immediate applications. Interventions to improve classroom experiences based on student psychological support and development could be made institution wide, could be easily tailored for each course and to student population needs, and could be quickly assessed and evaluated by instructors.

Summary of the integrated model. Across levels, it was proposed that students' course engagement cumulatively feeds from the classroom to the university level. Considering the immediacy and repeated exposure of course experiences, course engagement should both directly and indirectly contribute to student success and persistence. The quality of learning experiences in multiple classrooms over time would be expected to accumulate, shaping overall student university learning experiences and academic identity. Not only should the integrated model help flesh out the role of student experience in higher education but, more importantly, it could create another accessible lever for influencing student success. It is possible that by improving course engagement, the benefits of university supports would be maximized, and the educational costs of multiple commitments (demands) could be minimized. This issue of students' nonacademic commitments and supports is considered in the next section. 
College success and student engagement / 45

\section{Course Engagement and Student Circumstances in the Integrated Model}

Students bring a lot with them when they come to college or university. They bring their abilities, their cultural and ethnic backgrounds, their previous academic experiences, their gender and racial experiences, their social and economic backgrounds, their families, their friends, and their responsibilities (Aud \& Hannes, 2011;

Bronfenbrenner \& Morris, 1998; Conger \& Long, 2010; Donaldson \& Townsend, 2007; Livingston, 2008). This is just part of the list of characteristics associated with students referred to in the educational literature as the 'traditional' first-year student- 17 to 19 year olds, funded by parents, straight from high school, and living in the dorm.

There are also 'non-traditional' students, such as: first generation students who may be the first in their families to attend college as well as being in their first-year; students who are returning to college after an absence spent attending to other commitments in their lives; and more individuals who are returning to college because their old job may no longer exist due to economic conditions or advances in technology and information communication. These students bring with them their expertise, pragmatic knowledge, and generational and cultural fit (or mismatch) with the institution (Cantwell, Archer, \& Bourke, 2001; Carlson, Kacmar, Wayne, \& Grzywacz, 2006; Finan, 2004; Rosenbaum \& Rochford, 2008).

Working, caring for family, and the social support around the student role can aid or detract from energy and time available for student tasks (e.g., Lee et al., 2007); Broadbridge \& Swanson, 2005; Cooper \& Crosnoe, 2007; Padilla-Walker, Nelson, \& Carroll, 2012). These circumstances are inextricable from the student and can shape their 
College success and student engagement / 46

success at university. For example, it is easy to see how high work responsibility could detract from attending class physically and mentally (and thus course engagement), or low social support for academic tasks outside the university could affect academic identity and course grades. It is necessary then to include these concomitant nonacademic supports and responsibilities in any model attempting to understand postsecondary student success.

These are aspects that come with the individual student, and there is nothing that the university can do to change the presence of multiple roles in a students' life. However, as outlined in Figure 6, I proposed that course engagement components can bolster or alleviate the proximal effects of everyday student circumstance. This protective effect is carried upward into the system of university overall student success. The influence of course engagement adds to the university academic and social supports that are already in place to mitigate the demands of individual student life situations. This extra buffer against the numerous possible restraining factors that can interfere with student progress should increase the opportunity for those students with multiple demands or low social support to persist in their college endeavors.

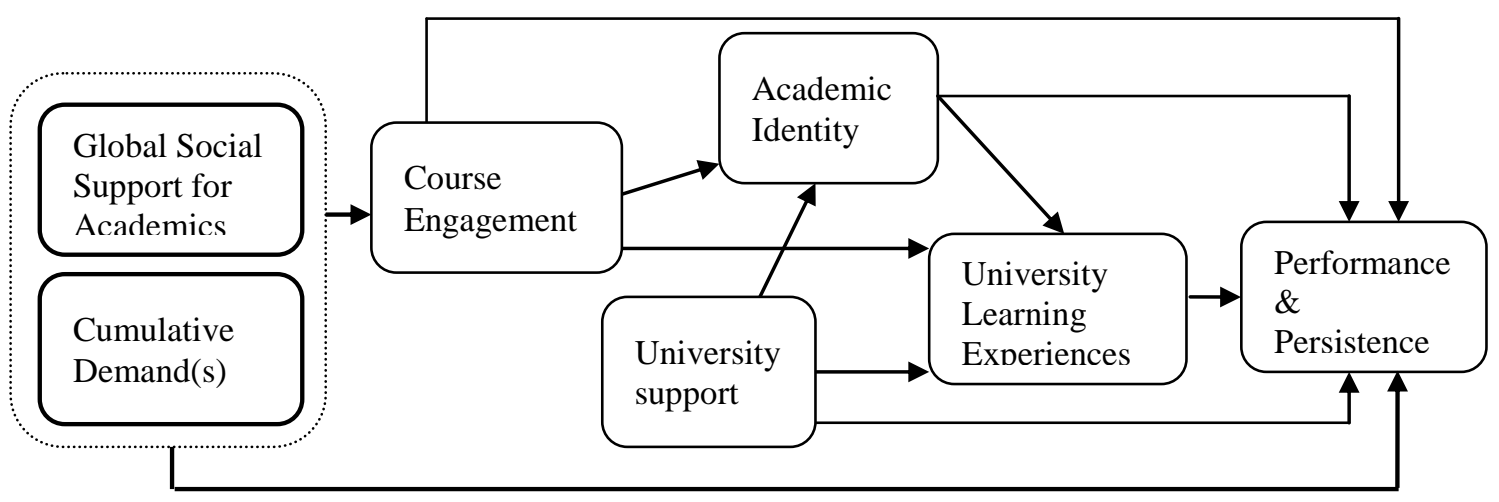

Figure 6. Circumstances in the Integrated model. 
College success and student engagement / 47

When responsibilities are high in other life areas, class attendance may fall dramatically. Course engagement, when high, can bolster class attendance even in the face of work or family demands. Work and family roles can limit time for studying, but when work and family support student tasks, these demands may be eased. When looking at the practicality and validity of using a classroom level student self- and otherperception measure (i.e., course engagement) to predict and aid academic success, it is important to include these markers of student circumstances and the strength of the possibly conflicting demands (Netemeyer, Boles, \& McMurrian, 1996; Netemeyer, Brashear-Alejandro, \& Boles, 2004; Netemeyer, Maxham III, \& Pullig, 2005; Van den Broeck, Vansteenkiste, De Witte, Soenens, \& Lens, 2010).

Global social support for academics. One important area of supports that a student has upon entry, even before they encounter anything on offer by their institution, is that provided by those who surround them in their non-academic life. This includes friends, family, co-workers, employers, and community and religious group peers and advisors. How supportive these social partners are of a students' academic identity and school tasks affects how the student role develops. Research on work and school has shown that being emotionally and practically supported in an endeavor (e.g., pursuing an education) and having someone to talk to in times of distress or joy predict continuation and success at pursuing job and educational goals (Brougham, Zail, Mendoza, \& Miller, 2009; Cooper \& Crosnoe, 2007; Guay, Marsh, Senecal, \& Dowson, 2008; Jelicic, Bobek, Phelps, Lerner, \& Lerner, 2007; Marks \& MacDermid, 1996; Minuchin, 1985; Verger et al., 2009). An individual's network of support for their student activities and goals is an 
College success and student engagement / 48

everyday experience - we cannot easily escape our lives when we move from one area of functioning to another, such as from home life to a college classroom. For example, a friend or family member with strong opinions about learning may influence a students' utilization of available institutional offerings. Or going to a university sponsored social event may lead to making a new friend. This new friend is now part of the student's social network outside of school, and contributes to social support for being a student. Thus, global social support for academics is an important contributor to a student's success in higher education.

\section{Demands: Student commitments requiring internal \& external resources.}

Non-academic supports are not the only factors that influence student success. The $21^{\text {st }}$ century students' life can be very complex. Responsibilities may exist in many areas. Part of the cost of an individuals' choice to pursue or continue in their education is the necessity of balancing the demands that multiple commitments make on internal and external resources (Bean, 1980; Boyar, Maertz, Pearson, \& Keough, 2003; Glogowska et al., 2007; Swanson, Broadbridge, \& Karatzias, 2006). Five areas of demands were identified for this study. The two immediate and obvious costs of matriculating are tuition and the number of student credit hours (SCHs) a student is enrolled in each term. The (1) financial demand can vary according to the source of funding depending on how strongly the financial support received is contingent on achieving a certain GPA, such as self, parents, loans, or grants and scholarships (Nora, Barlow, \& Crisp, 2006; Padilla-Walkerl et al., 2012). Credit hours (2) are a clear indicator of how much time a student can expect to allocate to academic work, and, as such, can limit or create zones of conflict with other 
College success and student engagement / 49

areas of responsibilities (e.g., family, work, or community). In a similar fashion, if a student works, the average number of hours worked per week in a term (3) also has certain time and resource requirements that can detract from academic responsibilities (Becker \& Moen, 1999; Butler, 2007; Lenaghan \& Sengupta, 2007).

Family demands (4) on time and energy can also detract from school performance (Deci, Connell, \& Ryan, 1989; Sweet \& Moen, 2007). Individuals' living circumstances vary in the resources they provide and/or require. The decrease of the nuclear family and the emergence of dual-care individuals (caring for children and for parents), for example, can place additional pressure on a student in terms of their availability for student tasks and the necessity to manage both internal and external resources. When the welfare of the rest of the family depends mainly (or solely) on the student, family and work responsibilities (5) usually take precedence over academic tasks. Beyond the time or mental attention needed to perform the duties of work or to properly attend to family interactions, family and work responsibilities reflect the importance of the individual's role in those arenas (Lenaghan $\&$ Sengupta, 2007). Working 15 hours a week running a cash register uses time, and surface level attention, but has low responsibility around the business: show up, ring up, balance the till, and clock out. However, working 15 hours a week as the engineer of a project vital to the business requires more attention, entails more responsibility, and is more likely to supersede student role needs as work (or family) responsibilities increase.

Summary of student circumstances. What students bring with them, besides their basic demographic characteristics, is as varied as the individuals themselves. Broad 
College success and student engagement / 50

areas of non-academic circumstances have been identified that can be examined for their impact on a student's success in higher education. It seems clear that social support for the student role is beneficial. Conversely, five general areas can present as demands on student internal and external resource allocation - cost, credit load, work, family, and levels of responsibility in work and family. It seems likely that these demands may exert a downward pressure on students' performance and persistence, may undermine their identity as a student, and interfere with the quality of their university learning experiences. What research has not made clear is how these supports and demands interact within the process of college attendance and success, more specifically, how aspect(s) of the system such as course engagement may be able to alleviate possible detrimental effects of student circumstances. Do the proximal daily experiences that take place in class buffer some of the unavoidable proximal daily demands of life outside of academia? Examining global social supports and the five demands in the integrated model addresses this question. Course engagement may act as a boost to student success and as a buffer to those circumstances. Examining this boost and buffer effect when course engagement is carried into the overall university model attempted to better provide a more complete account of the current reality of being a college student.

\section{Summary of course engagement as predictor and protective factor. In} summary, the macro-level model posits that there are university supports in place as well as the on-going development of students' academic identity and university learning experiences, which all relate to the likelihood of student success. At the micro level, class experiences contribute to the quality of a student's behavioral and emotional involvement 
College success and student engagement / 51

with the class (course engagement). Experiences are repeated in time both within a class and across classes. Course engagement integrates the macro and micro levels by cumulatively shaping the trajectories of both academic identity and university learning experiences, as well as directly affecting student performance and persistence. The impact of course engagement on student success should remain even when the influence of university supports are accounted for. These university supports are in place to mitigate potentially difficult student circumstances. The presence of global social support can increase student success. Five areas that can act as demands, by competing for student internal and external resources, are cost, credit load, work, family, and levels of responsibility in work and family. These diverse circumstances overlap most directly at the micro level. Because of the daily, repeated, proximal experiences of both academic course enrollment and non-academic "real life", course engagement may be a way to buffer some of the effects on student success of non-academic demands. As such, students who maintain their course engagement may be able to succeed in higher education despite high demands and low supports in their life outside of school. Along with measurement tool creation, taking a snapshot of this complex, overlapping system in relation to course engagement and student success was another goal of the following study. 
College success and student engagement / 52

\section{Chapter 4: Purpose of Study}

The purpose of this study was to examine the role of course engagement as a key factor in promoting college student success, especially for students who find themselves in challenging life circumstances. The primary contention was that course engagement, defined as enthusiastic, constructive participation in learning inside and outside the classroom, represents the heart of the student experience in college. If this is so, course engagement should play a role at both the classroom (micro) and university (macro) levels. In the current work, student "success" in higher education was considered to include two components, (1) persisting in a course of study to graduation (retention) and (2) achieving a level of class grades sufficient to produce a high GPA (performance). As outlined, when dealing with the macro-model the only real lever to improve student success at institutions such as colleges and universities are support organizations that address the many and varied circumstances of the $21^{\text {st }}$ century student. This area is vital, but may not reach the core of the student experience in higher education. Recently, research into student retention and performance has suggested that such psychological constructs as identity and involvement with organizations promotes goal achievement, and the literature in higher education supports this contention. The main construct of interest throughout this study, because it is a malleable intervention target that can improve student success, was course engagement. By including course engagement and its relation to student circumstances, performance, and persistence, the possibility arises of identifying another area open to university intervention through changes at a proximate (classroom) level (Barab \& Squire, 2004; Kindermann \& Skinner, 1992). 
College success and student engagement / 53

\section{Goals of the Study}

In order to examine the role of course engagement in student success at the university level, and to see whether it can buffer students with multiple life demands and few resources, the study and its research questions were organized into five goals. The

first goal was to refine the measure of course engagement by building on efforts started in my thesis to construct a self-report measure to capture developmentally equivalent course engagement from the student's perspective. Specifically, the goal was to model the multidimensionality found within some of the post-secondary engagement components, and to create a short survey version that reflected this larger multi-dimensional conceptualization but could be used by universities for brief assessments geared towards student success.

The second goal was to determine whether the measure fit within the self-system model of motivational development, and was valid and useful for modeling postsecondary classes. Third, the university, or macro- model was examined to see whether supports, identity, and overall experiences are a good account of student trajectories at this level. The fourth goal was to explore the possibility of an integrated model by examining linkages between the two levels provided by course engagement and to examine engagement's effects on student success at the university level. The fifth and final goal was to incorporate aspects of student circumstances (social support and competing responsibilities) into the integrated model to see whether course engagement can serve as a boost or buffer to the (typically negative) relationship between demanding life circumstances and student success. 
College success and student engagement / 54

1. Improved measurement of college course engagement. The first goal was

that of measure refinement and validity. By examining the factor structure of the full item scale of course engagement, the proposed model of multidimensionality can be tested. The item sets can then be distilled down to a short measure whose psychometric properties can be evaluated and their relation to other model components measured to see whether the short measure can be used as a proxy for the full engagement scale. In order to allow for clearer modeling of the multidimensionality found in the Behavioral subscales and hinted at in the Emotional subscales, and to strengthen the validity of the overall process model, additional and reworked items for the engagement scale were included. The structure of this revised engagement scale was examined, replicating the analyses performed in the thesis (psychometrics and CFAs), as were its links to other constructs within the self-system model. In addition to the expected grade item, real grades were available for analysis for a subset of participants. This allowed for a clearer examination of the connection between engagement and academic performance, and enabled a simple test of the accuracy of self-reported grades for this subset of participants. As a cross-sectional marker for retention and completion, student intentions to persist in their college careers were also examined - e.g., "I often think of quitting college".

Once structure and function of the revised engagement scale were tested, a shorter course engagement measurement instrument, that reflected all the underlying dimensions but used only 12 items from the structurally modeled revised scale, was created and tested for psychometrical soundness. Relations of this shorter scale to the other classroom 
College success and student engagement / 55

constructs were compared to the full scale relations to ensure similarity. The goal here was to create a short survey scale that can be used as a course evaluation or assessment, which reflects all the dimensions of course engagement.

2. Classroom (micro-) model. The second goal was to examine the self-system model of motivational development for post-secondary students. In the micro-model of the college classroom, course engagement should behave in the expected manner with its classroom context predictors - instructor structure, autonomy support, and involvement (positive connections) - and with its classroom outcome, class grade (positive connections).

3. University (macro-) model. The third goal addressed the macro-model which depicts the relations among university learning experiences, academic identity, university supports, and the tangible outcomes of success - GPA and persistence. When a framework of material supports, internal student perceptions of their fit with the role of a higher education student, and their belief in the efficacy of their institution are modeled together, is the picture a useful one for mapping out student success? Although supports should play a role in increasing student success, individual positive academic identity development and reflection on personal learning that has been supported by the academic institution should further promote this success.

4. Integrated model. The fourth goal of this dissertation was to create an integrated model with course engagement at the core. Questions revolved around how course engagement fits within the university (macro-) processes and outcomes. Because constructs in the macro-model are cumulative in nature over courses and terms of 
College success and student engagement / 56

attendance, course engagement should show effects on the university level aspects university learning experiences, academic identity, and university supports. Finally, although direct effects of course engagement on university performance (GPA) and persistence intentions may vary in significance based on college level (e.g., a senior's engagement level in his/her last class will have little effect on GPA), there should still be effects on university learning experiences and academic identity. The contribution of course engagement to student success should be detectable over and above any effects of university supports.

\section{Student circumstances in the integrated model, demands highlight. The}

fifth goal focused on how students' life circumstances may shape their college success, with a special focus on whether course engagement may act as a protective factor, buffering the typically negative effects of high demands and low supports. In order to consider aspects the student brings with them into the realm of higher education, the role demand and role conflict literatures suggest that it is important to include the influence of students' non-academic social supports for their student commitments (global social support for academics) as well as their non-academic commitments (cumulative demands). School represents a commitment similar to work or family. If an individual's internal and tangible resources were a pie to be shared among these three areas of commitment (and joy), it is easy to see how circumstances beyond the university's direct control must be included when looking at the effects of both classroom level and university level processes. By buffering the daily demands of non-academic 
College success and student engagement / 57

circumstances, course engagement is a way institutions may be able to offset these challenging life circumstances.

\section{Research Questions}

1. Improved measurement of course engagement. Does the proposed measurement tool reliably and validly assess course engagement for college students? Is class engagement structurally more complex for college students than for younger students?

a) Is the complex factor structure hinted at in the earlier study - a four part construct with multiple behavioral dimensions (comprising in-class engagement, out-of-class engagement, and engagement goals) - replicated with a more representative sample and additional items designed to tap these dimensions?

b) Does course engagement fit within the classroom model as predicted by SDT?

c) Can this conceptually rich measure be distilled into a short survey tool that is psychometrically sound? Does the short measure occupy the same construct space as the full scale (e.g., show similar relations with the motivational model and classroom constructs)?

2. Classroom (miro) model. Does the motivational model provide a good account of the hypothesized predictors and outcomes of course engagement for college students? 
College success and student engagement / 58

a) Predictors of course engagement: Are instructor context and student selfsystem processes important predictors of course engagement?

b) Outcomes of course engagement: Is course engagement an important predictor of class performance? Does perceived class difficulty play a role?

c) Mediational role of course engagement: Does course engagement mediate the effects of student self-system processes and classroom context on classroom performance?

3. University (macro) model. Does the motivational model provide a good account of student university learning experiences at the higher order level of the institution?

a) Do university supports and academic identity predict university learning experiences?

b) Are university learning experiences and academic identity each important predictors of student persistence and overall performance?

c) Do university learning experiences mediate the effects of university supports and academic identity on persistence and performance?

4. Integrated model. What is the role of course engagement in the macro-model of university learning experiences?

a) Course engagement and the antecedents in the macro-model: Is course engagement related to university learning experiences, academic identity, and university supports? 
College success and student engagement / 59

b) Course engagement and the outcomes of the macro-model: Does course engagement predict university level performance (GPA) and persistence?

c) The mediators of course engagement: Are the effects of course engagement on performance and persistence mediated by student academic identity and university learning experiences?

d) The unique effect of course engagement in the full macro-model: Do the relations between course engagement and performance and persistence (when mediated by university learning experiences and academic identity) remain when controlling for contributions from university support systems?

5. Student circumstances. How can course engagement help us understand the role of student circumstances in shaping overall student success?

a) Demands and performance: Are higher levels of cumulative demand associated with poorer student outcomes, in particular lower intentions to persist and overall GPA?

b) Supports and performance: Do students with higher global social support for academics also have higher levels in all the outcomes?

c) Mediational role of course engagement: Do student demands depress outcomes because they undermine course engagement? Do student supports boost outcomes because they promote course engagement?

d) Course engagement as an intervention target: With circumstances included in the model, do the relations between course engagement and success 
College success and student engagement / 60 (performance (GPA) and persistence) remain when controlling for contributions from university supports?

e) Moderating role of course engagement: Can course engagement buffer the effects of high demands on student outcomes? In other words, are the effects of high demands on performance reduced for students who are high in course engagement? 
College success and student engagement / 61

\section{Chapter 5: Methods}

\section{Settings and Participants}

The sample included 860 college students from 12 undergraduate psychology courses from the 2010/2011 Spring school term of an urban university in the Pacific Northwest United States. Of the 856 valid participants, $69.5 \%$ of the participants released their actual course grade to the researcher, though only $52.3 \%$ were received (subsample). The university student body is comprised of approximately $64.8 \%$ EuropeanAmerican, 8.5\% Asian, 3.3\% African-American, 6.1\% Hispanic, and 5.9\% international students (Office of Institutional Research and Planning, 2010). Study participants who reported single origin ethnicity comprised $86.1 \%$ of the sample $(n=737)$, and broke down into 70.9\% European-American, 15.6\% Asian, 2.3\% African-American, 7.3\% Hispanic, and 2.1\% Native American/Alaskan Native. These percentages do not include combinations of two or more ethnic identities (13.9\% of the sample, or 119 participants). $29.7 \%$ of the sample were first-generation students, and $4.8 \%$ were international students. Of the participants, $36.5 \%(\mathrm{n}=312)$ reported having psychology as their sole major. In parallel to the overall distribution of students at this university (52\%), $65.9 \%$ were

female. Student ages ranged from 16 to 66 years old, with $34.4 \%$ aged 19 to 21 . Ages 22 through 27 accounted for an additional $38.1 \%$ of the sample. Only $34.2 \%$ of the students indicated beginning their college career at the current institution.

\section{Human Subjects}

A human subjects proposal was submitted, approved, and renewed, with the university's Human Subjects Research Review Committee (HSRRC; see Appendix A. 
College success and student engagement / 62

IRB submission and approval for IRB submission and approval documentation).

Instructors were invited to participate via email by allowing their students the opportunity to take the 185 item survey. Only psychology instructors with class enrollment greater than 50 students were invited $(\mathrm{N}=16)$. Eleven instructors, teaching 12 courses, agreed to have the survey administered in their class during their normally scheduled final exam time slot. Of the 12 courses where data were collected, three were administered by peers in the graduate program - the remaining nine courses were administered by the researcher.

Based on the focus and nature of the questionnaire - student perceptions, feelings and cognitions about their classroom activities, class structure, and class instructor - it was desirable to administer the surveys via pen and paper while the students were sitting in the class during normal class time. Not only does this heighten ecological validity of the measure, the context is salient in the minds of the students, and some of the struggling students who might not otherwise fill out a questionnaire might do so after they've just finished their last chance at course points (their final). However, due to the nature of student participation (receipt of extra credit), take-home pencil and paper formats were available if requested by an instructor or student, for example when they used the full final time for their test. Only seventeen students out of all participants took the survey with them and subsequently returned them to the researcher.

\section{Design and Procedure}

All students were offered extra credit for participation or, should they choose not to participate, for an alternative short in-class essay on a class topic (amount of extra 
College success and student engagement / 63

credit determined by the course instructor; short in-class essay developed by the researcher based on the class focus and instructors' interest). Only one participant chose the essay option. At all times of survey administration, students were assured of confidentiality, that participation was fully voluntary, that no personally identifying data would used in reporting results, and that they could drop out at any time or request that their data not be used.

In each class, an announcement was made at the start of the final briefly explaining the survey, their rights and choices, the grade release (by separate signature) in the survey and its purpose, and the offered extra-credit from their instructor should they choose to participate (1-10 points). After students finished their final, they could opt to stay and complete a survey. When they were done, they wrote their name on the separate course extra-credit sheet, were given a copy of the informed consent, their signed consent from was separated from their survey, and they were heartily thanked. Both instructors and students were given information on how to contact the researcher should they wish to be informed of the results. Instructors were given individual extracredit lists and a separate list of those students who released their course grade. Grades were requested by the researcher a week after finals, again a week before Fall 2011 term, and a third time two weeks into the term. One instructor refused to give the grades, and one instructor never responded after all three contacts (courses with achievement data $\mathrm{n}=$ 9). This resulted in the actual grade sub-sample released versus received percentages reported above. 
College success and student engagement / 64

\section{Measures}

Based on the large number of measures and variables, a summary of relevant construct/items can be found in Appendix E. Scales used in current study., the codebook for items used in this study are listed in Appendix D. All items, all measures, by model/construct codebook., and the administered survey can be found in Appendix C: Administered survey..

Outcome measures. The outcomes of academic performance and college persistence are present as outcomes in the models. Two items assessed academic outcomes. First, the students were asked about their expected course grade, that is, the grade they expect to receive for their class performance (A, B, C, D, Fail, Pass). This served as an estimate of students' self-reported academic success for the classroom specific measures was available for use in the micro-model. As a self-report measure, this is less preferred than the administrative recorded actual grade, however they provided a validity check, along with the $52.3 \%$ sub-sample of received grade, for the imputed actual grade data. Participants whose actual grade was imputed as missing included those who declined to share their actual grade, and those who agreed to release their grade but for one of two reasons the actual grade was not received: 1) Instructor refused to release even though student agreed; 2) Survey was received after grade request was submitted to instructor. Based in research on self-reports and objective reports, missing real grades were estimated from existing performance data for these students (Crockett, Schulenberg, \& Petersen, 1987; Gillmore, 2000; Kuncel, Crede, \& Thomas, 2005; McDonald, 2008). Second, students were asked to report their overall (self-reported, estimated) GPA. This 
College success and student engagement / 65

was used as the more general academic outcome measure in the macro-model. After the recodes and re-categorization performed and outlined in the Results chapter, $34.2 \%$ of the sample fell in the B- to $\mathrm{B}+$ range.

Also in the macro model, four items assessed persistence (responses from not true to totally true) by asking about student intentions to continue with college. These items were gleaned and modified from work and school turnover intention research (e.g., "I am positive I will finish college"; "I often think about quitting college"; Netemeyer, Boles, \& McMurrian, 1996; Boyar et al., 2003).

Additional demographics. In order to make it possible to evaluate additional demographic factors on which post-secondary students differ from school students, information was collected on students' living situation (total number, with parents, with children, with partner, alone), employment status (full-time, half-time, not employed), and status as a care provider (children, spouse, parent). These percentages are reported in Chapter 6: Results, under cumulative demands. Also included were 16 categorical items which will allow future group comparison, representing various possible student conditions, such as first-generation student status, college level, international student status, transfer status, disability status.

Classroom model measures. Main construct definitions were based on prior theory and research in the areas of engagement, motivation, coping and self-regulation (Connell et al., no date; Skinner et al., 1990; Skinner \& Belmont, 1993). Measures were selected based on construct definitions and prior empirical studies which used the self- 
College success and student engagement / 66

system model of motivational development (SSMMD; Connell, 1990; Furrer \& Skinner, 2003; Patrick et al., 1993).

\section{Student Engagement: Student self-report of course engagement and}

disaffection. Student course engagement/disaffection was assessed using a 51-item measure that was adapted from my thesis work (Chi, 2009; see Appendix B: Partial 2009 study results. for measure statistics). These items were based on Wellborn's (1991) and Skinner and Belmont's (1993) original measures for middle and high school students, and from the Student-report of Engagement versus Disaffection in the Classroom used by Furrer and Skinner (2003) for elementary students. All source items were adapted for college students, and 31 new items were generated to further test and refine the constructs. Students were asked to answer items grouped into the four dimensions (subscales) of engagement (behavioral engagement, behavioral disaffection, emotional engagement, and emotional disaffection) using a five-point rating scale (from never to always). Negative items were reversed coded so higher scores indicate higher engagement and higher disaffection. Psychometrics from all thesis scales used were acceptable: behavioral engagement 6-item scale $\mathrm{M}=3.42, \mathrm{SD}=.74, \alpha=.90$; behavioral disaffection 6-item scale $\mathrm{M}=1.72, \mathrm{SD}=.53, \alpha=.85$; emotional engagement 4-item scale $\mathrm{M}=2.80, \mathrm{SD}=.89, \alpha=.90$; emotional disaffection 4-item scale $\mathrm{M}=1.88, \mathrm{SD}=$ $.63, \alpha=.85$ (Chi, 2009).

Behavioral engagement (BE) was measured with 12 items that assessed the motivated academic behaviors practiced by the student and in class. Four items came from the Skinner and Belmont (1993) measure (e.g., "I try hard to do well in this class"; 
College success and student engagement / 67

"I stay current with the readings"). Eight items were developed to capture college student behaviors (e.g., "I try hard to understand the professor's lectures"; "I set aside study time for this class").

Behavioral disaffection (BD) was measured with 13 items that assessed the behaviors that reflect lack of motivation of students in the classroom - two items from the Skinner and Belmont (1993) measure (e.g., "I don't try very hard in this class") and 11 items developed for this study (e.g., “Outside of class, I don't put much work in on this course"; "Anything I do for this class is always last minute").

Emotional engagement (EE) was measured using 14 items to assess students' energetic emotions associated with class - four items from the Skinner and Belmont (1993) measure (e.g., "I enjoy the time I spend in this class") and eight items developed for this survey (e.g., "I look forward to this class"; "The material we cover in class is challenging (in a good way)").

Emotional disaffection (ED) was measured with 11 items to assess student negative emotions towards class and class activities - two items from the Skinner and Belmont (1993) measure (e.g., "When in class, I feel bored"), one item from the School Burnout Inventory ("I feel overwhelmed [in] this class"; Salmela-Aro, Kiuru, Leskinen, \& Nurmi, 2009), and eight items developed for this study (e.g., "Sitting in class is a waste of my time"; "I dread going to this class").

Course engagement (CE). A main goal of the study was to design a reliable and valid assessment tool for college students' academic engagement in the classroom. The initial analyses was based on a relatively large experimental item pool (51 items), and 
College success and student engagement / 68

had as the goal a reduction of this pool to a set of 12-16 items that showed a similar nomenological net as an optimized item pool (36 items), arrived at through a series of confirmatory factor analyses (CFAs), and could be used in future studies. The optimized item pool was expected to represent the full factorial nature of course engagement, as found in the 2009 thesis. Appendix B: Partial 2009 study results. presents descriptive and model fit statistics from the thesis. Twelve representative items were selected for the course engagement measure used in later model analyses.

\section{Student self-reported Competence, Autonomy, and Relatedness in the}

classroom. Current experienced levels of competence and autonomy in the classroom were assessed using the 2009 thesis scales consisting of 10 items rated on a five-point scale (from not true to totally true). Negatively worded items were reversed coded so that higher scores indicate greater perceived levels of competence, autonomy and relatedness. Psychometrics from all thesis scales used were acceptable: perceived course competence 6-item scale $\mathrm{M}=4.54, \mathrm{SD}=.60, \alpha=.80$; perceived course autonomy 4-item scale $\mathrm{M}=$ $4.44, \mathrm{SD}=.66, \alpha=.80$. Current experienced levels of relatedness in the classroom were inadvertently not measured in the 2009 thesis, rather, relatedness to college was assessed. For this study, classroom relatedness was assessed with six items modified from the thesis relatedness to the college items.

Competence reflects the students' belief in their own ability to do well in the course and was assessed with 6 items modified from the Skinner and colleagues (1990) measure (e.g., "If I decide to ace this class, I can"; "This course is over my head"). 
College success and student engagement / 69

Autonomy (relevance) was measured with four items used to assess student perceived course relevance (adapted from Patrick et al., 1993; e.g., "I can apply what we are learning in this class to real life").

Relatedness was measured by six items to assess the students' perceptions of belonging with their peers in the classroom and in the course. Four were adapted from Furrer and Skinner (2003; e.g., "I have a lot in common with the other students in this class") and two developed for this study (e.g., "In this class, I feel like an outsider").

\section{Classroom context: Instructor involvement, structure, and autonomy support.}

Provisions of context that meet the motivational needs of students was assessed by the student perceptions of their instructors' behaviors using the thesis scales. Studentevaluation research shows that multidimensional ratings of teachers by students are reliable, reasonably valid, and useful for feedback to faculty (Gillmore, 2000; Marsh, 1984). Students answered 18 items using a five-point rating scale (from not true to totally true; see Appendix D. All items, all measures, by model/construct codebook. for full item codebook). These 18 items made up the three instructor context scales. Negatively worded items were reverse coded so that higher scores indicate greater perceived levels of instructor provision of needs (context). Psychometrics from all thesis scales used were acceptable: perceived instructor involvement/warmth 6-item scale $\mathrm{M}=3.53, \mathrm{SD}=.71, \alpha$ $=.73$; perceived instructor structure 6-item scale $\mathrm{M}=4.34, \mathrm{SD}=.57, \alpha=.73$; and perceived instructor autonomy support 6-item scale $\mathrm{M}=4.18, \mathrm{SD}=.52, \alpha=.62$.

Six items were used to measure Involvement/Warmth - student perceptions of the context caring, involvement, warmth and accessibility. These items were adapted to 
College success and student engagement / 70

better fit a college classroom from the Teacher as Social Context (student-report)

questionnaire developed by Skinner and Belmont (1993; e.g., "This instructor cares about how I do in his/her class"; “This instructor doesn't know I exist”).

Instructor Structure assesses the extent to which instructors provide clarity of expectations and consistency in follow through for the student and was measured with six items adapted from Skinner and Belmont (1993; e.g., "The assignments in this class are clear and reasonable"; "This instructor keeps changing the rules in class").

Instructor Autonomy Support assess the extent to which the instructor makes clear the value of student contributions to and relevancy of the class, and was measured with six items adapted from Skinner and Belmont (1993; e.g., "This instructor listens to student ideas"; "This instructor is bossy and controlling").

Class difficulty. Four items from the thesis were included to assess student selfperceptions of class difficulty (e.g., "This class requires a lot of work"; "This is an easy class") using a five-point rating scale (from not at all true to very true). The two items expressing the ease of the class were reverse coded so that higher scores indicate greater difficulty. A student's score for class difficulty was constructed by taking the average of the four items, where a higher score indicated greater difficulty. This was created to decide on the necessity of including class difficulty as a control when predicting course grade.

University model measures. Main construct definitions and measures were based on prior theory and research in the areas of engagement, motivation, coping and selfregulation (Connell et al., no date; Skinner et al., 1990; Skinner \& Belmont, 1993) for 
College success and student engagement / 71

academic identitiy. Items for university learning experiences were selected from the 2010 National Survey of Student Engagement, paper version (NSSE, 2009), though the interpretation of the construct being represented by the items here is not theirs. Along with the classroom model measures, university measures the item by construct codebook can be found in Appendix D. All items, all measures, by model/construct codebook..

\section{Academic identity (AI): Student autonomy, competence, and relatedness}

towards university. Current experienced levels of autonomy and competence in the arena of the overall university were assessed using 12 items, rated on a five-point scale (from not true to totally true). Current experienced levels of relatedness towards university was assessed using the 2009 thesis scale (6-item scale $\mathrm{M}=3.80, \mathrm{SD}=.79, \alpha=.74$ ). Negatively worded items in all scales were reverse coded so that higher scores indicate greater perceived levels of competence, autonomy and relatedness towards university.

General autonomy for college was assessed with six items based on Ryan and Connell's (1989) measure of identified self-regulation (self-valued goal; personal importance) modified and developed for this study (e.g., "What I'm learning here at university maps onto my career goals") and further informed by the work-school literature (e.g., Butler, 2007; Marks \& MacDermid, 1996; Swanso et al., 2006).

General competence toward college was assessed with six items $(\mathrm{M}=4.54, \alpha=$ .80) originally based from the Student Perceived Control Questionnaire: Academic Domain (Skinner et al., 1990) then further developed to apply to older students in the College academic domain for this study (e.g., "I am capable of being a good student here at college"; "I don't know how to do well in college"). 
College success and student engagement / 72

Relatedness was measured by 6 items to assess the students' perceptions of belonging in college and with their peers at the college (e.g., "I feel at home here at (college name)"; "I don’t really belong in college"), adapted from Furrer and Skinner (2003) and used in the 2009 thesis study with acceptable psychometrics $(M=3.80, \alpha=$ .74).

These three scales were combined into a composite scale (average) representing academic identity, and was used in the tested models. Were this variable to be structurally modeled, academic identity is a higher order latent construct measured by the three lower order constructs.

University learning experiences (UE ). Overall experiences at the university level were assessed using student responses to 14 items in answer to the question "To what extent has your experience at this institution contributed to your knowledge, skills, and personal development in the following areas", question \#11 from the 2010 National Survey of Student Engagement, paper version (NSSE, 2009; e.g., "Acquiring a broad general education"; "Writing clearly and effectively"). This question uses a four-point rating scale for the items (from very much to very little). Responses were reverse coded to match the other study scale response direction, so that higher scores indicate greater perceived levels of university learning experiences, and rescaled to a five-point response scale.

University support (US). University Support was assessed using student responses to 4 items in response to the question "To what extent does your institution emphasize the following?". This is question \#10 from the 2010 National Survey of 
College success and student engagement / 73

Student Engagement, paper version (NSSE, 2009). Items draw on such areas as "Providing the support you need to help you succeed academically" and "Helping you cope with your responsibilities (work, family, etc.)". Three of these items are from the 'Supportive campus Environment' benchmark of the NSSE, and the fourth is from their 'Enriching Educational Experiences' benchmark - "Encouraging contact among students from different economic, social, and racial or ethnic backgrounds" (NSSE, 2011b). This question stem used the NSSE original four-point rating scale in the survey (from very much to very little). All NSSE items were reverse coded and rescaled to match the other study constructs' five-point rating scale (from not true to totally true) during data cleaning.

Student circumstance measures. Two general areas of student circumstances were looked at as influencing the micro- and macro- models - Global Social Support for Academics, student perceptions of support available for academics by non-academic social partners, and Cumulative Demands, student report of presence and level of possible resource requirements from non-academic life areas. All items but one are from prior research scales in psychology and work/family/education studies, though their combination is unique to this study. Full details, as with the classroom and university model measures, are listed in Appendix D. All items, all measures, by model/construct codebook. and Appendix E. Scales used in current study..

Global social support for academics (GSSA). Of the four items used to assess Global Social Support around academics, two stem from Quimby and O'Brien's (2006) conception of perceived social support -"The people in my life support my going to 
College success and student engagement / 74 college", and "If something is going on at school, I have someone I can talk to about it". One derives from Lenaghan and Sengupta's (2007) working college student's well-being study - "My friends and family complain about how busy I am with school", and one was developed for this study - “Important people in my life don't get the whole 'going to college' thing”. Items used a five-point response scale (from not true to totally true), with negatively worded items reverse coded so that higher scores indicate greater perceived levels of global support for the student and their academics that are external to university provided supports.

Cumulative Demands. The five categorical areas associated with student circumstances that could create demands on their self-system processes examined in this study were (1) financial demand, (2) school demand, (3) work demand, (4) family demand, and (4) social responsibility. These five areas of possible student demand, representing the cost of attending college, were assessed with a total of 13 items.

Financial Demand (DFIN) was assessed with three items around finances that are most directly related to college attendance, two from the 2009 thesis and one new item informed by the results of that study. These three items have a dichotomous response (Yes/No), and ask about college funding - loans, parents, and scholarships, both applied for and received - money sources used to pay for college that may be dependent on academic performance. A yes response categorized to each item by student was accumulated into a new variable of financial demand, quantifying how many areas of possible financially associated demands were present, from one (45.9\%), two (32.8\%), or all three (8.2\%) examined areas. 
College success and student engagement / 75

Credit hours (DSCH), an indicator of scholastic demand, was assessed with one item, "How many credits are you taking this term?", with a dichotomous response of "6 credits or less" or "7 credits or more", and used as marker for part-time (6.4\%) and fulltime student $(93.6 \%)$ status.

Work, an indicator of employee role demand, was assessed with one item, "In an average week I work.", with a response range from None (0) to $32+(5)$ hours. This range of five responses was rescaled into three levels: Not working (26.2\%), working 1-25 hours (46.7\% part-time), and more than 26 hours (27.1\% full-time).

Family demand (DFAM) was assessed with one item: Who do you live with? the original response set (Alone, w/partner, w/parent(s), w/child(ren), w/roommate(s), other) allowed multiple response combinations ("Mark all that apply”). Responses were assigned to one of the six representative combinations - alone (13.1\%), with a partner (21.7\%), with parent/s (26.5\%), with family (5.3\%), as a single parent $(3.4 \%)$, or in a multi-generational household (2.7\%). These six categories were assigned a weight based on a number of considerations, so that living with parents represented the lowest level of family demand, and living in a multigenerational family represented the highest level of possible demand.

The fourth area of student demand, social responsibility (DSR), was assessed with three items. One item, "I have a lot of responsibility in my family" is from prior research in family/work measurement (Rothausen, 1999, as cited in Boyar, Maertz, Pearson, \& Keough, 2003), and the second item modified the original item by replacing the word 'family' with the word 'work'. The third item was modified from Butler's (2007) Work- 
College success and student engagement / 76

School Conflict scale by the removal of "and responsibilities" from his item to make it "My job demands interfere with my schoolwork". These items use a five-point rating scale (from not true to totally true). The three items-a lot of responsibility in family, in work, and job responsibility that interferes with schoolwork - were combined into a new categorical variable social responsibility ranging from presence of 'none' (23.1\%) to presence of 'all areas'(19.5\%), with higher scores indicating higher social responsibility demand.

Cumulative Demand (CDMD). To look at the presence of possibly demanding circumstances effects in overall success, cumulative demand was constructed from the five area demand scores for use in later analyses. These five student demand variables were combined to a single variable reflecting the presence and level of demands in each of the five areas added together into a response range of two to sixteen, with an average demand level of eight. 
College success and student engagement / 77

\section{Chapter 6: Results}

\section{Missingness Report: Scale Items}

Prior to examining the dataset for missing value patterns, the data were examined visually for indicators of invalid data. Two cases were deleted from the data set: one case listed all three's as responses, and one case was blank but for the first page. SPSS 12.0 was then used to examine missing data patterns for the remaining 857 participants. Of the 185 items collected from each participant in the dataset, 152 were not demographic or identifier items and thus appropriate for data imputation. A case-wise analysis revealed that the number of missing items ranged from zero to 93 items (60.8\%). Upon examination, the participant missing 93 items only filled in the first two pages of the survey. This participant was deleted from the dataset $(\mathrm{N}=856)$. In considering the participants who were missing the most data after this one incomplete survey, only five cases were missing over $20 \%$ of items. These participants were missing 37 items (24.2\%), 34 items (22.2\%), two were missing 33 items (21.6\%), and one was missing 32 items (20.9\%), respectively. A closer examination of the surveys suggested that the missing information demonstrated "missing at random" (MAR; Bodner, 2007) properties; in all cases a page of the survey was skipped (three missing page 2, one missing page 3 , and one missing the last page), and a couple of single items dropped throughout the surveys. So it is likely that the missing data on a particular variable do not depend on the item content and are thus eligible for imputation.

Variable-wise missing analysis demonstrated that for four (2.63\%) variables, none of the participants were missing data. The average number of participants who were 
College success and student engagement / 78

missing data on any given variable ranged from zero to 33 (3.9\%), with the next highest number of participants missing data on one variable at $24(2.8 \%), 18(2.1 \%), 15(1.8 \%)$, and $13(1.5 \%)$. For the variable missing 33 responses (INTAS1 - 'Our instructor gives us some latitude about the assignments in this class') no tabulated pattern of missingness arose. Only one tabulated pattern of missingness (greater than $1 \%$ of cases) was detected, where nine participants were missing only one item: DPCFS11 'I learned a lot in this course'.

Following this analysis of missing data patterns, the decision was made not to exclude any cases from the analysis. SPSS 12.0 maximum likelihood (ML) estimation with estimation maximization (EM) algorithm was used to impute the observed missing data in two steps. All non demographic items were used in the imputation, resulting in a complete item dataset of 856 cases.

\section{Missingness Report: Demographic and Categorical Items}

Once scale items were imputed, missing value patterns were examined for the 14 categorical study items. Before imputation, those cases who refused to release their actual grade or released their grade but no grade was received were re-coded to missing. A casewise analysis revealed that the number of missing items for these 14 items ranged from one $(7.1 \%, 0.7 \%$ overall) to nine items $(64.3 \%, 6.2 \%$ overall). Upon examination, the participant missing nine items did not answer the social responsibility items, the funding items, and did not release their actual grade. In considering the participants who were missing the most data after this one survey, 21 cases were missing three or four of the 14 categorical items (21.4\% and $28.6 \%$, respectively). Nine of these were missing the 
College success and student engagement / 79

funding items, seven were missing the funding items and refused to release their actual grade. Four refused to release their course grade as well as not answering two additional items - one missing their expected course grade and their student status, two missing two of the social responsibility items, and one missing one funding item and one social responsibility item. The last case missing over $20 \%$ was missing their actual grade, one social responsibility item, one funding item, and who they lived with.

Variable-wise missing analysis demonstrated that for one variable, college level, none of the participants were missing data. The average number of participants who were missing data on any given variable ranged from zero to 408 (47.7\%, actual grade), with the next highest number of participants missing data on one variable at 25 (2.9\%), three variables at $18(2.5 \%)$, and nine $(1.1 \%)$. Three tabulated patterns of missingness (greater than $1 \%$ of cases) were detected: (1) The obvious pattern of actual course grade, where 364 cases were missing only this variable; (2) Thirteen cases where actual and expected course grade were missing; (3) Nine cases missing only the funding items.

Following this analysis of missing data patterns, the decision was made not to exclude any cases from the analysis based on the density of the full dataset and the correlation between actual and expected course grade $(r=0.69, \mathrm{p}<.01, \mathrm{n}=435)$ of the non-imputed dataset. SPSS 12.0 maximum likelihood (ML) estimation with estimation maximization (EM) algorithm was used to impute the observed missing data. All nondemographic and demographic items were used in the imputation, resulting in a complete item dataset of 856 cases. 
College success and student engagement / 80

\section{Non-Engagement Scale Psychometrics}

Prior to addressing the research questions, properties of the scales used in the models that were not under creation (i.e., excluding the engagement scales) were examined. Non-engagement scales were treated as set scales, since measurement and development of their represented constructs was not the goal or within the scope of the current study.

Table 1 lists the scale reliability statistics (alpha and omega), scale means, and scale standard deviations. Of the 14 non-engagement scales, 12 showed internal consistency greater than .70 (range $0.72-0.93$ ). Two scales - global social support for academics and university relatedness - showed low Cronbach's alpha at 0.62 and 0.68 , respectively. Three of the four items making up global social support had factor loadings greater than 0.50 , with only one item ("My friends and family complain about how busy I am with school") displaying a low loading at 0.35 . As this item holds strong face validity for perceived support for academics, it was decided to keep all four items. Two of the six items making up university relatedness had low factor loadings ("I don't really belong in college" at 0.45 and "I am different from the other students at PSU" at 0.25 ). While this might indicate the existence of some other unknown factor at play, again, the decision was made to keep all items in the scales based on face validity of the sense of belonging and relating to others at university.

Of the 14 non-engagement scales, eight showed Mcdonald's omega $\left(\omega_{\mathrm{h}} ; 1999\right.$; Zinbarg, Revelle, \& Yovel, 2005) lower than 0.70 , ranging from 0.44 to 0.63 with the computed scale of academic identity excluded. The academic identity scale, computed as 
College success and student engagement / 81

Table 1. Non Engagement Scale Statistics

\begin{tabular}{lcccc}
\hline \multicolumn{1}{c}{ Scales } & Items & $\alpha$ & $\omega_{\mathrm{h}}$ & $\mathrm{M}(\mathrm{SD})$ \\
\hline Classroom Model & & & & \\
Student Autonomy & 4 & 0.80 & 0.71 & $4.16(0.84)$ \\
Student Competence & 6 & 0.79 & 0.88 & $4.46(0.65)$ \\
Student Relatedness & 6 & 0.77 & 0.58 & $3.58(0.75)$ \\
Instructor Autonomy & 8 & 0.81 & 0.86 & $4.21(0.63)$ \\
Support & 6 & 0.78 & 0.44 & $3.82(0.83)$ \\
Instructor Involvement & 6 & 0.76 & 0.63 & $4.09(0.74)$ \\
Instructor Structure & & & & \\
& & & & \\
University Model & 4 & 0.87 & 0.85 & $2.57(0.86)$ \\
University Support* & 14 & 0.93 & 0.99 & $2.87(0.67)$ \\
University Learning & 6 & 0.68 & 0.52 & $3.74(0.71)$ \\
Experiences* & 6 & 0.72 & 0.67 & $4.07(0.67)$ \\
University Relatedness & 6 & 0.77 & 1.00 & $4.53(0.58)$ \\
University Autonomy & 4 & 0.64 & 0.16 & $4.59(0.61)$ \\
University Competence & 18 & 0.75 & 0.19 & $4.11(0.54)$ \\
Persistence & & & &
\end{tabular}

Student Circumstances

Global Social Support for

Academics

$\begin{array}{clcc}4 & 0.62 & 0.51 & 4.12(0.76) \\ 5 \text { areas } & \text { Range: } & 2 \text { to } 16 & 8.11(2.81)\end{array}$

Confound

$\begin{array}{lllll}\text { Class Difficulty } & 4 & .81 & 0.53 & 3.13(0.98)\end{array}$

NOTE. $\mathrm{N}=856$. Response range: 1 (Not true) to 5 (Totally true). $*$ Response range: 1 (Very little) to 4 (Very much). ** Academic identity composed of the three University scales.

the mean of university competence, university relatedness, and university autonomy, showed an omega of 0.19. Considering that omega is an index of the saturation of a single factor by the measured items, rather than the relation of the items to each other as is Cronbach's alpha, the extremely low omega for academic identity was expected. The 
College success and student engagement / 82

other scales with low omegas indicate that much of the variance in the single factor being represented by the measured items is error variance. Since only the general factors are being used for prediction in this study, low omegas (true score variance of the items sum of the squared loadings on one general factor - to total score variance of the items sum of all covariance) and alphas (the average covariance between the items) will underestimate the true relation between the general factors and the outcomes (Revelle \& Zinberg, 2009). It is highly conceivable that scales with low omega actually consist of many related constructs, for example, instructor involvement may consist of perceptions of caring, actual experiences of practical involvement, and/or prior knowledge or hearsay about the instructor. Social support for academics from friends may be in the area of emotional support, while support from work may be in the area of pragmatics (time off), and support from family may be both emotional and pragmatic.

Of the 80 non-engagement scale items used in this study, 15 showed a level of skewness over the absolute value of 2.0. Examination of these items indicated that the skew was consistent with the item content - positive skew for negatively worded items, and negative skew for positively worded items. Once negatively worded items were reverse coded (so that higher numbers would indicate higher levels of the construct), all skewed items were in the negative direction, indicating very few low scale responses. While skewness affects the variance component of analyses, the decision was made to not transform these variables as the items were ones where a low frequency response at one end of the scale was face valid - for example, it would not be expected that very many students would highly endorse the statement "I'm not smart enough to make it through 
college" (item: Unv_Comp6), and the frequencies reflect this, with only 27 participants endorsing 'totally true' and 27 endorsing 'somewhat true'.

Scale scores. For later regression analyses, scale scores for the non-engagement scales were created by taking the mean of the items for each scale. Academic Identity, which consists of the university scales of competence, relatedness, and autonomy, was computed by taking the mean of the three university scales. All scale score variables showed acceptable levels of skew and kurtosis.

\section{Recodes and Re-categorization}

In order to create a cumulative demand score (family, financial, social responsibility, work, and school) and comparable grade categories (Expected, Actual, and GPA), recoding and categorization was necessary for 13 variables.

Grade re-categorization and imputation. The three outcome variables were recoded/re-categorized to match categories into A range (4: A, A-), B range (3: B+, B, B-), passing range (2: $\mathrm{C}+, \mathrm{C}$, Pass), and below passing (1: C-, C- or lower, D, F).

Respondents who listed two or more grades in any of the three variables were categorized into the lowest grade listed (e.g., A, B+, B was re-categorized into B). For GPA, five participants wrote in "this is my first term". These cases were coded as 0 , and were re-coded to missing for imputation. In the case of the actual grade, those participants who did not agree to release their grade were coded as $-1(n=261)$, and those who did agree but whose grades were not received were coded as $-2(n=147)$. For imputation, these cases were re-coded to missing. Missing values for all outcomes were imputed based on all scale and outcome variables. Pre-imputation correlations between 
College success and student engagement / 84

the expected course grade and GPA excluded these cases. Based on the frequencies, it seems highly probable that students who expected passing or lower grades did not agree to release their grades. While the number of actual grades in each category at the A range through passing were less than the number of expected in each category, the difference was much higher in the passing category: expected was $26.8 \%$ greater than actual in the A range; $62.4 \%$ higher in the $\mathrm{B}$ range; and $74.1 \%$ higher in the passing range. Of note, however, in the not passing category, the number not passing based on actual grade was higher than in the expected grade by $46.2 \%$. As seen in Table 2 , correlations between the three categories were all significant at the $\mathrm{p}<.01$ level with pre-imputation expected related to actual at $r=0.69$. and post- imputation at $r=0.71$.

Table 2. Correlations of GPA, expected course grade, and actual grade.

\begin{tabular}{lcc}
\hline \multicolumn{1}{c}{ Performance Measure } & $\begin{array}{c}\text { Actual Course Grade } \\
\text { Pre / Post imputation }\end{array}$ & $\begin{array}{l}\text { Expected Course } \\
\text { Grade } \\
\text { Pre / Post imputation }\end{array}$ \\
\hline Overall GPA (self-report) & $.465^{* *} / .480^{* *}$ & $.473^{* *} / .454^{* *}$ \\
Expected Course Grade (self-report) & $.694^{* *} / .713^{* *}$ & \\
$\begin{array}{l}\text { Note. } \mathrm{N}=456 ; \mathrm{n}=435(2 \text { of 2 variables present); } \mathrm{n}=856 \text { (3 of } 3 \text { variables present). } \\
\text { Prior to imputation, Expected to Overall }(\mathrm{n}=825) \mathrm{r}=.446^{* *} \\
* * \mathrm{p}<.01\end{array}$
\end{tabular}

Demands re-code and re-categorization. Each of the demand categories (family, financial, social responsibility, work, and school) were first recoded into individual area demand levels, then combined to create the cumulative demand score. Response frequency breakdowns for non-academic circumstances after these recodes and re-categorization are listed in Table 3. 
College success and student engagement / 85

Table 3. Response frequencies for Non-academic circumstances Area Response options

Demands

Working $26.2 \%$ None, $46.7 \%$ 1-25 hours, $27.1 \%$ 26+hours 27.3\% Other/roommate, $13.1 \%$ Alone, 26.5\% Parents, 21.7\% Partner, 5.3\% Family, 3.4\% Single parent, 2.7\%

Live with Multi-generational

Credit load $6.4 \% 6$ or less, $93.6 \% 7$ or more

Social Responsibility:

Work, interference, family $23.1 \% 0$ of $3,30.3 \% 1$ of $3,27.1 \% 2$ of $3,19.5 \% 3$ of 3

Funding: Loan, parents, scholarship $13.1 \% 0$ of $3,45.9 \% 1$ of $3,32.8 \% 2$ of $3,8.2 \% 3$ of 3

Social supports for academics

People support $15.8 \%$ Somewhat true, $74.4 \%$ Totally true $6.5 \%$ Not true, $8.5 \%$ A little true, $16.1 \%$ Fairly true, Someone to talk to $21.6 \%$ Somewhat true, $47.2 \%$ Totally true

Complaints about how busy $31.9 \%$ Not true, $22.2 \%$ A little true, $19.2 \%$ Fairly true, (reverse coded) $14.8 \%$ Somewhat true, $11.9 \%$ Totally true

Don't get going to college $70.4 \%$ Not true, $12.6 \%$ A little true, $9.0 \%$ Fairly true, (reverse coded) $\quad 4.3 \%$ Somewhat true, $3.6 \%$ Totally true $\mathrm{N}=856$

Work demand re-code and re-categorization. Average hours worked per week were re-categorized from five categories (None, 1-14, 15-25, 26-32, 32+) into three categories consisting of Not working (0: None), Part-time (1: 1-25) and Full-time (2: 26+). Full-time status, while not reflective of the general definition of 40 hours per week, was set at 26 hours based on the fact that these are individuals with a second job - being a college student enrolled in courses. Of the 231 cases in the re-categorized full-time group, $57.1 \%(\mathrm{n}=132,15.5 \%$ of the full sample) worked $32+$ hours per week. Of the 851 
College success and student engagement / 86 participants who responded to this question, $26.1 \%$ responded as not working, $46.8 \%$ as working part-time, and $27.1 \%$ as working full-time. Post imputation, $26.2 \%$ responded as not working $(\mathrm{n}=224), 46.7 \%$ as working part-time $(\mathrm{n}=400)$, and $27.1 \%$ as working fulltime $(\mathrm{n}=232)$.

School demand re-code and re-categorization. Credit load was coded as parttime (1: 6 or less) and full-time (2: 7 or more). This variable required a recode as data were entered as 6 and 7. Of the 850 student who responded to this item, $92.9 \%$ were fulltime students $(\mathrm{n}=795)$. Post imputation, 93.6\% were categorized as full-time $(\mathrm{n}=801)$ and $6.4 \%$ as part-time $(\mathrm{n}=55)$.

Social responsibility re-code and re-categorization. Social responsibility consisted of three items, with response choices of Yes (1), No (0), and Not applicable (2): "I have a lot of responsibility in my work"; "I have a lot of responsibility in my family"; "My job demands interfere with my work".

Each variable was first re-coded so that Not applicable became a No (from 2 to 0 ), based on the assumption that if the item was not applicable, there were no job or family responsibilities. A new variable (D_SocResp) was created which categorized cases based on the number of responsibilities reported, with higher number of social responsibility demands coded higher. The combination of all three variable responses by case endorsed at No $(0,0,0)$ were calculated as Zero of three demands $(0)$ in the new D_SocResp variable. Cases which reported Yes (any combination of 1,0,0) were calculated to one of three demands (1). If Yes was reported on any combination of two items $(1,1,0)$, the case was re-categorized to Two of three demands (2), and if Yes was reported on all three 
College success and student engagement / 87

items, the case was given a Three of three demands (3) code. Of the participants who responded to all three items $(n=845), 23.2 \%$ reported no social responsibility, $30.3 \%$ had one of the three present, $27.2 \%$ had two of the three responsibilities present, and $19.3 \%$ had all three areas of responsibility. Post imputation at the item level $(\mathrm{N}=856)$, the newly computed zD_SocResp variable (calculated as listed above) showed $23.1 \%$ with no social responsibility $(n=198), 30.3 \%$ had one of the three present $(n=259)$, $27.1 \%$ had two of the three responsibilities present $(n=232)$, and $19.5 \%$ had all three areas of responsibility $(\mathrm{n}=167)$.

Funding re-code and re-categorization. Three items were used to assess financial demand, based on the assumption that being in debt or receiving money based on academic performance increases pressure on a student. The items used were: "Are you using college loans to fund your schooling"; "Do you receive any scholarship or grant money for schooling that depends on academic performance"; and "Do you receive money from other sources (like parents) that depends on your academic performance". The item "Did you apply for scholarship or grant money to fund your schooling?" was not used as a demand though initially it was included in the survey as a possible indicator of financial stress. The response choices consisted of Yes (1), No (0), and Not applicable (2).

Each variable was first re-coded so that Not applicable became a No (from 2 to 0 ), based on the assumption that if the item was not applicable, there were no financial pressures on the student based on their academic performance. A new variable (D_Fund) was created which categorized cases based on the number of funding sources reported, 
College success and student engagement / 88

with higher numbers of sources coded higher. The combination of all three variable responses by case endorsed at No $(0,0,0)$ were calculated as Zero of three demands $(0)$ in the new D_Fund variable. Cases which reported Yes (any combination of 1,0,0) were calculated to One of three demands (1). If Yes was reported on any combination of two items $(1,1,0)$, the case was re-categorized to Two of three demands (2), and if Yes was reported on all three items, the case was given a Three of three demands (3) code. Of the participants who responded to all three items $(n=828), 13.2 \%$ reported no funding demands, $45.5 \%$ had one of the three present, $32.9 \%$ had two of the three funding demands present, and $8.5 \%$ reported all three areas of funding demand. Post imputation at the item level $(\mathrm{N}=856)$, the newly computed zD_Fund variable (calculated as listed above) showed $13.1 \%$ no funding demand $(n=112), 45.9 \%$ had one of the three present ( $n=393), 32.8 \%$ had two of the three funding demands $(n=281)$, and $8.2 \%$ had all three areas of funding demand $(\mathrm{n}=70)$.

Family re-code and re-categorization. One item with multiple response options and combinations was used to assess levels of potential family demand. Participants could endorse all responses that applied to their living situation ("Who do you live with?”). Responses (with their original codes) were Alone (0), with Partner (1), with Parents (2), with Child(ren) (3), with Roommate(s) (4), and Other (5).

Besides the main six categories, there were 19 unique combination categories $(\mathrm{n}=$ 114) that appeared in the data. Each combination was examined for re-categorization into one of six new categories. Five cases endorsed living alone and a second category - these were re-coded to the second category listed. Cases that listed Partner and Child(ren) were 
College success and student engagement / 89 re-coded to Family, and any combination of Partner, Parent, and Child(ren), Parent and Child(ren), or Partner and Parent became Multi-generational. Eleven combination cases had additional written in information that allowed for accurate placement (e.g., "boyfriend" placed the case in the Partner category, and "pet" placed the case in the Alone category). Roommate(s) was combined with the Other category. Of the 848 participants who responded to this question, $27.2 \%$ lived with roommates or others, $13.0 \%$ lived alone, $26.2 \%$ lived with parents, $21.9 \%$ lived with a partner, $5.3 \%$ had families, $3.4 \%$ were single parents, and $2.7 \%$ lived in multi-generational households. Post imputation $(\mathrm{N}=856), 27.3 \%$ lived with roommates or others $(\mathrm{n}=234), 13.1 \%$ lived alone $(\mathrm{n}=112), 26.5 \%$ lived with parents $(\mathrm{n}=227), 21.7 \%$ lived with a partner $(\mathrm{n}=186)$, $5.3 \%$ had families $(n=45), 3.4 \%$ were single parents $(n=29)$, and $2.7 \%$ lived in multigenerational households $(\mathrm{n}=23)$.

The re-coded family demand variable was then ordered and re-coded, conceptually, from the lowest possible family demand to highest: Parents (0), Partner (1), Family (2), Alone (3), Child(ren) only (4), Roommate/Other (5), and Multi-generational (6). This ordering was based on a number of considerations, including literature that students living with parents show high levels of achievement (e.g., Downing, Ho, Shin, Vrijmoed, \& Wong, 2007), whereas those living with roommates show some of the lowest levels of achievement (e.g., Beekhoven, De Jong, \& Van Hout, 2004); moreover, partners can offer support as well as act as a potential demand source versus living alone where no such daily and intimate support is available. Outcome means were also examined by living situation categories. 
College success and student engagement / 90

Cumulative Demand scale creation. Cumulative demand scores were created by summing the values of the five created demand category scores. At least one category had to be present to create the cumulative demand score in order to ensure all participants received a score (51 cases were missing at least one of the category scores). Cumulative demand possible range would be from 1 (as credit load had only two categories, coded 1:part-time and 2:full-time) to 16 (cases with 6: multi-generational, 3: three of three funding sources, 3: three of three social responsibilities, 2: full-time credit load, and 2: working over 25 hours per week). The actual cumulative demand score ranged from $2-$ 16, with a mean of 8.11 (Median and Mode $=8.0$ ). While this does not weight demands by type, it does allow for levels of demands that might be present in a student's nonacademic life to be quantified.

\section{RQ1: Improved Measurement of Course Engagement.}

Does the proposed measurement tool reliably and validly assess course engagement for college students? Is class engagement structurally more complex for college students than for younger students?

The first goal of this study was refinement and validation of the engagement measure. This involved examining the structure of college course engagement (Research Question 1a), examining its relations to the classroom model (Research Question 1b), and then creating and testing a short form of course engagement that retained aspects of any multi-dimensionality found with the full item set and maintained classroom model relations (Research Question 1c). The final shortened 12 item Course Engagement scale can be seen in Table 10, under Research Question 1c. 
College success and student engagement / 91

For Research Question 1a, the fit of each CFA model was derived using maximum likelihood estimates. To assess model fit, the $X^{2}$ statistic ideally would be nonsignificant, indicating that there is no significant difference between observed and estimated covariance (between the data and the theorized model). Since $X^{2}$ can be significant even when other indices indicate an adequate and even a good fit (due to its sensitivity to sample size and to violations of the assumptions of multivariate normality), the fit indices CMIN/df, RMSEA, and CFI were also examined (Dillon, Kumar, \& Mulani, 1987; Hu \& Bentler, 1999; Kline, 2005; Tanaka, 1993). CMIN/df reports the ratio of the $X^{2}$ to the degrees of freedom as an absolute fit index. Acceptable magnitudes are variously reported from as low as 2:1 to as high as 5:1 (Hu \& Bentler, 199). The RMSEA (Root Mean Square Error of Approximation) index is a measure of error based on the difference between the observed and estimated model covariance. This noncentrality $\chi^{2}$ based index is ideally 0.08 or less for acceptable error levels in the model (values of 0.05 or less suggest low error). The CFI, a non-centrality index that looks at the relative fit of the hypothesized model against the null (independence) model, was used for nested model comparisons using the CFI difference, where a difference greater than or equal to 0.01 is considered an indication of a significant improvement in model fit (Cheung \& Rensvold, 2002). CFI values range from 0 to 1, with magnitudes greater than 0.90 considered acceptable and 0.95 considered good (Hu \& Bentler, 1999).

Research Question 1a. Is the complex factor structure hinted at in the earlier study - a four part construct with multiple behavioral dimensions (comprising in-class 
College success and student engagement / 92

engagement, out-of-class engagement, and engagement goals) - replicated with a more representative sample and additional items designed to tap these dimensions?

A goal of this dissertation was to construct a psychometrically sound and developmentally appropriate measure of engagement for college students and to examine whether the structure is similar or more complex than that found in measures of engagement for younger children. The first step in assessing the structure was to check for confirmation of four distinct, internally consistent item sets. Starting with each of the four components found in child measures (behavioral engagement, behavioral disaffection, emotional engagement, and emotional disaffection), the hypothesized multidimensional structure was examined using the full set of 47 items. For each dimension of subscale, CFAs were run and the item loadings examined. Subscale item pools were reduced as an initial step towards item reduction. This resulted in four nine-item dimensions (36 items total), with each set showing an improvement in model fit than the dimensions modeled with the full 47 item set based on CFI differences. Internal consistency was assessed with Cronbach's Alpha ( $\alpha$, correlations among items) and McDonald's Omega $\omega_{h}$, true to total item variance, the saturation of the factor by the items) statistics (Cronbach, 1951; Zinbarg, Revelle, Yovel, \& Li, 2005). If no evidence for multi-dimensionality had been found, structural analyses would have stopped. However, as expected, item sets were not uni-dimensional, so structural analyses to model the multi-dimensionality were conducted.

A series of CFAs to replicate the model fit examinations done in the 2009 thesis were conducted, but with additional items included. These CFAs first examined: (1) the 
College success and student engagement / 93

uni-dimensionality of the proposed sub-dimensions of the four individual factors, as outlined above; (2) the hierarchical structure versus uni-dimensionality of the four individual factors - Behavioral Engagement, Behavioral Disaffection, Emotional Engagement, and Emotional Disaffection; (3) followed by two sets of dual-factor compared to bi-polar models - Engagement versus Disaffection; Behavior versus Emotion; (4) then one single overall factor; and finally (5) one model consisting of all four interrelated factors.

Finally, decisions about which items to delete from the item pools in order to create the shortened 12 item Course Engagement scale which reflected the found complexity were based on statistical and theoretical considerations, including whether the items as a set mapped onto the multiple dimensions, covered the full spectrum of subsets, and functioned well in the structural models. Statistically, first the item means and standard deviations were examined to determine whether the full range of responses (1-5) was utilized, whether ceiling or floor effects were present, and whether each item showed adequate variance. Second, (a) Cronbach's alpha for each full subscale and for each subscale dimension when specific items were removed was examined to ensure scale internal consistency (based on the average inter-item correlation) above .70, and (b) coefficient Omega for single factor scales to assess uni-dimensionality (ratio of true score variance to total score variance of the scale) indicated by a value of .70 or greater. The standardized path coefficients (factor loadings) were examined as indicators of how well the item represents the latent construct (range -1.0 to +1.0 ), and the squared multiple correlations (SMCs) were also examined to assess the proportion of variance in the item 
College success and student engagement / 94

that is explained by the latent construct. The criteria for a "good" item was considered the presence of factor loadings greater than .5 and SMCs greater than .2 (Maruyama, 1998; Tabachnick \& Fidell, 2007). Theoretically, item content was examined for face validity, alternative interpretations, and connection to the overall construct definitions.

Structural and psychometric analyses for the four single-factor scales, all items. Table 4 contains item level psychometrics (means, standard deviations, skew, kurtosis, factor loading, and SMCs for each item) and scale level information (Cronbach's alpha, McDonald's omega, and fit indices for the single-factor models) for all the original items of each subscale of engagement. As can be seen, most of the items showed satisfactory psychometric properties, including the full range of responses, absence of floor or ceiling effects except for two items (ED11FM_AMOT4 and BD10_OC), factor loadings greater than .50, and SMCs greater than .20. At the level of the scale, all item pools showed high internal consistencies ( .80 or higher), but not acceptable omegas. Considering the hypothesized multidimensionality of the engagement subscales, it was not expected that the omegas would indicate one-dimensional factor saturation by the items.

Uni-dimensionality of the items pools. The uni-dimensionality of the item pools was examined for each subscale by conducting a CFA for a one-factor model in which all the items in the respective subscale loaded on a single factor. These are also presented in Table 4. None of the initial item pools were a particularly good fit to single-factor models. CFIs ranged from .78 to .87 ; CMIN/dfs ranged from 9.73 to 22.22 , and RMSEAs ranged from .10 to .16 . 
College success and student engagement / 95

Table 4. Structural and Psychometric analyses for the four, single-factor scales - all items.

\begin{tabular}{|c|c|c|c|c|c|}
\hline \multicolumn{6}{|l|}{ Emotional Engagement } \\
\hline$\chi^{2}$ & $\alpha$ & $\omega_{h}$ & $C M I N / d f$ & RMSEA & $C F I$ \\
\hline \multirow[t]{2}{*}{$996.5(54), \quad p<.00$} & 0.93 & 0.63 & 18.46 & 0.14 & 0.86 \\
\hline & $M(S D)$ & Skew & Kurtosis & $\lambda(S t d)$ & $R^{2}$ \\
\hline $\begin{array}{l}\text { EE1_OC The material we } \\
\text { cover is interesting. }\end{array}$ & $3.93(1.06)$ & -0.79 & -0.01 & 0.75 & 0.57 \\
\hline $\begin{array}{l}\text { EE10_IC The instructor gives } \\
\text { great lectures. }\end{array}$ & $3.67(1.31)$ & -0.64 & -0.74 & 0.76 & 0.58 \\
\hline $\begin{array}{l}\text { EE11_IC The material we } \\
\text { cover in class is challenging } \\
\text { (in a good way). }\end{array}$ & $3.29(1.20)$ & -0.24 & -0.79 & 0.61 & 0.38 \\
\hline $\begin{array}{l}\text { EE12_OA This class gets my } \\
\text { mind bubbling with thoughts } \\
\text { and ideas. }\end{array}$ & $3.19(1.21)$ & -0.17 & -0.88 & 0.69 & 0.48 \\
\hline $\begin{array}{l}\text { EE13_IC Time flies when I'm } \\
\text { in this class. }\end{array}$ & $2.68(1.29)$ & 0.24 & -1.00 & 0.73 & 0.54 \\
\hline $\begin{array}{l}\text { EE14_OC I like telling others } \\
\text { about what I've learned in this } \\
\text { class. }\end{array}$ & $3.65(1.25)$ & -0.67 & -0.57 & 0.66 & 0.44 \\
\hline EE2_OA This class is fun. & $3.44(1.26)$ & -0.42 & -0.82 & 0.79 & 0.62 \\
\hline $\begin{array}{l}\text { EE3_IC I enjoy the time I } \\
\text { spend in this class. }\end{array}$ & $3.21(1.26)$ & -0.12 & -1.01 & 0.86 & 0.73 \\
\hline $\begin{array}{l}\text { EE5_IC I look forward to this } \\
\text { class. }\end{array}$ & $3.19(1.28)$ & -0.18 & -1.00 & 0.87 & 0.75 \\
\hline $\begin{array}{l}\text { EE7_OA It's exciting to make } \\
\text { connections between the ideas } \\
\text { learned in this class. }\end{array}$ & $3.97(1.08)$ & -0.90 & 0.03 & 0.64 & 0.41 \\
\hline $\begin{array}{l}\text { EE8_OA It's really fun to } \\
\text { think about the material for } \\
\text { this class. }\end{array}$ & $3.46(1.18)$ & -0.38 & -0.69 & 0.77 & 0.60 \\
\hline $\begin{array}{l}\text { EE9_OC The readings for this } \\
\text { class are interesting. }\end{array}$ & $3.45(1.15)$ & -0.39 & -0.60 & 0.62 & 0.39 \\
\hline
\end{tabular}


Table 4. Structural and Psychometric analyses for the four, single factor scales - all items (continued).

\begin{tabular}{|c|c|c|c|c|c|}
\hline $\begin{array}{l}\text { Emotional Disaffection } \\
\qquad \chi^{2}\end{array}$ & $\alpha$ & $\omega_{h}$ & $C M I N / d f$ & RMSEA & CFI \\
\hline \multirow[t]{2}{*}{$\begin{array}{l}11 \\
\text { item }\end{array}$} & 0.86 & 0.58 & 22.22 & 0.16 & 0.78 \\
\hline & $M(S D)$ & Skew & Kurtosis & $\lambda(S t d)$ & $R^{2}$ \\
\hline ED1_BU This class is no fun. & $1.76(1.13)$ & 1.46 & 1.18 & 0.76 & 0.58 \\
\hline $\begin{array}{l}\text { ED10_WA When assignments } \\
\text { are coming up in this class, I } \\
\text { worry a lot. }\end{array}$ & $2.75(1.31)$ & 0.31 & -1.01 & 0.15 & 0.02 \\
\hline $\begin{array}{l}\text { ED11_BU The instructor's } \\
\text { lectures are pretty dull. }\end{array}$ & $2.14(1.31)$ & 0.90 & -0.38 & 0.73 & 0.53 \\
\hline $\begin{array}{l}\text { ED11_FM_AMOT4 I don't } \\
\text { really care about how well I do } \\
\text { in this class. }\end{array}$ & $1.35(0.78)$ & 2.59 & 6.78 & 0.33 & 0.11 \\
\hline $\begin{array}{l}\text { ED12_WA I feel overwhelmed } \\
\text { in this class. }\end{array}$ & $1.93(1.12)$ & 1.13 & 0.46 & 0.32 & 0.10 \\
\hline $\begin{array}{l}\text { ED13_FM Sitting in class is a } \\
\text { waste of my time. }\end{array}$ & $1.75(1.15)$ & 1.49 & 1.21 & 0.77 & 0.59 \\
\hline $\begin{array}{l}\text { ED14_FM If I could have } \\
\text { gotten out of taking this class, } \\
\text { I would have. }\end{array}$ & $1.70(1.19)$ & 1.70 & 1.74 & 0.62 & 0.39 \\
\hline $\begin{array}{l}\text { ED2_BU When in class, I feel } \\
\text { bored. }\end{array}$ & $2.61(1.33)$ & 0.39 & -0.99 & 0.78 & 0.61 \\
\hline $\begin{array}{l}\text { ED3_FM When I am in this } \\
\text { class, I can't wait for it to be } \\
\text { over. }\end{array}$ & $2.36(1.29)$ & 0.66 & -0.67 & 0.82 & 0.67 \\
\hline $\begin{array}{l}\text { ED8_WA I dread going to this } \\
\text { class. }\end{array}$ & $1.81(1.13)$ & 1.31 & 0.81 & 0.76 & 0.58 \\
\hline $\begin{array}{l}\text { ED9_WA This class is } \\
\text { stressing me out. }\end{array}$ & $2.04(1.22)$ & 1.00 & -0.05 & 0.39 & 0.16 \\
\hline
\end{tabular}


Table 4. Structural and Psychometric analyses for the four, single factor scales - all items (continued).

\begin{tabular}{|c|c|c|c|c|c|}
\hline $\begin{array}{c}\text { Behavioral Engagement } \\
\chi^{2}\end{array}$ & $\alpha$ & $\omega_{h}$ & $C M I N / d f$ & RMSEA & $C F I$ \\
\hline \multirow[t]{2}{*}{$\begin{array}{cc}12 \\
\text { item }\end{array} \quad 619.58(54), \mathrm{p}<.00$} & 0.88 & 0.64 & 11.47 & 0.11 & 0.86 \\
\hline & $M(S D)$ & Skew & Kurtosis & $\lambda(S t d)$ & $R^{2}$ \\
\hline $\begin{array}{l}\text { BE1_AB I try hard to do well } \\
\text { in this class. }\end{array}$ & $3.87(0.99)$ & -0.74 & 0.16 & 0.69 & 0.48 \\
\hline $\begin{array}{l}\text { BE11_AB I try to get the most } \\
\text { I can out of this class. }\end{array}$ & $3.58(1.17)$ & -0.45 & -0.69 & 0.75 & 0.56 \\
\hline $\begin{array}{l}\text { BE13_AB This class makes } \\
\text { me want to learn more about } \\
\text { the topic. }\end{array}$ & $3.76(1.15)$ & -0.68 & -0.37 & 0.51 & 0.26 \\
\hline $\begin{array}{l}\text { BE14_IC I try hard to } \\
\text { understand the professor's } \\
\text { lectures. }\end{array}$ & $3.60(1.31)$ & -0.68 & -0.66 & 0.43 & 0.19 \\
\hline $\begin{array}{l}\text { BE15_OC I keep up with the } \\
\text { work for this class. }\end{array}$ & 3.87 (1.09) & -0.79 & -0.06 & 0.49 & 0.24 \\
\hline $\begin{array}{l}\text { BE16_IC When in class, I } \\
\text { keep track of things I don't } \\
\text { understand. }\end{array}$ & $2.91(1.20)$ & -0.02 & -0.91 & 0.53 & 0.28 \\
\hline $\begin{array}{l}\text { BE17_AB I work hard to } \\
\text { really understand the material } \\
\text { covered in this class }\end{array}$ & $3.43(1.17)$ & -0.26 & -0.79 & 0.79 & 0.62 \\
\hline $\begin{array}{l}\text { BE18_OC I set aside study } \\
\text { time for this class. }\end{array}$ & $3.00(1.26)$ & 0.10 & -1.03 & 0.67 & 0.45 \\
\hline $\begin{array}{l}\text { BE2_IC I pay attention in } \\
\text { class. }\end{array}$ & $3.86(1.03)$ & -0.79 & 0.19 & 0.63 & 0.39 \\
\hline $\begin{array}{l}\text { BE5_IC When the instructor } \\
\text { explains new material, I take } \\
\text { careful notes. }\end{array}$ & $3.15(1.37)$ & -0.15 & -1.19 & 0.64 & 0.41 \\
\hline $\begin{array}{l}\text { BE7_OC I stay current with } \\
\text { the readings. }\end{array}$ & $2.96(1.25)$ & -0.04 & -1.01 & 0.60 & 0.36 \\
\hline BE9_OC I study for this class. & $3.62(1.17)$ & -0.43 & -0.77 & 0.73 & 0.54 \\
\hline
\end{tabular}


Table 4. Structural and Psychometric analyses for the four, single factor scales - all items (continued).

\begin{tabular}{|c|c|c|c|c|c|}
\hline \multicolumn{6}{|l|}{ Behavioral Disaffection } \\
\hline$\chi^{2}$ & $\alpha$ & $\omega_{h}$ & $C M I N / d f$ & RMSEA & $C F I$ \\
\hline \multirow[t]{2}{*}{$\begin{array}{c}12 \\
\text { item }\end{array}$} & 0.87 & 0.58 & 9.73 & 0.10 & 0.87 \\
\hline & $M(S D)$ & Skew & Kurtosis & $\lambda(S t d)$ & $R^{2}$ \\
\hline $\begin{array}{l}\text { BD10_OC I don't even try to } \\
\text { keep up with the homework. }\end{array}$ & $1.44(0.84)$ & 2.18 & 4.63 & 0.53 & 0.28 \\
\hline $\begin{array}{l}\text { BD11_OC I don't really } \\
\text { study for the class. }\end{array}$ & $2.14(1.19)$ & 0.81 & -0.31 & 0.70 & 0.49 \\
\hline $\begin{array}{l}\text { BD12_IC I work on other } \\
\text { things when I'm in this class. }\end{array}$ & $2.00(1.26)$ & 1.02 & -0.19 & 0.48 & 0.23 \\
\hline $\begin{array}{l}\text { BD13_IC It's hard to make } \\
\text { myself come to this class. }\end{array}$ & $2.17(1.30)$ & 0.80 & -0.57 & 0.53 & 0.28 \\
\hline $\begin{array}{l}\text { BD14_CL I just learned the } \\
\text { stuff in class to pass the } \\
\text { test(s) }\end{array}$ & $2.32(1.31)$ & 0.62 & -0.82 & 0.55 & 0.30 \\
\hline $\begin{array}{l}\text { BD15_CL_AMOT2 I don't } \\
\text { care if I miss class. }\end{array}$ & $1.97(1.17)$ & 1.04 & 0.05 & 0.51 & 0.26 \\
\hline $\begin{array}{l}\text { BD15_OC Anything I do for } \\
\text { this class is always last } \\
\text { minute. }\end{array}$ & $2.38(1.27)$ & 0.62 & -0.70 & 0.64 & 0.41 \\
\hline $\begin{array}{l}\text { BD16_OC Outside of class, I } \\
\text { don't put much work in on } \\
\text { this course. }\end{array}$ & $2.43(1.21)$ & 0.52 & -0.70 & 0.76 & 0.58 \\
\hline $\begin{array}{l}\text { BD2_CL I don't try very hard } \\
\text { in this class. }\end{array}$ & $2.08(1.18)$ & 0.83 & -0.33 & 0.77 & 0.60 \\
\hline $\begin{array}{l}\text { BD3_CL In this class, I do } \\
\text { just enough to get by. }\end{array}$ & $2.32(1.28)$ & 0.60 & -0.81 & 0.66 & 0.44 \\
\hline $\begin{array}{l}\text { BD4_IC When I'm in this } \\
\text { class, my mind wanders. }\end{array}$ & $2.96(1.27)$ & 0.17 & -1.01 & 0.54 & 0.30 \\
\hline $\begin{array}{l}\text { BD7_IC I don't try to take } \\
\text { good notes in this class. }\end{array}$ & $2.19(1.36)$ & 0.79 & -0.70 & 0.50 & 0.25 \\
\hline
\end{tabular}

Note. $N=856$. Response range from 1 (Not true) to 5 (Totally true). 
College success and student engagement / 99

As hypothesized in this study, for the item sets measuring Emotional

Engagement, Emotional Disaffection, Behavioral Engagement and Behavioral

Disaffection, the multi-dimensionality indicated previously within the subscales of engagement were modeled, and uni-dimensionality was examined for each hypothesized sub-dimension. As described for the analyses of each of the subcomponents below, the final reduced factor scales consisted of nine items representing emotional engagement, nine emotional disaffection items representing three sub-dimensions within disaffected emotions, nine behavioral engagement items representing three sub-dimensions of engaged behaviors, and nine behavioral disaffection items representing three subdimensions of disaffected behaviors. The item level and scale level psychometric properties of these engagement components are summarized in Table 1.

Emotional engagement. The three sub-dimensions of within emotional engagement were hypothesized as consisting of : (1) positive emotions experienced in class ('In-class, or IC), consisting of five items; (2) positive emotions about the class experienced outside the classroom ('Out-of -class, or OC), made up of three items; and (3) a generally positive outlook around the class and learning ('Overarching', or OA), with four items. As a just identified model with zero degrees of freedom, the model fit for the 'Out-of-class' sub-dimension could not be computed. However, the uni-dimensional model fit to the data for the other two sub-dimensions was supported: Overarching with $\chi^{2}(2,856)=6.19, p=.045, \mathrm{CFI}=.99, \mathrm{CMIN} / \mathrm{df}=3.09, \mathrm{RMSEA}=.05$; and In-class at $\chi^{2}(5,856)=4.41, p=.492, \mathrm{CFI}=1.00, \mathrm{CMIN} / \mathrm{df}=.88, \mathrm{RMSEA}=.00$. While the 12-item based on the CFI difference (.06) it was a better fit than the model of a uni-dimensional 
College success and student engagement / 100

Table 5. Psychometrics for the four dimensions -36 items (reduced full scale).

\begin{tabular}{|c|c|c|c|c|c|}
\hline \multicolumn{6}{|l|}{ Emotional Engagement (EE6) } \\
\hline$\chi^{2}$ & $\omega_{h}$ & $C M I N / d f$ & $R M S E A$ & $C F I$ & $\begin{array}{l}12 \text { item } \Delta \\
C F I\end{array}$ \\
\hline \multirow[t]{2}{*}{9 items } & 0.91 & 12.86 & 0.12 & 0.93 & 0.07 \\
\hline & $M(S D)$ & Skew & Kurtosis & $\lambda(S t d)$ & $R^{2}$ \\
\hline $\begin{array}{l}\text { EE11_IC The material we } \\
\text { cover in class is challenging } \\
\text { (in a good way). }\end{array}$ & $3.29(1.20)$ & -0.24 & -0.79 & 0.60 & 0.36 \\
\hline $\begin{array}{l}\text { EE3_IC I enjoy the time I } \\
\text { spend in this class }\end{array}$ & $3.21(1.26)$ & -0.12 & -1.01 & 0.74 & 0.55 \\
\hline $\begin{array}{l}\text { EE12_OA This class gets my } \\
\text { mind bubbling with thoughts } \\
\text { and ideas. }\end{array}$ & $3.19(1.21)$ & -0.17 & -0.88 & 0.74 & 0.55 \\
\hline EE2_OA This class is fun. & $3.44(1.26)$ & -0.42 & -0.82 & 0.67 & 0.45 \\
\hline $\begin{array}{l}\text { EE7_OA It's exciting to } \\
\text { make connections between } \\
\text { the ideas learned in this class }\end{array}$ & $3.97(1.08)$ & -0.90 & 0.03 & 0.72 & 0.52 \\
\hline $\begin{array}{l}\text { EE8_OA It's really fun to } \\
\text { think about the material for } \\
\text { this class. }\end{array}$ & $3.46(1.18)$ & -0.38 & -0.69 & 0.85 & 0.71 \\
\hline $\begin{array}{l}\text { EE1_OC The material we } \\
\text { cover is interesting. }\end{array}$ & $3.93(1.06)$ & -0.79 & -0.01 & 0.82 & 0.67 \\
\hline $\begin{array}{l}\text { EE9_OC The readings for } \\
\text { this class are interesting. }\end{array}$ & $3.45(1.15)$ & -0.39 & -0.60 & 0.69 & 0.48 \\
\hline $\begin{array}{l}\text { EE14_OC I like telling other } \\
\text { about what I've learned in } \\
\text { this class. }\end{array}$ & $3.65(1.25)$ & -0.67 & -0.57 & 0.74 & 0.54 \\
\hline
\end{tabular}


Table 5. Psychometrics for the four dimensions - 36 items (reduced full scale; continued)

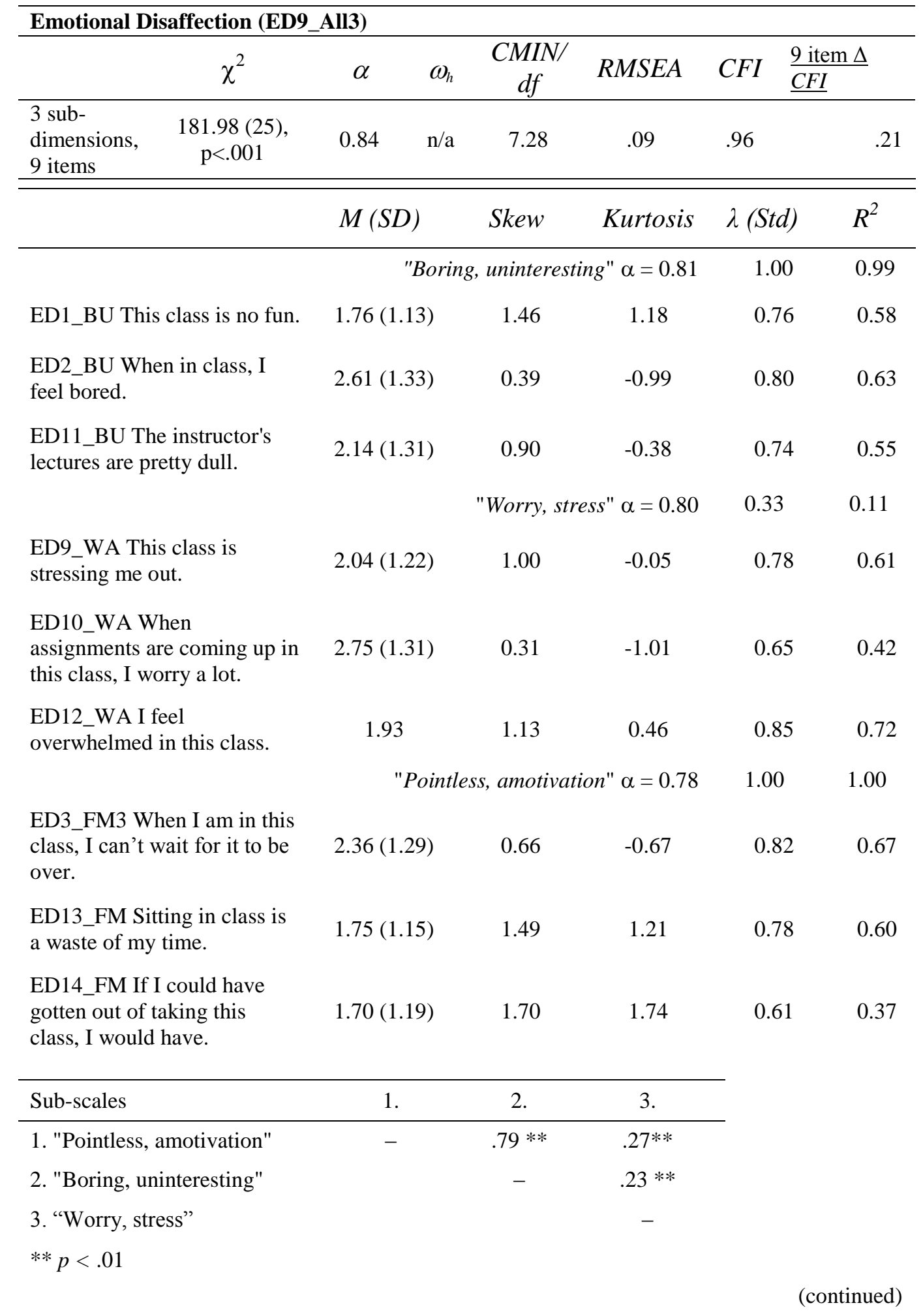


Table 5. Psychometrics for the four dimensions - 36 items (reduced full scale; continued)

\begin{tabular}{|c|c|c|c|c|c|}
\hline \multicolumn{6}{|c|}{ Behavioral Engagement (BE9_All3) } \\
\hline$\chi^{2}$ & $\omega_{h}$ & $C M I N / d f$ & RMSEA & $C F I$ & $\begin{array}{l}\text { item } \Delta \\
C F I\end{array}$ \\
\hline \multirow[t]{3}{*}{$\begin{array}{l}\text { sub- } \\
\text { dimensions, } \\
9 \text { items } \\
\end{array}$} & 0.83 & 6.70 & 0.08 & 0.94 & 0.02 \\
\hline & $M(S D)$ & Skew & Kurtosis & $\lambda(S t d)$ & $R^{2}$ \\
\hline & \multicolumn{3}{|c|}{ "In-Class" $\alpha=0.57$} & 0.93 & 0.86 \\
\hline $\begin{array}{l}\text { BE2_IC I pay attention in } \\
\text { class. }\end{array}$ & $3.86(1.03)$ & -0.79 & 0.19 & 0.73 & 0.53 \\
\hline $\begin{array}{l}\text { BE14_IC I try hard to } \\
\text { understand the professor's } \\
\text { lectures. }\end{array}$ & $3.60(1.31)$ & -0.68 & -0.66 & 0.43 & 0.19 \\
\hline \multirow{2}{*}{$\begin{array}{l}\text { BE16_IC When in class, I } \\
\text { keep track of things I don't } \\
\text { understand. }\end{array}$} & $2.91(1.20)$ & -0.02 & -0.91 & 0.52 & 0.27 \\
\hline & \multicolumn{3}{|c|}{ "Above and beyond" $\alpha=0.72$} & 1.00 & 1.00 \\
\hline $\begin{array}{l}\text { BE1_AB I try hard to do well } \\
\text { in this class. }\end{array}$ & $3.87(0.99)$ & -0.74 & 0.16 & 0.66 & 0.44 \\
\hline $\begin{array}{l}\text { BE11_AB I try to get the } \\
\text { most I can out of this class. }\end{array}$ & 3.58 (1.17) & -0.45 & -0.69 & 0.83 & 0.68 \\
\hline \multirow[t]{2}{*}{$\begin{array}{l}\text { BE13_AB This class makes } \\
\text { me want to learn more about } \\
\text { the topic. }\end{array}$} & \multirow[t]{2}{*}{$3.76(1.15)$} & -0.68 & -0.37 & 0.60 & 0.37 \\
\hline & & "Out-of-clas & $s^{\prime \prime} \alpha=0.70$ & 0.81 & 0.65 \\
\hline $\begin{array}{l}\text { BE15_OC I keep up with the } \\
\text { work for this class. }\end{array}$ & 3.87 (1.09) & -0.79 & -0.06 & 0.57 & 0.32 \\
\hline $\begin{array}{l}\text { BE7_OC I stay current with } \\
\text { the readings. }\end{array}$ & $2.96(1.25)$ & -0.04 & -1.01 & 0.70 & 0.48 \\
\hline $\begin{array}{l}\text { BE9_OC I study for this } \\
\text { class. }\end{array}$ & $3.62(1.17)$ & -0.43 & -0.77 & 0.72 & 0.52 \\
\hline Sub-scales & 1. & 2. & 3. & & \\
\hline 1. "Above and beyond" & - & $.59 * *$ & $.61 * *$ & & \\
\hline \multicolumn{2}{|l|}{ 2. "Out-of-class" } & - & $.46 * *$ & & \\
\hline \multicolumn{2}{|l|}{ 3. "In-class" } & & - & & \\
\hline \multicolumn{2}{|l|}{$* * p<.01$} & & & & \\
\hline
\end{tabular}

(continued) 
Table 5. Psychometrics for the four dimensions - 36 items (reduced full scale; continued)

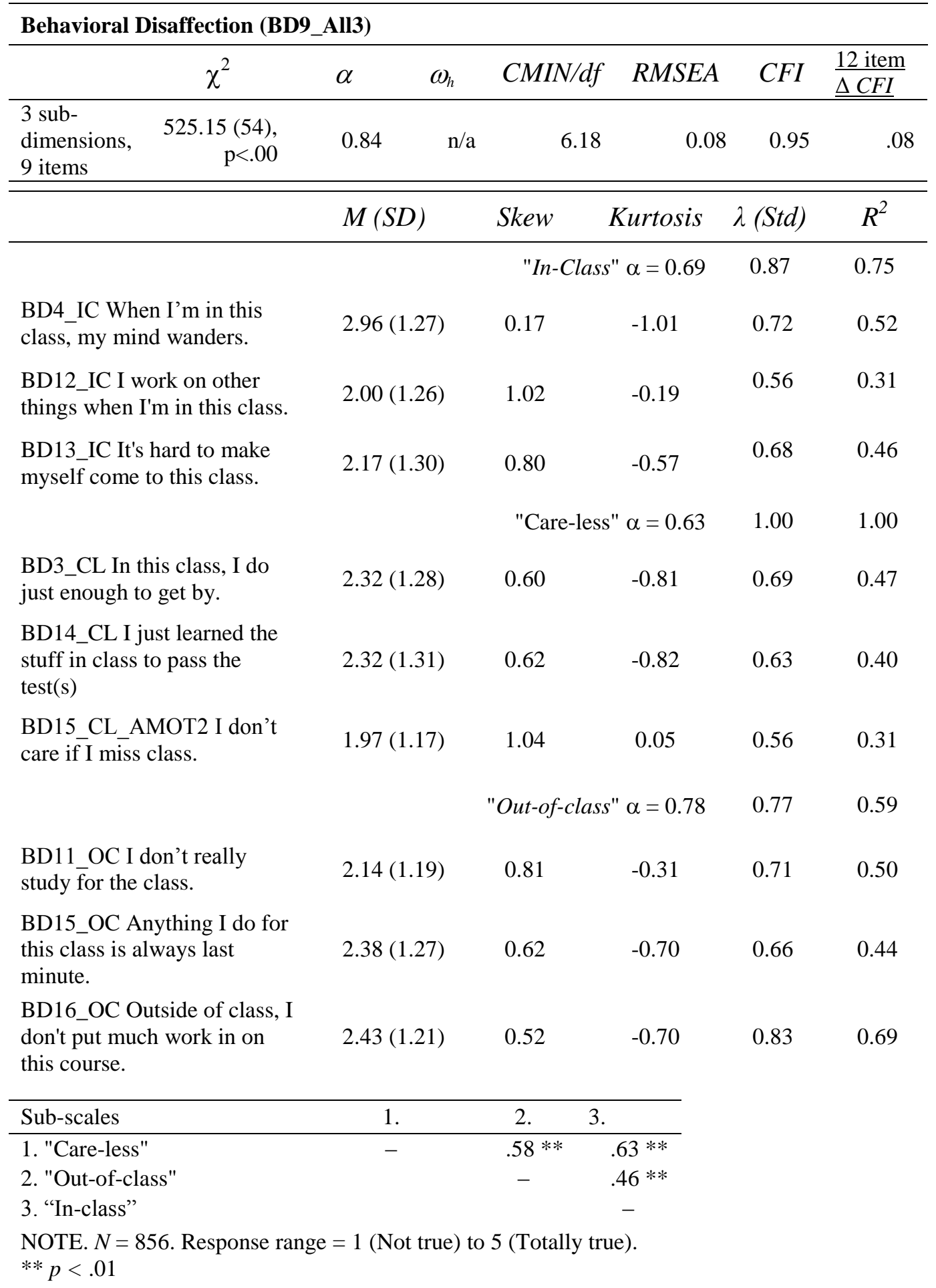


College success and student engagement / 104

model of these three sub-dimensions within emotional engagement was not a good fit to the data $\left(\chi^{2}(52,856)=611.824, p=.000, \mathrm{CFI}=.92, \mathrm{CMIN} / \mathrm{df}=11.77, \mathrm{RMSEA}=.11\right)$, factor of emotional engagement (12-item CFI of .86 minus the 12-item, three subdimensions CFI of .92) once the error variance for the 'Overarching' sub-dimension was set to .0001 . The error variance for this sub-dimension in the hierarchical model was negative (-0.12), necessitating setting a positive error variance to address this Heywood case (Dillon et al., 1987).

Three items were removed from the hierarchical model, all from the 'In-class' sub-dimension, based on high covariance between four of the items in this scale. "The instructor gives great lectures" (EE10_IC), "Time flies when I'm in this class" (EE13_IC), and "I look forward to this class" (EE5_IC) all showed possible colinearity with "I enjoy the time I spend in this class" (EE3_IC).

The resultant nine-item Emotional Engagement hierarchical factor showed a significant CFI difference of .01 from the 12 item hierarchical factor $\left(\chi^{2}(25,856)=327.33, p<.001, \mathrm{CFI}=.93, \mathrm{CMIN} / \mathrm{df}=13.09, \mathrm{RMSEA}=.12\right)$, though not from a nine-item uni-dimensional emotional engagement factor $\left(\chi^{2}(27,856)=347.20, p<\right.$ $.001, \mathrm{CFI}=.93, \mathrm{CMIN} / \mathrm{df}=12.86, \mathrm{RMSEA}=.12$ ). The nine-item uni-dimensional scale was thus carried forward into the analyses for Research Questions 1b and 1c.

Emotional disaffection. The 11 emotional disaffection item responses were modeled based on the a-priori sub-dimensions of "Boring, uninteresting" (BU, three items), "Worry, stress" (WA, four items), and "Pointless, Amotivation" (FM, four items). 
Again, model fit statistics were not computed for the "Boring, uninteresting" subdimension based on the model being just identified (no degrees of freedom). The unidimensional model fit for the other two sub-dimensions was close to acceptable ("Worry": $\chi^{2}(2,856)=16.94, p<.001, \mathrm{CFI}=.98, \mathrm{CMIN} / \mathrm{df}=8.47$, RMSEA $=.09$; and "Pointless": $\left.\chi^{2}(2,856)=14.50, p<.001, \mathrm{CFI}=.99, \mathrm{CMIN} / \mathrm{df}=7.25, \mathrm{RMSEA}=.09\right)$. Modeling these three sub-dimensions in a hierarchical structure of emotional disaffection proved to be a better fit to the data than a one-dimensional 11-item measure based on a CFI difference of $0.06\left(\chi^{2}(42,856)=749.31, p<.001, \mathrm{CFI}=.84, \mathrm{CMIN} / \mathrm{df}=17.84\right.$, RMSEA $=.14$ ) once the error variance for the Pointless sub-dimension was set to .0001 .

A similar approach as with emotional engagement was used to reduce items from this 11-item pool. Two items were removed. "I dread going to this class" (ED8_WA) was removed based on the extreme wording and having the lowest factor loading onto the subdimesion of WA. "I don't really care about how well I do in this class" (ED11_FM_AMOT4) was removed based on initial loading and SMC, as well as theoretical and face validity reasons.

Model fit indices for this nine-item hierarchical model were acceptable $\left(\chi^{2}(25,856)=181.98, p<.001, \mathrm{CFI}=.96, \mathrm{CMIN} / \mathrm{df}=7.28, \mathrm{RMSEA}=.09\right)$ and internal consistency for this scale was still above .80 (see Table 5). The data were a better fit to a model with three sub-dimensions than the single factor nine-item model $\left(\chi^{2}(27,856)=915.23, p<.001, \mathrm{CFI}=.75, \mathrm{CMIN} / \mathrm{df}=33.90, \mathrm{RMSEA}=.20\right)$ as indicated by a large CFI difference of .21 (nine-item CFI $=.75$ minus the nine-item/three dimensions CFI $=.96$ ), and the correlations between the sub-dimensions were all 
College success and student engagement / 106 significant at the $p<.01$ level (Pointless with Worry $r=.27$; Pointless with Boring $r=$ .79; Boring with Worry $r=.23$ ). The final 9-Item Emotional Disaffection hierarchical factor showed good item-level psychometric characteristics, and was used in the subsequent analyses in Research Question $1 \mathrm{~b}$ and to select items for the composite scale in Research Question 1c.

Behavioral engagement. The 12 behavioral engagement item responses were modeled based on the a-priori sub-dimensions of four items each: "In-class" (IC);“"Outof-class" (OC); and "Above-and-beyond" (AB). Of the three sub-dimensions, only "Inclass" demonstrated good uni-dimensional model fit indices $\left(\chi^{2}(2,856)=4.98, p=.083\right.$, $\mathrm{CFI}=1.00, \mathrm{CMIN} / \mathrm{df}=2.49, \mathrm{RMSEA}=.04)$. Both "Above-and-beyond" and "Out-ofclass" did not show uni-dimensionality $\left(\mathrm{AB}: \chi^{2}(2,856)=43.52, p<.001, \mathrm{CFI}=.96\right.$, $\mathrm{CMIN} / \mathrm{df}=21.76, \mathrm{RMSEA}=.16 ;$ and OC: $\chi^{2}(2,856)=42.28, p<.001, \mathrm{CFI}=.96$, $\mathrm{CMIN} / \mathrm{df}=21.14, \mathrm{RMSEA}=.15)$. However, when modeled hierarchically, the 12-item three sub-dimensional model was a better fit to the data $\left(\chi^{2}(52,856)=391.45, p<.001\right.$, $\mathrm{CFI}=.92, \mathrm{CMIN} / \mathrm{df}=7.53, \mathrm{RMSEA}=.09)$ than the 12 -item uni-dimensional model $(\mathrm{CFI}$ difference of .06) once the error variance for the "Above-and-beyond" sub-dimension was set to .0001 .

After considerable scrutiny and modeling, three items were removed. The three removed items - "I work really hard to understand the material covered in this class" (BE17_AB), "I set aside study time for this class" (BE18_OC), and "When the instructor explains new material, I take careful notes" (BE5_IC) - were removed based on language (intensity and choice) and on item redundancy. 
College success and student engagement / 107

The model fit indices supported the sub-dimensions as belonging to the higher order nine-item construct of behavioral engagement $\left(\chi^{2}(25,856)=167.51, p<.001\right.$, CFI $=.94, \mathrm{CMIN} / \mathrm{df}=6.70, \mathrm{RMSEA}=.08)$ better than the 12 -item hierarchical model $(\mathrm{CFI}$ difference $=.02$ ). In addition, the data were a better fit to a three sub-dimension model than the single factor nine-item model $\left(\chi^{2}(27,856)=252.23, p<.001, \mathrm{CFI}=.90\right.$, $\mathrm{CMIN} / \mathrm{df}=9.34, \mathrm{RMSEA}=.10)$ based on a CFI difference of .04 . The correlations between these three subsets were high and significant at the $p<.01$ level (In-class with Out-of-class $r=.46$; In-class with Above-and-beyond $r=.61$; Out-of class with Aboveand-beyond $r=.59$ ), supporting the notion of a hierarchical structure for behavioral engagement. As can be seen in Table 5, the final 9-item behavioral engagement subscale showed good item level characteristics, had high internal consistency $(\alpha=.83)$, and was used for the subsequent analyses in Research Question $1 \mathrm{~b}$ and for item selection in Research Question 1c.

Behavioral disaffection. Using the same procedures, a similar structure was modeled a-priori within the behavioral disaffection item pool. The 12 behavioral engagement item responses were modeled based on the a-prior four-item sub-dimensions of "In-class" (IC), "Out-of-class" (OC) and "Care-less" (CL). All three sub-dimensions showed adequate model fit indices: In-class at $\chi^{2}(2,856)=15.63, p<.00, \mathrm{CFI}=.93$, $\mathrm{CMIN} / \mathrm{df}=7.82, \mathrm{RMSEA}=.09 ;$ Out-of-class at $\chi^{2}(2,856)=3.87, p<.00, \mathrm{CFI}=1.00$, $\mathrm{CMIN} / \mathrm{df}=1.94, \mathrm{RMSEA}=.03 ;$ and Care-less at $\chi^{2}(2,856)=7.69, p<.05, \mathrm{CFI}=.99$ $\mathrm{CMIN} / \mathrm{df}=3.84, \mathrm{RMSEA}=.06$. This 12 -item hierarchical model was a better fit to the data $\left(\chi^{2}(52,856)=394.63, p<.00, \mathrm{CFI}=.90, \mathrm{CMIN} / \mathrm{df}=7.59, \mathrm{RMSEA}=.09\right)$ than the 
College success and student engagement / 108 12-item uni-dimensional model of the behavioral disaffection factor (CFI difference $=$ .03 ) once the error for Care-less was set to .0001 .

After running various models, three items were removed. The item "I don't even try to keep up with the homework" (BD10_OC) was removed based on extreme wording and the validity of having homework in the surveyed class, as well as showing high skew and kurtosis. "I don't try very hard in this class" (BE2_CL) was removed based on the probability of being a complex item (loading on all three factors strongly) based on various ways of applying the phrase. Similarly, “I don't try to take good notes in this class" (BD7_IC) was removed based on extreme and/or confusing wording.

When these three dimensions were fit to a nine-item hierarchical model nested within behavioral disaffection, the model fit indices supported these sub-dimensions as belonging to the higher order construct $\left(\chi^{2}(25,856)=154.50, p<.00, \mathrm{CFI}=.95\right.$, $\mathrm{CMIN} / \mathrm{df}=6.18, \mathrm{RMSEA}=.08$ ), and was a better fit than the nine-item single factor model $\left(\chi^{2}(27,856)=378.52, p<.00, \mathrm{CFI}=.85, \mathrm{CMIN} / \mathrm{df}=14.02, \mathrm{RMSEA}=.12\right)$ based on a CFI difference of .10. The correlations between the subsets were acceptable ( $p<$ .01 ), supporting the notion of a hierarchical structure for behavioral disaffection (In-class with Out-of-class $r=.46$; In-class with Care-less $r=.63$; Out-of-class with Care-less $r=$ .58). The 9-Item behavioral disaffection subscale, as can be seen in Table 5, showed good item level characteristics, an acceptable fit to a hierarchical model, and a high internal consistency $(\alpha=.84)$, and was used for the subsequent analyses in Research Question $1 \mathrm{~b}$ and for the composite scale item selection in Research Question 1c. 
College success and student engagement / 109

Bipolar versus multi-dimensional construct. The second step in assessing the structure of engagement for college students was to examine whether the structure of the engagement/disaffection construct is best conceptualized as bipolar (i.e., engagement versus disaffection) or multidimensional (i.e., engagement and disaffection) and whether these dimensions should be further distinguished by behavioral and emotional components.

A series of confirmatory factor analyses (CFAs) organized into three sets were conducted using AMOS 17.0: (1) to examine whether, within engagement and within disaffection, behavior and emotion should be combined (one-factor model) or should be distinguished (two-factor model); (2) to examine whether, within behavior and within emotion, engagement and disaffection are bipolar (one-factor model) or should be distinguished (two-factor model); and (3) to examine whether overall engagement should be considered a single bipolar dimension (one-factor model) or should be marked by emotional and behavioral components (two-factor model), by engagement and disaffection components (two-factor model), or by all four factors. Bi-polar to multidimensional model fit indices and comparisons are summarized in Table 6, a-g.

(1a) Engagement and disaffection - Behavior. The first pair of models to examine whether engagement and disaffection should be combined or distinguished were based on the behavioral components. Analyses compared a model in which items marking Behavioral Engagement and Behavioral Disaffection loaded on two different correlated factors (two-factor model, Model 2.22) and a model in which they loaded on the same factor with behavioral engagement items loading positively and behavioral disaffection 
College success and student engagement / 110

Table 6. (a-g) Bi-polar model fit comparisons,(h) four-factor model intercorrelations.

\begin{tabular}{rlllll}
\hline Model & $\chi^{2}(d f)$ & $C M I N / d f$ & $C F I$ & $R M S E A$ & $C^{2} I_{\text {diff }}$
\end{tabular}

6a. Behavioral engagement and disaffection. $r=-0.89$

1. One-Factor Behavior

EngDis (1.22)

2. Two-factor BehEng \&

BehDis (2.22)

Difference between Model 2 and Model 1

$\begin{array}{cccc}\begin{array}{c}1132.50^{*} \\ (131)\end{array} & 8.65 & 0.83 & 0.10 \\ \begin{array}{c}841.42 * \\ (130)\end{array} & 8.17 & 0.85 & 0.09\end{array}$

0.02

6b. Emotional engagement and disaffection. $r=-0.80$

3. One-Factor Emotional 1648.53*

EngDis (1.21)

4. Two-factor EmoEng \&

EmoDis (2.21)

(134)

$1122.37 *$

(133) $\begin{array}{lll}12.30 & 0.83 \quad 0.12\end{array}$

$\begin{array}{lll}8.44 & 0.89 & 0.09\end{array}$

Difference between Model 4 and Model 3

0.06

6c. Emotional and behavioral engagement. $r=.92$

5. One-Factor Engaged

EmoBeh (1.31)

6. Two-factor Engaged Emo

\& Beh (2.31)

Difference between Model 6 and Model 5
$1301.43 *$

$$
9.79
$$

$1252.63^{*}$

(132)
$0.85 \quad 0.10$

$9.49 \quad 0.86 \quad 0.10$

0.01

6d. Emotional and behavioral disaffection. $r=.89$

$\begin{array}{lcccc}\text { 7. One-Factor Disaffected } & 1004.63 * & 7.55 & 0.88 & 0.09 \\ \text { EmoBeh (1.32) } & (133) & & & \\ \text { 8. Two-factor Disaffected } & 896.67 * & 6.79 & 0.89 & 0.08 \\ \text { Emo \& Beh (2.32) } & (132) & & & \end{array}$

Difference between Model 8 and Model 7

0.01

6e. Behavior and Emotion. $r=0.87$

9. One-Factor All Items 5065.53*

(1.11)

$\begin{array}{lll}8.60 & 0.74 \quad 0.09\end{array}$

10. Two-factor

(EngDis)Beh \&

(EngDis)Emo (3.11)

$4764.08 *$

(588)
8.10
0.76
0.09

Difference between Model

10 and Model 9

0.02 
College success and student engagement / 111

Table 6. Bi-polar model fit comparisons (continued)

\begin{tabular}{|c|c|c|c|c|c|}
\hline Model & $\chi^{2}(d f)$ & $C M I N / d f$ & $C F I$ & RMSEA & $C F I_{\text {diff }}$ \\
\hline \multicolumn{6}{|c|}{ 6f. Engagement and Disaffection. $r=-0.80$} \\
\hline $\begin{array}{l}\text { 11. One-Factor All Items } \\
\text { (1.11) }\end{array}$ & $\begin{array}{l}5065.53 * \\
(589)\end{array}$ & 8.60 & 0.74 & 0.09 & \\
\hline $\begin{array}{l}\text { 12. Two-factor } \\
\text { (EmoBeh)Dis \& } \\
\text { (EmoBeh)Eng (2.11) }\end{array}$ & $\begin{array}{l}4176.95^{*} \\
\quad(588)\end{array}$ & 7.10 & 0.79 & 0.08 & \\
\hline $\begin{array}{r}\text { Difference between Model } \\
12 \text { and Model } 11\end{array}$ & & & & & 0.05 \\
\hline \multicolumn{6}{|l|}{ 6g. Four factor ${ }^{a}$. } \\
\hline $\begin{array}{l}\text { 13. One-Factor All Items } \\
\text { (1.11) }\end{array}$ & $\begin{array}{l}5065.53^{*} \\
(589)\end{array}$ & 8.60 & 0.74 & 0.09 & \\
\hline $\begin{array}{l}\text { 14. Four-factor EmoDis \& } \\
\text { BehDis \& EmoEng \& } \\
\text { BehEng (4) }\end{array}$ & $\begin{array}{l}3851.95^{*} \\
(583)\end{array}$ & 6.61 & 0.81 & 0.08 & \\
\hline $\begin{array}{r}\text { Difference between Model } \\
14 \text { and Model } 13\end{array}$ & & & & & 0.07 \\
\hline \multicolumn{6}{|c|}{$\begin{array}{l}\text { Note. } N=856 .{ }^{a} \text { Solution non-admissible due to item colinearity - see Table } 7 . \\
{ }^{*} p<.05\end{array}$} \\
\hline 6h. Factors & 1. & 2. & 3. & & \\
\hline 1. "Behavioral Engagement" & - & $-.71 * *$ & $.73 * *$ & & $4 * *$ \\
\hline 2. "Behavioral Disaffection" & & - & $-.60 * *$ & & 1** \\
\hline 3. "Emotional Engagement & & & - & & $4 * *$ \\
\hline 4. "Emotional Disaffection" & & & & & - \\
\hline $\begin{array}{l}\text { NOTE. } N=856 . \text { Response range }= \\
* * p<.01\end{array}$ & Not true & Гotally & & & \\
\hline
\end{tabular}

items loading negatively (one-factor bipolar behavioral model, Model 1.22). Model fit indices suggested that the data were only a marginal fit to both two-factor $\left(\chi^{2}(130,856)=1062.18, p<.00, \mathrm{CFI}=.85, \mathrm{CMIN} / \mathrm{df}=8.17, \mathrm{RMSEA}=.09\right)$ and the one-factor models $\left(\chi^{2}(131,856)=1132.50, p<.00, \mathrm{CFI}=.83, \mathrm{CMIN} / \mathrm{df}=8.65, \mathrm{RMSEA}\right.$ $=.10$ ), though the $X^{2}$ difference indicated that data were a significantly better fit to the two-factor model than the one-factor model, as did the CFI difference (Model 1.22/Model 2.22: $X^{2}$ difference $=70.32,1, \mathrm{p}<.001, \mathrm{CFI}$ difference $=.03$, see Table 6a). These 
College success and student engagement / 112

analyses suggested that behavioral aspects of college classroom engagement are better conceptualized as distinguishing engaged from disaffected components which are negatively related to each other (path coefficient $=-0.89)$.

(1b) Engagement and disaffection - Emotion. The second pair of models to examine whether engagement and disaffection should be combined or distinguished focused on the emotional components. They compared a model in which items marking Emotional Engagement and Emotional Disaffection loaded on two different correlated factors (two-factor model, Model 2.21) to a model in which they loaded on the same factor with emotional engagement items loading positively and emotional disaffection items loading negatively (one-factor bipolar model, Model 1.21). For emotions, model fit indices suggested that the data were a marginal fit to both the two-factor model $\left(\chi^{2}(132,856)=896.67, p<.00, \mathrm{CFI}=.89, \mathrm{CMIN} / \mathrm{df}=6.79, \mathrm{RMSEA}=.08\right)$ and the onefactor model $\left(\chi^{2}(134,856)=1648.53, p<.00, \mathrm{CFI}=.83, \mathrm{CMIN} / \mathrm{df}=12.30, \mathrm{RMSEA}=\right.$ .12; see Table $6 \mathrm{~b}$ ), but this was only after adding an additional constraint to the subdimension of Boring (setting the error variance to .0001). However, the data were a better fit to the model including separate factors for emotionally engaged items and emotionally disaffected items than to the one-factor model (Model 1.21/Model 2.21: $\chi^{2}$ difference $=$ $526.16,1, p<.001, \mathrm{CFI}$ difference $=.06)$. These analyses suggested that emotional aspects of college classroom engagement are better conceptualized as distinguishing engaged from disaffected components which are negatively related to each other (path coefficient $=-0.80)$. 
(2a) Emotion and behavior - Engagement. The first pair of models to examine whether emotion and behavior should be combined or distinguished focused on engagement. They compared a model in which items marking Emotional Engagement and Behavioral Engagement loaded on two different correlated factors (two-factor model, Model 2.31) to a model in which they loaded on the same factor (one-factor model, Model 1.31). Model fit indices suggested the data were a better fit to the two-factor model $\left(\chi^{2}(132,856)=1252.63, p<.00, \mathrm{CFI}=.86, \mathrm{CMIN} / \mathrm{df}=9.49, \mathrm{RMSEA}=.10\right)$ than to the one-factor model $\left(\chi^{2}(133,856)=1301.43, p<.00, \mathrm{CFI}=.85, \mathrm{CMIN} / \mathrm{df}=9.79\right.$, RMSEA $=.10$; see Table $6 \mathrm{c}$ ). For engagement, the data were a better fit to the model including separate factors for emotional items and behavioral items than to the one-factor model $\left(\right.$ Model 1.31/Model 2.31: $\chi^{2}$ difference $=48.80,1, \mathrm{p}<.001$, CFI difference $\left.=.01\right)$. These analyses suggested that college classroom engagement is better conceptualized as distinguishing engaged emotions from engaged behaviors than as a single engaged factor. The engaged behaviors were highly positively related to the engaged emotions (path coefficient $=.92$ ).

(2b) Emotion and behavior - Disaffection. The second pair of models to examine whether emotion and behavior should be combined or distinguished focused on disaffection. They compared a model in which items marking Emotional Disaffection and Behavioral Disaffection loaded on two different correlated factors (two-factor model, Model 2.32) to a model in which they loaded on the same factor (one-factor model, Model 1.32). Model fit indices suggested the data were a better fit to the two-factor model $\left(\chi^{2}(132,856)=896.67, p<.00, \mathrm{CFI}=.89, \mathrm{CMIN} / \mathrm{df}=6.79, \mathrm{RMSEA}=.08\right)$ and 
College success and student engagement / 114

the one-factor model $\left(\chi^{2}(133,856)=1004.63, p<.00, \mathrm{CFI}=.88, \mathrm{CMIN} / \mathrm{df}=7.55\right.$, RMSEA = .09; see Table 6d). For disaffection, both the $\chi^{2}$ difference and the CFI difference indicated the data were a better fit to the two-factor model than the one-factor model $\left(\right.$ Model 1.32/Model 2.32: $\chi^{2}$ difference $=107.96,1, \mathrm{p}<.001$, CFI difference $=.01$ ) . These analyses suggested that college course disaffection is better conceptualized as distinguishing behavioral from emotional components within disaffection, which are positively related to each other $($ path coefficient $=.89$ ).

(3a) Engagement and disaffection. This pair of models examined whether overall engagement is better modeled by two factors consisting of disaffection (both behavioral and emotional) and engagement (both behavioral and emotional), or by one single factor. By combining the previously modeled hierarchical structures into a six sub-dimensional measure of disaffection and a four sub-dimensional model of engagement, a correlated two factor model of disaffection versus engagement (two-factor model, Model 2.11) was compared to a model in which the sub-dimensions all loaded on the same factor (onefactor model, Model 1.11). Model fit indices suggested the data were a better fit to the two-factor model $\left(\chi^{2}(588,856)=4176.95, p<.00, \mathrm{CFI}=.79, \mathrm{CMIN} / \mathrm{df}=7.10\right.$, RMSEA $=.08)$ than to the one-factor model $\left(\chi^{2}(589,856)=5065.53, p<.00, \mathrm{CFI}=.74\right.$, CMIN/df $=8.60$, RMSEA $=.09$; see Table $6 f$ ). Overall, both the $X^{2}$ difference and the CFI difference indicated the two-factor model data was a better fit to the data than the one-factor model (Model 1.11/Model 3.11: $\chi^{2}$ difference $=888.58,1, p<.001, \mathrm{CFI}$ difference $=.05$ ). These analyses suggested that college course overall engagement is 
College success and student engagement / 115

better conceptualized as distinguishing all disaffection from all engagement components which are negatively related to each other (path coefficient $=-0.80$ ).

(3b) Emotions and behavior. This comparison examined whether overall engagement is better modeled by two factors consisting of emotions (both engaged and disaffected) and behaviors (both both engaged and disaffected), or by the single factor overall engagement. By combining the previously modeled hierarchical structures into a six sub-dimensional measure of behavior and a four sub-dimensional model of emotions, a correlated two factor model of emotions versus behaviors (two-factor model, Model 3.11) was compared to a model in which the sub-dimensions all loaded on the same factor (one-factor model, Model 1.11). Model fit indices suggested the data were a better fit to the two-factor model $\left(\chi^{2}(588,856)=4764.08, p<.00, \mathrm{CFI}=.76, \mathrm{CMIN} / \mathrm{df}=8.10\right.$, $\operatorname{RMSEA}=.09)$ than to the one-factor model $\left(\chi^{2}(589,856)=5065.53, p<.00, \mathrm{CFI}=.74\right.$, $\mathrm{CMIN} / \mathrm{df}=8.60, \mathrm{RMSEA}=.09$; see Table $6 \mathrm{e})$. Overall, both the $X^{2}$ difference and the CFI difference indicated the two-factor model data was a better fit to the data than the one-factor model (Model 1.11/Model 2.11: $\chi^{2}$ difference $=301.45,1, \mathrm{p}<.001, \mathrm{CFI}$ difference $=.02$ ). These analyses suggested that college course overall engagement is better conceptualized as distinguishing emotions from all behavior components which are positively related to each other (path coefficient $=.87$ ).

(3c) Four-factor engagement. The final CFA examined the model fit comparison of a full four-factor hierarchical model to a single factor model of overall engagement. While the model fit indices for the four-factor model were acceptable $\left(\chi^{2}(583,856)=3851.95, p<.00, \mathrm{CFI}=.81, \mathrm{CMIN} / \mathrm{df}=6.61, \mathrm{RMSEA}=.09 ;\right.$ Table $\left.6 \mathrm{~g}\right)$, 
College success and student engagement / 116

the solution was considered non-admissible due to colinearity or suppression effects of six items (Kline, 2005). These six items showed covariances greater than 1.0 when combined together into the full four factor model. Three were emotional disaffection items, two were emotional engagement items, and one was a behavioral disaffection item. Based on the use of antonyms in the similarity of meaning in the items, this was not surprising. The items and their covariances are shown below, Table 7 .

Table 7. Four-factor problem item covariances.

\begin{tabular}{|c|c|c|c|c|c|c|}
\hline Covariances & 1. & 2. & 3. & 4. & 5. & 6. \\
\hline $\begin{array}{l}\text { 1. When in class, I feel bored. } \\
\text { (ED2_BU) }\end{array}$ & & 1.20 & 1.10 & -1.06 & -1.09 & 1.18 \\
\hline $\begin{array}{l}\text { 2. When I am in this class, I can't } \\
\text { wait for it to be over. } \\
\text { (ED3_FM) }\end{array}$ & 1.20 & & & & -1.02 & 1.05 \\
\hline $\begin{array}{l}\text { 3. The instructor's lectures are } \\
\text { pretty dull. (ED11_BU) }\end{array}$ & 1.10 & & & -1.06 & & \\
\hline 4. This class is fun. (EE2_OA) & -1.06 & & -1.06 & & 1.15 & \\
\hline $\begin{array}{l}\text { 5. I enjoy the time I spend in this } \\
\text { class. (EE3_IC) }\end{array}$ & -1.09 & -1.02 & & 1.15 & & \\
\hline $\begin{array}{l}\text { 6. When I'm in this class, my } \\
\text { mind wanders. (BD4_IC) }\end{array}$ & 1.18 & 1.05 & & & & \\
\hline
\end{tabular}

Even so, correlations among the four factors showed the expected negative relations between engaged and disaffected components, both between behavioral aspects and opposite emotional aspects (BE to $\mathrm{ED} r=-.71$, $\mathrm{BD}$ to $\mathrm{EE} r=-.71$ ) as well as within behavior and emotion (BE to $\mathrm{BD} r=-.85, \mathrm{EE}$ to $\mathrm{ED} r=-.80$ ). Also as expected, there were positive relations between the disaffected emotions and behaviors and the engaged emotions and behaviors (BD to $\mathrm{ED} r=.88$, BE to $\mathrm{EE} r=.90$ ). Hence, this 36 -item scale will be used in the analyses for Research Question 1b., and will provide the items for selection into the composite scale created in Research Question 1c. and carried forward. 
All correlations between the factors in all multi-factor models were significant at the $p<.00$ level in the theoretically expected directions: positive between behavior and emotion within engagement and within disaffection, and negative between engagement and disaffection within behavior and within emotion. The direction of these relations are identical to patterns found in elementary, secondary, and the 2009 college research (Chi).

Research Question 1b. Does course engagement fit within the classroom model as predicted by SDT?

In order to examine the relation of the full 36 -item engagement scale to the social contextual antecedents and student self-perceptions that are part of the classroom model, a composite score for engagement was computed. This was done by taking the average of the 36 items to create an overall engagement score which incorporated the hierarchical and multidimensional nature of the construct. Disaffection items were reverse coded so that higher responses indicated lower endorsement of overall engagement. Correlations between the full engagement composite and both the instructor need provisions (context) and student self-perceptions were examined. Also examined was the relation between engagement and class difficulty, to determine whether or not to include this possible confound as a covariate in subsequent analyses.

Descriptive statistics and psychometrics. Table 8 presents the basic psychometrics for the full engagement composite scale, the context scales, the student self-perception scales, and the confound scale of class difficulty. All scales showed satisfactory internal consistency (above .70) and no skew. In general, students reported that their instructors fairly (3.0) and somewhat (4.0) displayed contextual support in the 
College success and student engagement / 118

form of autonomy support, structure, and involvement (mean range 3.82 to 4.21 ). Self perceptions were similarly endorsed at these levels (mean range: 3.58 to 4.46). The average class difficulty was 3.13 , and students showed moderate course engagement (3.66). The full range of responses was present in all the scales.

Table 8. Psychometrics for Full Engagement, Context and Self-perception scales.

\begin{tabular}{ccccc}
\hline Measure & Items & $\alpha$ & $\mathrm{M}(\mathrm{SD})$ & Skew \\
\hline Full Engagement Scale & & & & \\
Overall Engagement & 36 & 0.94 & $3.66(0.70)$ & -0.49 \\
& & & & \\
Context Scales & & & & \\
Instructor Autonomy Support & 8 & 0.81 & $4.21(0.63)$ & -1.33 \\
Instructor Involvement/Warmth & 6 & 0.78 & $3.82(0.83)$ & -0.49 \\
Instructor Structure & 6 & 0.76 & $4.10(0.74)$ & -0.96 \\
& & & & \\
Self-perception Classroom Scales & & & & \\
Perceived Autonomy & 4 & 0.80 & $4.16(0.84)$ & -1.01 \\
Perceived Relatedness & 6 & 0.77 & $3.58(0.75)$ & -0.51 \\
Perceived Competence & 6 & 0.79 & $4.46(0.65)$ & -1.49
\end{tabular}

Confound scale

$$
\begin{array}{lllll}
\text { Class Difficulty } & 4 & 0.81 & 3.13(0.98) & -0.14
\end{array}
$$

Note. $\mathrm{N}=856$. Response range from 1 (Note true) to 5 (Totally true). $* * \mathrm{p}<.01$

Correlations among SDT model components. Correlations of the 36-item course engagement scale with the classroom model constructs can be seen in Table 9. The full engagement score was positively related to all aspects of the classroom model at the $\mathrm{p}<$ 
Table 9. Relations between the full course engagement measure and the classroom constructs.

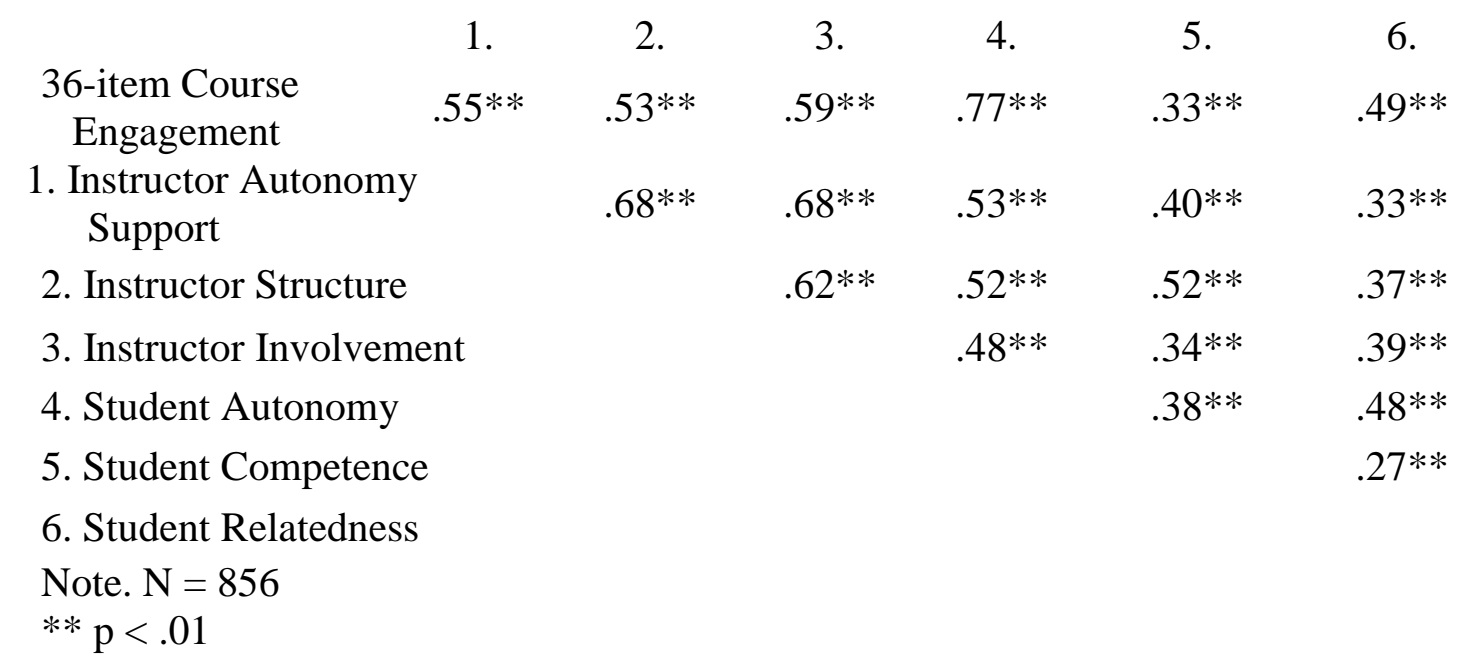

.01 level, as expected. Students who reported higher engagement also reported higher instructor context and student self-perceptions. Correlations ranged from .33 (with competence) to .77 (with autonomy) as expected by the model. Instructor context supports also related positive $(\mathrm{p}<.01)$ to student perceptions. Ratings of class difficulty were positively related to the full engagement score as well $(\mathrm{p}<.01)$, indicating that students were more engaged in classes they perceived to be more difficult. Class difficulty was thus included in later analyses which included engagement.

Research Question 1c. Can this conceptually rich measure be distilled into a short survey tool that is psychometrically sound? Does the short measure occupy the same construct space as the full scale (that is, does it show similar relations with the motivational model and classroom constructs)?

In order to arrive at a short, 12-item measure of course engagement that included at least one item for every sub-dimension found in the structural analyses, 24 items were removed from the full course engagement scale. Items were kept based on item and scale 
College success and student engagement / 120

statistics (e.g., factor loadings and item means), careful consideration of theoretical meaning and word choice, face validity to the sub-dimension being represented, and status as a complex or confounding item. the chosen emotional engagement item "I enjoy the time I spend in this class". As a

Table 10 gives the scales psychometrics for the 12 -item course engagement scale (compared to the 36-item statistics), along with the items chosen for inclusion.

Item choice for Emotional Engagement. From the nine emotional engagement items, "This class is fun" and "I enjoy the time I spend in this class" showed covariances over one, both with each other and with emotional disaffection items. While "This class is fun" is an prototype item, "I enjoy the time I spend in this class" was chosen for inclusion based on a higher factor loading onto the emotional engagement factor and as representing a more general sense of positive emotions experienced in the classroom than just 'fun'. The item "The material we cover is interesting", besides having a high factor loading (.82) was retained as incorporating the 'readings' found in other items under the heading of 'material' and included the idea of interest. Finally, the item 'It's exciting to make connections between the ideas learned in this class" was chosen for its wording, high factor loading, and its relation to the cognitive aspects of positive emotions and learning.

Item choice for Emotional Disaffection. Out of the nine emotional disaffection items, one item was selected from each of the three sub-dimensions. The prototype item "When in class, I feel bored" was selected even though it showed covariance (-1.09) with the chosen emotional engagement item "I enjoy the time I spend in this class". As a 
College success and student engagement / 121

Table 10. 12-item Course Engagement Scale

\begin{tabular}{cccccc}
\hline Items & $\mathrm{M}(\mathrm{SD})$ & Skew & Kurtosis & $\begin{array}{c}\lambda \\
(\mathrm{Std}) *\end{array}$ & $\mathrm{SMC}^{*}$ \\
\hline $\begin{array}{c}\text { 12-Item Course } \\
\begin{array}{c}\text { Engagement } \\
\text { Vs: 36-Item Course } \\
\text { Engagement }\end{array}\end{array}$ & $3.78(0.76)$ & -0.53 & -0.13 & $\mathrm{n} / \mathrm{a}$ & $\mathrm{n} / \mathrm{a}$ \\
$\quad$ & & & & $\mathrm{n} / \mathrm{a}$ & $\mathrm{n} / \mathrm{a}$ \\
\hline
\end{tabular}

Behavioral Engagement

1. I pay attention in class. ${ }^{a}$

$\begin{array}{lllll}3.86(1.03) & -0.79 & 0.19 & 0.73 & 0.53 \\ 3.58(1.17) & -0.45 & -0.69 & 0.83 & 0.68 \\ 3.62(1.17) & -0.43 & -0.77 & 0.72 & 0.52\end{array}$

3. I study for this class. ${ }^{\text {a }}$

$\begin{array}{lllll}3.62(1.17) & -0.43 & -0.77 & 0.72 & 0.52\end{array}$

Behavioral Disaffection

4. It's hard to make myself come to this class.

$\begin{array}{lllll}2.17(1.30) & 0.80 & -0.57 & 0.68 & 0.46\end{array}$

5. In this class, I do just enough to get by.

$\begin{array}{lllll}2.32(1.28) & 0.60 & -0.81 & 0.69 & 0.47\end{array}$

6. Outside of class, I don't $\begin{array}{llllll}\text { put much work in on this } & 2.43(1.21) & 0.52 & -0.70 & 0.83 & 0.69\end{array}$ course.

Emotional Engagement

7. I enjoy the time I spend in this class. ${ }^{\mathrm{a}}$

$3.21(1.26) \quad-0.12 \quad-1.01 \quad 0.74 \quad 0.55$

8. It's exciting to make connections between the ideas learned in this class.

9. The material we cover is interesting. ${ }^{\text {a }}$

$\begin{array}{lllll}3.97(1.08) & -0.90 & 0.03 & 0.72 & 0.52\end{array}$

$3.93(1.06) \quad-0.24 \quad-0.80 \quad 0.82 \quad 0.67$

Emotional Disaffection

10. The instructor's lectures are pretty dull.

$2.14(1.31) \quad 0.90 \quad-0.38 \quad 0.74 \quad 0.55$

11. This class is stressing me out.

$2.04(1.22) \quad 1.00 \quad-0.05 \quad 0.78 \quad 0.61$

12. Sitting in class is a waste of my time.

$1.75(1.15) \quad 1.49 \quad 1.21 \quad 0.78 \quad 0.60$

NOTE: $\mathrm{N}=856$. Response range from 1 (Not true) to 5 (Totally true). ${ }^{*}$ Loadings and squared multiple correlations (SMC) shown are from the hierarchical structural factors modeled in Table 5. ${ }^{\mathrm{a}}$ Items used in the final scale from the 2009 study (Chi) 
College success and student engagement / 122

prototype item, it was the best indicator of the three 'Boring' sub-dimension when looking at the emotional disaffection nine-item structural model. This item showed the highest loading $(.74, \mathrm{SMC}=.63)$, with a mean of $2.61(\mathrm{SD}=1.33)$ and non-significant levels of skewness or kurtosis. For the "Worry' category, "This class is stressing me out" was selected as being the middle item of the three in terms of mean and factor loading, and as being more general in terms of the anxiety class of negative emotions than the highest loading item of "I feel overwhelmed in this class". Finally, for overall 'Pointlessness', the item "Sitting in class is a waste of my time" was selected as the next highest loading item after "When I'm in class, I can't wait for it to be over", which seemed to be a complex item based on covariances over one with items both within emotional disaffection, and between behavioral disaffection and emotional engagement.

Item choice for Behavioral Engagement. Behavioral engagement and behavioral disaffection item pools were treated in the same manner as emotional disaffection. For the 'In-class' sub-dimension, the behavioral engagement item chosen was "I pay attention in class", as statistically the best indicator and less ambiguous then "I try hard to understand the professor's lecture" and more overarching in wording than "When in class, I keep track of things I don't understand" (which could imply that the professor is hard to understand). The 'Out-of-class' category was represented by "I study for this class" as the most inclusive of the 'Out-of-class' items, and with the highest factor loading. The item "I try to get the most I can out of this class" was selected as the item that best encompassed the 'Above-and-beyond' category. "I try hard to do well in this class" seemed too universal a statement, and "This class makes me want to learn more 
College success and student engagement / 123

about the topic" did not seem to accurately reflect a behavior - "This class makes me go out and learn more about the topic" would be more in line with the theory behind the item. Wanting is more of an emotion than a behavior. It is an emotion that may motivate an observable engaged behavior, and the item could be interpreted and responded to from either an emotional or a behavioral perspective.

Item choice for Behavioral Disaffection. For 'In-class', the behavioral disaffection item selected was "It's hard to make myself come to class", as the second highest loading item and the clear behavioral component to the item. "Outside of class, I don't put much work in on this course" was the easy choice for the 'Out-of-class' behavioral disaffection item. With the highest mean and factor loading of the three in this category, the wording itself clearly mapped onto the sub-dimension that it represented. Finally, for the 'Care-less' sub-dimension the item "In this class I do just enough to get by" was the highest loading item, and incorporates the minimal effort of students who are disaffected but still enrolled (recognizing that students who are highly disaffected, emotionally or behaviorally, generally drop out).

As shown in Table 11, this shortened 12-item course engagement measure showed high similarity to the model constructs as the 36 -item, full hierarchical scale. The greatest difference was of the .02 magnitude, and the two scales were highly positively related (.97). As an additional check, the relations between the composite scales (12 and 36) and the composite scale scores of each of the four, nine-item, hierarchically modeled factor items were examined (see Table 12). Relations between the engagement scales and 
the factor scores were high (range -.80 to .88 for the 36 -item scale, and -.78 to .85 for the 12-item scale), in the expected direction, and significant to the .01 level.

Table 11. Comparison of relations between the reduced course engagement measure and the full 36-item measure with the classroom constructs.

\begin{tabular}{lcc}
\hline \multicolumn{1}{c}{ Measure } & 12-item Course Engagement & 1. \\
\hline 1. 36-item Course Engagement & $.97^{* *}$ & - \\
2. Instructor Autonomy Support & $.54^{* *}$ & $.55^{* *}$ \\
3. Instructor Structure & $.53^{* *}$ & $.53^{* *}$ \\
4. Instructor Involvement & $.59^{* *}$ & $.59^{* *}$ \\
5. Student Autonomy & $.75^{* *}$ & $.77^{* *}$ \\
6. Student Competence & $.32^{* *}$ & $.33^{* *}$ \\
7. Student Relatedness & $.49^{* *}$ & $.49^{* *}$ \\
8. Class Difficulty & $.22^{* *}$ & $.22^{* *}$ \\
Note. N $=856$ & & \\
$* * \mathrm{p}<.01$ (2-tailed), & &
\end{tabular}

Table 12. The four hierarchical structured dimensions: Comparing relations between the reduced course engagement measure (12-items) and the full measure (36items) with

\begin{tabular}{ccccc} 
Scales & $\begin{array}{c}\text { Emotional } \\
\text { Engagemen } \\
\mathrm{t}(9 \text { items })\end{array}$ & $\begin{array}{c}\text { Emotional } \\
\text { Disaffection } \\
(9 \text { items })\end{array}$ & $\begin{array}{c}\text { Behavioral } \\
\text { Engagemen } \\
\mathrm{t}(9 \text { items })\end{array}$ & $\begin{array}{c}\text { Behavioral } \\
\text { Disaffection } \\
(9 \text { items })\end{array}$ \\
\hline $\begin{array}{r}\text { 12-item Course } \\
\text { Engagement }\end{array}$ & $.85^{* *}$ & $-.78^{* *}$ & $.81^{* *}$ & $-.84^{* *}$ \\
$\begin{array}{r}36-\text {-item Course } \\
\text { Engagement }\end{array}$ & $88^{* *}$ & $-.80^{* *}$ & $.84 * *$ & $-.86^{* *}$ \\
$\begin{array}{l}\text { Note. } \mathrm{N}=856 \\
* * \mathrm{p}<.01\end{array}$ & & & &
\end{tabular}

Summary results for Research Question 1. Research Question one examined the structure of course engagement, its relations to the classroom model constructs, and whether a shortened scale with items that represented all the sub-dimensions could be created that shared the same construct space as the longer measure and retained 
College success and student engagement / 125

acceptable psychometric characteristics. Although some ambiguity about the hypothesized sub-dimensions remained due to limitations in number of items available, findings from the 2009 study (Chi, 2009) were replicated around the additional complexity within three of the four factors that make up course engagement. Emotional engagement, as in the previous work, was carried forward as a uni-dimensional factor. The inclusion of more items did lead to as good fitting a model with three subdimensions as with the single factor model. Emotional disaffection showed structure comprising three sub-dimensions hinted at in the earlier study. Boredom, anxiety, and overall pointlessness, or amotivation, were supported as components of negative emotions, though additional items would allow a better test of the fit of the hierarchical model. Behavioral engagement and behavioral disaffection both fit a model of in-class, out-of-class, and overarching behaviors better than uni-dimensional models. The 'Aboveand-beyond' and 'Care-less' sub-dimensions were particularly strong predictors of their factors (behavioral engagement and behavioral disaffection), indicating that these areas, when present to a high degree, may subsume other areas within the factor. This was true for the 'Pointless' sub-dimension of emotional disaffection as well.

The 36 items, when formed into a single composite scale of overall course engagement with the disaffection items reverse coded, showed the expected relations with the context and self-perception constructs of the classroom model. Course engagement was positively related to instructor autonomy support, structure, and involvement (indicators of the context), as well as student self-perceptions of autonomy, competence, and relatedness. These six aspects of the classroom model were also 
College success and student engagement / 126

positively related to each other, as predicted by the model. Also as expected, class

difficulty was positively related to course engagement.

After extensive examination and thought about the 36 items and the overarching constructs they were intended to tap, 12 items - three per factor, one per sub-dimension were selected to make up the shortened, administratively useful course engagement scale. This scale was then examined as to its internal consistency, face validity, and construct space equivalence. Not only was this reduced scale highly correlated to the longer version $(.97, \mathrm{p}<.01)$, but it maintained relations with the classroom model constructs that very closely resembled the 36 item scale. As an added check, the relations between both composite scales and each of the four dimensions making up the 36-item structural model were examined. All relations were significant, above $.70(\mathrm{p}>.01)$, and in the expected direction - negatively with disaffection factors, and positively with engagement factors. When the relations of the two scales were examined side by side, it was clear the reduced scale was still tapping into the complex structure modeled with the longer scale. Their correlations with the class constructs were very close to each other, deviating from each other in any one factor by no more than $|.03|$. Thus, while still tapping into the complexity of the factors and their sub-dimensions, a short yet inclusive measure of course engagement can function in the classroom model in ways that are comparable to a measure made up of three to five times as many items.

\section{RQ2: Classroom (micro) model.}

Does the motivational model provide a good account of the hypothesized predictors and outcomes of course engagement for college students? 
While the theory would predict differences in student course engagement by instructor, and this can be examined as a recognizable aspect of course context and reflection of instructor aspects brought to the context, this is not a goal of this study. Thus recognized, student course engagement in this study was looked at across all courses as 'university population' representative, which also allows comparison to measures of the university model.

In order to determine whether the motivation model is a good account of the processes in college classrooms, the direction and significance of the relations between the model constructs, including the reduced course engagement scale, and the outcomes were examined. First, simple regressions examined context and self perceptions on course engagement (Research Question 2a), followed by simple regressions of course engagement on the classroom outcomes of actual grades. Based on the significant relation between class difficulty and course engagement found in Research Question 1c, class difficulty was controlled for in separate simple multiple regression equations (Research Question 2b).

Finally, six mediation analyses using Sobel's (1982) method (Baron \& Kenny, 1986; Hayes \& Preacher, 2010; Miller \& Salkind, 2002; Preacher \& Hayes, 2004) were conducted to examine whether the three context and three self constructs were mediated by levels of course engagement (Research Question 2c). Sobel's (1982) method examines the products of the direct effects (cause to effect, cause to mediator and mediator to effect) to arrive at the indirect effects, then uses the ratio of this indirect effect to its approximate standard error to test for significance (Preacher \& Hayes, 2004). Since class 
College success and student engagement / 128

difficulty did need to be controlled for in the mediation models, the total indirect effect was calculated using the indirect effect SPSS syntax offered by Preacher and Hayes (2008) more suitable to possible non-random distribution of the indirect effect and multiple mediator models. This estimates the total, direct, and single-step indirect effects of causal variables on an outcome through one or more mediator variables while controlling one or more covariates - partialled out of the outcome and mediator(s) - and calculates the Sobel test for the indirect effects. Because the Sobel test is based on the assumption that the sampling distribution of the indirect effect is normal, this syntax also includes a macro which generates $99 \%$ bias-corrected bootstrap confidence intervals. The macro was set to 1,000, 3 000, or 5,000 bootstrap samples for all mediation analyses.

Research Question 2a. Predictors of course engagement: Are instructor context and student self-system processes important predictors of course engagement?

Relations between these three self-system measures, classroom context, and the engagement measure were examined for congruence with theory. It was expected for both context and SSP measures that the relations will be in line with theory - positive with positive, negative with negative (e.g., low structure with low competence with low engagement). All six classroom constructs were expected to positively predict course engagement.

As expected, significant positive effects were found for each of the six predictors of course engagement (see Table 13 for regressions; Table 11 presents model constructs to course engagement correlations). Betas ranged from .32 (student competence) to .75 (student autonomy). Students who reported higher levels of engagement also reported 
their instructors provided higher levels of each kind of support, and that they themselves felt more autonomous, competent, and related in the course.

Table 13. Context and Self coefficients on Course Engagement.

\begin{tabular}{lrrrr}
\hline \multirow{1}{*}{ Predictor } & \multicolumn{5}{c}{ Self-reported engagement (12-item) } \\
\cline { 2 - 5 } & $\mathrm{B}$ & $\mathrm{SE}$ & $\beta$ & $95 \% \mathrm{CI}$ \\
\hline Instructor & & & & \\
1. Autonomy Support & $0.65^{* *}$ & 0.035 & 0.54 & {$[0.59,0.72]$} \\
2. Structure & $0.55^{* *}$ & 0.030 & 0.52 & {$[0.49,0.61]$} \\
3. Involvement & $0.54^{* *}$ & 0.025 & 0.59 & {$[0.49,0.59]$} \\
Student & & & & \\
4. Autonomy & $0.68^{* *}$ & 0.020 & 0.75 & {$[0.64,0.72]$} \\
5. Competence & $0.38^{* *}$ & 0.038 & 0.32 & {$[0.31,0.46]$} \\
6. Relatedness & $0.50^{* *}$ & 0.030 & 0.49 & {$[0.44,0.56]$} \\
Note. $\mathrm{N}=856 . \mathrm{CI}=$ confidence interval & & & \\
$* * \mathrm{p}<.01$ & & & &
\end{tabular}

As an added check on the validity of the classroom model, the relations between the predictors were also examined (see Table 14). All inter-predictor correlations were

Table 14. Comparison of relations between the classroom constructs.

\begin{tabular}{lcccccc}
\hline & \multicolumn{3}{c}{ Instructor } & \multicolumn{3}{c}{ Student } \\
\cline { 2 - 7 } & 2. & 3. & 4. & 5. & 6. & 7. \\
\hline 1. 12-item Course & $.54^{* *}$ & $.53^{* *}$ & $.59^{* *}$ & $.75^{* *}$ & $.32^{* *}$ & $.49^{* *}$ \\
$\quad$ Engagement & & $.68^{* *}$ & $.64^{* *}$ & $.53^{* *}$ & $.40^{* *}$ & $.33^{* *}$ \\
2. Autonomy Support & & & $.62^{* *}$ & $.52^{* *}$ & $.52^{* *}$ & $.37^{* *}$ \\
3. Structure & & & & $.48^{* *}$ & $.34^{* *}$ & $.39^{* *}$ \\
4. Involvement & & & & & $.38^{* *}$ & $.48^{* *}$ \\
5. Autonomy & & & & & & $.27^{* *}$ \\
6. Competence & & & & & & - \\
7. Relatedness & & & & &
\end{tabular}


College success and student engagement / 130

positive and significant at the $p>.01$ level. Additionally, the pattern of connections was consistent with predictions from SDT: the strongest correlate of instructor provided autonomy support was with student autonomy; and the strongest correlate of instructor structure was student competence, its directly theorized supported student selfperception, as well student autonomy. While the strongest correlate of instructor involvement was also with student sense of autonomy, student relatedness showed the next highest correlation.

Research Question 2b. Outcomes of course engagement: Is course engagement an important predictor of class performance? Does perceived class difficulty play a role?

Relations between the engagement measure and class grade were examined for congruence with theory. High engagement was expected to relate to high performance. Class difficulty was shown to be relevant (via simple multiple regression examination: Course Grade $=\beta 0+\beta 1$ Course Engagement $+\beta 1$ Class Difficulty $+\varepsilon)$.

As expected, course engagement significantly predicted both expected class grade and actual class grade at the $\mathrm{p}<.00$ level (Table 15 lists Bs, Betas, standard errors and confidence intervals). For every additional unit of engagement, actual grades were .27 units higher. When class difficulty was controlled for, course engagement remained a significant positive predictor of and actual grades $(\beta=.32)$. As expected, class difficulty was itself a significant negative predictor of grades both on its own, and when combined with course engagement. When class difficulty was included, the effect of course engagement on grades increased, controlling for the significant effects of difficulty. From 
these results, class difficulty was included as a covariate in later analyses that included course engagement in the classroom model.

Table 15. Course engagement coefficients on actual grade.

\begin{tabular}{|c|c|c|c|c|c|c|c|c|}
\hline \multirow[b]{3}{*}{ Variable } & \multicolumn{8}{|c|}{ Actual class grade } \\
\hline & \multirow[b]{2}{*}{ B } & \multirow[b]{2}{*}{$\mathrm{SE}$} & \multirow[b]{2}{*}{$\beta$} & \multirow[b]{2}{*}{$\begin{array}{c}95 \% \\
\text { CI }\end{array}$} & \multicolumn{4}{|c|}{ Model 2} \\
\hline & & & & & B & SE & $\beta$ & $\begin{array}{c}95 \% \\
\text { CI }\end{array}$ \\
\hline Constant & & & & & $2.83 * *$ & & & \\
\hline Difficulty & $-0.18 * *$ & 0.03 & $\begin{array}{c}- \\
0.22\end{array}$ & $\begin{array}{l}{[-0.23,} \\
-0.12]\end{array}$ & $-0.24 * *$ & 0.03 & -0.29 & $\begin{array}{c}{[-0.29,} \\
-0.18]\end{array}$ \\
\hline Engagement & $0.27 * *$ & 0.04 & 0.25 & $\begin{array}{c}{[0.20} \\
0.33]\end{array}$ & $0.33 * *$ & 0.03 & 0.32 & $\begin{array}{l}{[0.27} \\
0.40]\end{array}$ \\
\hline $\mathrm{R}^{2}$ & & & & & & & & \\
\hline $\mathrm{F}$ & & & & & & 71. & $2 * *$ & \\
\hline
\end{tabular}

Research Question 2c. Mediational role of course engagement: Does course engagement mediate the effects of student self processes and classroom context on classroom performance?

Six mediation analyses were conducted to test whether course engagement mediates the relationship between each of the three context and three self variables of the classroom model, when effects of class difficulty are partialled out of actual grades and course engagement. Partial, not full, mediation was expected for all six context and self variables. Using the Sobel test with 1,000 bootstrap samples to estimate the confidence intervals for the indirect effects, all six variables had significant indirect effects on actual grades through the mediating variable of course engagement with class difficulty controlled for, although for two constructs the mediation was only partial. As expected, class difficulty maintained a significant negative partial effect on class grades in all six 
mediation analyses, indicating that students' grades were lower in classes they perceived as more difficult. These regressions are presented in Table 17.

Of the contextual variables, instructor autonomy support and instructor structure were fully mediated by course engagement when class difficulty was controlled for, whereas instructor involvement was only partially mediated. All three contextual variables met the preliminary conditions needed to analyze for mediation effects: All three were significantly related to both the course engagement (the mediator) and actual grades (the outcome) at the $\mathrm{p}<.00$ level (see Table 16), as were course engagement and Table 16. Relations of class constructs to outcome and confound.

\begin{tabular}{lcc}
\hline \multicolumn{1}{c}{ Scale } & Grade & Difficulty (Confound) \\
\hline Instructor & & \\
1. Autonomy Support & $.16^{* *}$ & .01 \\
2. Structure & $.21^{* *}$ & $-0.09^{* *}$ \\
3. Involvement & $.24^{* *}$ & .05 \\
Student & & \\
4. Autonomy & $.20^{* *}$ & $.17^{* *}$ \\
5. Competence & $.40^{* *}$ & $-0.36^{* *}$ \\
6. Relatedness & $.14^{* *}$ & $.10^{* *}$ \\
Note. N $=856$ & & \\
$* * \mathrm{p}<.01$ & &
\end{tabular}

class difficulty (the control) to actual grades. Using the Sobel test modified to include a control variable and confidence intervals arrived at through 1,000 bootstrap samples, all three context variables had a significant positive indirect effect on actual grades through the mediating variable of course engagement, when class difficulty's effect was partialled out (autonomy support $\mathrm{ab}=.21$, structure $\mathrm{ab}=.18$, and involvement $\mathrm{ab}=.14$ ). Only instructor involvement still showed a significant direct effect on grades after the effects of course engagement and class difficulty were accounted for $(b=.11, t=2.93, p=.00)$. 
College success and student engagement / 133

Of the self perception variables, which all also met preliminary conditions, student autonomy $(\mathrm{ab}=.20)$ and relatedness $(\mathrm{ab}=.16)$ were fully mediated by course engagement when class difficulty was controlled for. In this area, it was student competence that was only partially mediated, and continued to have a significant direct effect on grades $(b=.34, t=7.51, p=.00)$ as well as an indirect effect through course engagement $(a b=.11)$. Table 17 lists the coefficients and confidence intervals for all six of the indirect effects.

Table 17. Mediation of Context \& Self variables on Actual grades by Course engagement, controlling for class difficulty.

\begin{tabular}{|c|c|c|c|c|c|c|c|c|}
\hline \multirow[b]{3}{*}{ Variable } & \multicolumn{8}{|c|}{ Actual class grade } \\
\hline & \multirow[b]{2}{*}{$\mathrm{a}$} & \multirow[b]{2}{*}{$\mathrm{b}$} & \multirow[b]{2}{*}{ c } & \multirow[b]{2}{*}{$c^{\prime}$} & \multirow[b]{2}{*}{$\begin{array}{l}\text { Adj. } \\
\mathrm{R}^{2}\end{array}$} & \multirow[b]{2}{*}{$\mathrm{F}^{\mathrm{a}}$} & \multicolumn{2}{|c|}{ Indirect effect } \\
\hline & & & & & & & $a b$ & $99 \% \mathrm{CI}$ \\
\hline \multicolumn{9}{|l|}{ Instructor } \\
\hline $\begin{array}{r}\text { Autonomy } \\
\text { Support }\end{array}$ & $.63 * * *$ & $.33 * * *$ & $.21 * * *$ & .00 & .14 & 47.75 & .21 & $\begin{array}{c}{[0.14,} \\
0.28]\end{array}$ \\
\hline Structure & $.57 * * *$ & $.32 * * *$ & $.20 * * *$ & .02 & .14 & 47.89 & .18 & $\begin{array}{c}{[0.12} \\
0.24]\end{array}$ \\
\hline Involvement & $.53 * * *$ & $.26 * * *$ & $.25 * * *$ & $.11 * *$ & .15 & 51.10 & .14 & $\begin{array}{c}{[0.07,} \\
0.20]\end{array}$ \\
\hline \multicolumn{9}{|l|}{ Student } \\
\hline Autonomy & $.67 * * *$ & $30 * * *$ & $.24 * * *$ & .03 & .14 & 47.93 & .20 & $\begin{array}{c}{[0.12,} \\
0.31]\end{array}$ \\
\hline Competence & $.54 * * *$ & $.21 * * *$ & $.45 * * *$ & $.34 * * *$ & .19 & 69.74 & .11 & $\begin{array}{l}{[0.07,} \\
0.17]\end{array}$ \\
\hline Relatedness & $.50 * * *$ & $.32 * * *$ & $.17 * * *$ & .02 & .14 & 47.81 & .16 & $\begin{array}{l}{[0.11,} \\
0.23]\end{array}$ \\
\hline
\end{tabular}

Note. $\mathrm{N}=856 . \mathrm{CI}=$ confidence interval. ${ }^{\mathrm{a}}$ All models significant at the $\mathrm{p}<.001$ level. $* * \mathrm{p}<.01, * * * \mathrm{p}<.001$

Summary results for Research Question 2. Research Question two examined the validity of the classroom model as applied to college students, and the role that course engagement plays in course performance, in this case, class grades. The validity of the 
College success and student engagement / 134

model was supported by significant relations between the model components that were completely consistent with theory. Instructor autonomy support, instructor structure, and instructor involvement were all positively related to course engagement and directly to grades. This pattern held for the student self perceptions of autonomy, competence, and relatedness. Course engagement itself was positively related to actual grades received, and this held even when the effects of class difficulty were controlled for (e.g., Course Grade $=\beta 0+\beta 1$ Course Engagement $+\beta 2$ Class Difficulty $+\beta 3[$ context $\&$ SSP's $]+\varepsilon)$. As expected, class difficulty was negatively related to grades in all equations. Based on these findings, class difficulty was controlled for when the mediation effects of course engagement were examined.

Examination of the direct and total indirect effects of the context (instructor) and self (student) on grades when mediated by course engagement, controlling for class difficulty, showed full and partial mediation by course engagement. The effects of instructor autonomy support, instructor structure, student autonomy and student relatedness were fully mediated through their effects on course engagement, when the effects of class difficulty were partialled out. Instructor structure and student relatedness showed partial mediation through their effects on course engagement by maintaining significant, positive relations to grades even with course engagement in the model, even when controlling for class difficulty, whose partial effect on class grade remained negatively significant in all six mediation analyses. 


\section{RQ3: University (macro) model.}

Does the motivational model provide a good account of student university learning experiences at the higher order level of the institution?

To examine this model, similar steps were taken as performed on the classroom model constructs. First, simple regressions examined the relation of university supports and academic identity on university learning experiences - these were expected to be high and positive (Research Question 3a). This was followed by simple regressions of academic identity and course engagement on the macro model outcomes of student persistence and student overall performance - here measured by student reported overall GPA (Research Question 3b). Finally, the indirect effects of university supports and academic identity on persistence through university learning experiences were examined using the Sobel test methodology incorporating bootstrap sampling (5,000 samples) for the $95 \%$ confidence intervals for testing the significance of the indirect effects (Preacher and Hayes, 2004).

Before running these analyses, two scales, derived from NSSE items, were converted from a 4-point response scale to a 5-point response scale in order to make meaningful comparisons between scores on these scales and the other scales used in this study. The was accomplished by taking the full range of the responses and dividing them by five. The resultant number was then considered the scale metric, and was added to the lowest value to create the lowest category (1, Not True), again to create the range for the second lowest category (2, A little True), and so forth until five response ranges were set and recoded (where $5=$ Totally True). This resulted in a shift of the means and standard 
College success and student engagement / 136

deviations for the scales. The University supports scale increased to a mean of 3.01 (out of 5) with a standard deviation of 1.33 (from $\mathrm{M}=2.57$ out of $4.0, \mathrm{SD}=.86$ ). University learning experiences increased to a mean of 3.58 with a standard deviation of 1.15 (from $\mathrm{M}=2.87$ out of $4.0, \mathrm{SD}=.70$ ). Table 18 lists the descriptive and psychometric statistics for the university model constructs.

Table 18. Descriptive and psychometric statistics for University model constructs.

\begin{tabular}{|c|c|c|c|c|c|c|}
\hline Measure & Items & $\alpha$ & $\omega_{\mathrm{h}}$ & $\mathrm{M}(\mathrm{SD})$ & Skew & Kurtosis \\
\hline \multicolumn{7}{|l|}{ University Model } \\
\hline University support & 4 & 0.87 & 0.85 & $3.10(1.33)$ & -0.03 & -1.14 \\
\hline $\begin{array}{l}\text { University Learning } \\
\text { Experiences }\end{array}$ & 14 & 0.93 & 0.99 & 5) & -0.45 & -0.58 \\
\hline University Autonomy & 6 & 0.72 & 0.67 & $4.07(0.67)$ & -0.92 & 0.66 \\
\hline University Competence & 6 & 0.77 & 1.00 & $4.53(0.58)$ & -1.42 & 1.81 \\
\hline University Relatedness & 6 & 0.68 & 0.52 & $3.74(0.71)$ & -0.57 & 0.14 \\
\hline Academic Identity ${ }^{a}$ & 18 & 0.75 & 0.19 & $4.11(0.54)$ & -0.86 & 0.48 \\
\hline
\end{tabular}

Outcomes

$\begin{array}{lcccccc}\text { Persistence } & 4 & 0.64 & 0.86 & 4.59 & -2.02 & 4.92 \\ \text { GPA } & 1 & \mathrm{n} / \mathrm{a} & \mathrm{n} / \mathrm{a} & 3.31 & -0.60 & 0.38\end{array}$

Note. $\mathrm{N}=856$. Response range: 1 (Not true) to 5 (Totally true). ${ }^{\mathrm{a}}$ Academic identity composed of the three University scales (see Table 1).

Research Question 3a. Do university supports and academic identity predict university learning experiences?

As hypothesized, both university supports and academic identity were significantly positively related to university learning experiences. When students reported higher university supports their ratings of university learning experiences were higher by 
0.55 units $(\mathrm{b}=.55, \mathrm{t}=19.19, \mathrm{p}<.001)$. For every one unit higher in academic identity, university learning experiences were higher by 0.33 units $(b=.70, t=10.10, p<.001$; see Table 19 for confidence intervals). This relationship can also be seen in the university constructs zero-order correlation table (Table 20).

Table 19. University support and academic identity relations to University Learning Experiences

\begin{tabular}{|c|c|c|c|c|c|c|c|}
\hline \multirow[b]{2}{*}{ Predictor } & \multicolumn{7}{|c|}{ University learning experiences (14-item) } \\
\hline & Constant & $\mathrm{B}$ & SE & $\beta$ & $95 \% \mathrm{CI}$ & $\mathrm{R}^{2}$ & $\mathrm{~F}^{\mathrm{b}}$ \\
\hline 1. University support & $2.12 * * *$ & $0.47 * * *$ & 0.03 & 0.55 & $\begin{array}{l}0.42 \\
0.52]\end{array}$ & .30 & 367.40 \\
\hline 2. Academic Identity ${ }^{a}$ & $0.71 * *$ & $0.70^{* * *}$ & 0.07 & 0.33 & $\begin{array}{c}{[0.56,} \\
0.83]\end{array}$ & .11 & 102.00 \\
\hline
\end{tabular}

Note. $\mathrm{N}=856 . \mathrm{CI}=$ confidence interval. ${ }^{\text {a }}$ Academic identity composed of the three University scales (see Table 1). ${ }^{\mathrm{b}}$ All models significant at the $\mathrm{p}<.001$ level. $* * \mathrm{p}<.01, * * * \mathrm{p}<.001$

Research Question 3b. Are university learning experiences and academic identity each important predictors of student persistence and overall performance? As can be seen by the zero-order correlations, only the university construct of academic identity related to GPA. Persistence was related to all three (see Table 20 for correlations). As hypothesized, both university learning experiences and academic identity were significantly positively related to intentions to persist in college. Students who reported greater university learning experiences throughout also reported higher intentions to persist, by 0.17 units $(\mathrm{b}=.09, \mathrm{t}=4.95, \mathrm{p}<.001)$. For every one unit of increase in academic identity, intentions to persist increased by 0.60 units $(\mathrm{b}=.68, \mathrm{t}=$ $21.75, \mathrm{p}<.001)$. Unexpectedly from the hypothesized relations but expected due to the zero-order correlations, university learning experiences were not significant predictors of GPA $(b=-.00, t=-.09, p=.93)$, although increases in academic identity significantly 
positively predicted overall GPA $(b=.34, t=7.88, \mathrm{p}<.001$; see Table 21 for confidence intervals).

Table 20. Comparison of relations between the University constructs.

\begin{tabular}{|c|c|c|c|c|c|}
\hline Variables & 1. & 2. & 3. & 4. & 5. \\
\hline \multicolumn{6}{|l|}{ Constructs } \\
\hline 1. University support & - & $.55^{* *}$ & $.26^{* *}$ & $.13 * *$ & -.01 \\
\hline $\begin{array}{l}\text { 2. University learning } \\
\text { experiences }\end{array}$ & & - & $.33^{* *}$ & $.17 * *$ & -.00 \\
\hline 3. Academic identity ${ }^{a}$ & & & - & $.60 * *$ & $.29 * *$ \\
\hline \multicolumn{6}{|l|}{ Outcomes } \\
\hline 4. Persistence & & & & - & $.48^{* *}$ \\
\hline 5. GPA & & & & & - \\
\hline $\begin{array}{l}\text { NOTE. } \mathrm{N}=856 . \text { Respo } \\
\text { identity composed of th } \\
* * p<.01\end{array}$ & & $\begin{array}{l}\text { ot true } \\
\text { y scale }\end{array}$ & $\begin{array}{l}\text { (Totat } \\
\text { Tab }\end{array}$ & ${ }^{a} \mathrm{Ac}$ & \\
\hline
\end{tabular}

Table 21. University learning experiences and academic identity as predictors of Persistence and Performance

\begin{tabular}{|c|c|c|c|c|c|c|c|}
\hline \multirow[b]{2}{*}{ Predictor } & \multicolumn{7}{|c|}{ Persistence (4-item) } \\
\hline & Constant & $\mathrm{B}$ & SE & $\beta$ & $95 \% \mathrm{CI}$ & $\mathrm{R}^{2}$ & $\mathrm{~F}^{\mathrm{b}}$ \\
\hline $\begin{array}{l}\text { 1. University learning } \\
\text { experiences }\end{array}$ & $4.67 * * *$ & $0.09 * * *$ & 0.02 & 0.17 & $\begin{array}{r}0.05, \\
0.13]\end{array}$ & .03 & $\begin{array}{c}24.54, \\
\text { ns }\end{array}$ \\
\hline \multirow[t]{2}{*}{ 2. Academic Identity ${ }^{a}$} & $1.78 * * *$ & $0.68^{* * *}$ & 0.03 & 0.60 & $\begin{array}{l}{[0.62,} \\
0.74]\end{array}$ & .36 & 472.87 \\
\hline & \multicolumn{7}{|c|}{ GPA } \\
\hline Predictor & Constant & B & $\mathrm{SE}$ & $\beta$ & $95 \% \mathrm{CI}$ & $\mathrm{R}^{2}$ & $\mathrm{~F}^{\mathrm{b}}$ \\
\hline $\begin{array}{l}\text { 1. University learning } \\
\text { experiences }\end{array}$ & $3.32 * * *$ & -0.00 & 0.02 & -0.00 & $\begin{array}{c}-0.04 \\
0.04]\end{array}$ & .00 & $\begin{array}{c}0.01, \\
\text { ns }\end{array}$ \\
\hline 2. Academic Identity ${ }^{a}$ & $1.90 * * *$ & $0.34 * * *$ & 0.04 & 0.29 & $\begin{array}{l}{[0.27,} \\
0.42]\end{array}$ & .08 & 77.23 \\
\hline
\end{tabular}

Note. $\mathrm{N}=856 . \mathrm{CI}=$ confidence interval. ${ }^{\mathrm{a}}$ Academic identity composed of the three University scales (see Table 1 ). ${ }^{\mathrm{b}}$ Models significant at the $\mathrm{p}<.001$ level unless specified as non-significant (ns). $* * * \mathrm{p}<.001$ 
College success and student engagement / 139

Research Question 3c. Do university learning experiences mediate the effects of university supports and academic identity on persistence and performance?

Originally, four mediation analyses were envisioned to test whether university learning experiences mediates the relations between university support and academic identity and the outcome variables of the university model - persistence and performance (GPA). University learning experiences and, separately, academic identity and university supports were to be regressed onto the two outcome measures - performance (GPA) and persistence. It was expected that university supports and academic identity effects on performance and persistence would show at least partial mediation by university learning experiences. Since neither the mediator, university learning experiences, nor the predictor of university supports showed a significant relation to the outcome of GPA, the conditions for mediation were not met for this outcome and these two analyses were not conducted. All conditions for mediation were met for the outcome of persistence, so it was decided to proceed with university learning experiences as the mediator. Using the Sobel test with 5,000 bootstrap samples to estimate the confidence intervals for the indirect effects, results were mixed. Table 22 presents the results reported in the following paragraphs with a $99 \%$ confidence interval for the indirect effects.

When looking at the outcome of persistence, no mediation by university learning experiences were found for academic identity $(\mathrm{ab}=-.01, \mathrm{Z}=-1.06, \mathrm{p}=.29)$. University learning experiences was no longer significantly related to persistence when academic identity was controlled for $(b=-.02, t=-1.07, p=.28)$, while academic identity remained a significant predictor of persistence when university learning experiences were 
College success and student engagement / 140

controlled for $(\mathrm{b}=.69, \mathrm{t}=20.91, \mathrm{p}<.001)$. However, for university support, full

mediation by university learning experiences was found $(\mathrm{ab}=.04, \mathrm{z}=3.39, \mathrm{p}<.001)$.

The effect of university supports on persistence dropped until it was no longer significant $(\mathrm{b}=.02, \mathrm{t}=1.26, \mathrm{p}=.21)$ with university learning experiences in the model, and the effects of university learning experiences on persistence remained significant $(b=.07, t=$ $3.45, \mathrm{p}<.001)$.

Table 22. Mediation of University support and academic identity on Persistence and Performance by University Learning Experiences.

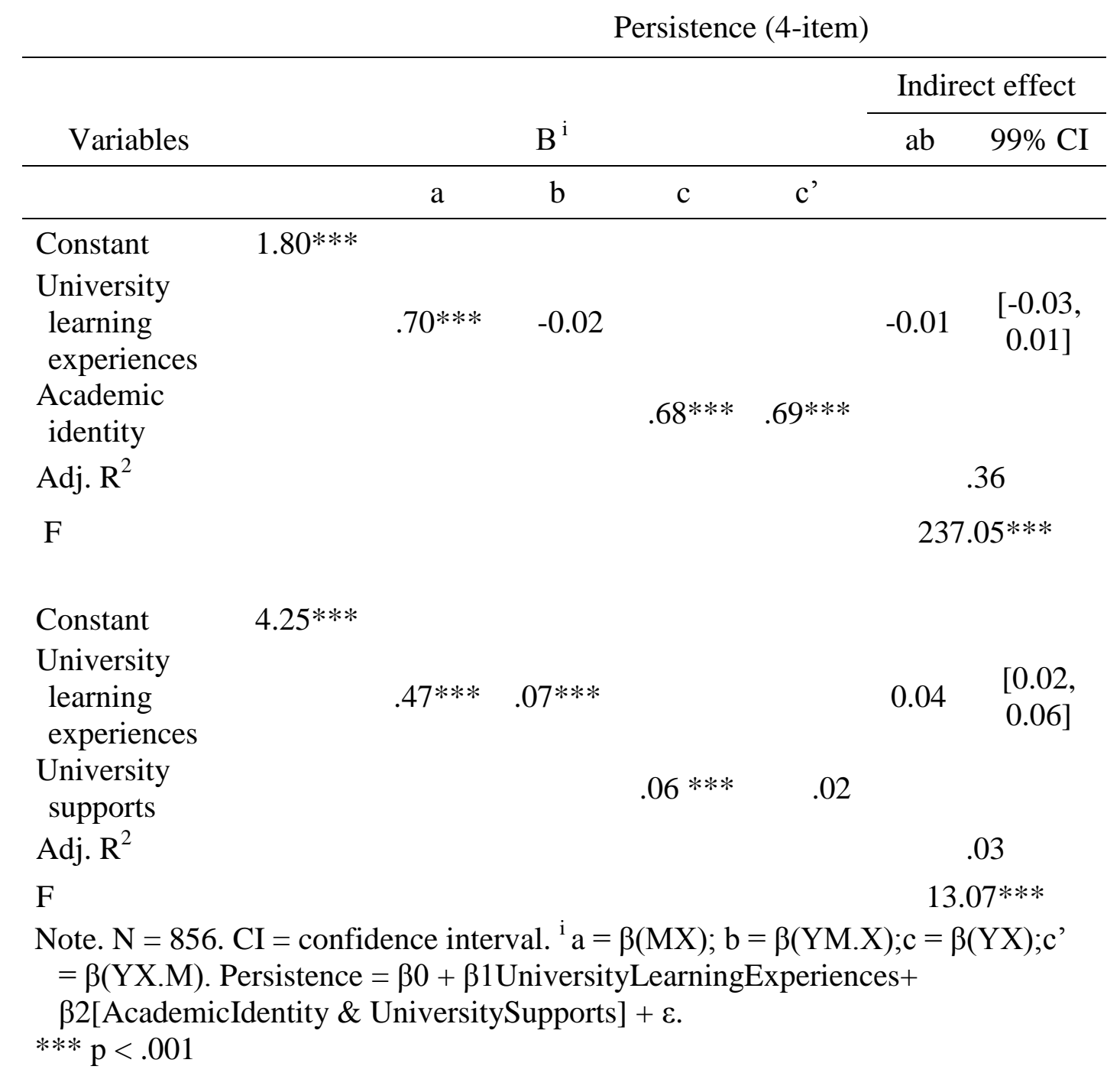


College success and student engagement / 141

Summary results for Research Question 3. Research Question three examined the validity of the proposed motivational model as applied to the overall experiences of students at university in predicting persistence and overall performance. University supports and academic identity (the composite of student perceptions of autonomy, competence and relatedness for being a student at university) were both positive predictors of student ratings of their overall learning experiences while at university (which was a composite of the NSSE (2010) question around contributions of the university to student experiences of learning, practical skills, and self-knowledge). However, when academic identity and university learning experiences were examined for direct effects on the outcomes of persistence and performance, only academic identity was a positive predictor of both. Alone, university learning experiences were not a significant predictor of GPA, although they did positively predict persistence.

When persistence was the outcome of interest, university learning experiences did not mediate effects of academic identity: academic identity maintained its positive direct effect on persistence even when university learning experiences was in the model as a mediator $($ Persistence $=\beta 0+\beta 1$ University Experiences $+\beta 2$ Academic Identity $+\varepsilon)$. There was no indirect effect through university learning experiences, and the direct effect of university learning experiences alone on persistence disappeared once academic identity was included in the model. For this outcome, university learning experiences did mediate effects of university supports (Persistence $=\beta 0+\beta 1$ University Experiences + $\beta 2$ University Supports $+\varepsilon$ ). Overall effects were not very high. University supports showed a significant positive indirect effect on persistence when mediated by university 
learning experiences. The direct effect of university support on persistence was fully mediated by university learning experiences.

\section{RQ4: Integrated model.}

What is the role of course engagement in the macro-model of university learning experiences?

This set of analyses aimed at examining how course engagement might act as a process that integrates the classroom, proximal experiences into a students' distal, overall process and trajectory in the higher education university system. In order to examine this possibility, the first analyses examined the relations of course engagement to the antecedents hypothesized in the macro model - university learning experiences, academic identity, and university supports (Research Question 4a). The second set of relations of interest were those of course engagement to the outcomes of the macro model persistence and performance (Research Question 4b). These two sets of relations were expected to be high and positive

These relations to outcomes were then examined with academic identity and university learning experiences acting as mediators - in other words, does course engagement affect overall performance and persistence through its (cumulative) influence on these two macro level processes (Research Question 4c)? Four Sobel tests were run, as in Research Question 3c, two with academic identity as a mediator and two with university learning experiences as the mediator, on the outcomes of persistence and, separately, performance. Though not addressed directly in the Research Question, an additional two mediation analyses were conducted which included both mediators in the 
models, using the multiple medication method outlined in Research Question 2c, but without a control variable.

Finally, if course engagement continues to have effects on overall university success even when the effects of academic identity and university learning experiences are taken into account, does this unique effect remain when university support effects are controlled for (Research Question 4d)? Four multiple mediation Sobel tests were run, following the methodology of Research Question 2c, the equations of 4c but with university support effects partialled out. Again, although not specifically outlined in the research question, a final two mediation analyses were conducted which included both mediators and the control when looking at the effects of course engagement on overall persistence and performance.

It was expected that course engagement effects on performance and persistence would show at least partial mediation by university learning experiences and academic identity. The effects of course engagement were expected to remain significant, though partially mediated, when the effects of university supports were controlled for.

Research Question 4a. Course engagement and the antecedents in the macromodel: Is course engagement related to university learning experiences, academic identity, and university supports?

Research Question 4b. Course engagement and the outcomes of the macro model: Does course engagement predict university level performance (GPA) and persistence? 
College success and student engagement / 144

Correlations between the micro-model construct of course engagement and the macro-model constructs are listed in Table 23. Correlations between course engagement and the macro model constructs.. As expected, course engagement was significantly

Table 23. Correlations between course engagement and the macro model constructs.

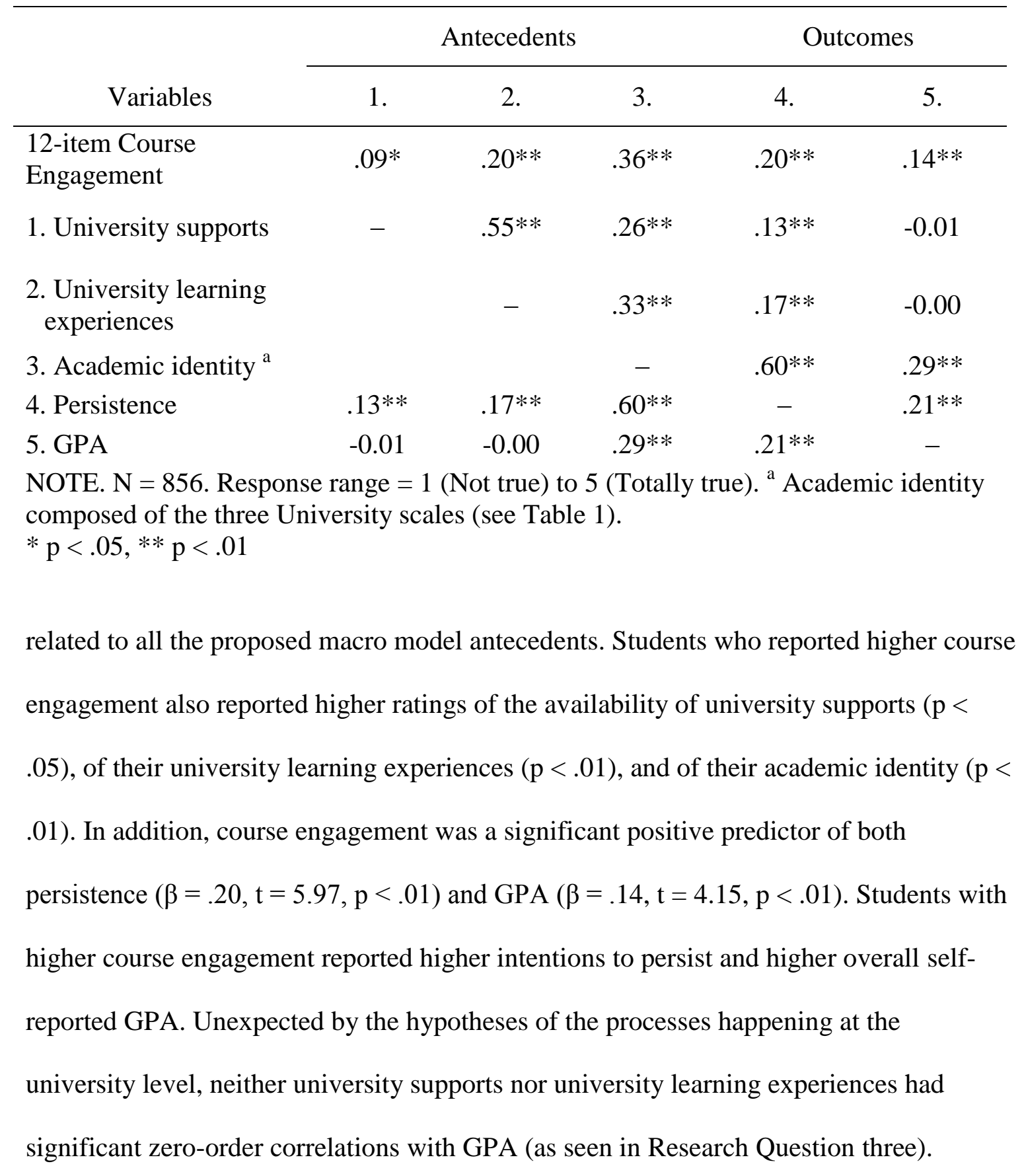


College success and student engagement / 145

Research Question 4c. The mediators of course engagement: Are the effects of course engagement on performance and persistence mediated by student academic identity and university learning experiences?

Sobel's (1982) method to test for indirect effects was used to examine the role of academic identity in mediating the effect of course engagement on the university level outcomes of persistence and GPA. The role of university learning experiences as a mediator was only examined on persistence, as the conditions for mediation were not met with GPA. Bootstrapping with 5,000 samples was used to examine the $95 \%$ confidence intervals of the indirect effects. As a final check with persistence, a multiple mediation model (bootstrap of 3,000 samples) was conducted with both mediators included (see Table 24 for mediation results).

Mediation of course engagement effect on persistence. When looking at the outcome of persistence, course engagement showed both full and partial mediation by macro antecedents. When academic identity acted as a mediator, full mediation appeared so that the significant effect of course engagement on persistence was only through its effect on academic identity $(\mathrm{ab}=.17, \mathrm{z}=9.47, \mathrm{p}<.001)$. This indirect effect was significant based on a $95 \%$ confidence interval. When university learning experiences acted as a mediator, course engagement showed only partial mediation. The direct effect of course engagement on persistence remained positively significant $(b=.14, t=5.11, p$ $<.01)$ when effects of the mediator were partialled out, as did the effect of university learning experiences when course engagement effects were partialled out $(b=.30, t=$ $3.88, \mathrm{p}<.001)$. There was also a significant positive indirect effect of course engagement 
Table 24. Mediation of Course Engagement effects on Persistence and GPA by academic identity and university learning experiences.

\begin{tabular}{|c|c|c|c|c|c|c|c|}
\hline \multirow{4}{*}{ Variables } & & \multicolumn{6}{|c|}{ Persistence (4-item) } \\
\hline & & \multirow{2}{*}{\multicolumn{2}{|c|}{$\mathrm{B}^{\mathrm{i}}$}} & \multirow[b]{3}{*}{$\mathrm{c}$} & \multirow[b]{3}{*}{$c^{\prime}$} & \multicolumn{2}{|c|}{ Indirect effect } \\
\hline & & & & & & \multirow[t]{2}{*}{$\mathrm{ab}$} & \multirow[t]{2}{*}{$\begin{array}{c}95 \% \\
\text { CI }\end{array}$} \\
\hline & & $a$ & $\mathrm{~b}$ & & & & \\
\hline \multicolumn{8}{|l|}{ Model 1} \\
\hline Constant & $1.80 * * *$ & & & & & & \\
\hline Course engagement & & & & $.16^{* * *}$ & -0.01 & .17 & $\begin{array}{l}{[0.13} \\
0.21]\end{array}$ \\
\hline Academic identity & & $.25^{* * *}$ & $.69 * * *$ & & & & \\
\hline Adj. $\mathrm{R}^{2}$ & & & & & & \multirow{2}{*}{\multicolumn{2}{|c|}{$\begin{array}{c}.36 \\
236.33 * * *\end{array}$}} \\
\hline $\mathrm{F}$ & & & & & & & \\
\hline \multicolumn{8}{|l|}{ Model 2} \\
\hline Constant & $3.82 * * *$ & & & & & & \\
\hline Course engagement & & & & $.16^{* * *}$ & $.14 * * *$ & 0.02 & $\begin{array}{l}{[0.01} \\
0.04]\end{array}$ \\
\hline $\begin{array}{l}\text { University learning } \\
\text { experiences }\end{array}$ & & $.30 * * *$ & $.07 * * *$ & & & & \\
\hline Adj. $R^{2}$ & & & & & & & 6 \\
\hline $\mathrm{F}$ & & & & & & & $5 * * *$ \\
\hline \multicolumn{8}{|l|}{ Model 3} \\
\hline Constant & $1.81 * * *$ & & & & & & \\
\hline Course engagement & & & & $.16^{* * *}$ & -0.01 & & \\
\hline Academic identity & & $.25 * * *$ & $.70 * * *$ & & & 0.17 & $\begin{array}{l}{[0.13,} \\
0.22]\end{array}$ \\
\hline $\begin{array}{l}\text { University learning } \\
\text { experiences }\end{array}$ & & $.30 * * *$ & -0.02 & & & -0.01 & $\begin{array}{c}{[-0.02,} \\
0.01]\end{array}$ \\
\hline Adj. $R^{2}$ & & & & & & & 6 \\
\hline $\mathrm{F}$ & & & & & & 157 & $2 * * *$ \\
\hline
\end{tabular}

\section{GPA}

Model 4

Constant

$1.84 * * *$

Course engagement

Academic identity Adj. $R^{2}$

Note. $\mathrm{N}=856 . \mathrm{CI}=$ confidence interval. ${ }^{\mathrm{i}} \mathrm{a}=\beta(\mathrm{MX}) ; \mathrm{b}=\beta(\mathrm{YM} . \mathrm{X}) ; \mathrm{c}=\beta(\mathrm{YX}) ; \mathrm{c}^{\prime}=\beta(\mathrm{YX} . \mathrm{M})$. [Persistence \& GPA] $=\beta 0+\beta 1$ CourseEngagement $+\beta 2$ [AcademicIdentity \& UniversityLearningExperiences] $+\varepsilon$. $* * * \mathrm{p}<.001$ 
on persistence through university learning experiences $(a b=.02, \mathrm{z}=3.24, \mathrm{p}<.001)$.

When both mediators were included, course engagement once again was fully mediated $(\mathrm{b}=.05, \mathrm{t}=1.58, \mathrm{p}=.12)$. While academic identity's partial direct effect $(\mathrm{b}=$ $.37, t=8.42, \mathrm{p}<.001)$ and course engagement's partial indirect effect through academic identity remained significant and positive $(\mathrm{ab}=.09,95 \mathrm{CI}=.06$ to .12$)$, the influence of university learning experiences became non-significant.

Mediation of course engagement effect on performance (GPA). When looking at the outcome of GPA, course engagement showed full mediation by academic identity, with a positive indirect effect of course engagement on GPA through academic identity $(\mathrm{ab}=.08, \mathrm{z}=5.86, \mathrm{p}<.001)$. When both macro-model constructs were included as multiple mediators of course engagement's effect on persistence, course engagement effects remained fully mediated. As with the separate simple mediation situation, both mediators positively related to course engagement, and academic identity kept its direct effect on persistence $\left(b_{1}=.70, t=19.96, p<.00\right)$. University learning experiences, however, lost its direct and mediation effects on persistence in this multiple mediation model. Course engagement's indirect effect on persistence was only through academic identity $\left(\mathrm{a}_{1} \mathrm{~b}_{1}=.17,95 \mathrm{CI}=.13\right.$ to .22$)$.

Research Question 4d. The unique effect of course engagement in the full macro model: Do the relations between course engagement and performance and persistence (when mediated by university learning experiences and academic identity) remain when controlling for contributions from university support systems? 
The same original six analyses as in Research Question $4 \mathrm{c}$ were planned for, but with university supports included as a control (see Table 25 for mediation results). Since

Table 25. Mediation of Course Engagement effects on Persistence and GPA by academic identity and university learning experiences, controlling for university supports

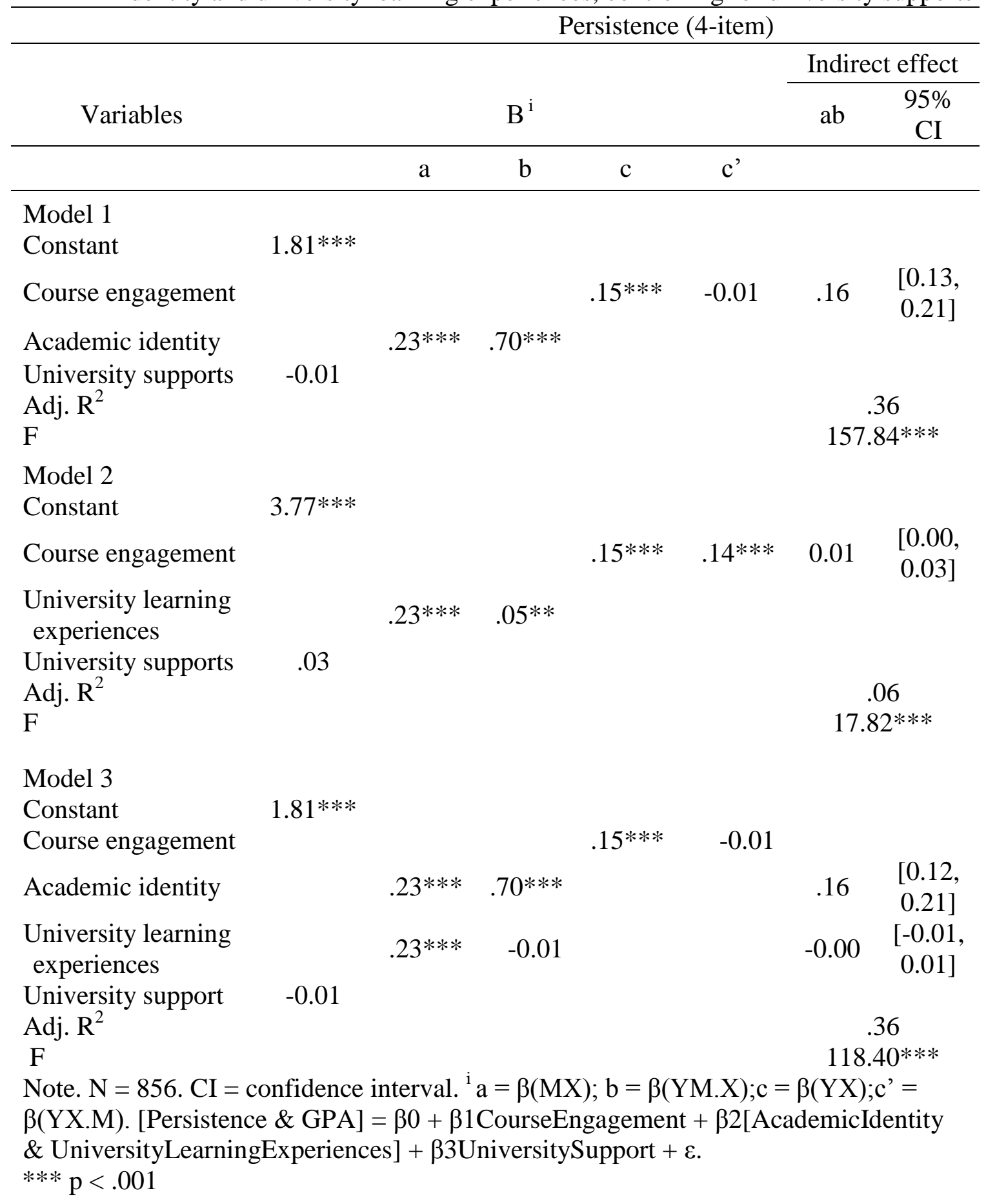


there was no zero-order correlation between university supports and GPA, only persistence was examined. Bootstrapping with 3,000 samples was used to examine the 95\% confidence intervals of the indirect effects.

Mediation of course engagement effect on persistence when controlling for university supports. When looking at the outcome of persistence, university social supports lost its significant effects in all of the three multiple mediation analyses. Course engagement remained partially mediated by university learning experiences $\left(\mathrm{c}^{\prime}=.14, \mathrm{t}=\right.$ $5.15, \mathrm{p}<.001)$ with a significant positive indirect effect $(\mathrm{ab}=01,95 \mathrm{CI}=.00$ to .03$)$, and fully mediated by academic identity $(\mathrm{ab}=.16,95 \mathrm{CI}=.12$ to .21$)$, when controlling for university supports. When both mediators were included, along with the control, the exact same pattern as found without the control (4c) was replicated. University supports showed no partial effects on persistence. There was a significant indirect effect of course engagement through academic identity $\left(a_{1} b_{1}=.16,95 \mathrm{CI}=.12\right.$ to .21$)$ on persistence, but not through university learning experiences $\left(\mathrm{a}_{2} \mathrm{~b}_{2}=-.00,95 \mathrm{CI}=-.01\right.$ to .01$)$.

Summary results for Research Question 4. Research Question four attempted to integrate the classroom and university models through the affects of course engagement. Correlations of course engagement with the macro model constructs were positive and significant, as expected. The highest correlation to the antecedents of success at the university level was with academic identity $(\mathrm{r}=.36, \mathrm{p}<.01)$, the composite of perceptions of autonomy, competence, and relatedness to being a student at the university. For the outcomes, or university level success markers, persistence showed the strongest relation to course engagement $(r=.20, p<.01)$, though the relation to GPA was 
College success and student engagement / 150 still strong $(\mathrm{r}=.14, \mathrm{p}<.01)$. Students who reported higher engagement, even just in a single class, also reported higher perceptions of (1) the availability of university supports, (2) the university's contributions to their learning, (3) their sense of self as a student, (4) their intentions to persist in the role of a student, and (5) their self-reported overall GPA.

Next examined was whether course engagement's direct effects on overall persistence and performance at the university were in part or fully mediated by its effect on the university level antecedents of academic identity and university learning experiences. Academic identity acted as a full mediator of the effects of course engagement on both persistence and performance. Higher course engagement led to higher intentions to persist and higher reported GPA only indirectly by fostering higher academic identity $(\mathrm{GPA}=\beta 0+\beta 1$ Course Engagement $+\beta 2$ Academic Identity $+\varepsilon)$. Of the university level constructs, only academic identity showed significant effects on GPA. University learning experiences acted as a partial mediator of course engagement with persistence - mediation with GPA was not conducted because of a non-significant relation to GPA. Higher course engagement both directly and indirectly, though increasing university learning experiences, effected higher intentions to persist.

When both antecedents of academic identity and university learning experiences were simultaneously included in the mediation model of course engagement's effects on persistence, course engagement was fully mediated (Persistence $=\beta 0+\beta 1$ Course Engagement $+\beta 2$ Academic Identity $+\beta 3$ University Experience $+\varepsilon)$. Significant indirect effects through academic identity on persistence remained. However, university learning 
experiences no longer mediated any effects of course engagement on persistence when academic identity was included.

Finally, the mediation models were examined to see whether course engagement exerted influence, though its mediators, even when any effects of university support availability was included. GPA as an outcome was not examined, based on the nonsignificant relation between university supports and GPA, and university learning experiences and GPA. In both simple mediation analyses, there was no effect of university supports on persistence $($ Persistence $=\beta 0+\beta 1$ Course Engagement + $\beta 2$ Academic Identity $+\beta 3$ University Experience $+\beta 4$ University Supports $+\varepsilon$ ). In all cases, the mediation effects of academic identity and university learning experiences remained the same as when the control of university supports was not included academic identity acted as a full mediator of course engagement, and university learning experiences acted as a partial mediator. Course engagement was fully mediated for persistence when both mediators and the effects of university supports were included. In the multiple mediation case university social experiences showed no relation to university level persistence. Persistence was indirectly positively affected by course engagement through academic identity. Course engagement's only influence on persistence was through influencing academic identity, where high course engagement predicts high academic identity. $35.45 \%$ of the variance in persistence was accounted for with these constructs in the model. 


\section{RQ5: Student Circumstances.}

How can course engagement help us understand the role of student circumstances in shaping overall student success?

Finally, the possible role of course engagement in understanding student nonacademic circumstances was examined. Correlations examined the relations between course engagement and both the demands and social supports available to the student outside the university environment (Research Question 5a and 5b). Cumulative demand was expected to be high and negative with performance and persistence, while global social support for academics was expected to be high and positive. After examining the zero-order correlations, course engagement was examined as a possible mediator between non-academic circumstances and overall student success outcomes (persistence and GPA; Research Question 5c). It was expected that course engagement would at least partially mediate the performance effects from student circumstances - decreasing the effect of demands and increasing the effect of social supports.

University supports were then added as a covariate to the model to examine whether course engagement maintained its mediation role of non-academic circumstances when to student success in relation to non-academic circumstances remained (Research Question 5e). It was expected that course engagement would continue to at least partially mediate the effects on performance of student circumstances - decreasing the effect of demands and increasing the effect of social supports - perhaps to a lesser degree with the effects of university supports included. Since these already in place university level 
supports had no relation to GPA, only the outcome of university persistence was examined.

Finally, course engagement was then examined for its potential as a proximal moderator of the cumulative effects of the non-academic demands that students might face, which would provide the university system with an intervention that could be delivered to all students (Research Question 5d). It was expected that students with high demands and high course engagement would have higher outcomes than students with low course engagement. Response frequency breakdowns for non-academic circumstances can be seen in Table 26.

Research Question 5a. Demands and performance: Are higher levels of cumulative demand associated with poorer student outcomes, in particular, lower intentions to persist and overall GPA? Supports and performance: Do students with higher global social support for academics also have higher levels in all the outcomes?

Research Question 5b. Supports and performance: Do students with higher global social support for academics also have higher levels in all the outcomes?

Five demand areas were included in the cumulative demand score $(\mathrm{M}=8.11, \mathrm{SD}$ $=2.81$, range $=2$ to 16 ): financial, work, credit load, family, and social responsibility. Zero-order correlations were significant and negative for one of the two student success outcomes (see Table 27 for all correlations). Increased levels of cumulative demand related to lower intentions to persist $(\mathrm{r}=-.07, \mathrm{p}<.05)$. There was no direct relation between cumulative demands and self-reported overall GPA $(\mathrm{r}=-.05, \mathrm{p}=.15)$. 
Table 26. Response frequencies for Non-academic circumstances.

\begin{tabular}{|c|c|c|}
\hline Factor & Area & Response options \\
\hline \multicolumn{3}{|c|}{ Cumulative Demands } \\
\hline & Working & $\begin{array}{l}26.2 \% \text { None, } 46.7 \% 1-25 \text { hours, } \\
27.1 \% \text { 26+hours }\end{array}$ \\
\hline & Live with & $\begin{array}{l}27.3 \% \text { Other/roommate, } 13.1 \% \\
\text { Alone, 26.5\% Parents, } 21.7 \% \\
\text { Partner, 5.3\% Family, 3.4\% Single } \\
\text { parent, 2.7\% Multi-generational }\end{array}$ \\
\hline & Credit load & $6.4 \% 6$ or less, $93.6 \% 7$ or more \\
\hline & $\begin{array}{r}\text { Social Responsibility: } \\
\text { Work, interference, } \\
\text { family }\end{array}$ & $\begin{array}{l}23.1 \% 0 \text { of } 3,30.3 \% 1 \text { of } 3,27.1 \% \\
2 \text { of } 3,19.5 \% 3 \text { of } 3\end{array}$ \\
\hline & $\begin{array}{l}\text { Funding: Loan, parents, } \\
\text { scholarship }\end{array}$ & $\begin{array}{l}13.1 \% 0 \text { of } 3,45.9 \% 1 \text { of } 3,32.8 \% \\
2 \text { of } 3,8.2 \% 3 \text { of } 3\end{array}$ \\
\hline
\end{tabular}

Social supports for academics

$$
\begin{aligned}
& \text { People support } \quad 0.7 \% \text { Not true, } 2.2 \% \text { A little true, } \\
& \text { 6.9\% Fairly true, } 15.8 \% \text { Somewhat } \\
& \text { true, } 74.4 \% \text { Totally true } \\
& 16.1 \% \text { Fairly true, } 21.6 \% \\
& \text { Somewhat true, } 47.2 \% \text { Totally true } \\
& \text { Complaints about how } 31.9 \% \text { Not true, } 22.2 \% \text { A little true, } \\
& \text { busy (reverse coded) } 19.2 \% \text { Fairly true, } 14.8 \% \\
& \text { Somewhat true, } 11.9 \% \text { Totally true } \\
& \text { Don't get going to } 70.4 \% \text { Not true, } 12.6 \% \text { A little true, } \\
& \text { college (reverse coded) } \quad 9.0 \% \text { Fairly true, } 4.3 \% \text { Somewhat } \\
& \text { true, } 3.6 \% \text { Totally true }
\end{aligned}
$$

Note. $\mathrm{N}=856$

Reports of social support for academics from areas of non-academic life $(\mathrm{M}=$

$4.11, \mathrm{SD}=.76$, range $=1$ to 5 ) were significant and positive for both of the outcomes.

Students who reported higher levels of global social support for academics also reported higher overall reported GPA $(r=.10, \mathrm{p}<.01)$ and higher intentions to persist $(\mathrm{r}=.31, \mathrm{p}<$ .01). As expected, the relation between cumulative demands and global social supports was negative $(r=-.15)$ and significant at the $\mathrm{p}<.01$ level. 
Table 27. Correlations between student success outcomes and student non-academic circumstances.

\begin{tabular}{lcccc}
\hline & 2. & $\begin{array}{c}\text { Persistence } \\
\text { (Outcome) }\end{array}$ & $\begin{array}{c}\text { GPA } \\
\text { (Outcome) }\end{array}$ & $\begin{array}{c}\text { Course } \\
\text { Engagement } \\
\text { (Mediator) }\end{array}$ \\
\hline $\begin{array}{l}\text { 1. Cumulative Demands } \\
\text { 2. Global Social }\end{array}$ & $-0.15^{* *}$ & $-0.07^{*}$ & -0.05 & .00 \\
$\begin{array}{l}\text { Supports for } \\
\text { Academics }\end{array}$ & & $.31^{* *}$ & $.10^{* *}$ & $.08^{*}$ \\
Note. $\mathrm{N}=856$ & & & \\
$* \mathrm{p}<.05, * * \mathrm{p}<.01$ & & & &
\end{tabular}

Research Question 5c. Mediational role of course engagement: Do student demands depress outcomes because they undermine course engagement? Do student supports boost outcomes because they promote course engagement?

Mediational analysis was not performed to examine the mediation effects of course engagement on the direct relation between cumulative demands and overall success outcomes as there was no direct relation between demands and course engagement $(r=.00, p=.99)$. Course engagement was significantly related to global social supports $(\mathrm{r}=.08, \mathrm{p}<.05)$, which related significantly to both outcomes so mediation analysis could proceed. Table 28 presents the mediation coefficients.

When the relations of global social support for academics to persistence and performance were examined with course engagement included, partial mediation was found for both outcomes. There was a direct effect of global social support $(\mathrm{b}=.25, \mathrm{t}=$ $9.56, \mathrm{p}<.001)$ on persistence and a direct effect on course engagement $(b=.08, t=2.26$, $\mathrm{p}<.05)$. When the direct effect of global social supports was included, course engagement remained positively significant $(b=.14, t=5.53, \mathrm{p}<.001)$, as did the direct effect of global social supports on persistence when course engagement was controlled 
Table 28. Mediation of Global Social Support for Academics effects on Persistence and GPA by Course Engagement.

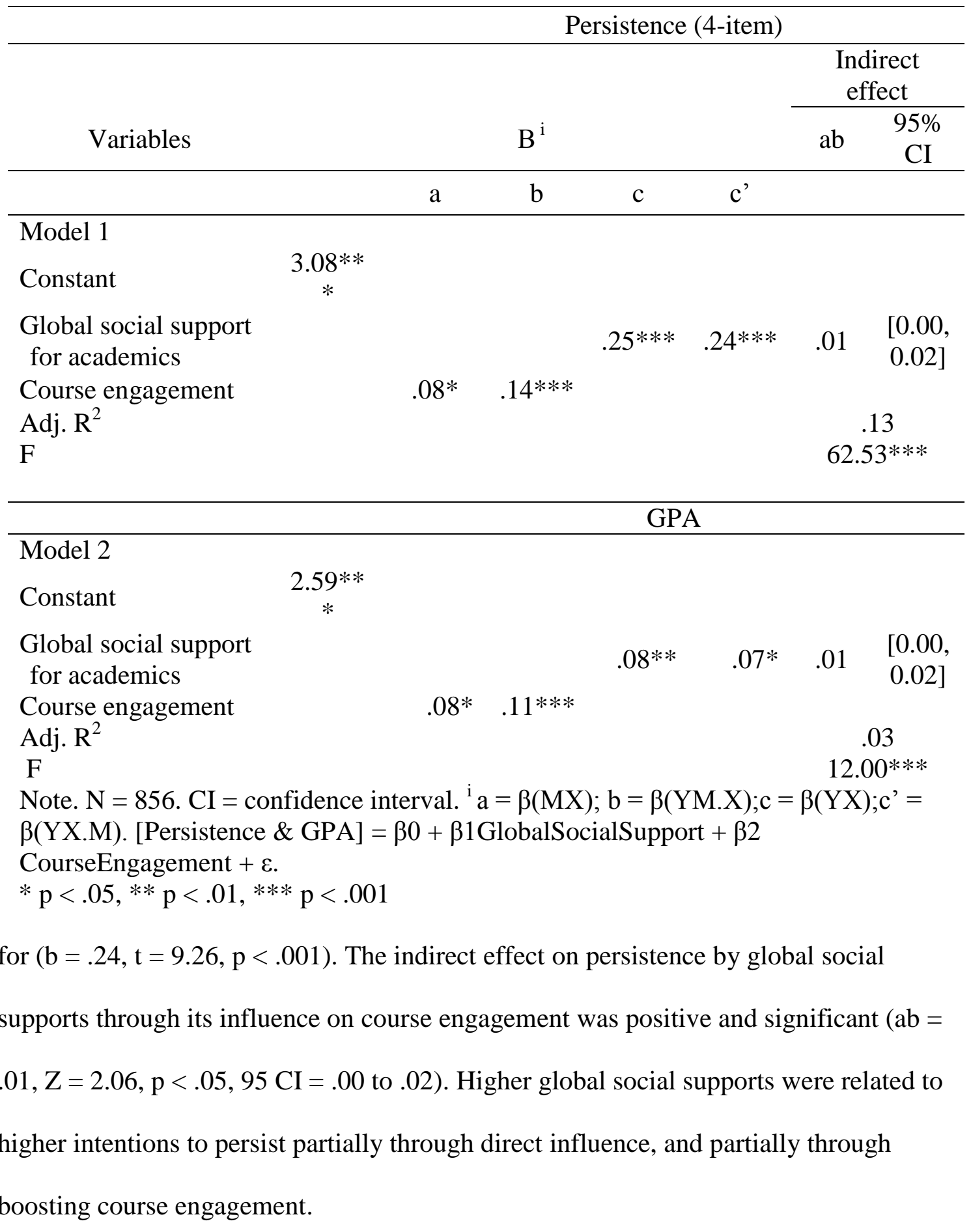


College success and student engagement / 157

When examining the outcome of GPA, global social supports was significantly directly related to GPA $(\mathrm{b}=.08, \mathrm{t}=2.87, \mathrm{p}<.001)$ and to course engagement $(\mathrm{b}=.08, \mathrm{t}$ $=2.26, \mathrm{p}<.05)$. When the effect of course engagement on GPA was partialled out, the direct effect of global social supports on GPA remained significant $(b=.07, t=2.58, p=$ $.01)$, as did the effect of course engagement when partialling out the effects of global social support $(b=.11, t=3.96, p<.001)$. The results of the indirect effect test of global social supports on GPA through course engagement was marginal based on a single sample $(\mathrm{b}=.01, \mathrm{Z}=1.91, \mathrm{p}=.06)$, but significant when 5,000 bootstrap sampling was employed $(\mathrm{b}=.01,95 \mathrm{CI}=.00$ to .02$)$. Higher global social supports was linked to higher GPA both directly and indirectly, by boosting course engagement.

Research Question 5d. Course engagement as an intervention target: With circumstances included in the model, do the relations between course engagement and success (performance (GPA) and persistence) remain when controlling for contributions from university supports?

Based on the non-significant zero-order correlation between course engagement and cumulative demands, mediation analysis, when controlling for university supports, was only conducted for global social supports through course engagement on persistence. Since university supports showed no zero-order relation to GPA, no analyses including GPA were conducted. See Table 29 for coefficients.

When looking at persistence, controlling for university supports, global social support for academics was significantly related to the mediator, course engagement $(b=$ 
Table 29. Mediation of Global social supports for academics effects on Persistence by course engagement, controlling for university supports

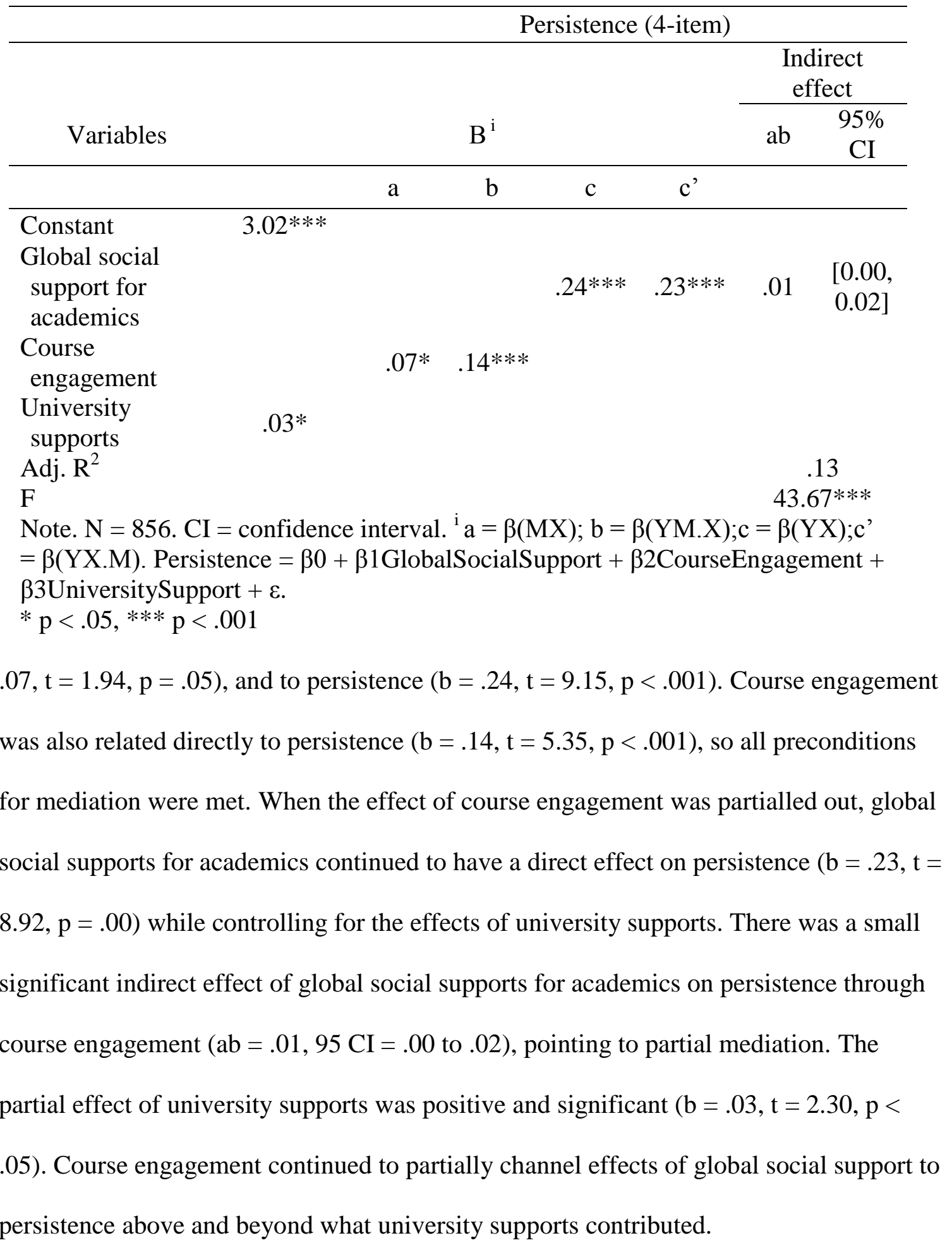


Research Question 5e. Moderating role of course engagement: Can course engagement buffer the effects of higher demands on student outcomes? In other words, are the effects of high demands on performance reduced for students who are high in course engagement?

While there was no mediation indicated for cumulative demands on persistence or performance by course engagement, the relationship between demands and outcomes may change as a function of course engagement levels. In order to examine the possible moderating influence of course engagement, both cumulative demands and course engagement were first grand mean centered and then an interaction term of these centered variables was computed. This allowed for ease of interpretation when results were examined as reflecting the average levels (among all students) of the predictive and the moderation variables.

Overall, the model of cumulative demands, course engagement, and the interaction of the two variables was significant in predicting persistence $(\mathrm{F}(3,852)=$ 14.72, $\mathrm{p}<.00$; See Table 30 for coefficients). This model accounted for $4.6 \%$ of the variance in intentions to persist. Both tolerance and VIF statistics were high (.99 to 1.00), indicating no colinearity among the variables included. There was a main effect for level of course engagement, indicating that as cumulative demands increased, persistence decreased $(b=-.02, t=-2.08, p<.05)$. Conversely, at the average level of cumulative demands, higher course engagement was associated with higher intentions to persist $(b=$ $.16, \mathrm{t}=5.91, \mathrm{p}<.001)$. The interaction between cumulative demands and course 
Table 30. Moderation of Cumulative Demand effects on Persistence and GPA by Course both cumulative demands and for course engagement on persistence. At the average Engagement (grand mean centered variables).

\begin{tabular}{|c|c|c|c|c|c|c|c|}
\hline \multirow[b]{2}{*}{ Variables } & \multicolumn{7}{|c|}{ Persistence (4-item); Constant $=4.59 * * *$} \\
\hline & B & $\mathrm{SE}$ & $\beta$ & $\mathrm{t}$ & $95 \% \mathrm{CI}$ & $\mathrm{R}^{2}$ & $\mathrm{~F}^{\mathrm{b}}$ \\
\hline Model 1 & & & & & & .05 & 14.72 \\
\hline Cumulative demand & $-.02 *$ & .01 & -.07 & $-2.08 *$ & $\begin{array}{c}{[-0.03} \\
-0.00]\end{array}$ & & \\
\hline Course engagement & $.16^{* * *}$ & .03 & .20 & $5.91 * * *$ & $\begin{array}{c}{[0.10} \\
0.21]\end{array}$ & & \\
\hline \multirow[t]{2}{*}{ Interaction } & $.02^{\mathrm{a}}$ & .01 & .06 & 1.93 & $\begin{array}{l}{[0.00,} \\
0.04]\end{array}$ & & \\
\hline & \multicolumn{7}{|c|}{ GPA; Constant $=3.31 * * *$} \\
\hline Model 2 & & & & & & .02 & 6.69 \\
\hline Cumulative demand & -.01 & .01 & -.05 & -1.43 & $\begin{array}{c}{[-0.03} \\
0.00]\end{array}$ & & \\
\hline Course engagement & $.12 * * *$ & .03 & .14 & $4.12 * * *$ & $\begin{array}{c}{[0.06,} \\
0.17]\end{array}$ & & \\
\hline Interaction & .01 & .01 & .03 & .84 & $\begin{array}{c}{[-0.01} \\
0.03]\end{array}$ & & \\
\hline
\end{tabular}

Note. $\mathrm{N}=856 . \mathrm{CI}=$ confidence interval. ${ }^{\mathrm{a}} \mathrm{p}=.055 .{ }^{\mathrm{b}}$ Models significant at the $\mathrm{p}<$ .001 level unless specified as non-significant (ns).

$* \mathrm{p}<.05, * * * \mathrm{p}<.001$

engagement was marginal $(b=.02, t=1.93, \mathrm{p}=.06)$. If the interaction was significant, this would imply that the relationship between demands and persistence depends on levels of course engagement (from the average) and the relationship between average levels of course engagement and persistence depends on levels of cumulative demand (from the average).

Due to the marginal results, the role of course engagement in moderating the effects of cumulative difficulty on persistence were further examined. Raw variables were used to understand the interaction. The raw variable regression equation was: Persistence $=4.68-.08($ Demands $)+.01($ Course Engagement $)+.02($ Demands $*$ Course 
Engagement. Levels of persistence were computed for three levels of course engagement and three levels of cumulative demand. One standard deviation below the mean (2.97) was used as a marker of low engagement $(\mathrm{M}=3.74, \mathrm{SD}=.77)$, the mean was used as average engagement, and high engagement was based on scores one standard deviation above the mean (4.51). In a similar manner, low cumulative demands was based on one standard deviation below the mean $(5.31$, where $\mathrm{M}=8.12, \mathrm{SD}=2.81)$, the mid level by average cumulative demands, and high cumulative demands by one standard deviation above the mean (10.93). See Figure 7 for the predicted values of persistence based on the low, moderate, and high levels of course engagement.

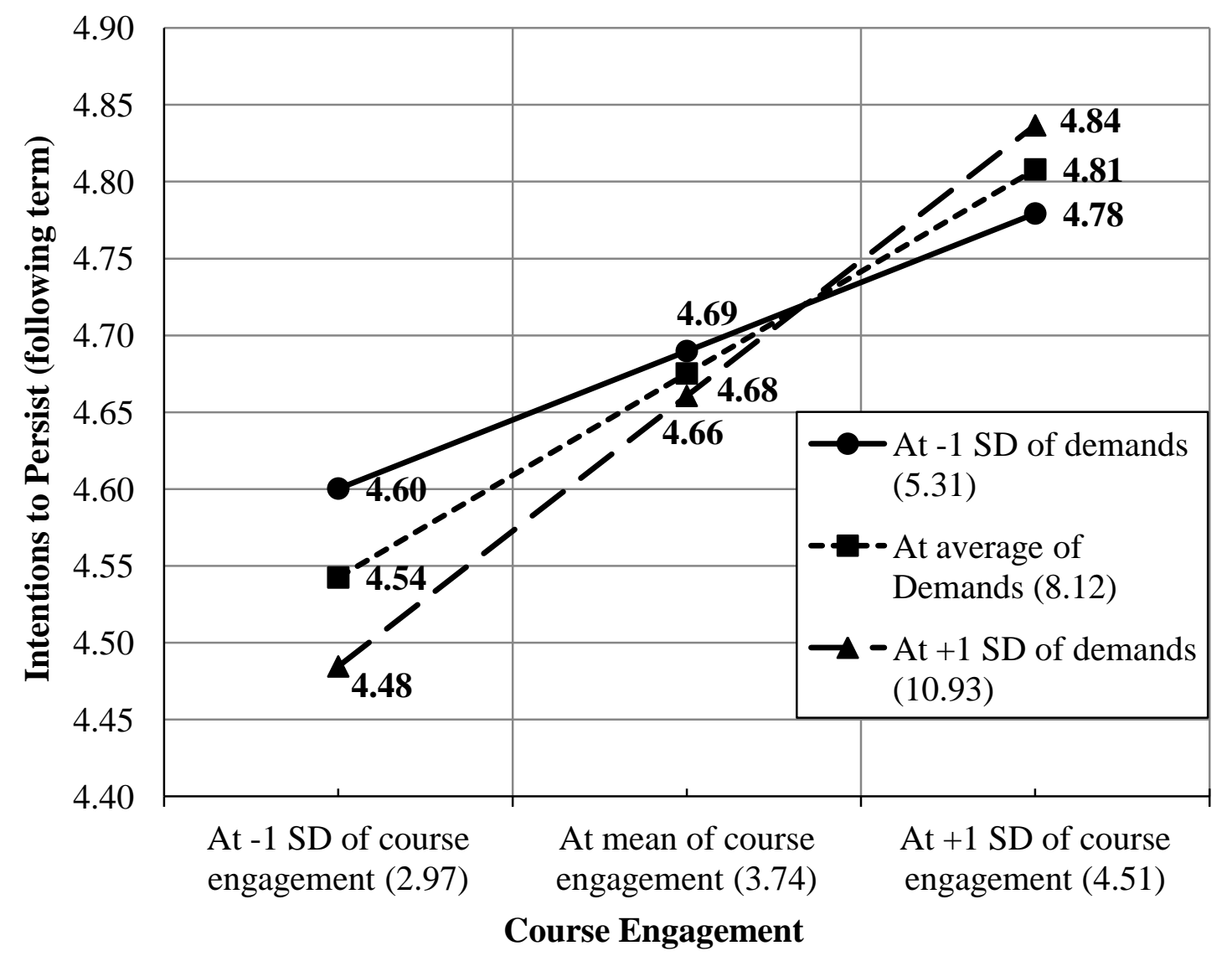

Figure 7. Moderation of relationship between cumulative demands and persistence by course engagement. 
College success and student engagement / 162

Further examination revealed that there was a positive relationship between demands and persistence for students with high engagement, and a negative relationship between demands and persistence for students with low course engagement. At low levels of course engagement, students with high level of demands had lower intentions to persist (4.48) than students with average demands (4.54) who, in turn, had lower intentions to persist than those with low demands (4.60). At the average level of course engagement, while this pattern remained, the difference was on the order of .02 points of magnitude, as reflected in the zero order correlation between cumulative demands and course engagement. At high levels of course engagement, students with high demands had the highest level of intentions to persist (4.84), followed by students at the average level of demands (4.81), with low demand, high engagement students showing the lowest, but still high, level of intentions to persist (4.78).

With GPA, the overall model was significant $(\mathrm{F}(3,852)=6.69, \mathrm{p}<.001)$; of cumulative demands, course engagement, and the interaction of the two variables, however, there was no moderation. This model accounted for $2.0 \%$ of the variance in reported GPA. Both tolerance and VIF statistics were high (.99 to 1.00), indicating no colinearity among the variables included (Tabachnick \& Fidell, 2007). There was a main effect for course engagement on GPA, but not for cumulative demands, as was known from the zero-order correlations. At the average level of cumulative demands, higher course engagement was associated with higher intentions to persist $(b=.12, t=4.12, p<$ .001). The interaction between cumulative demands and course engagement was not significant $(b=.01, t=.84, p=.40)$. The positive main effect of course engagement on 
College success and student engagement / 163

GPA did not depend on cumulative demands, and there was no main effect of demand levels on overall GPA, regardless of levels of course engagement.

Summary results for Research Question 5. Research Question five examined the role of course engagement in the integrated model when effects of student nonacademic circumstances were included in the model. These non-academic circumstances included cumulative demands (from five areas) and perceptions of support for the academic role by non-academic social partners (family, work, 'people'). While higher global social support for academics was significantly related to both higher intentions to persist and higher reported overall GPA, as expected, cumulative demands were only significantly related to persistence, where higher levels of demand related to lower intentions to persist. The two non-academic circumstances were negatively related to each other, as might be expected though not specifically included in the model.

Based on there being no relation between course engagement and cumulative demands $(\mathrm{r}=.00)$, only mediation of global social support effects on persistence and performance by course engagement was examined. Partial mediation was found with both outcomes. While global social support for academics had a positive effect on persistence and GPA, even when the effects of course engagement on the outcomes was partialled out, there was a significant indirect effect through course engagement as well. High global social supports for academics related to high intentions to persist and GPA directly and indirectly by increasing course engagement which then also contributes to higher levels of the outcomes. 
College success and student engagement / 164

The partial mediation found of global social support for academics by course engagement on persistence was re-examined with the effects of university supports included as a control in the model (Persistence $=\beta 0+\beta 1$ Course Engagement $+\beta 2$ Global Social Support for Academics $+\beta 3$ University Supports $+\varepsilon)$. Because university supports showed no relation to GPA, this mediation with covariate analysis was not conducted. Partial mediation of effects on persistence remained even when controlling for the effect of university supports. The indirect effect of global social support for academics through course engagement, while small, was significant, where university supports also had a significant partial effect on the outcome. However, once the effects of university support on persistence was accounted for, global social support for academics no longer showed a significant indirect effect through course engagement, though all three areas maintained their positive and significant direct effects (see Table 29). This model accounted for $13.02 \%$ of the variance in persistence.

Finally, it was then examined whether course engagement moderated, or buffered, the effects of cumulative demands on intentions to persist and overall GPA. Based on the cumulative demands, course engagement (both grand mean centered), and their interaction, there was no indication of moderation when it came to overall GPA. In fact, with GPA as the outcome, only a main effect for course engagement was found (positive). With persistence, however, there was a marginal indicator $(\mathrm{p}=.055)$ for the interaction $($ Persistence $=\beta 0+\beta 1$ Course Engagement $+\beta 2$ Cumulative Demand + $\beta 3\left(\right.$ Course Engagement ${ }^{*}$ Cumulative Demand $)+\varepsilon$ ), in that the effects of high demands on persistence were reduced to a greater extent for students with high course engagement 
College success and student engagement / 165

than those with low course engagement, with a main negative effect of cumulative demands and a main positive effect of course engagement. At the average level of course engagement, there was the expected slight decrease in intentions to persist as demands increased, though intentions were still higher at all levels of demand than for students with low course engagement. 


\section{Chapter 7: Discussion}

Curricular Engagement / There has been, and remains, a "triad" of interrelated core purposes for liberal education: the epistemic (coming to know, discovery, and the advancing of knowledge and understanding); the eudemonic (the fuller realization of the learner, the actualizing of the person's potential—classically to achieve individual well-being and happiness); and the civic (the understanding that learning puts the learner in relation to what is other, to community and its diversity in the broadest sense, as well as the responsibility that comes from sustaining the community and the civic qualities that make both open inquiry and selfrealization possible).

the Bringing Theory to Practice project (2013)

Universities are by nature interested in promoting both student success and graduation. Stakeholders in higher education have begun to develop models that specify the kinds of university supports that are most widely effective in promoting these goals for the sake of their students as well as their own economic stability. These evidencebased supports include university services and/or referrals incorporated into centers for academic, family, legal, cultural, health, wellness, and fitness support, to name a few areas. One additional area that could be targeted by these support systems focuses on students' experience of their university, the core of which is their cumulative experiences in the classroom: experiences of participation and learning in the classroom. At the classroom level, a students' course grade and decision to persist in pursuing their educational goals can be shaped by the proximal, daily, repeated interactions they experience. Central to these experiences is their course engagement.

This study was based on the idea that this conceptualization of student engagement and the model of motivational development, of which it is a part, may also be useful to the study and improvement of student success in higher education. To see if 
this is the case, researchers need a theoretically-based, psychometrically sound measure developed specifically for college students that is short in items but broad in its conceptual breadth. This measure then needs to be examined in relation, not only to features of the classroom, but also in relation to key constructs at the university level, in order to examine the role of this core component, namely, college student course engagement, in interacting with the features of university experience that have already been studied (including university supports, academic identity, and university learning experiences) and in relation to overall student success.

The purpose of this study was to examine the role that course engagement, that is, students' enthusiasm and behavioral involvement in their college classes, plays in shaping student success in higher education. In order to do this, a measure of engagement for college-age students was first constructed based on findings from previous research suggesting that a more complex structure of engagement might be required compared to that typically found for measures used with elementary and secondary students. A larger item set, capturing this structure, was distilled into a 12-item measure of college course engagement that spanned the full construct space. Using self determination theory (SDT), a model of the classroom for college students (i.e., micro-model) and a model for overall university relations (i.e., macro-model) were examined in order examine the function of course engagement in integrating these proximal and distal experiences. A final step examined how students' non-academic circumstances might mediate or moderate the role of course engagement. 


\section{Summary of the Findings}

The students and the constructs. In general, students seemed to be functioning well motivationally and academically at both at the classroom and university levels. In the classroom, students reported their needs for autonomy and competence were being met, with the need for relatedness being met the least. Students reported that instructors provided a high level of support for these needs - provision of instructor autonomy support, structure, and involvement were all moderately high. In general, students reported themselves as being relatively engaged in their classes. The average course grade fell in the category of B- to B+. Although the mean for the actual course grade was slightly higher than the grades students expected, expected average course grade also fell into this category. Individual aspects, such as the perceived difficulty of the course and student non-academic circumstances showed a bit more variety. Students reported their course as being relatively difficult, that global social support for academics was high, and that they had an average demand weight of eight (out of 16) $-50 \%$ of the cumulative demand circumstances - present in their lives (range: 2 to 16 ).

At the university level, students reported their needs for autonomy and relatedness as a student at their institution as being met fairly well. The self-assessment of perceived ability to do well and knowledge on how to do well (competence) was reported as being very high. Combined into a reflection of the students self-perceptions about themselves as a student in higher education (academic identity), students reported a fairly high level of academic identity. Students reported that the university generally provided the supports needed (coping with responsibilities, support for academics, encouraging 
College success and student engagement / 169

diverse student contact and social thriving). Students also reported relatively high levels of university learning experiences - the contributions of the institute to the students' success, a 3-factor outcome to the NSSE and a marker of interactions over time between the student and the university in this study. Students reported very high intentions to persist in their studies, even accounting for the Senior students who were graduating. The most common and average GPA was reported as $\mathrm{B} / \mathrm{B}+$.

In terms of measurement characteristics, the internal consistency reliabilities for all the scales of both the micro- and macro- models were high (greater than $\alpha=.70$ ), with the exception of three scales, which showed moderate internal consistencies ( $\alpha$ range .62 - .68) - global social support for academics, university relatedness, and persistence. Some of McDonald's coefficient omega $\left(\omega_{\mathrm{h}}\right)$ were poor (e.g., student relatedness $\omega_{\mathrm{h}}=.58$ ) which indicates there may be more than one latent construct being represented by the items. Some scales intentionally incorporated multiple latent constructs, such as academic identity $\left(\omega_{\mathrm{h}}=.19\right)$ which is a composite scale of university autonomy, university competence, and university relatedness. For the purpose of this study, however, the alphas were considered high enough to make interpretations of model relations valid.

Research Question 1: Measurement. This research question focused on improving the measurement of course engagement at the college level, and making sure that it functioned in the classroom in the same manner as with younger students (Skinner et al., 2009). Previous research has indicated that, as with younger students, the structure for college students comprised four-factors (confirmed in this study), but that there was also additional complexity within these factors. For the most part, this additional 
complexity was confirmed in the current study (see Figure 8), with a few issues to consider as addressed in the Strengths and Limitations section.

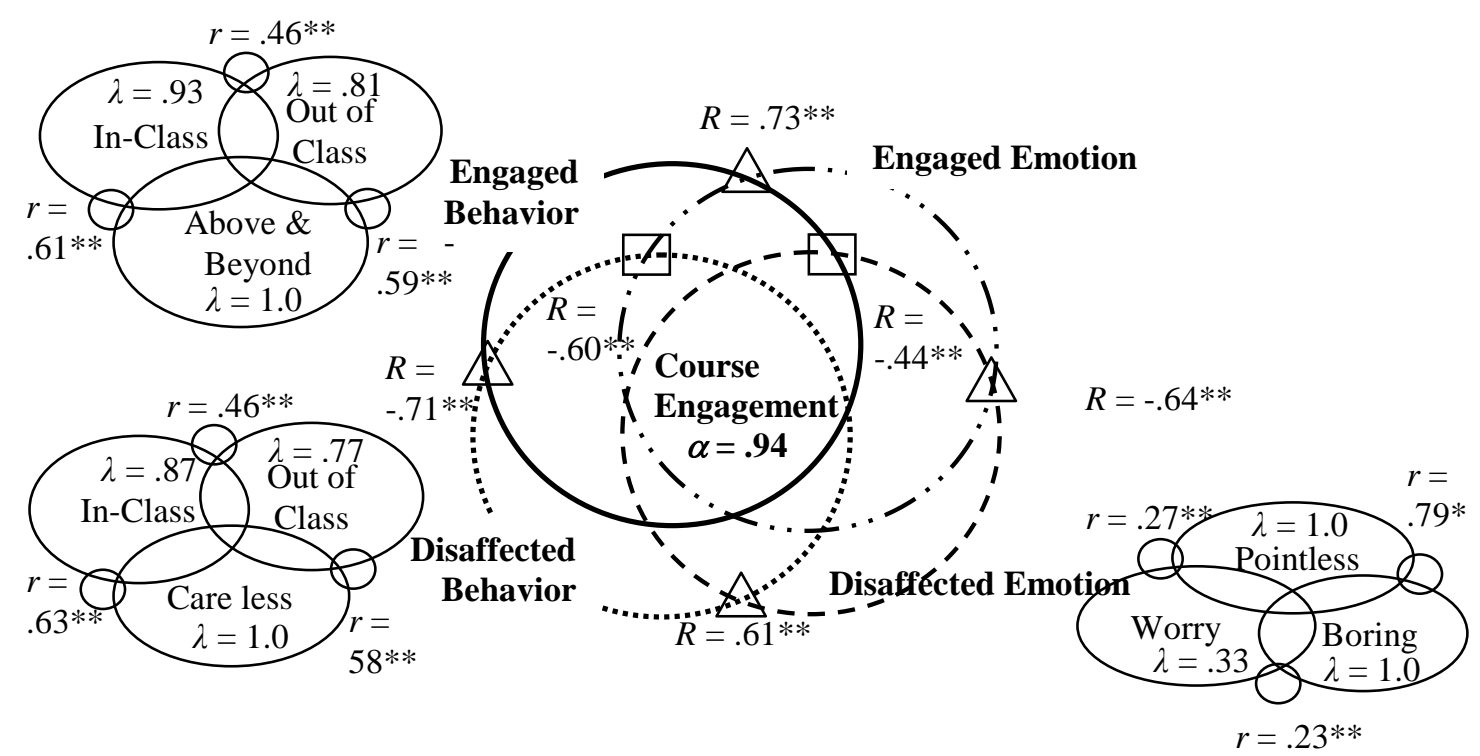

Figure 8. Structure and internal relations of 36-item course engagement.

Un-standardized betas on lines (zero-order correlations appear in parentheses). $\bigcirc=$ between sub-factor correlation; $\triangle$ = factor correlation; $\square$ = factor cross correlation. $* * \mathrm{p}<.01$.

As hypothesized, three sub-dimensions were confirmed for three of the four factors; the fourth factor, namely, emotional engagement maintained its unidimensionality. Motivated behaviors, both engaged and disaffected, showed a distinction among student behaviors that took place in-class, out-of-class, and overall academic orientation. Emotional disaffection broke down into feelings of worry, boredom, and pointlessness associated with the course. All these sub-dimensions within each factor correlated significantly and positively with each other. In addition, when each factor was looked at in combination with its opposites - for example, behavioral disaffection and behavioral engagement, or emotional disaffection and behavioral disaffection - two 
factor models consistently showed a better fit to the data than models which combined the pairs into one factor.

Analyses examining the function of course engagement, using both the full 36item composite scale and the reduced 12-item scale, replicated the classroom model found for younger students very well (Skinner et al., 2009). All relations between the course engagement scales and the six classroom model constructs (i.e., students' selfsystems and instructor provisions of support) were positive and significant, as were the relations among the six classroom constructs. Relations with course engagement dropped very little from the 36 -item scale when the 12 -item scale was used -0.03 was the greatest drop in correlations between engagement and any of the six classroom constructs. The full and reduced scales were highly correlated at $0.97(\mathrm{p}>.01)$, and both scales showed the expected relations among the four factors of the full structural model - positive with engaged behaviors and emotions, and negative with disaffected emotions and behaviors. With a mean of 3.78 and alpha $=0.88$, the reduced scale seemed to be a good representation of the larger, more structurally complex model, without the larger number of items needed to actually confirm this structure, thus indicating that the scale not only has conceptual breadth but also can be easily utilized.

Research Question 2: Micro- (Classroom) model. The second research question focused on the processes and outcome of the classroom model. Results suggest, as predicted by the model, that course engagement channels the influence of individual and contextual factors to course performance. Instructor involvement and student competence alone show unique influences on actual course grades. 
College success and student engagement / 172

As expected from the positive relations between the six classroom constructs and course engagement found during scale development, all simple regressions on course engagement by the six classroom model constructs were positive and significant, suggesting that there is a process happening among these seven constructs. Separately, the three instructor contexts and the three student met needs predicted course engagement, and relations among the six constructs were all significant and positive. These predictive relationships are hypothesized to be a reciprocal interactive process, repeated over the whole course, between the context provided by the instructor and the students' self-perceptions in the class, in which the action produced from these interactions, namely, course engagement, also can feed back into the context. Further support for the functionality of the classroom model was that, in line with SDT, the strongest relations among components of the context and student constructs were found between their corresponding pair for two of the three needs - instructor autonomy support with student autonomy, and instructor structure with student competence. Course engagement was a significant predictor of actual course grades, whether or not class difficulty was controlled for - engaged students performed better in their course, no matter the difficulty. It was necessary to include subjective course difficulty as a control, however, since it had both a significant negative relation to grades (indicating that students did not perform as well in difficult classes) and a positive association with engagement (indicating that students were more engaged when they perceived the class to be difficult). 
College success and student engagement / 173

Mediational analyses, examining whether engagement mediated the effects of instructor context and student self-perceptions on class grades, revealed that engagement did indeed partially or fully mediate their effects. The influence of instructor provisions of support and the met needs of students exert influence on class grade by motivating student course engagement, which predicts class performance. As seen in Figure 9, the effects on grades of two instructor contexts, namely, autonomy support and structure, and two student self-perceptions, namely, autonomy and relatedness, were fully mediated by course engagement. The way these four classroom constructs predicted grades seemed to be based on their effects on students' engagement in the course, with higher levels promoting and lower levels undermining course engagement. This supports the theorized model, since the way that these reciprocal constructs had an impact on class grades was solely through course engagement - which is as it should be if engagement is a necessary motivational condition for learning and performance. The effects of two classroom constructs, namely, instructor involvement and student competence, were only partially mediated by course engagement. Although these two exerted effects on grades through the pathway of course engagement, they also showed direct effects that were separate from both course engagement and class difficulty. Possibilities about what these direct paths might represent are addressed in the Implications section. 


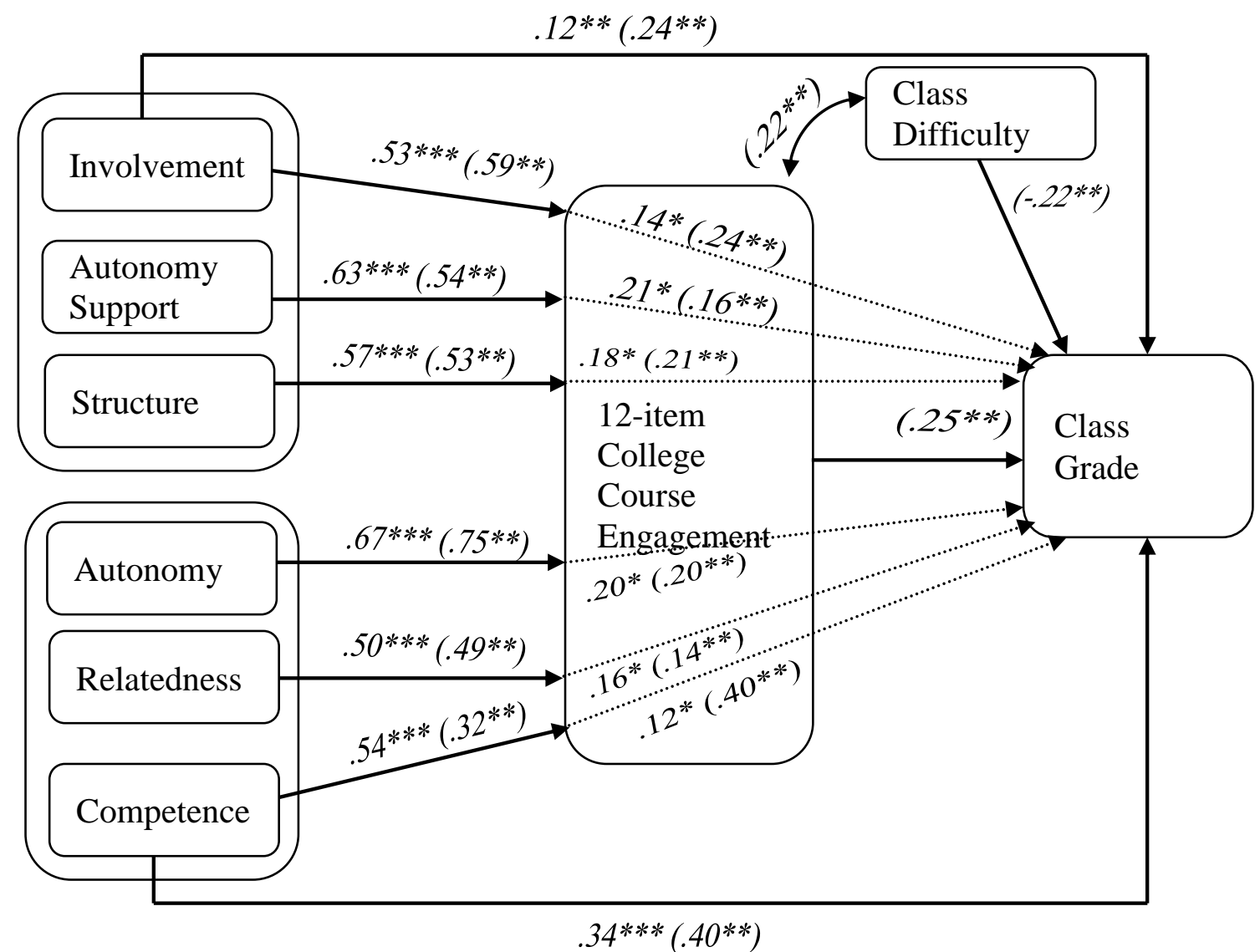

Figure 9. Course engagement as mediator of classroom constructs, controlling for class difficulty.

Un-standardized betas on lines from individual mediation analyses for each potential antecedent (zero-order correlations appear in parentheses); Dotted lines = indirect effect; Beta's for course engagement to class grade ranged from $0.21 * * *$ (competence) to $0.33 * * *$ (autonomy support). $* * * p<.00, * * p<.01, * \mathrm{p}<.05$.

Research Question 3: Macro- (University) model. The third research question focused on whether university supports and academic identity cumulatively influence university learning experiences which motivate (directly predict) students' intentions to persist and their overall GPA. Although some connections did exists at the university level between these constructs, counter to expectations, it was academic identity and not 
university learning experiences that emerged as the most important predictor of persistence and the only predictor of GPA.

Although university supports and academic identity both showed positive relations to university learning experiences and to each other, the university constructs showed different patterns of connections to the two outcomes, namely, overall GPA and intentions to persist. As expected, university support, academic identity, and university learning experiences all showed positive relationships to student intentions to persist. Higher intentions to persist were seen with students who reported higher levels of each of the three university constructs. However, only academic identity showed a significant (positive) relationship to GPA. This unexpected finding, namely, the lack of a relationship between GPA and the hypothesized antecedent (university support) and mediator (university learning experiences) precluded further examination of any mediational models for this outcome, although investigation into the mediational model for persistence continued.

The effects of university support on persistence were fully mediated by university learning experiences. This finding is consistent with the theory that contextual supports influence experiences within a context, and only through this effect do they influence success in that context. Support programs seem to be important in promoting persistence, because they increase the positive experiences students have at their university. The same pattern of mediation was expected with academic identity, but was not found (see Figure 10 for models of each separate mediator). When mediation of academic identity by university learning experiences was examined, academic identity turned out to be the sole 
significant predictor of persistence. Rather than being mediated, academic identity acted as a mediator for the effects of university learning experiences on persistence. The high relation between academic identity and university learning experiences may indicate

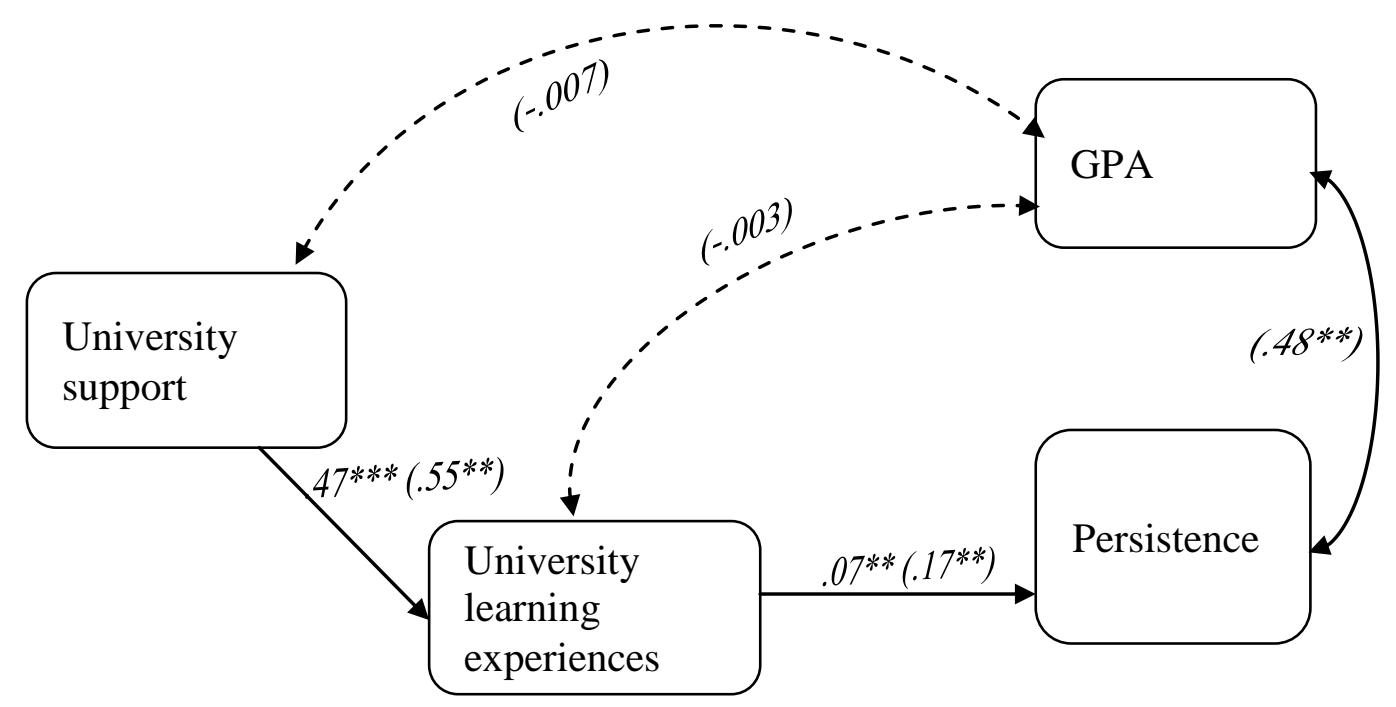

A) University support mediated by university learning experiences.

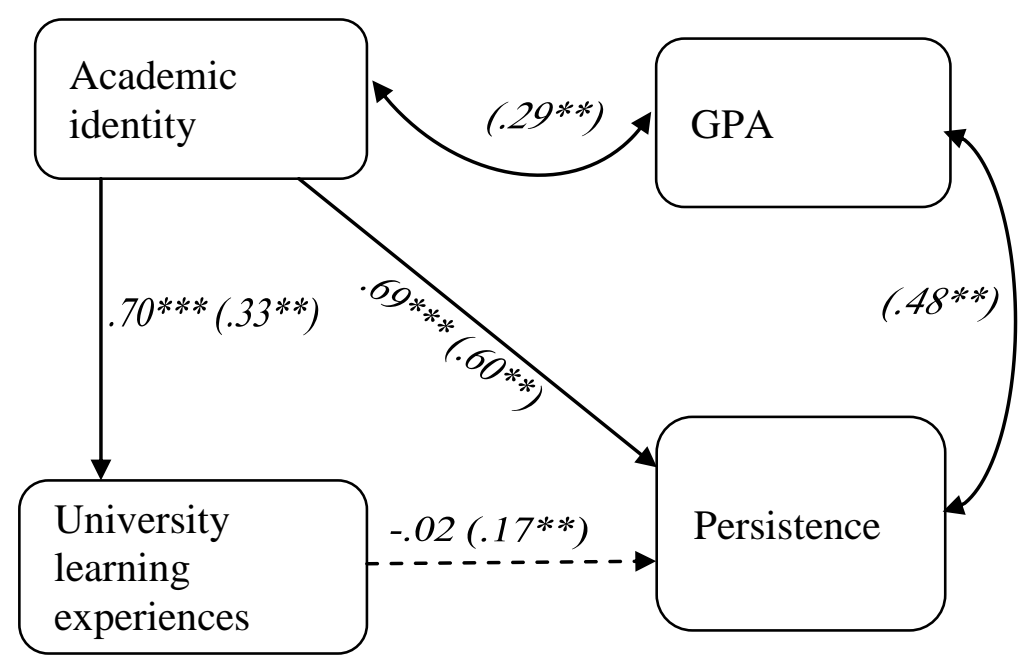

B) Academic identity mediated by university learning experiences.

Figure 10. University learning experience as mediator of (A) university support and (B) academic identity effects on persistence (with relations of university constructs.

Un-standardized betas on lines (zero-order correlations appear in parentheses).

$* * * \mathrm{p}<.00, * * \mathrm{p}<.01$. Dashed line $=$ non-significant. 
a strong reciprocity between how a student views themselves as a student and what they experience, but it seems that experiences may affect persistence by contributing to the formation of student academic identity, rather than students' academic identity affecting persistence by guiding university learning experiences.

Research Question 4: Integrated model. The fourth research question considered course engagement (as the culmination of proximal classroom experience) as part of the greater macro model of overall university success and examined the role it plays.

As expected, course engagement related positively and significantly to each of the constructs of the macro model as well as to the macro model outcomes of GPA and intentions to persist. As course engagement increased, so did reported university support, academic identity, university learning experiences, intentions to persist, and self-reported GPA. As seen in Figure 11, course engagement's direct effect on GPA was fully

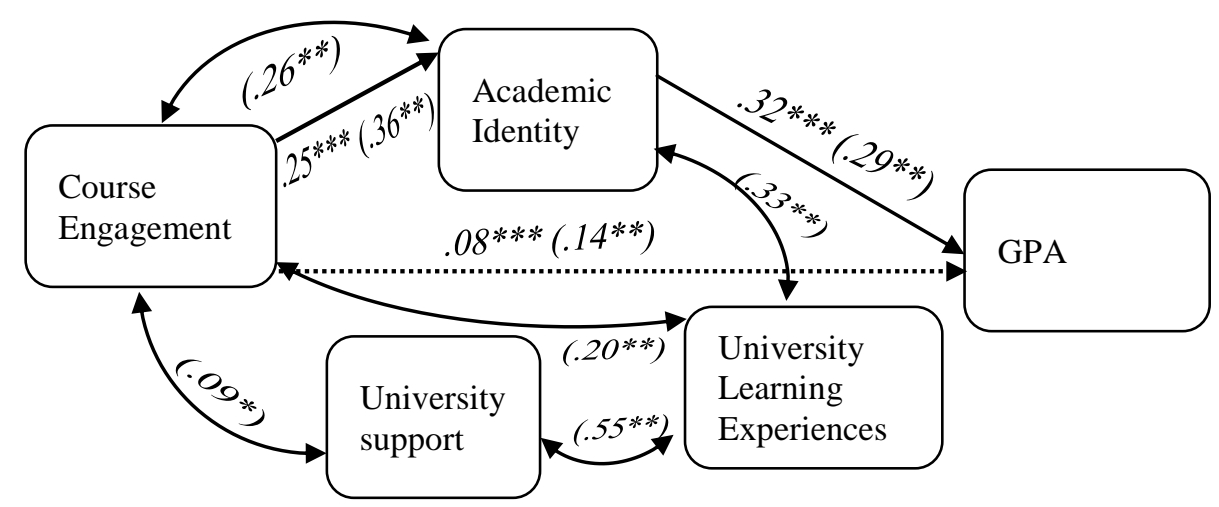

Figure 11. Relations of course engagement to the macro model constructs, and academic identities full mediation of course engagements direct effect on GPA.

Un-standardized betas on lines (zero-order correlations appear in parentheses). Dotted line $=$ indirect effect. $* * * \mathrm{p}<.00, * * \mathrm{p}<.01$. 
College success and student engagement / 178

mediated by academic identity, consistent with the idea that academic identity is a culmination of engagement over many classes and many terms. Because of the initial unexpected lack of relation between GPA and university learning experiences, overall experiences could not be examined as a mediator of the effects of course engagement on performance.

Academic identity also fully mediated the effects of course engagement on the second university level outcome, namely, persistence. The self-system processes that make up academic identity - autonomy, competence, and relatedness in the role of the student at the university - seem to channel course engagement into the motivation to continue to engage (behaviorally and emotionally) in the university, shown by intentions to persist (see Figure 12). Surprisingly, university learning experiences only partially mediated the effects of course engagement on persistence. Although experiences in a course predict self-assessment of overall university learning experiences, or gains in learning as defined by the NSSE (2010), course engagement still directly predicted persistence intentions. Possible explanations for the unique effect of course engagement on persistence over and above university learning experiences are explored in the Implications section.

With the pathway from classroom experiences to university success partially clarified here as routed through academic identity, university supports were added as covariates in the model. The goal was to examine whether the variance in overall success remained after accounting for the university level interventions students perceived as already being in place. In other words, do students with higher engagement still report 


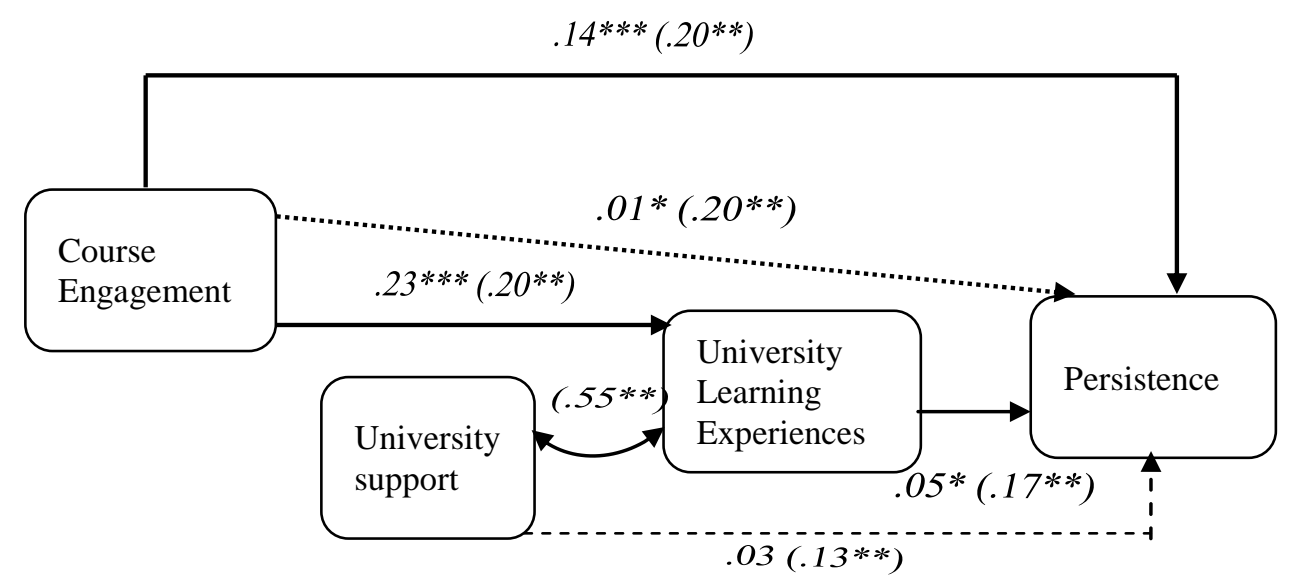

A) Course engagement mediated by university learning experiences, controlling for university support (partial).

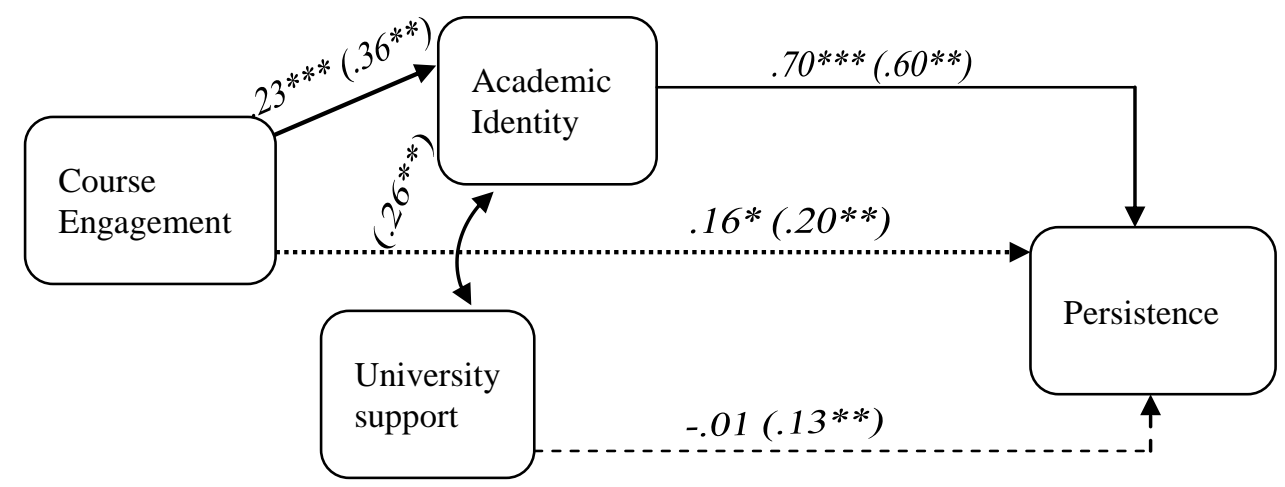

B) Course engagement mediated by academic identity, controlling for university support.

Figure 12. Direct and indirect effects of course engagement on persistence mediated by (A) university learning experiences and (B) academic identity, when controlling for university support.

Un-standardized betas on lines (zero-order correlations appear in parentheses). Dotted line $=$ indirect effect; Dashed line $=$ non significant.

$* * * p<.00, * * p<.01, * p<.05$

higher success, both directly and through academic identity, above any influence of their perceptions of university support availability? Not only were effects unchanged, but in both cases - full mediation by academic identity and partial mediation by university learning experiences - university support no longer showed any significant relation to intentions to persist. As mentioned in the macro-model, examination of university 
College success and student engagement / 180

supports as a covariate in the model with academic identity as the mediator of course engagement on GPA was not possible, because university support showed no direct connection to GPA.

While not hypothesized, a slight foray into exploratory analyses was conducted to test the integrated model when both mediators of the effects of course engagement on persistence were included, along with the covariate of university support. In this case, the significance of university learning experiences in mediating course engagement disappeared. Academic identity remained the sole mediator of course engagement, and all the effects of the covariate became non-significant when looking at persistence.

\section{Research Question 5: Circumstances and Course Engagement in the}

Integrated model. The fifth question focused on the role of course engagement as a possible protective factor, over and above perceived university level supports, for difficult student life circumstances by buffering the typically negative effects of high demands and low supports. Thus the circumstances analyses, by adding cumulative demand and global social supports as the added student circumstances, built on the integrated model, which included university support, persistence, and GPA from the macro model, and course engagement from the micro model. All three supports (university supports, social supports, and engagement) contributed to intentions to persist and GPA - global social supports through partial mediation by course engagement when university supports' influence was accounted for; however, demands did not. At the same time, there were some indications that course engagement has the strongest effect on intentions to persist for students with high demands. 
As expected, global social support significantly and positively related to GPA, persistence, and course engagement. Students with greater global support also were more engaged, performed better, and were more likely to persist in school. Counter to predictions, cumulative demands, a score based on overall presence and level from five possible demand areas (family, credit load, responsibility levels, work, and finance), showed no relation to either GPA or course engagement, although the expected significant negative relations to global social support for academics and persistence were present. This lack of relationship to GPA and course engagement is explored in the later sections. The immediate implication was the inability to examine engagement as a mediator of demand effects for either university outcome, though the course engagement as the mediator of the effects of global social supports on GPA and persistence proceeded.

As seen in Figure 13, with course engagement included as a mediator of the effects of global social support for academics on GPA, global social support was partially mediated, positively effecting GPA by boosting course engagement (significant based on the 5,000 sample bootstrap at $95 \%$ confidence interval), as well as directly predicting GPA. This direct relation is discussed along with cumulative demands in the Implications and Future directions section. The lack of relations between university support and GPA in the macro model precluded examination of the unique effect of course engagement on GPA, when boosted by global social support and controlling for the influence of university level supports. 


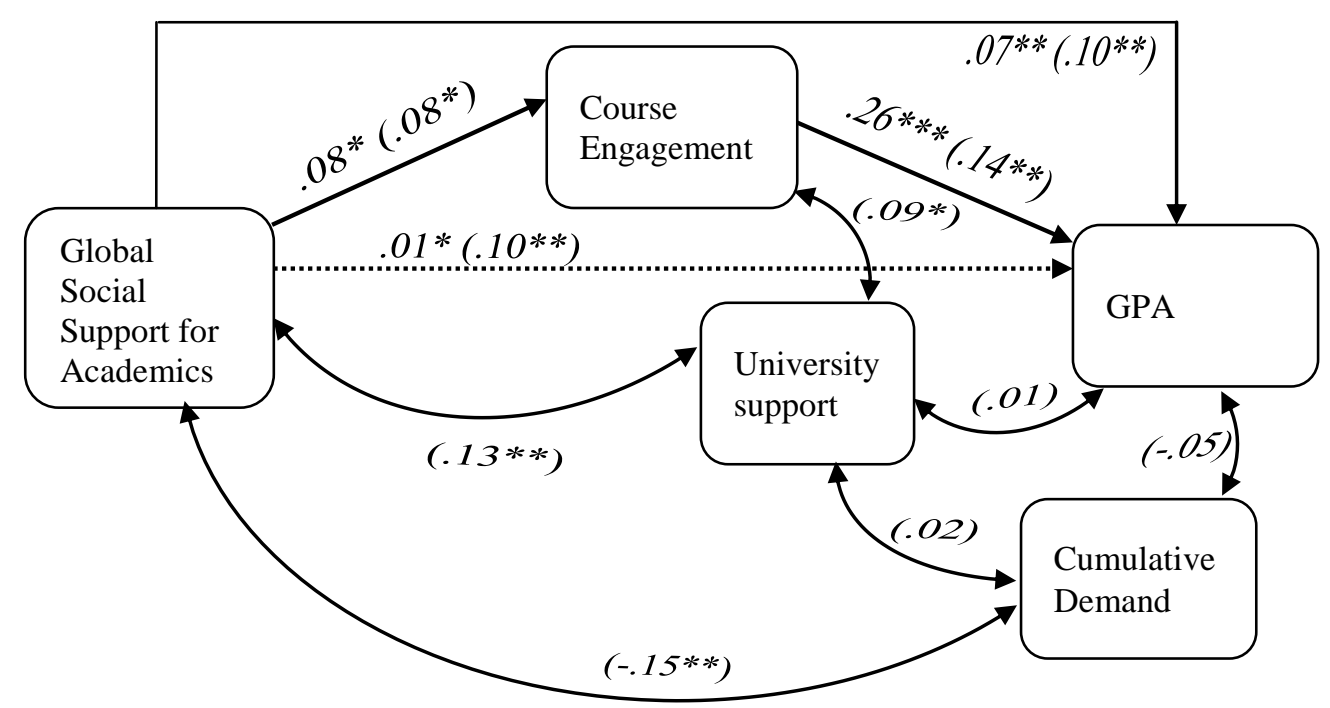

Figure 13. Relations of global social support for academics and cumulative demand to the macro constructs of university support and GPA, and the micro construct of course engagement, along with partial mediation by course engagement of global social support for academics effect on GPA.

Un-standardized betas on lines (zero-order correlations appear in parentheses).

Dotted line $=$ indirect effect. $* * * p<.00, * * p<.01, * p<.05$.

When the effects on the outcome of persistence were examined, course engagement partially mediated the effects of global social support for academics.

However, once the effects of university support on persistence was accounted for, global social support for academics no longer showed a significant indirect effect through course engagement, though all three areas maintained their positive and significant direct effects (see Figure 14). Together, this model of course engagement, global support for academics, and university supports accounted for $13.02 \%$ of the variance in persistence, and incorporates three aspects of student life: non-academic supports, institution provided supports, and experiences within the classroom While demands did significantly and negatively relate to overall persistence, this model did not control for any effects of cumulative demand on persistence (as addressed in later sections). 


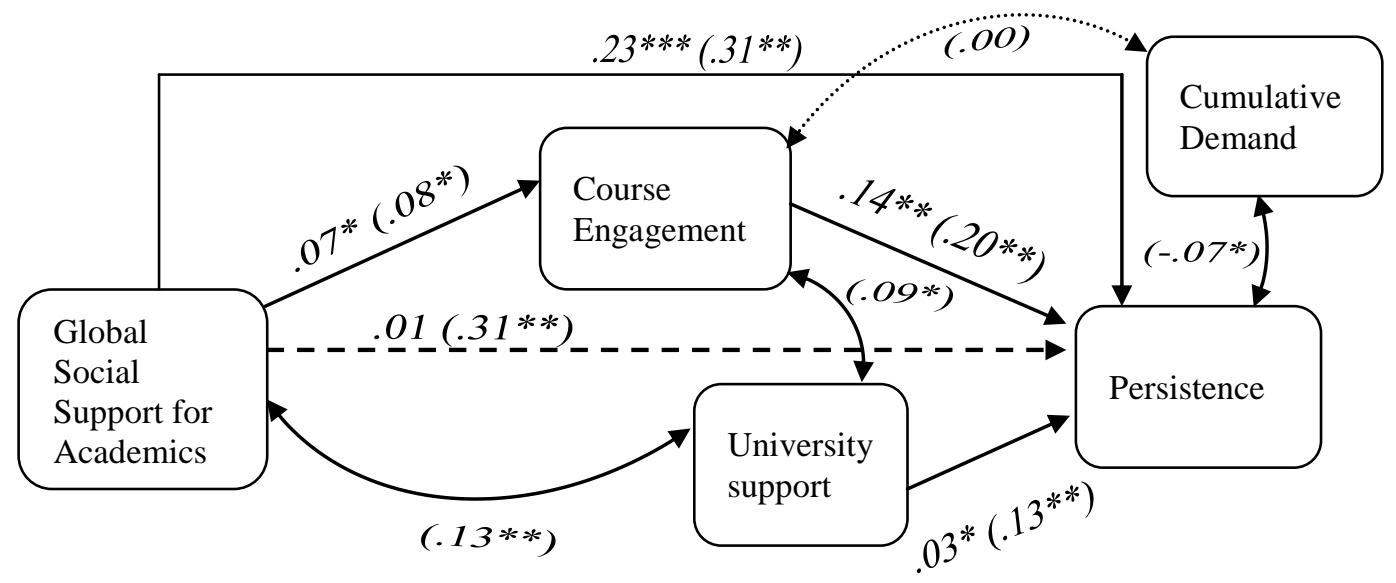

Figure 14. Course engagement as mediator of global social support for academics on persistence, controlling for university supports (indirect effect is significant at .01* without the control in the model).

Un-standardized betas on lines (zero-order correlations appear in parentheses). Dotted line $=$ indirect effect, dashed line $=$ non-significant $* * * p<.00, * * p<.01, *$ $p<.05$.

As stated earlier, due to the unexpected lack of relations of cumulative demand to either GPA or course engagement, the role of course engagement in mediating external demand circumstances could not be examined. However, the effect of demands on persistence may be moderated by the interaction with the effects of course engagement where course engagement has an effect on persistence only when cumulative demands are high. The role of course engagement as moderator of demand effects on persistence was so close to significance (interaction significant at $0.055,95 \%$ CI $0.000-0.037$ ) that this interaction along with the two significant main effects were interpreted (see Table 31 for interactions, or Figure 7 in Results). At the grand mean of both engagement and demands, engagement significantly and positively predicted grades and cumulative demands significantly and negatively predicted grades. The strongest effect of course engagement was seen for students in the highest demand category (one standard deviation 
above the grand mean). Students with high demands, who were low in engagement, reported the lowest intentions to persist of all profiles. However, high demand students who were high in engagement reported the highest intentions to persist of all demand/engagement combinations. Students with high demands showed the most variation in persistence intentions across engagement levels, while students with low engagement showed the most variation across demand levels. Further consideration of these profiles is addressed in later sections.

Table 31. Interactions of course engagement and cumulative demand on intentions to persist.

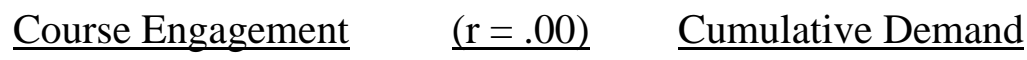

$\begin{array}{rrrrc} & \text { High }^{\mathrm{e}} & \text { Average } & \text { Low }^{\mathrm{d}} & \text { Difference } \\ \text { High }^{\mathrm{a}} & 4.84 & 4.81 & 4.78 & 0.06 \\ \text { Average }^{\mathrm{b}} & 4.66 & 4.67 & 4.69 & 0.03 \\ \text { Low }^{\mathrm{c}} & 4.48 & 4.54 & 4.60 & 0.12 \\ \text { Difference } & 0.36 & 0.27 & 0.18 & \text { Persistence }\end{array}$

${ }^{a}$ Highly engaged students who were low in demands had the lowest intentions to persist, while those who were high in demands showed the highest intentions to persist of the group (difference $=.06$ ).

${ }^{\mathrm{b}}$ Students at an average level of engagement show the smallest difference in average intentions to persist across all demand levels (difference $=.03$ ). ${ }^{c}$ Students with low engagement showed the greatest spread of intentions to persist across demand groups (difference $=0.12$ )

${ }^{\mathrm{d}}$ Low demand students show the smallest increase of persistence intentions across engagement levels (difference $=.18$ ).

${ }^{\mathrm{e}}$ High demand students with low engagement showed the lowest average intention to persist of the high demand group (difference $=.36$ ).

\section{Strengths and Limitations of the Current Study}

The implications of the findings from the current study should be considered in the context of the study's limitations, while remaining mindful of its strengths. Areas of 
this study that will be considered here are measurement, design, data analysis, and the models - micro-, macro-, and integrated.

Measurement. A primary goal of the current study was measurement development. It is a strength that the 12-item course engagement measure was built on a well-validated conceptualization of engagement and on earlier work that suggested a more complex structure of the construct for college students (compared to elementary and secondary school students). At the same time, when looking at the measurement aspects of course engagement, there were some aspects of the structural models that could be improved upon. There were negative co variances in some cases, and the item pool was not sufficient to test better combinations of items. Although the hypothesized complexity was adequately documented for the purpose of this study (which was to create a short measure that included items that represented that complexity), it is recognized that should particular aspects of engagement be the focus of interest, such as, for example, mapping emotional disaffection, additional modeling with item pools of at least six items per hypothesized sub-dimension should be conducted. Should this be done, special attention should be paid to item selection or generation when a factor or sub-dimension has strong prototype items (e.g., 'When in class, I feel bored') to avoid redundancy in item sets.

This study did point out some additional ways to improve the items for college students should others wish to further develop the separate factor scales. One example would be to reword some items from concrete ("Instructors care about students") to more perceptual items ("I believe this instructor cares about students"). Cultural jargon used in both relatedness scales (at the classroom level, e.g. "I don't really understand where the 
College success and student engagement / 186

other students in this class are coming from; and at the university level, e.g. "Important people in my life don't get the whole 'going to college' thing") are not necessarily interpretable by students from all cultures at any point in time, and so results for relatedness in this study should be interpreted judiciously and the items reworded if cross cultural invariance is of particular interest.

As the focus of this study was course engagement, the measurement properties of the other scales used in the classroom and university models were not intensely developed. Although most showed good internal consistencies, and all were based on previous research in the area of education and engagement, more in-depth item selection and model testing would be in order if one of these non-engagement constructs were of primary interest. With the exception of the two NSSE scales (addressed shortly), the scales used in this study appeared to be adequate representations of the hypothesized model components.

A final limitation in overall measurement is the reliance on student self reports. Specifically to the micro-model, only students reported on perceptions of instructors or their own engagement. As for student report of instructor quality, research on the validity of such reports suggests that instructor ratings by students are reliable across courses (Gilmore, 2000). However, valid measures of constructs and in-classroom process would best be captured from multiple points of view, including instructor- reports of students' and their own behavior, in-class observations of both students and instructors by independent observers, and peer reports to confirm which observable indicators that students self-report are particularly salient. However, while self-reports may not be the 
best indicator in longitudinal prediction of student performance (Bowman, 2011), and construct validity would be improved through the use of multiple measures (McDonald, 2008; Kindermann, 2007), it is through self report that the 'out-of-class' and 'above and beyond' aspects of student course engagement can practically be captured.

Design. At the same time, several limitations were imposed by the design of the study. A first limitation was based on the cross-sectional nature of the design. Unfortunately, without multiple time points to assess the various classroom and university constructs, the reciprocity of repeated interaction across time that is so central to the self-system model of motivational development (SSMMD) could not be examined. The theorized model is a dynamic, reciprocal one. However, the data collected represents only a single time point. In order to make conclusions about causality, time series or experimental study designs would be needed.

Sampling. Generalizability is limited to students in undergraduate psychology classes with high enrollments at a public, urban, northwestern United States university. In addition, since the sample for this study consists only of those students who made it to the final exam, those students who were possibly highly disaffected or had extremely difficult circumstances are underrepresented (sample mortality through selective dropout), which limits the utility of this measurement construction when applied to students who might already be on a trajectory toward dropout. However, $6 \%$ of U.S. awarded undergraduate degrees are in psychology (COD, Indicator 40; Aud et al., 2011), and additional analyses and studies can apply the classroom model examined here to determine any differences by major. Psychology is also a popular elective for health and 
social science students. Data from the current study are available to categorize participants by major, as well as by various aspects of their course (such as day/night, required, registered with friend, prior course with instructor, syllabus requirements, course level), which might be additional areas of possible differences. In a similar vein, follow up analyses could explore possible differences based on non-traditional demographic populations, such as international, first generation, or returning students.

Selection effects. In addition to the selection effects based on students who are self- or advisor- selected into the larger undergraduate psychology courses, two more kinds of selection effects should be considered in interpreting the current findings. First, because data were collected on the last day of class, these results only represent those students who made it through the final. This does not, however, necessarily mean that the results do not apply to those students that dropped off the radar (i.e., out of the course, whether officially or not). The fact that course engagement shows distinct patterns of correlations as well as significant mediating and moderating effects with such a restricted sample (i.e., those students who finished the course) can be considered evidence of its efficiency and sensitivity in a more homogeneous sample of "successful" students! Further studies could examine whether this measure, if administered near the beginning of a course (it is only 12 items, easy to put on the university online course supplements), and after the midterm grades are received, could predict drop-out from the course. Finally, in terms of additional possible selection effects, it would be possible to argue that these results only apply to a subset of the students who completed the course, namely, those students who, after rather grueling seeming final exams, self-selected into the study 
by choosing to take the 185-item survey, and/or finished their exam and the survey in the allotted time. However, and perhaps surprisingly, little selection is evident at this point. Class records showed $99.42 \%$ of students enrolled in the courses $(\mathrm{N}=861)$ participated in the survey (the post-cleaning study sample consisted of 856 students). And, while the option was given in each class for those students who felt the pressures of time, for whatever reason, to return the survey later to the researcher, only 17 surveys were received this way. Hence, the primary selection effects were based on subject (psychology) and course completion versus withdrawal.

Data analytic strategies. From a data analytic standpoint, all research questions were examined using correlations and multiple regressions for separate pieces of the model. Examination of the data, however, indicates that a hierarchical linear modeling (HLM; student within course) approach is warranted for the classroom model, since classroom constructs showed high interclass correlation coefficients (ICC's; MacCallum \& Austin, 2000; Miller \& Salkind, 2002; Snijders \& Bosker, 1999; Vogt, 2011). However, these findings also lend strength to the validity of the classroom model. Expected course grade, class difficulty, and instructor context (autonomy support, structure, involvement) all showed ICC's greater than 0.12 . This is in line with theory since each course and instructor can be expected to offer different combinations of supports and for the individual student needs and developmental processes. The three course self-perceptions (autonomy, competence, and relatedness) and actual grades showed lower ICC's (0.10 to 0.07$)$, indicating the somewhat more consistent self-system processes that are continually building across courses that theory suggests. Course 
College success and student engagement / 190

engagement itself had an ICC of 0.12, indicating that the behavior motivated by the reciprocal interactions within each course context varies by course. This indicates that using SEM and multi-level modeling would improve the partitioning of the variance to the classroom and the course when looking at the classroom model. This may also be an effective way to look at the integrated and circumstances models.

\section{Micro-model: Examining the functioning of engagement at the classroom}

level. It was a strength of the present study that the micro-system model was based on a clear conceptualization of the processes and relations happening at the classroom level, and that the bivariate associations and mediational analyses provided clear support for this model. A strength of the micro-measurement was that it utilized an objective measure of classroom performance - actual grade received. $69.6 \%$ of participants released their actual course grades, which allowed imputation for the remaining sample. Expected and actual grade were highly related pre- imputation $(\mathrm{r}=.69, \mathrm{p}<.01$, for the 435 students who had all three performance variables pre-imputation), and remained so postimputation $(\mathrm{r}=.71, \mathrm{p}<.01$, for the full sample of 856$)$. The average engagement level was lower for students who did not release their grades than for those who did.

A limitation at this level was not including any way to assess the uniqueness and usefulness of the newly created measure. The existence of the Classroom Survey of Student Engagement (CSSE, also produced by Indiana University, 2010; Laird, Smallwood, Niskode-Dossett, \& Garver, 2009) was not discovered until after data collection. Inclusion would have allowed for the examination of overlap and uniqueness of the two scales in representing classroom engagement as a predictor of performance - 
between the psychologically driven course engagement measured here and measure of classroom engagement from the CSSE, which focuses on frequency of self-reported behaviors, type of behavior, and task requirements.

Macro-model of student success at the university level. Exploration of the processes contributing to GPA at the university level was limited by the findings that neither of the NSSE item constructs, namely university support and university learning experiences, showed a significant relationship to GPA. This drawback does highlight the distinction between student intentions to persist compared to GPA as markers of overall student success, and that not all predictors show the same connections to both aspects. However, in this study, GPA was measured by student self-report so this distinction may not carry over to studies in which GPA is tapped via administrative record.

The unexpected behavior of university supports and university learning experiences may partially be due to construct definitions. While the items from the NSSE for university support are considered part of a benchmark (supportive campus climate) in predicting success, the 14 items used as university learning experiences in this study are considered a three-factor outcome by the creators of the NSSE: gains in (1) general edcuation, (2) practical competence, and (3) personal and social development (Carini et al., 2006). In the current study, the items were interpreted as representing students' perceptions of what they had cumulatively gained from their participation in university live base on the interactions over time between the student and the university as a whole, and thus as a direct predictor of success, as well as a possible mediator of any effects of student's identity as a student, and of any effects of university support programs (and 
College success and student engagement / 192

later, of course engagement). As it turned out, although when examined alone in this study, university supports was correlated with university learning experiences as would be expected, but academic identity took over the role hypothesized for university learning experiences. It seems clear that further investigation is needed for the macro-level model, and just as clear that academic identity (i.e., autonomy, competence and relatedness within the context of the whole institution) should be further considered as an important contributor to (or outcome of) student success.

A final note on the NSSE items: Much of the validation studies performed on the NSSE considers multiple university samples (Kuh, 2009; Pike, 2006; Fuller, Wilson, \& Tobin, 2011). Recently, inconsistent results have begun to appear involving psychometric properties; this may be attributable to sample level differences - one university/one-type university studies versus multiple/mixed-type university studies (Campbell, \& Cabrera, 2011). For example, this might explain why university support - consisting of the three Support for Student Success subscale items (Pike, 2006) plus one diversity item from the NSSE (2010) - showed no relation to GPA in the current single university sample (alternatively, the relation may be there for student recorded GPA rather than the selfreported GPA used here). The relations between the two NSSE constructs used in this study may be applicable only to the type of university where the study was conducted (urban, public, mid-level research orientated), and may not be found when part of an aggregate institution study.

Integrated model and circumstances in the integrated model. As with the macro model alone, the lack of relations to GPA for both the NSSE inspired constructs 
College success and student engagement / 193

presented some limitations to exploring the integrated model as hypothesized. A direct relation was expected between university support and university level success outcomes. While both Pike (2006) and Carini, Kuh, and Kline (2006) showed positive bivariate and partial correlations between the subscale of Supportive Campus Climate, which includes three of the four items used here for university support, and GPA, these results were replicated in this study. Neither were the expected relations of student circumstances. Since cumulative demands showed no direct relation to either macro-level GPA or microlevel course engagement, many of the specific hypotheses could not be tested as planned.

One possible explanation for the lack of connection between demands and the study constructs (course engagement and GPA) could be based on a limitation in how study cumulative demands were measured and calculated. The use of an aggregated measure of cumulative demands limits what can be said about specific demands and any differential effects on student success were conceptualized as part of an overall general level of demands. The data exists to look at specific demand areas in the future, but in this study cumulative demands can only be interpreted as the lower or higher presence of some possible combination of number and intensity of the five demand areas in a student's life.

A similar explanation may account for the lack of relations between the NSSE inspired constructs and GPA, and for potential differences in student demand and outcome (GPA and course engagement) relations by institution type. Besides the possible differences based on self-reported versus administrative GPA, it may be the single 4-year public university sample versus a multiple institution, mixed type sample that explains 
College success and student engagement / 194

the results in this study. According to the Condition of Education report (2011), the percentage of the students who can be categorized into demand presence profiles differs by institute and student type. This revisits the idea that the NSSE based constructs as used in this study may mean different things for different types of samples (multiple versus individual institutes), but here applied to the behavior of non-academic life circumstances by institute type. The lack of relations of cumulative demand to GPA and course engagement may be an effect of the kinds and distribution of demand profiles characterizing students from an urban 4-year public university: perhaps the subset of students showing negative effects of demands on performance cancel out the influence of the subset of students showing positive effects from the demands in their lives when considered in the aggregate. The same may be happening with university supports. In a mixed, somewhat diverse university, the relation of university supports may become statistically non-significant to performance, because of this moderation via student nonacademic circumstances effects cancelling each other out overall.

\section{Implications and Future Directions}

Course engagement is a marker of student psychological well-being within their courses; it is the visible manifestation of students' current motivation and has ties to their performance and overall engagement with learning. Overall, this study highlighted a useful, theoretically-based model of processes within the classroom feeding, via course engagement, into general institution-level student processes that can predict student success, even while accounting for general support and possible demand levels experienced in students' non-academic lives. The aspect of this model that institutions of 
College success and student engagement / 195

higher education can target or assesses as an indicator of high quality learning experiences - beyond the general supports universities already provide and the department/course level instructor evaluations already in place - is student-reported course engagement.

Course engagement and the process model of the classroom are based on previous theoretical and empirical work on classroom engagement and student success at the elementary and secondary levels. Specifically, students' engagement, that is, their active, involved, effortful, constructive, and enthusiastic participation in learning activities within the classroom (Skinner \& Belmont, 1993; Skinner et al., 1990) are a result of repeated interactions over time between the contextual support provided by teachers and the extent to which students feel their needs are being met, per self determination theory (Deci \& Ryan, 2000). This study supports the contention that the elements of this model function in a similar manner as they do in younger students, and confirms that postsecondary students experience a more complex form of engagement with and in their learning environments, as would be expected during transition periods such as from middle childhood to adolescence, adolescence to young adulthood, and to adulthood.

The study focused on improving the measurement of course engagement and examining its functioning at the classroom level as well as its primary goal, which was to explore the role of course engagement in the overall academic performance and intentions to persist for non-traditional students; a special interest was whether course engagement could boost success for students who were at risk for underperformance and drop-out, due to non-academic demands and low social supports in their lives. In general, 
College success and student engagement / 196

findings were largely in line with expectations. In the following sections, some possible deeper explanations for the patterns of finding are offered, along with some of the key issues at each of the levels (classroom, university, integrated), and with student circumstances. Along with these considerations, both interpretive and analytic, are some brief suggestions about different aspects for future studies to more fully examine these issues. Finally, one possible next step in reworking and expanding the current model is presented.

Course engagement and the classroom. The results of the current study are encouraging - a solid 12-item measure of course engagement was constructed and validated within a process model for looking at the antecedents and consequences of student engagement and performance in college classrooms: Links were found from course engagement to the processes of institution level experiences and general student success, and complex relations were uncovered between non-academic circumstances and course engagement and student success. The course engagement measure constructed can be used immediately - for example, as a unique or complementary tool for instructors to use in improving their courses, as a departmental course evaluation form, or as an administrative and program evaluation tool. An immediate first step would be to use the current data set to examine measurement invariance in course engagement as a function of student profiles of demographics and life circumstances.

Complexity of course engagement. Why is it that engagement in the academic learning environment is more complex for college students than that so far found for younger students? Along with cognitive and biological development, older students also 
experience (a) increased complexity and external demands (both material and in interpersonal relationships) in their private lives - at home, at work, in their communities, (b) greater reliance on self in regards to future direction (e.g., course selection, major selection), regulation (e.g., whether to attend a lecture, do the reading), and encouragement, and motivation (i.e., no one is going to make them do anything). Course engagement's emergence as a complex, multi-dimensional latent construct not only reflects the development of the student in higher education, but may also point to an area for exploration in connection to classroom engagement with younger students - perhaps their "out-of-class" behaviors, as found with college students, could add complexity to the current picture of engagement in earlier grades. The complexity, levels of support, and external demands may affect younger students' overall engagement in ways similar to those shown here for college students. For example, structure, autonomy support, and involvement experienced around school homework from their non-academic environment(s) may play a significant role in student performance.

The course engagement measure. Beyond addressing the limitations already outlined for the measurement of course engagement, further examination of structural invariance and equivalence across students with difference academic majors (NSSE, 2010b; Raine \& Symons, 2012) would be useful in order to ensure the measure is valid for all students. Because SDT posits that the three needs are universal, the measurement properties and general model processes would be expected to be replicated when examined in non-social science courses, but it is conceivable that different aspects of the context, or different levels of the needs, might emerge as more or less important for 
College success and student engagement / 198 student success depending on the area of study. Course difficulty would be relevant here as well (e.g., math and science are considered more difficulty subjects). It would be good to conduct the same examination of invariance for course engagement by student personcentered characteristics (such as personality type) and by course characteristics (such as instruction format or assessment practice), if only to gain a better understanding of the trajectories of certain combinations of student, context, and area.

Convergent and predictive validity for the newly developed course engagement measure does need to be examined. Comparative analyses of the 12-item College Classroom Engagement Measure with at least the Classroom Survey of Student Engagement (CSSE, 2010; Smallwood \& Ouimet, 2009) or the Student Course Engagement Questionnaire (SCEQ; Handelsman et al., 2005), two course assessment tools currently in use (Mandernach et al., 2011), would further clarify both the concept of engagement and what uses can be made of the data gathered. Further studies which compare and contrast the new measure with other extant classroom assessments, such as Form B of the Instructional Assessment System (IAS, 2012; Lowell \& Gillmore, 1991) could be highly informative. This undergraduate course evaluation form has common items across all departments of another Pacific Northwest institution of higher education, and would be interesting and informative to explore. Such compare and contrast studies would help clarify the overlap and uniqueness of the construct space created by extant measures which use the term "engagement". Alone or combined with other scales, the 12-item college course engagement measure would be a useful additional tool for faculty as an aid to determining effective teaching strategies, instructional mode, or other 
targeted course context aspects that are within their control in order to boost their students' motivation and success.

It would be very useful to examine a detailed picture of the full NSSE benchmarks and outcomes - as interpreted through the lens of self-determination theory, a task that is merely hinted at in the macro model in the current study. If relations could be established between NSSE subscales and a university level self-system model of motivational development, a number of uses could be made of the results. Underlying SSMMD processes represented by the NSSE items could be identified (and used as a basis for current proximal interventions) from past years of NSSE data, while also clarifying the uniqueness of their items in representing the concrete aspects of academic life (such as hours studying). This information can be incorporated into current assessment and decision-making as a specific marker of student motivational well-being. Uniqueness and overlap of the four pieces of the university model proposed here and the extant NSSE data may lead to a shorter assessment tool than the full NSSE which could be used to identify these processes for faculty, administration, and budgeting use, as well as add a psychologically-based marker of student educational experience and motivational well-being to the current data profile of today's undergraduate, which fills out a picture that otherwise is more focused on concrete performance and demographic characteristics.

Further examination of functioning: Direct effects in the models. Although most of the effects of classroom constructs on grades showed full mediation by course engagement, nevertheless, instructor involvement and student competence showed 
College success and student engagement / 200 additional direct effects. Some possible explanations for these direct impacts are outlined to generate ideas for further research into these alternative paths to grades. First, for both involvement and competence, the direct effects may represent reciprocal effects - based on the timing of the data collection. Since the survey was only conducted right after the final exam in each course, these direct paths might represent feedback effects of final performance (i.e., expected grades) on the student's evaluation of the instructor's involvement and the students' own competence (e.g., "I didn't do well in this class because the professor doesn't like me"). This type of thinking might be reflected in ratings of how involved the instructor was (caring how students do) and feelings of competence (figuring out how to do well, externally validated through grading).

An alternative, or concurrent, explanation for the direct effects of instructor involvement on students' grades may be that involved actions by the instructor, might improve students' performance through other means than boosting student engagement. For example, by making supports repeatedly known to the class, or by inspiring a student. This might increase the likelihood of a student seeking out additional help, and not just boosting their direct course engagement. Knowing there are supports available, which is what this study assessed, is not the same as utilizing them, and instructor involvement may boost utilization by those students who are on the fence about needing such help, and not just those who are already tapped into the resource assistance network within the university. In terms of the possible explanations for the direct effects of competence, it is possible that students' perceptions of competence may be less class specific compared to self-perceptions of either autonomy or relatedness, since they are new for each course, 
College success and student engagement / 201

and competence in academic ability is carried forward and builds over terms. Although autonomy and relatedness cumulate as well, they are more dependent on specific instructor interactions, whereas competence, while still influenced by the specific instructor of a course, is likely based on all the previous schooling experiences in general.

The same logic may apply when looking at the classroom model from the instructors' perspective. Instructor provided supports, with instructor involvement being a more strongly person-centered aspect (as competence is for student perceptions), may reflect a more general individual instructor style of interacting with students and so carries across all classes to directly affect student performance as well as indirectly, through student interactions which result in student course engagement. If so, the context scales could in themselves be useful for instructors to evaluate their own performance and make adjustments with each new group of students as needed, since each class of students will differ in aggregate from any other in terms of which needs are in most need of scaffolding by the instructor. Instructor autonomy support and structure may be more specific to each course due to student aggregate observable engagement - in other words, these two aspects of the instructors' developing experience may be more reactive to the feedback that the instructor perceives about overall student engagement. These ideas the classroom experiences from the instructors' point of view - could be incorporated into a fuller model study, as briefly outlined later.

An alternative for the partial mediation found for competence at the classroom level, is also suggested from the mental health fields. Clinical research has shown links between mental emotional states, such as anxiety or depression, and the 'brain space' 
College success and student engagement / 202

available for critical thinking and focus (e.g., Everson, 1997). When the mind is full of concerns, worries about past and future events, or issues that need to be addressed, time and energy is spent ruminating which is time and energy lost from critical thinking. Thus, competence may impact grades directly because students who feel more competent spend less time on negative cognitions and emotions, and so have access to more of their cognitive resources to devote to academics. Therefore, the environment inside the mind is more conducive to focusing on productive behavior and results in more effective engagement and higher performance.

Longitudinal study of classroom model. While the classroom model was very well behaved in this study, it would be interesting to explore the model longitudinally using full structural equation modeling with all the classroom constructs included in one model, especially should any of the dynamics be of particular interest. This would undoubtedly give a clearer picture of the interactions among the components, as these constructs do not impact class performance (whether fully or partially mediated) nor student well-being in a vacuum (as suggested by each of the six constructs separately), but as an integrated and interacting whole, and may solve some problems in mediation and reciprocal effects. Ideally, at least two cohorts of all entering Fall undergraduates would be followed across six years, with multiple measurements of students within multiple courses within each term to fully explore the classroom model and the long-term outcomes (psychological and academic) of course engagement. This design and model would ideally be incorporated into the university systems model, discussed further on, by including markers of the university constructs and student circumstances. This design 
College success and student engagement / 203

would not only allow for a clearer picture of possible successful trajectories, and evaluation of support programs based on effectiveness in fostering these trajectories, but would also allow comparison of the pathways of students who leave college with those who graduate.

The role of class difficulty and course engagement. It would also be informative to further study the relations of class difficulty, course engagement, and class grade. As expected, class difficulty had a consistent, significant, negative relation to course grade - students did not perform as well in classes they perceived as difficult. At the same time, difficulty related to engagement positively (i.e., students worked harder on classes they perceived as more difficult). Hence, this complementary relation between the two correlates of difficulty suggests a possible interaction between them that would be interesting to explain. If it is the case that the perceived difficulty of the course increases the engagement in a course, and yet achievement is still increased despite the course being seen as harder, there may be some level of difficulty where engagement is abandoned and students drop out, for whatever reason. Knowing such threshold levels, when specifically measured (by certain items or item combinations), could serve as early warning markers for students in danger of dropping out or failing a course.

For this, and other reasons, it is important to include some subjective measure of course difficulty in future studies of engagement. Without such a control, relations of engagement might be underrepresented and relevant findings possibly masked. While pursuing the idea of threshold values indicating at-risk difficulty and engagement levels, it would be interesting to this researcher to explore the interaction between difficulty and 
College success and student engagement / 204

engagement in a confirmatory manner, as SDT posits an optimum level of challenge for boosting engagement, where both too much and too little can be detrimental to goal achievement in the relevant context. Potentially, if a 'standard difficulty level' course, such as Freshman Inquiry, was taken by all entering students, their difficulty by engagement interaction score or threshold value could be a useful tool for advisors to scaffold areas in need of development and suggest course choices to the student where they might be most likely to be motivated and to succeed.

University level processes and success. While the exact sequence and shape of the process model of university student development stills needs some clarification, it seems clear that a student's psychological identity - incorporating both their selfperceptions and their perceptions of their institution and campus - is an important predictor or marker of overall student success. The exact placement of the four components proposed in the original model would be an interesting question for future studies, but as our knowledge stands now, it seems clear that the support programs that institutions provide, student academic identity, and student satisfaction (or general learning self-assessments) are all important factors at the university level that seem to support student overall success.

Even though GPA in this study is self-reported by students, research on selfreports and objective inferences made can be equivalent to recorded grades (Crockett et al., 1987; Kuncel et al., 2005). However, in a study examining the NSSE benchmarks and GPA from a cross-sectional and longitudinal approach, Fuller, Wilson, and Tobin (2011) found these benchmarks do not serve as a strong predictor for GPA measured via 
College success and student engagement / 205 students' actual records, and suggest that latent factors more directly related to GPA are being represented by the benchmarks and should be explored. In partial answer to this call, by examining the macro-model hypothesized in this study, two things were added to our knowledge about post-secondary student success, GPA, retention, and assessment of university performance: (1) academic success, as indexed by GPA, is different from intentions to persist, and (2) academic identity may be a latent factor that directly relates to GPA and to which constructs such as university learning experiences (satisfaction with experiences as a student) are representing or contributing.

Intentions to persist may be a marker of dropout which is also related to GPA. However, it is clear from this study that persistence represents an aspect of success that is distinct from that of overall performance. This becomes especially clear once classroom experiences and non-academic circumstances are added into the system represented in this study. It may be that persistence and circumstances are more closely linked than performance and circumstances. This suggests that highly demanding student circumstances may not impair students' academic performance so much as they lead students to decide to drop out of college (at least temporarily). This can be important to consider when thinking about student success - that success itself is multi-dimensional; and knowing which dimension is out of balance for various student profiles would provide a useful tool in resource, scaffolding, and research allocations.

Integration and circumstances process model. The key, or fulcrum point for student motivation in these models are the everyday experiences of matriculation, "going to school", particularly course interactions (be they face to face or virtual) which drive 
College success and student engagement / 206

positive participation in college academics. The visible manifestation of this motivation, course engagement, is strongly predictive of overall success through its relations with academic identity and other university level aspects, and thus integrates the two levels. Student circumstances are differentially predictive of success in the classroom - demands relating to recorded class grade, global supports showing no relation - and overall demands related only to persistence while global supports also related to GPA - and showed unexpected differences in their relation to course engagement - demands showing no relation to course engagement.

While perceptions of the availability of university supports were not directly related to performance, their relations to academic identity, course engagement, university learning experiences and persistence were all positive. The supports provided by universities seem to be a vital and strong contributor of student success, so more targeted research into actual support programs offered by institutions and their relations academic identity, which in turn predicts both outcomes here, would clarify a possible pathway through which university supports promote student success. However, while we have not fully mapped the relations at the university level, we do know that course engagement affects both classroom grades and academic identity, and so it may also be an important contributor to overall student success.

Results obtained here have highlighted many additional areas for further exploration and clarification, as well as possible uses of course engagement and the models. The next sections explore some of these areas. First, direct effects from the classroom and integrated models are considered. Second, course engagement in the 
College success and student engagement / 207

integrated model is briefly considered. Third are thoughts on the role of student circumstances - specifically, demands and class grades, student profiles and profile trajectories, circumstances as global support and demands, and possible uses for the university of this information. Next, some thoughts are put forth on the assessment of the complementary and unique variance in student success accounted for by course engagement compared to other extant classroom and university level measures of engagement. This is followed by a brief section on the possible role of academic identity as an outcome/marker for cumulative course engagement and as a predictor/marker of positive persistence and GPA. Sixth, suggestions for more fully applying the classroom model, and especially involving instructors and the reciprocal nature of interactions is briefly outlined. Finally, some thoughts on a next study are entertained.

Course engagement in the integrated model. A possible explanation for course engagements' direct effect on persistence, over and above its influence through university level constructs is through students having an increasing positive attitude about taking another course, with greater interest and clearer goals for the next class. This could also be a more proximal effect on persistence, in that, over time, course engagement increases overall intentions to persist by mitigating short-term, proximal difficulties. Because one average 10-week quarter may look very different from another in terms of students' nonacademic circumstances, the effect of course engagement on persistence may be through mitigating the effects of high levels of short-term proximal non-academic demands.

The surprising strength of academic identity in predicting overall student success and channeling the effects of course engagement. One somewhat surprising 
College success and student engagement / 208

notion that emerged from the current study was the importance and centrality of the indicator of student academic identity. When this study was being designed, the conceptualization of the university model required a 'self' component. University supports were part of the context and university learning experiences were thought to be a marker of university engagement - it was actually called that in earlier conversations. Therefore, to apply the self-system model of motivational development to the university level student experiences, a construct was needed to represent the 'self' aspect - a student's sense of autonomy, competence, and relatedness in their overall university experience. Since, from previous research $(\mathrm{Chi}, 2009)$ there already existed a "short relatedness to college" scale, all that was needed was to come up with items for short autonomy and competence scales. This was done, and then to simplify modeling - after all, the purpose of this study was the development and testing of the 12-item course engagement measurement tool - these three university level short scales were combined and aggregated into what was referred to as 'academic identity'.

Apparently, the composite of academic identity could serve as an outcome/marker for cumulative course engagement, as a predictor of persistence and GPA, and as a mediator of other university constructs, such as university learning experiences and university support. Surprisingly, this composite of self-perceptions about the extent to which overall university experiences meet basic student needs turned out to be a very strong predictor of many desired university outcomes - at all steps in the process, including self-reported GPA - and seemed to act as a direct conduit for the cumulative proximal student experiences that are captured by student course engagement. This 
College success and student engagement / 209

discussion into how academic identity came about is in order to distinctly restate and reaffirm that, while the relatedness aspect of this construct includes much of what researchers into "belonging" would be familiar with, and those whose specialty incorporates research into "identity" may wonder at the use of this particular term, "academic identity" in this study was not an attempt to represent either of these areas of specialized research. It was conceptualized as a supporting character and, in a fairly superficial way, used as an umbrella construct to aggregate three self-system measures and then it ended up stealing much of the show. More study on the overall psychological sense of met needs at the university level (aka academic identity) may be highly profitable in the sense of understanding and addressing the ever more complex context of education and student success - be it post-secondary or prior schooling systems.

Were a study designed at only the university level, additional improvements in supporting student success, including those mentioned in the Strengths and Limitations section, could be made. Further examination of academic identity in a reciprocal process model is needed, similar to that outlined previously for course engagement. Academic identity may channel influence from university learning experiences and university support (and classroom experiences, as seen in the integrated model) to persistence and to GPA. This idea is explained further in the Next Study section (see Figure 15 for hypothetical full system model).

One possible implication from a collection of findings is that the overall system model (the integrated circumstances final model suggested at the end of this section) should be reexamined with academic identity as the focal point. A further indication of 
College success and student engagement / 210

the possible importance of this construct is that academic identity was the only direct predictor of both persistence and performance (GPA) in the current study. Findings that support this contention include: (1) the mediation of course engagement effects on outcomes, partially by university learning experiences and fully by academic identity; (2) the unexpected mediation of university learning experiences by academic identity; and (3) that academic identity became the sole mediator when both the second mediator (university learning experiences) and the covariate of university supports are included. Academic identity may be the mediator both between contextual support and learning gains at the university level and between classroom experiences and overall student success. Specifically, academic identity seems to have the potential to channel influence from three areas - the proximal experiences from the classroom, the student assessment of learning gains, and the availability of overall university contextual support - into a view of the self that exerts a powerful and positive influence on both persistence and performance.

Role of student circumstances. This study highlights the importance of student non-academic circumstances, particularly demands. Circumstances did not behave as expected, outlined shortly, and some possible explanations for the relations found are considered. The non-academic circumstances of students showed differential relations to the outcomes at the micro- and macro-levels and to course engagement. Although cumulative demands showed no relation to GPA or course engagement, it did negatively predict class grade, while global social support for academics related to all constructs but course grade. This revisits the possibility that, compared to global supports, demands can 
College success and student engagement / 211

be more immediate and unpredictable in general. Global social support for academics aspect of student circumstances seems to interact at the more overall level - if you have supportive people in your life, they are generally consistent in their presence in student lives - while demands can be long-term but they can also be completely unexpected and out of individual control. Similar to the marginal moderation of demands found with GPA by course engagement, particular demand combinations or levels may interact differentially. Depending on what level is examined, global social support for academics may moderate the relation university support has with GPA or persistence - where university supports are particularly influential for students with low supportive circumstances; or proximate demands effects on persistence (at the university level) and class grade (at the classroom level) may be moderated by course engagement - where it is the students with high current demand who really benefit, in terms of improved grades and persistence, from any increased amount of course engagement.

Although there was no interaction between cumulative demands and course engagement when predicting persistence or GPA, this may be an affect of the timing of the survey such that those students with the most difficult combination of outside circumstances had already withdrawn or dropped out. Alternatively, it may reflect the combined, non-weighted calculation of demand levels. Specific combinations of demands may have different effects on outcomes based on other life circumstances and demographics. Hypothetically, students who are doing well per GPA may be in a better position overall in other areas - financially, demographically, environmentally - and thus not only having an increased likelihood of knowing about all the supports available, but 
College success and student engagement / 212

also may not necessarily need them. Thus there would be overall no relation between global social supports or university supports to GPA.

This relation may look different for students with difficult circumstances, who may have a greater need for institutional support but at the same time whose demanding circumstances may prevent them from being aware of their availability or having the time or personal resources to utilize them. For example, a high level of non-school stress may, especially when partially due to an individual having to maintain multiple roles, make untenable even the idea of seeking support and trying to carve out even more time and/or resources to devote to school. Thus, average level of demand across time may continue to play a role in persistence as well as influence outcomes in a particular class, such as course grade and course engagement. There seems to be a clear benefit for students with high overall demands to maintain high course engagement. For this group, the connection of university support utilization, and other predictive and outcome constructs, with course engagement may be stronger than found in this study, especially when profiles of different combinations of circumstances are identified and their trajectories examined, especially in relation to course engagement.

Why cumulative demands did not work exactly as hypothesized. In addition to the overall problem of trying to conceptualize and measure the complex intrapersonal construct of "life demands", there are at least four other possible reasons demands did not function as expected in this study. One, universities specifically try to compensate for demand areas that are recognized from research studies - childcare, cultural diversity and health, wellness and mindfulness. Two, if any one of the demand areas became too high, 
College success and student engagement / 213

the student most likely left prior to the class final (self-selected out). Again, this could be useful information to have near the beginning and the middle of a course in order to help direct intervention effort and type. Three, those students who have survived the course, despite, that is high demand, those who reported high cumulative demand (so they could have been high in one or two areas, or just have demand present in all five areas, for example) and yet still took a 185 -item survey after completing the course and the final, have apparently found some way to compensate for the high levels present in their lives. These 'optimization with compensation' practices (Bronfenbrenner \& Morris, 1998) used by these students has carried them through. These individual, as yet unknown practices, were aided by high course engagement - for high demand students, high course engagement was associated with the highest intentions to persist in their education the following Fall term (statistically compensating for those graduating seniors).

Fourth and finally for here, what one group of individuals would consider a high demand may actually be an inspiration and strong motivation for other individuals. This too, would be useful to know in order to spot early warning signs and silent calls for external help, support, and encouragement. This may have a strong association with cultural, ethnic, and/or environmental upbringing backgrounds. Latino/a, Native American, various Asian ethnic groups, all have distinctly different cultural norms, practices, and beliefs around what is a joy and what is a trial. From personal conversations with students, I can report that on at least three distinct occasions, the situation of supporting children, being a single male parent, and sending money home to one's own parents, was explained to me with great pride, joy, and motivational spark. 
College success and student engagement / 214

Personally, that would be a high demand situation for me, even though I myself would be categorized as a 'non-traditional', ' 1 st generation (per American methods)', 'Asian', 'woman of color', 'returning' student - being 50\% Asian and 50\% Dutch, raised in a household where no one spoke the other persons native language, in a foreign country for both parents.

The demands an individual feels in their life is an incredibly complex and intrapersonal thing, resulting from lifelong experiences, biology, etcetera. As scientists, we strive to somehow capture and compartmentalize what might be construed as a demand - something external and/or internal to self that requires allocation of some limited resource. This is necessary to model and understand the processes and interactions of systems. In this respect, any definition of 'demand' is appropriate, as long as it is justified, backed up, and explained in context to the problem under research (including research into demands themselves). However, even given this rather lenient definition, the actual operational definition utilized in this study did act in unexpected ways. Without confirming that these results are not due to the way cumulative demands were measured, it is difficult to say with much assurance that these are a good, useful, or effective way to calculate this latent construct.

Profiles of student circumstances. There are many possible profiles of student circumstances to examine and developmental and evaluative uses to be made of the course engagement measure. For instance, the percentages of students in different circumstance and demographic categories vary by university type - 4-year private, 4-year public, and so on. According to the Condition of Education report (COE; Aud, et al., 
College success and student engagement / 215 2012) some of the classifications fit into the models explored in this study. For example, section Five reports on characteristics of undergraduate institutions. Indicator 45, college student employment, reports that in $200941 \%$ of full-time and $76 \%$ of part-time students were working. These percentages differed by institution type - the employment rate was higher for full-time students at a 4-year public institution than a 4-year private one. More full-time female students were employed (45\%) than full-time males (36\%), and employment rates differed by ethnicity. Employment for full-time students was lowest for Black (29\%) and Asian (26\%) students; more White (45\%), Hispanic (39\%), and students of two or more races (44\%) were full-time students and employed (categories based on the COE, 2012).

Considering the findings for student circumstances as defined in this study, its construction, and the individual and institution type differences in demographics and institutional attributes, it seems fair to conclude that the most effective allocation of university resources will depend on the student population served. Course engagement can not only be used to target and track students who could benefit from specific types of contextual scaffolding (e.g., supports for autonomy, competence, and relatedness at either the classroom or overall level), but can also be used to evaluate the effectiveness of current university support programs and resources already in place.

Fuller model application - reciprocity and instructors.

The self-system model of motivational development (SSMMD; Connell, 1990; Connell \& Wellborn, 1991; Ryan \& Connell, 1989) was shown to function in college lecture classes in a manner similar to findings with younger students and their class 
College success and student engagement / 216

performance: unsupportive contexts relate to poor outcomes because they undermine course engagement, and lower levels of engagement predict lower course grades. The quality of an instructors' observable engagement in instruction (as captured by student reports of instructor autonomy support, structure, and involvement) interacts with student self-perceptions in the context of the course. These self-perceptions, indicating that the psychological needs of autonomy, competence and relatedness have been met, predict students' observable (and self-reported) behaviors and emotions with learning the course material; in turn, students' engagement predicts their learning and achievement in the class.

Instructor course engagement. The model and theory underlying course engagement can also easily be applied to instructors, also through consideration of their own contexts at the two levels: their courses and their employer (i.e., the institute of higher education). The extent to which instructors feel that their contexts are supporting their own needs for autonomy, competence, and relatedness should influence instructors' own engagement in teaching - the very behaviors and feelings that create a large part of the context for student course engagement. The reciprocal nature of the model was not tested in this study. In fact, mentioned in Strengths and Limitations, data represents the perceptions of students only, and does not illuminate the perspective of another major social partner in college courses - the instructor - or how student engagement affects instructor engagement. Nor are the administrative and institutional contextual supports available for the instructors examined. However, as a tool for the professional development of instructors at the classroom level, information that helps instructors 
recognize the areas that need scaffolding for each student group allows instructors to increase their own engagement in teaching to support those areas. This should also increase their students' engagement, which both increases student well-being and performance, and creates a positive teaching context for the instructor.

Potential next study. An important next step would be to examine the full systems model, as outlined in Figure 15, incorporating many if not all of the suggestions outlined above for the separate pieces of the system model. Such a study, focused on the hypothesized reciprocal processes at both the micro- and macro- levels, would further explore the utility of an intervention study aimed at increasing the psychological engagement of students. A separate study could examine the psychological engagement of instructors based on a model, which is very similar but would pull more of the structure, goals, and climate of higher education institution types into the picture. The effects of demands would be hypothesized to be carried into the macro model through their effects on course engagement. This systems model would examine whether cumulative demands interact with course engagement in the micro-model (as depicted in the figure as pathway 1) to shape actual course grade (pathway 2), which in turn would directly affect overall GPA (pathway 3). Course engagement would carry into student success through actual grades (pathway 2) and through the influencing the macro constructs (pathway 4) of university supports, student academic identity, and student learning experiences (possibly a marker for overall student satisfaction with their education). Global social supports for academics would be included in the macro-model where they would directly and indirectly affect both student success outcomes. 


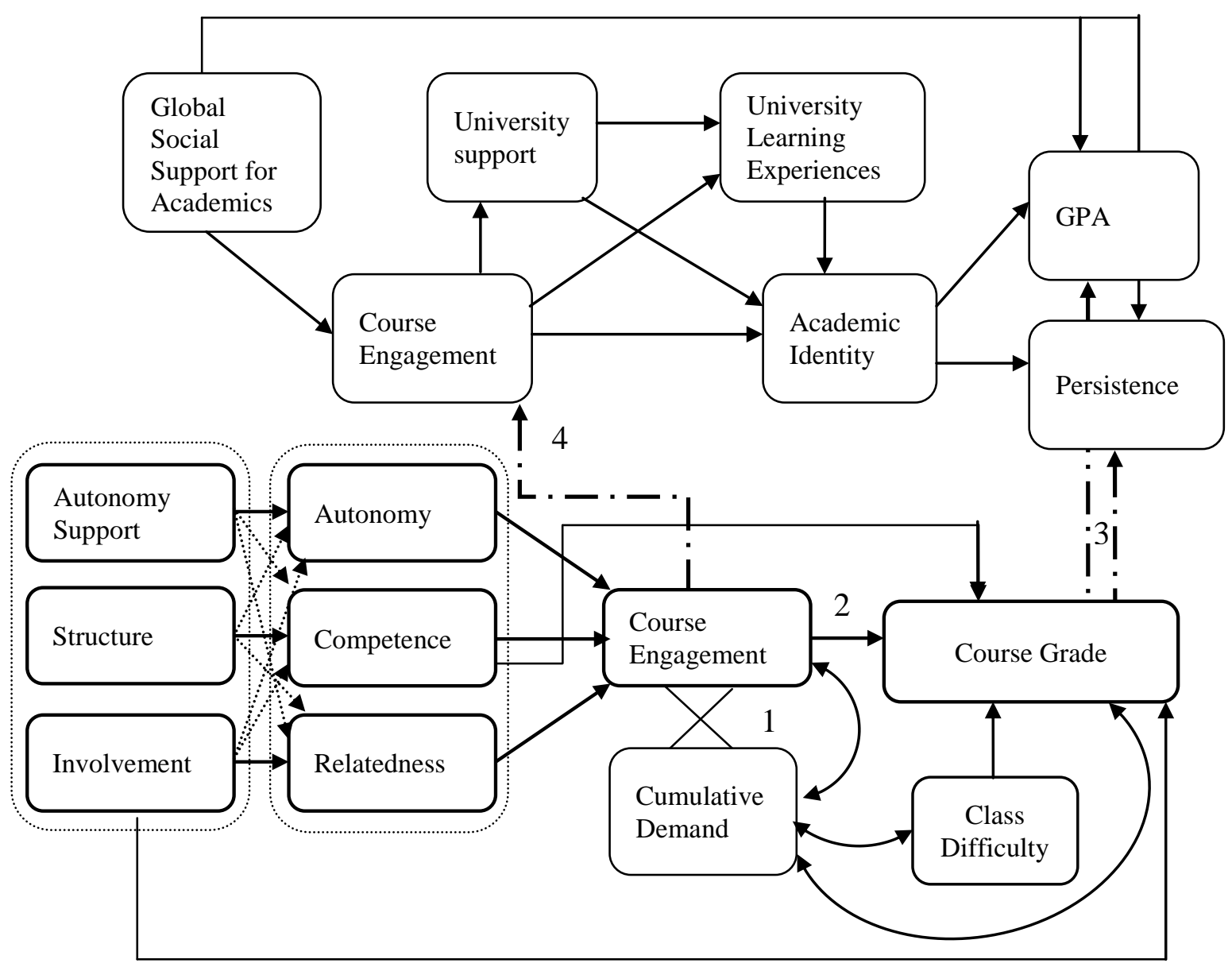

Figure 15. Full systems model of the university and classroom process of student success based on the theory of universal human needs (self-determination theory; SDT) and dynamic, reciprocal process of motivation (self-system model of motivational development; SSMMD), visibly manifested by engagement. 1 through 4 indicates pathways of interest.

Beyond the limitations mentioned earlier about the other constructs as measured in this study, it would be especially important to examine demands, however parceled, at the classroom level as a reflection of proximal daily interactions occurring in other arenas of student life. In general, when considering the integration of the models, decisions need to be made about the level at which student circumstances should be incorporated, based on the precise question being asked. From an analytical perspective, using HLM, the 
College success and student engagement / 219 influence of the circumstances needs to either be a) assigned to Level 1 (university) - for example, supports existent in students non-academic life should be examined at this level - or b) Level 2 (classroom) - as outlined above for demands - based on theoretical ideas and examination of the circumstance measures' ICCs. As examined in the current study, this decision was postponed (due to resource limitations) by angling the question to address separate pieces of the integrative model, rather than an overall model of the integration. Now, however, there is a much clearer understanding on where these circumstances might fit and how to build the structural model around the key motivation piece of course engagement, in concert with the apparently important construct of academic identity.

In addition to the ideas brought up in previous sections, some other interesting areas for further exploration of the classroom model and for the use of the course engagement measure include: (1) inclusion of syllabi and course format/structure (Boylan, 2004) into analyses of the effects of the classroom context - allowing for assessment of curricula, academic activities, and structure; and (2) incorporation and relation(s) of mental health and well-being (Roeser \& Peck, 2009; Sengupta, 2011) of the students and the instructors to student course engagement, instructor course engagement, and the classroom model. Programs, curricula, or skills training could be evaluated as they exist, or experimentally implemented and tested within this systems model as a natural next step. An intervention study to improve course engagement, where course engagement would be the outcome of interest, could provide universities with a marker of success that is so much more than just class performance. 
College success and student engagement / 220

\section{Real World Application.}

\section{Uses of course engagement to address student circumstances for universities}

and instructors. The university could benefit by using course engagement to evaluate their support programs or departmental offerings. At the administrative level, the course engagement measure could be added to any existing assessment tools, such as the NSSE or AIS. Engagement data collected on an annual or quarter/semester basis, would allow student success trajectories of student engagement/life circumstance combinations to be examined. This repeated testing would not only allow for the examination of trends of engagement over time for students from different demographic groups, but could also assist in improving overall retention, specifically by addressing low engagement. Even more useful would be the identification of specific threshold scores that could serve as an early warning system for students heading toward a negative trajectory.

Instructors could also benefit from longitudinal course engagement data from the students in their courses. If collected each term, measurement of course engagement could be conducted at the beginning or end of every term, or both. This could be accomplished if instructors incorporated the survey into each course they taught. For example, widespread use of online components makes it very simple to include short surveys and tests into a course. A 'pre-class' survey (optional or with credit), could assess students before the first day of the course, or sometime very near the beginning. The same 'exit' survey could be given at the end of the course, perhaps (as done here), as a last bit of extra credit after taking the final exam. Instructors could utilize the survey for their own professional development using the results at the beginning, middle, or end of 
College success and student engagement / 221

each course to assess their own instruction in relation to a group of students. This allows them to know which areas of student support they might concentrate on to get the most 'bang' for their own personal resource 'buck'. By examining the item means, relative levels of engagement and disaffection (for behavior or emotion or both), could be assessed and the area most in need of scaffolding could be identified. Aggregation of items and simple examination of their means would be well within the available time and ability of instructors.

Institutional message. In general, I believe the findings and resultant 12-item measurement tool created here sounds a call to action at many fronts in the fight to improve education and student success. Accountability has institutions looking for ways to show others why and how they are doing their jobs. Student engagement is being tossed back and forth in conversations, mission statements, ranking systems, and initiative programs and proposals. With this measure, a theoretically-based, psychometrically sound, face valid, system component is now available for applied use. When claims related to student engagement are made, hard statistical numbers can be offered to support such assertions. On-going student success programs and support services can self-examine their effectiveness, easily and at almost no cost, and be able to state upon evidence that they support student engagement - which is good from all perspectives that I have so far considered. Faculty can use the short scale in their courses, both as a professional development tool, as a dynamic feedback tool, as a course evaluation, and many other ways limited only by the individuals' creativity, motivation, management support, and resources. As can departments. If, as suspected, the measure 
College success and student engagement / 222

works in all disciplines, comparing aggregate course engagement per tern and/or academic year across university departments would be a useful and informative way of comparing departmental performance, besides just grant and student credit hour dollars.

As you may guess, I could extrapolate at length on the different uses that can be made of this simple, cheap (i.e., the tool is free, supplies and implementation would constitute the cost), psychologically sound 12 -item scale. It is my sincere hope that it is used by as many individuals, departments, colleges, universities, on-line courses, Washington D.C. political maneuvering, and etcetera, as possible. The sole motivation for this study is to increase the probability of a successful educational career for all types of students from all types of backgrounds with all types of personalities, where learning and self-development are a natural outcome of the interactions involved in academic endeavors in the United States of America.

Final thoughts. The trend of traditional 4-year colleges and universities toward diverse and engaged students - defined as students "in community-university partnerships through academic courses, research and other service efforts worldwide" (e.g., Portland State University, 2013) - at sustainable, international institutions is heartening. Balancing the concrete needs of our society and the world involving innovation, change, competition, and material resources and the responsibility of raising well-rounded, competent, insightful, critically thinking, thoughtful and compassionate young adults into adulthood is an honor and a responsibility of traditional four year institutions of higher education. Strong efforts are continuously made to improve the quality of instruction, student performance, and graduation rates, and increasingly, 
College success and student engagement / 223

student well-being. Awareness of the psychological processes that motivate students in their lectures and other classes allows institutions and individuals to scaffold the context into supporting the least met area of needs for their diverse and changing student body. Fostering this daily, reciprocal process (by applying the awareness to the motivation of instructors concurrently) results in the student and teacher behaviors that are often called "engaged," as defined above. This contributes not only to individual development and well-being for students (and potentially instructors) and to "community engagement" as motivated by their developing academic identity, but to increased retention and success for both student and institution.

Because the psychological needs underpinning engagement are posited as universal, the SSMMD and applications of course engagement should function in all types of higher education institutions, and with all course types (e.g., on-line, large lecture, hands-on). When combined with the possible outcomes for all shareholders touched by education, including students, instructors, administrators, and policy makers, course engagement and the larger framework of self-determination theory of which it is part, fit firmly with the stated goals of the Bringing Theory to Practice Project (AACU, 2013), which encourages colleges and universities to "reassert their core purposes as educational institutions, not only to advance learning and discovery, but to advance the potential and well-being of each individual student, and to advance education as a public good that sustains a civic society" (AACU, 2013).

Understanding underlying motivational states of individuals (which can be fostered for both students and instructors), having objectively measurable and relevant 
College success and student engagement / 224

performance markers, and remaining mindful of the influence of life outside academics provides three solid legs for higher education to best serve its students, its instructors, itself, and its society. It is said it takes a village to raise a child. It is higher education's responsibility to model and foster critical thinking and considered decision making, competition and compassion, proficiency and quality, with the flexibility to adapt to the short term while looking far into the future. Our higher education system is our village, and it is raising the future of our society, and by extension, our world. 
College success and student engagement / 225

\section{References}

ACT 2010, P. F.-Y. (2010, July 1). What works in student Retention? Fourth National Survey. ACT, Inc.

Ahlfeldt, S., Mehta, S., \& Sellnow, T. (2005). Measurement and analysis of student engagement in university classes where varying levels of PBL methods of instruction are in use. Higher Education Research and Development, 24(1), 5-20.

Anctil, T. M., Ishikawa, M. E., \& Scott, A. T. (2008). Academic identity development through self-determination: Successful college students with learning disabilites. Career Development for Exceptional Individuals, 31(3), 164-174. doi: $10.1177 / 0885728808315331$

Appleton, J. J., Christenson, S. L., Kim, D., \& Reschly, A. L. (2006). Measuring cognitive and psychological engagement: Validation of the Student Engagement Instrument. Journal of School Psychology, 44, 427-445.

Archambault, I., Janosz, M., Morizot, J., \& Pagani, L. (2009). Adolescent behavioral, affective and cognitive engagement in school: Relationship to dropout. Journal of School Health, 79(9), 408-415.

Assor, A., Kaplan, H., \& Roth, G. (2002). Choice is good, but relevance is excellent: Autonomy-enhancing and suppressing teacher behaviors predicting students' engagement in schoolwork. British Journal of Educational Psychology, 72, 261278.

Assor, A., Kaplan, H., Feinberg, O., \& Tal, K. (2009). Combining vision with voice: A learning and implementation structure promoting teachers' internalization of practices based on self-determination theory. Theory and Research in Education, 7(2), 234-243. doi:10.1177/1477878509104328

Aud, S., \& Hannes, G. (2011). The condition of education 2011 in brief (NCES 2011034). National Center for Education Statistics, U.S. Department of Education. Washington: U.S. Government Printing Office. Retrieved from http://nces.ed.gov/pubsearch.

Aud, S., Hussar, W., Johnson, F., Kena, G., Roth, E., Manning, E., . . Zhang, J. (2012). The Condition of Education 2012 (NCES 2012-045). U.S. Department of Education. Washington, D. C.: National Center for Education Statistics. Retrieved 2013, from http://nces.ed.gov/pubsearch

Baltes, P. B. (1987). Theoretical propsitions of life-span developental psychology: On the dynamics between growth and decline. Developmental Psychology, 23(5), 611626. 
College success and student engagement / 226

Baltes, P. B., Lindenberger, ,. U., \& Staudinger, U. M. (2006). Life span theory in developmental psychology. In R. M. Lerner, \& D. William (Eds.), Handbook of Child Psychology (Vols. 1, Theoretical models of human development, pp. 569664). Hoboken: John Wiley \& Sons Inc.

Barab, S., \& Squire, K. (2004). Design-based research: Putting a stake in the ground. The Journal of the Learning Sciences, 13(1), 1-14.

Barlow, A. E., \& Villarejo, M. (2004). Making a difference for minorities: Evaluation of an educational enrichment program. Journal of Research in Science Teaching, 41(9), 861-881. doi:10.1002/tea.20029

Baron, R. M., \& Kenny, D. A. (1986). The moderator-mediator variable distinction in social psychological research: Conceptual, strategic, and statistical considerations. Journal of Personality and Social Psychology, 51(6), 1173-1182.

Beachboard, M. R., Beachboard, J. C., Li, W., \& Adkison, S. R. (2011). Cohorts and relatedness: Self-determination theory as an explanation of how learning communities affect educational outcomes. Research in Higher Education, 52, 853874. doi: 10.1007/s11162-011-9221-

Bean, J. P. (1980). Dropouts and turnover: The synthesis and test of a causal model of student attrition. Research in Higher Education, 12(2), 155-187.

Becker, P. E., \& Moen, P. (1999). Scaling back: Dual-earner couples' work-family strategies. Journal of Marriage and Family, 61(4), 995-1007.

Beekhoven, S., De Jong, U., \& Van Hout, H. (2004). The impact of first-year students' living situation on the integration and the study progress. Educational Studies, 30(3), 277-290.

Bembenutty, H. (2010). Homework completion: The role of self-efficacy, delay of gratification, and self-regulatory processes. The International Journal of Educational and Psychological Assessment, 6(1), 1-20.

Black, A. E., \& Deci, E. L. (2000). The effects of instructors' autonomy support and students' autonomous motivation on learning organic chemistry: A selfdetermination theory perspective. Science Education, 84(6), 740-756.

Boatright-Horowitz, S. L., Langley, M., \& Gunnip, M. (2009). Depth-of-processing effects as college studens use academic advising websites. CyberPsychology \& Behavior, 12(3), 331-335.

Bodner, Todd E. (2007). Missing data: prevalence and reporting practices. Psychological Reports, 99(3), 675-680. 
Bouffard, T., Boileau, L., \& Vezeau, C. (2001). Students' transition from elementary to high school and changes of the relationship between motivation and academic performance. European Journal of Psychology of Education, 16(4), 589-604. doi:10.1007/BF03173199

Boyar, S. L., Maertz, J. C., Pearson, A. W., \& Keough, S. (2003). Work-Family Conflict: A Model of Linkages Between Work and Family Domain Variables and Turnover Intentions. Journal of Managerial Issues, 175-190.

Boylan, M. (2004). What have we learned from 15 years of supporting the development of innovative teaching technology? Social Science Computer Review, 22(4), 405425. doi:10.1177/0894439304268646

Brewster, A. B., \& Bowen, G. L. (2004). Teacher support and the school engagement of latino middle and high school students at risk for school failure. Child and Adolescent Social Work Journal, 21(1), 47-67.

Broadbridge, A., \& Swanson, V. (2005). Earning and learning: How term-time employment impacts on students' adjustment to university life. Journal of Education and Work, 18(2), 235-249.

Bronfenbrenner, U., \& Morris, P. A. (1998). The Ecology of Developmental Processes. In Handbook of Child Psychology, 5th Ed. (pp. 993-1028). Wiley \& Sons, Inc.

Brougham, R. R., Zail, C. M., Mendoza, C. M., \& Miller, J. R. (2009). Stress, sex differences, and coping strategies among college students. Current Psychology, $28,85-97$.

Butler, A. B. (2007). Job Characteristics and College Performance and Attitudes: A Model of Work-School Conflict and Facilitation. Journal of Applied Psychology, 92(2), 500-510.

Campos, C. M., Phinney, J. S., Perez-Brena, N., Kim, C., Ornelas, B., Nemanim, L., . . . Ramirez, C. (2009). A mentor-based targeted intervention for high-risk Latino college freshmen: A pilot study. Journal of Hispanic Higher Education, 8(2), 158178. doi:10.1177/1538192708317621

Cantwell, R., Archer, J., \& Bourke, S. (2001). A comparison of the academic experiences and achievement of university students entering by traditional and non-traditional means. Assessment \& Evaluation in Higher Education, 26(3), 221-234.

Carini, R. M., Kuh, G. D., \& Klein, S. P. (2006). Student engagement and student learning: Testing the linkages. Research in Higher Education, 47(1), 1-32. doi:10.1007/s11162-005-8150-9 
College success and student engagement / 228

Carlson, D. S., Kacmar, K. M., Wayne, J. H., \& Grzywacz, J. G. (2006). Measuring the positive side of the work-family interface: Development and validaiton of a workfamily enrichment scale. Journal of Vocational Behavior, 68, 131-164.

Carney-Crompton, S., \& Tan, J. (2002). Support systems, psychological functioning, and academic performance of nontraditional female students. Adult Education Quarterly, 52(2), 140-154.

Chi, U. J. (2009). Engagement versus disaffection in the college classroom : construction and validation of a measurement tool to assess students' motivation to learn. Portland: Portland State University, Department of Psychology.

Chirkov, V. I. (2009). A cross-cultural analysis of autonomy in education. Theory and Research in Education, 7(2), 253-262.

Cheung, G. W., \& Rensvold, R. B. (2002). Evaluationg goodness-of-fit indexes for tesing measurement invariance. Structural Equation Modeling, 9(2), pp. 233-255.

Clark, M. R. (2005). Negotiating the Freshman year: Challenges and strategies among first-year college students. Journal of College Student Development, 46(3), 296316. doi: $10.1353 / \operatorname{csd} .2005 .0022$

Coll, C. G., Crnic, K., Lamberty, G., Wasik, B. H., Jenkins, R., Garcia, H. V., \& McAdoo, H. P. (1996). An integrative model for the study of developmental competencies in minority children. Child Development, 67, 1891-1914.

Coll, R. K., \& Eames, C. (2008). Developing an understanding of higher education science and engineering learning communities. Research in Science \& Technology Educaton, 26(3), 245-257.

Conger, D., \& Long, M. C. (2010). Why are men falling behind? Gender gaps in college performance and persistence. The ANNALS of the American Academy of Political and Social Science, 627, 184-214. doi:10.1177/0002716209348751

Connell, J. P. (1985). A new multidimensional measure of children's perceptions of control. Child Development, 56, 1018-1041.

Connell, J. P. (1990). Context, self, and action: A motivational analysis of self-system processes across the lifespan. In D. Cicchette, \& B. Marjorie (Eds.), The self in transition: Infancy to childhood (pp. 61-97). Chicago: University of Chicago Press.

Connell, J. P., \& Wellborn, J. G. (1991). -Competence, autonomy and relatedness: A motivational analysis of self-system processes. In M. R. Gunnar, \& L. A. Sroufe (Eds.), Self-processes and development: The Minnesota Symposia on child psychology (Vol. 23, pp. 43-77). Hillsdale: Erlbaum. 
Connell, J. P., Halpem-Felsher, B. L., Clifford, E., Crichlow, W., \& Usinger, P. (1995). Haning in there: Behavioral, psychological, and contextual factors affecting whether African American adolescents stay in high school. Journal of Adolescent Research, 10(1), 41-63. doi:10.1177/0743554895101004

Connell, J. P., Spencer, M. B., \& Aber, J. L. (1994). Educational risk and resilience in African-American youth: Context, self, action, and outcomes in school. Child Development, 65, 493-506.

Cooper, C. E., \& Crosnoe, R. (2007). The engagement in schooling of economically disadvantaged parents and children. Youth \& Society, 38(3), 372-391. doi:10.1177/0044118X06289999

Crockett, L. J., Schulenberg, J. E., \& Petersen, A. C. (1987). Congruence between objective and self-report data in a sample of young adolescents. Journal of Adolescent Research, 2(4), 383-392.

Cronbach, L. J. (1951). Coefficient alpha and the internal structure of tests. Psychometrika, 16(3), pp. 297-334.

CSSE. (2010). Classroom survey of student engagement 2010. Indiana University Center for Postsecondary Research.

de Bilde, J., Vansteenkiste, M., \& Lens, W. (2011). Understanding the association between future time perspective and self-regulated learning through the lens of self-determination theory. Learning and Instruction, 21, 332-344.

de Bruyn, E. H. (2005). Role strain, engagement and academic achievement in early adolescence. Educational Studies, 31(1), 15-27. doi:10.1080/0305569042000310930

Deci, E. L. (2009). Large-scale school reform as viewed from the self-determinaion theory perspective. Theory and Reserach in Education, 7(2), 244-253. doi: $10.1177 / 1477878509104329$

Deci, E. L., \& Ryan, R. M. (2000). Self-Determinaion Theory and the facilitation of intrinsic motivation, social development, and well-being. American Psychologist, 55(1), 68-78.

Deci, E. L., Connell, J. P., \& Ryan, R. M. (1989). Self-determination in a work organization. Journal of Applied Psychology, 74(4), 580-590.

Dillon, W. R., Kumar, A., \& Mulani, N. (1987). Offending estimates in covariance structure analysis: Comments on the causes of and solutions to Heywood cases. Psychological Bulletin, 101(1), 126-135. 
College success and student engagement / 230

Donaldson, J. F., \& Townsend, B. K. (2007). Higher education journals' discourse about adult undergraduate students. The Journal of Higher Education, 78(1), 27-50.

Downing, K., Ho, R., Shin, K., Vrijmoed, L., \& Wong, E. (2007). Metacognitive development and moving away. Educational Studies, 33(1), 1-13.

Driscoll, A., \& Lynton, E. A. (1999). Making outreach visible: A guide to documenting professional service and outreach. Washington, DC: American Association for Higher Education.

Elliot, A. J., \& Dweck, C. S. (2005). Competence and motivation: Competence as the core of achievement motivation. In Handbook of Competence and Motivation (pp. 3-14). New York, NY: The Guilford Press.

Elliot, A. J., \& Murayama, K. (2008). On the measurement of achievement goals: Critique, illustration, and application. Journal of Educational Psychology, 100(3), 613-328. doi:10.1037/0022-0663.100.3.613

Everson, H. T. (1997). Emotions, cognition and performance. Anxiety, Stress \& Coping, 10(1), 1-3.

Fall, A.-M., \& Roberts, G. (2012). High school dropouts: Interactions between social context, self-perceptions, school engagement, and student dropout. Journal of Adolescence(35), 787-798.

Filak, V. F., \& Sheldon, K. M. (2003). Student psychological need satisfaction and college teacher-course evaluations. Educational Psychology, 23(3), 235-247.

Finan, M. C. (2004). Experience as teacher: Two techniques for incorporating student experiences into a course. Journal of Management Education, 28(4), 478-491.

Finn, J. D., \& Rock, D. A. (1997). Academic success among students at risk for school failure. Journal of Applied Psychology, 82(2), 221-234.

Fitzgerald, H. E., \& Zimmerman, D. L. (2005). Carnegie reclassification pilot study: Michigan State University response. University Outreach and Engagement. East Lansing: Michigan State University.

Fowler, J., \& Zimitat, C. (2008). Common Time: Embedding the concept of academic and social integration across cognate degree programmes. Innovations in Education and Teaching International, 45(1), 37-46.

doi:10.1080/14703290701757435

Fredricks, J. A., Blumenfeld, P. C., \& Paris, A. H. (2004). School engagement: Potential of the concept, state of the evidence. Review of Educational Research, 74(1), 59109. 
College success and student engagement / 231

Fredricks, J. A., Blumenfeld, P. C., \& Paris, A. H. (2004). School Engagement: Potential of the Concept, State of the Evidence. Review of Educational Research, 74(1), pp. 59-109.

Fulmer, S. M., \& Frijters, J. C. (2011). Motivation During an Excessively Challenging Reading Task: The Buffering Role of Relative Topic Interest. Journal of Experimental Education, 79(2), 185-208.

Furlong, M. J., Whipple, A. D., St. Jean, G., Simental, J., Soliz, A., \& Punthuna, S. (2003). Multiple contexts of school engagement: Moving toward a unifying framework for edcuational research and practice. The California School Psychologist, 8, 99-113.

Furrer, C., \& Skinner, E. (2003). Sense of relatedness as a factor in children's academic engagement and performance. Journal of Educational Psychology, 95(1), 148162.

Gambone, M. A., Klem, A. M., \& Connell, J. P. (2002). Finding out what matters for youth: Testing key links in a community action framework for youth development. Philadelphia: Youth Development Strategies, Inc., and Institute for Research and Reform in Education.

Gillmore, G. M. (2000). Drawing inferences about instructors: The inter-class reliability of student ratings of instruction. University of Washington Office of Educational Assessment.

Glanville, J. L., \& Wildhagen, T. (2007). The measurement of school engagement: Assessing dimensionality and measurement invariance across race and ethnicity. Educational and Psychological Measurement, 67(6), 1019-1041. doi: $10.1177 / 0013164406299126$

Glogowska, M., Young, P., \& Lockyer, L. (2007). Should I go or should I stay?: A study of factors influencing students' decisions on early leaving. Active Learning in Higher Education, 8(1), pp. 63-77.

Gore Jr., P. A. (2006). Academic self-efficacy as a predictor of college outcomes: Two incremental validity studies. Journal of Career Assessment, 14(1), 92-115.

Gottfried, A. E., Marcoulides, G. A., Gottfried, A. W., Oliver, P. H., \& Guerin, D. W. (2007). Multivariate latent change modeling of developmental decline in academic instrinsic math motivation and achievement: Childhood through adolescence. International Journal of Behavioral Development, 31(4), 317-327.

Grolnick, W. S., Farkas, M. S., Sohmer, R., Michaels, S., \& Valsiner, J. (2007). Facilitating motivation in young adolescents: Effects of an after-school program. 
College success and student engagement / 232

Journal of Applied Developmental Psychology, 28, 332-344.

doi:10.1016/j.appdev.2007.04.004

Grouzet, F. M., Otis, N., \& Pelletier, L. G. (2006). Longitudinal cross-gender factorial invariance of the Academic Motivation Scale. Structural Equation Modeling, 13(1), 73-98.

Guay, F., Marsh, H. W., Senecal, C., \& Dowson, M. (2008). Representations of relatedness with parents and friends and autonomous academic motivation during the late adolescence-early adulthood period: Reciprocal or unidirectional effects? British Journal of Educational Psychology, 78, 621-637.

Hackett, G. (1985). Role of mathematics self-efficacy in the choice of math-related majors of college women and men: A path analysis. Journal of Couseling Psychology, 32(1), 47-56.

Handelsman, M., Briggs, W. L., Sullivan, N., \& Towler, A. (2005). A measure of college student course engagement. Journal of Educational Research, 98(3), 184-191.

Harackiewicz, J. M., Barron, K. E., Tauer, J. M., \& Elliot, A. J. (2002). Predicting sucess in college: A longitudinal study of achievement goals and ability measures as predictors of interest and performance from Freshman year through graduation. Journal of Educational Psychology, 94(3), 562-575. doi:10.1037//00220663.94.3.562

Harackiewicz, J. M., Durik, A. M., Barron, K. E., Linnenbrink-Garcia, L., \& Tauer, J. M. (2008). The role of achievement goals in the development of interest: Reciprocal relations between achievement goals, interest, and performance. Journal of Educational Psychology, 100(1), 105-122. doi:10.1037/0022-0663.100.1.105

Hausmann, L. R., Schofield, J. W., \& Woods, R. L. (2007). Sense of belonging as a predictor of intentions to persist among African American and White first-year college students. Research in Higher Education, 48(7), 803-839.

Hayes, A. F., \& Preacher, K. J. (2010). Quantifying and testing indirect effects in simple mediation models when the constituent paths are nonlinear. Multivariate Behavioral Research, 45, 627-660.

Horstmanshof, L., \& Zimitat, C. (2007). Future time orientation predicts academic engagement among first-year university students. British Journal of Educational Psychology, 77, 703-718.

Hu, L., \& Bentler, P. M. (1999). Cutoff criteria for fit indexes in covariance structure analysis: Conventional criteria versus new alternatives. Structural Equation Modeling, 6(1), 1-55. 
Hu, L., \& Bentler, P. M. (1995). Evaluating model fit. In R. H. Hoyle (Ed.), Structural Equation Modeling. Concepts, Issues, and Applications (pp. 76-99). London: Sage.

Hu, S., \& Kuh, G. D. (2002). Being (dis)engaged in educationally purposeful activities: The influences of student and institutional characteristics. Research in Higher Education, 43(5), 555-575.

Huebner, E. S., Antaramian, S. P., Hills, K. J., Lewis, A. D., \& Saha, R. (2011). Stability and predictive validity of the Brief Multidimensional Students' Life Satisfaction Scale. Child Indicators Research, 4(1), 161-168.

Hughes, J. N., Luo, W., Kwok, O.-M., \& Loyd, L. K. (2008). Teacher-student support, effortful engagement, and achievement: A 3-year longitudinal study. Journal of Educational Psychology, 100(1), 1-14. doi:10.1037/0022-0663.100.1.1

IAS. (2012). Form A. Seattle: University of Washington. Retrieved 2012, from http://www.washington.edu/oea/pdfs/course_eval/FormA.pdf.

Jackson, J. W., Miller, D. A., Frew, E. J., \& Gilbreath, B. (2011). Group identification and university involvement. Journal of Applied Social Psychology, 41(4), 798822.

Jang, H. (2008). Supporting students' motivaton, engagement, and learning during an uninteresting activity. Journal of Educational Psychology, 100(4), 798-811. doi:10.1037/a0012841

Jang, H., Reeve, J., \& Deci, E. L. (2010). Engaging students in learning activities: It is not autonomy support or structure but autonomy support and structure. Journal of Educational Psychology, 102(3), 588-600. doi:10.1037/a0019682

Jang, H., Reeve, J., Ryan, R. M., \& Kim, A. (2009). Can Self-Determination Theory explain what underlies the productive, satisfying learning experiences of collectivistically oriented Korean students? Journal of Educational Psychology, 101(3), 644-661. doi:10.1037/a0014241

Janosz, M., Archambault, I., Morizot, J., \& Pagani, L. S. (2008). School engagement trajectories and their differential predictive relations to dropout. Journal of Social Issues, 64(1), 21-40.

Jansen, E. P., \& Bruinsma, M. (2005). Explaining achievement in higher education. Educational Research \& Evaluation, 11(3), 235-252.

Jelicic, H., Bobek, D. L., Phelps, E., Lerner, R. M., \& Lerner, J. V. (2007). Using positive youth development to predict contribution and risk behaviors in early adolescence: Findings from the first two waves of the 4-H Study of Positive 
College success and student engagement / 234

Youth Development. International Journal of Behavioral Development, 31(3), 263-273.

Jennings, G. (2003). An exploration of meaningful participation and caring relationships as contexts for school engagement. The California School Psychologist, 8, 43-52.

Jimerson, S. R., Campos, E., \& Greif, J. L. (2003). Toward an understanding of definitions and measures of school engagement and related terms. The California School Psychologist, 8, 7-27.

Kanter, R. M., Khurana, R., \& Nohria, N. (2007). Moving higher education to its next stage: A call to action for universities. Harvard Business School. Cambridge: Forum for the Future of Higher Education.

Kapitanoff, S. H. (2009). Collaborative testing: Cognitive and interpersonal processes related to enhanced test performance. Active Learning in Higher Education, 10(1), 56-70.

Karcher, M. J. (2005). The Hemmingway: Measure of Adolescent Connectedness. A manual for scoring and interpretation: Adolescent version 5.5 and Child version 5. San Antonio, TX.

Kasworm, C. (2005). Adult student identity in an intergenerational community college classroom. Adult Education Quarterly, 56(1), 3-20.

Katz, I., \& Assor, A. (2007). When choice motivates and when it does not. Educational Psychology Review, 19(4), 429-442.

Kenney-Benson, G. A., Pomerantz, E. M., Ryan, A. M., \& Patrick, H. (2006). Sex differences in math performance: The role of children's approach to schoolwork. Developmental Psychology, 42(1), 11-26.

Kim, Y. K., Chang, M. J., \& Park, J. J. (2009). Engaging with faculty: Examining rates, predictors, and educational effects for Asian American undergraduates. Journal of Diversity in Higher Education, 2(4), 206-218.

Kindermann, T. A. (1993). Natural peer groups as contexts for individual development: The case of chidren's motivation in school. Developmental Psychology, 29(6), 970-977.

Kindermann, T. A. (2007). Effects of naturally existing peer groups on changes in academic engagement in a cohort of sixth graders. Child Development, 78(4), 1186-1203.

Kindermann, T. A. (2011). Commentary: The invisible hand of the teacher. Journal of Applied Developmental Psychology, 32, 304-308. 
Kindermann, T. A., \& Skinner, E. A. (1992). Modeling environmental development: Individual and contextual trajectories. In J. B. Asendorpf, \& J. Valsiner (Eds.), Stability and Change in Development: A Study of Methodological Reasoning. (pp. 155-190). Sage.

Kindermann, T. A., \& Skinner, E. A. (2009). How do naturally existing peer groups shape children's academic development during sixth grade? European Journal of Developmental Science, 3(1), 31-43.

Klem, A. M., \& Connell, J. P. (2004). Relationships matter: Linking teacher support to student engagement and achievement. Journal of School Health, 74(7), 262-273.

Kline, R. B. (2005). Principles and practice of structural equation modelling (2nd ed.). New York: The Guilford Press.

Kuh, G. D. (2004). The National Survey of Student Engagement: Conceptual framework and overview of psychometric properties. Retrieved from http://nsse.iub.edu/2004_annual_report/pdf/2004_Conceptual_Framework.pdf

Kuh, G. D. (2009). What Student Affairs professionals need to know about student engagement. Journal of College Student Development, 50(6), 683-706. doi:10.1353/csd.0.0099

Kuh, G. D., Cruce, T. M., Shoup, R., Kinzie, J., \& Gonyea, R. M. (2008). Unmasking the effects of student engagement on first-year college grades and persistence. The Journal of Higher Education, 79(5), 540-563.

Kuh, G. D., Kinzie, J., Buckley, J. A., Bridges, B. K., \& Hayek, J. C. (2006). What matters to student success: A review of the literature. National Postsecondary Education Cooperative.

Kuncel, N. R., Crede, M., \& Thomas, L. L. (2005). The validity of self-reported grade point averages, class ranks, and test scores: A meta-analysis and review of the literature. Review of Educational Research, 75(1), 63-82.

Laird, T. F., Smallwood, R. A., Niskode-Dossett, A. S., \& Garver, A. K. (2009). Effectively involving faculty in the assessment of student engagement. In R. M. Gonyea, \& G. D. Kuh (Eds.), Using NSSE in Institutional Research. Jossey-Bass.

Laird, T. F., Shoup, R., \& Kuh, G. D. (2005). Measuring deep approaches to learning using the National Survey of Student Engagement. Chicago: Annual Meeting of the Association for Institutional Research.

Le, H., Casillas, A., Robbins, S. B., \& Langley, R. (2005). Motivational and skills, social, and self-management predictors of college outcomes: Constructing the Student 
College success and student engagement / 236

Readiness Inventory. Educational and Psychological Measurement, 65(3), 482508.

Lee, P., Hamman, D., \& Lee, C. C. (2007). The relationship of family closeness with college students' self-regulated learning and school adjustment. College Student Journal, 779-787.

Lee, S. W., \& Tsai, C. (2011). Students' perceptions of collaboration, self-regulated learning, and information seeking in the context of Internet-based learning and traditional learning. Computers in Human Behavior, 27, 905-914.

Lenaghan, J. A., \& Sengupta, K. (2007, Sep). Role conflict, role balance and affect: A model of well-being of the working student. Journal of Behavioral and Applied Management, 9(1), 88-109.

Livingston, A. (2008). The condition of education 2008 in brief (NCES 2008-032). Institute of Education Sciences, National Center for Educatoin Statisitcs. Department of Education.

Lowell, G. N., \& Gillmore, G. M. (1991). Reliability of the items of the Instructional Assessment System: Forms A-G (OEA 91-01). Office of Educational Assessment. Seattle: University of Washington.

Lubbers, M. J., Van Der Werf, M. P., Snijders, T. A., Creemers, B. P., \& Kuyper, H. (2006). The impact of peer relations on academic progress in junior high. Journal of School Psychology, 44, 491-512.

Luyckx, K., Schwartz, S. J., Soenens, B., Vansteenkiste, M., \& Goossens, L. (2010). The Path From Identity Commitments to Adjustment: Motivational Underpinnings and Mediating Mechanisms. Journal of Counseling \& Development, 88(1), 52-60.

Lynch, M. F., La Guardia, J. G., \& Ryan, R. M. (2009). On being yourself in different cultures: Ideal and actual self-concept, autonomy support, and well-being in China, Russia, and the United States. The Journal of Positive Psychology, 4(4), 290-304.

MacCallum, R. C., \& Austin, J. T. (2000). Applications of structural equation modeling in psychological research. Annual Review of Psychology, 51, 201-226.

Maeda, Y., Thoma, S. J., \& Bebeau, M. J. (2009). Understanding the relationship between moral judgment development and individual characteristics: The role of educational contexts. Journal of Educational Psychology, 101(1), 233-247. doi: $10.1037 / \mathrm{a} 0013381$

Mandernach, J. B., Donnelli-Sallee, E., \& Dailey-Hebert, A. (2011). Assessing course student engagement. In R. L. Miller, E. Amsel, B. Marsteller Kowalewski, B. C. 
Beins, K. D. Keith, \& B. F. Peden (Eds.), Promoting Student Engagement: Programs, Techniques and Opportunities. (pp. 277-281). Washington, D.C.: Society for the Teaching of Psychology.

Marks, H. M. (2000). Student engagement in instructional activity: Patterns in the elementary, middle, and high school years. American Educational Research Journal, 31(1), 153-184. doi:10.3102/00028312037001153

Marks, S. R., \& MacDermid, S. M. (1996, May). Multiple Roles and the Self: A Theory of Role Balance. Journal of Marriage and Family, 58(2), 417-432. Retrieved 9 04, 2011, from http://www.jstor.org/stable/353506

Martin, A. J. (2007). Examining a multidimensional model of student motivation and engagement using a construct valication approach. British Journal of Educational Psychology, 77, 413-440.

Martin, A. J. (2009). Age appropriateness and motivation, engagement, and performance in high school: Effects of age within cohort, grade retention, and delayed school entry. Journal of Educational Psychology, 101(1), 101-114. doi: $10.1037 / \mathrm{a} 0013100$

Martin, A. J. (2009b). Motivation and engagement across the academic life span: A developmental construct validity study of elementary school, high school, and university/college students. Educational and Psychological Measurement, 69(5), 794-824.

McCarthy, M., \& Kuh, G. D. (2006). Are students ready for college? What student engagement data say. Bloomington: Phi Delta Kappa International.

McClenney, K. M. (2007). Research update: The Community College Survey of Student Engagement. Community College Review, 35(2), 137-146. doi: $10.1177 / 0091552107306583$

McDonald, J. D. (2008). Measuring personality constructs: The advantages and disadvantages of self-reports, informant reports and behavioural assessments. Enquire, 1(1), 1-18.

McGregor, H. A., \& Elliot, A. J. (2002). Achievement goals as predictors of achievement-relevant processes prior to task engagement. Journal of Educational Psychology, 94(2), 381-395.

McMilan, W. J. (2010). 'Your thrust is to understand' - how academically successful students learn. Teaching in Higher Education, 15(1), 1-13. 
College success and student engagement / 238

Mcmillan, J. H., Simonetta, L. G., \& Singh, J. (1994). Student opinion survey: Development of measures of student motivation. Educational and Psychological Measurement, 54(2), 496-505.

Michie, F., Glanchan, M., \& Bray, D. (2001). An evaluation of factors influencing the academic self-concept, self-esteem and academic stress for direct and re-entry students in higher education. Educational Psychology, 21(4), 455-472. doi:10.1080/01443410120090830

Miller, D. C., \& Salkind, N. J. (2002). An overview of other statistical tehcniques and examples of their application. In Handbook of Research Design \& Social Measurement (pp. 408-426). Sage. doi:10.4135/9781412984386

Miller, D. C., \& Salkind, N. J. (2002b). Causation and multivariate analysis: From univariate and bivariate problems to multivariate analysis of social behavior. In Handbook of Research Design \& Social Measurement (pp. 394-407). Sage. doi:10.4135/9781412984386

Minuchin, P. (1985). Families and individual development: Provocations from the field of family therapy. Child Development, 56, 289-302.

Morrison, G. M., Cosden, M. A., O'Farrell, S. L., \& Campos, E. (2003). Changes in Latino students' perceptions of school belonging over time: Impact of language proficiency, self-perceptions and teacher evaluations. The California School Psychologist, 8, 87-98.

Morrison, G. M., Robertson, L., Laurie, B., \& Kelly, J. (2002). Protective factors related to anitsocial behavior trajectories. Journal of Clinical Psychology, 58(3), 277-290. doi:10.1002/jclp.10022

Muller, F. H., \& Louw, J. (2004). Learning environment, motivation and interest: Perspectives on self-determination theory. South African Journal of Psychology, 34(2), 169-190.

Munro, B. H. (1981). Dropouts from higher education: Path analysis of a national sample. American Educational Research Journal, 18(2), 133-141.

Murayama, K., \& Elliot, A. J. (2009). The joint influence of personal achievement goals and classroom goal structures on achievement-relevant outcomes. Journal of Educational Psychology, 101(2), 432-447. doi:10.1037/a0014221

Museus, S. D., \& Quaye, S. J. (2009). Toward an intercultural perspective of racial and ethnic minority college student persistence. The Review of Higher Education, 33(1), 67-94. 
National Research Council. (2009). Letter report to the U.S. Department of Education on the Race to the Top Fund. Washington, D.C.: The National Academies Press. Retrieved from http://www.nap.edu/catalog.php?record_id=12780

Nes, L. S., Evans, D. R., \& Segerstrom, S. C. (2009). Optimism and college retention: Mediation by motivation, performance, and adjustment. Journal of Applied Social Psychology, 39(8), 1887-1912.

Netemeyer, R. G., Boles, J. S., \& McMurrian, R. (1996). Development and Validation of Work-Family Conflict and Family-Work Conflict Scales. Journal of Applied Psychology, 81(4), 400-410.

Netemeyer, R. G., Brashear-Alejandro, T., \& Boles, J. S. (2004). A cross-national model of job-related outcomes of work role and family role variables: A retail sales context. 32(1), 49-60. doi:10.1177/0092070303259128

Netemeyer, R. G., Maxham III, J. G., \& Pullig, C. (2005). Conflicts in the work-family interface: Links to job stress, customer service employee performance, and customer purchase intent. Journal of Marketing, 69, 130-143.

Niemiec, C. P., \& Ryan, R. M. (2009). Autonomy, competence, and relatedness in the classroom: Applying self-determination theory to educational practice. Theory and Research in Education, 7(2), 133-144.

Niemiec, C. P., Lynch, M. F., Vansteenkiste, M., Bernstein, J., Deci, E. L., \& Ryan, R. M. (2006). The antecedents and consequences of autonomous self-reguation for college: A self-determination theory perspective on socialization. Journal of Adolescence, 29, 761-775.

Nonis, S. A., Philhours, M. J., \& Hudson, G. I. (2006). Where does the time go? A diary approach to Business and Marketing students' time use. Journal of Marketing Education, 28(2), 121-134.

Nora, A., Barlow, L., \& Crisp, G. (2006). Examining the tangible and psychosocial benefits of financial aid with student access, engagement, and degree attainment. American Behavioral Scientist, 49(12), 1636-1651. doi:10.1177/0002764206289143

NSSE. (2009). Administering NSSE. Retrieved 03 18, 2011, from http://nsse.iub.edu/pdf/US_paper_10.pdf

NSSE. (2009b). National Survey of Student Engagement 2010. Indiana University Center for Postsecondary Research. 
NSSE. (2010). Factor analysis 2009 internal structure for deep learning: Validity construct validity. Retrieved 10 13, 2010, from NSSE's Psychometric Profile: nsse.iub.edu/links/psychometric_portfolio

NSSE. (2010b). Major differences: Examining student engagement by field of study annual results 2010. Bloomington: Indiana University Center for Postsecondary Research.

NSSE. (2011). Fostering student engagement campuswide - annual results 2011. Bloomington: Indiana University Center for Postsecondary Research.

NSSE. (2011b). Benchmarks of Effective Educational Practice. Indiana University. Bloomington: Indiana University Center for Postsecondary Research. Retrieved May 2011, from http://nsse.iub.edu/_/?cid=403

O'Farrell, S. L., \& Morrison, G. M. (2003). A factor analysis exploring school bonding and related constructs among upper elementary students. The California School Psychologist, 53-72.

OIRP (2010). Student Profile, Inload Enrollment: Fall 2010, 4th week. Retrieved from Student Statistical Portrait 2010-2011: http://www.oirp.pdx.edu/source/port1011/psu_all.htm

Oregon GEAR UP. (2009). Reaching higher: Oregon GEAR UP annual report 2008-09. Oregon University System, Eugene. Retrieved from http://gearup.ous.edu

Oregon GEAR UP. (2009b). Celebrating success: Final report 2002-2008. Oregon University System, Eugene. Retrieved from http://gearup.ous.edu

Padilla-Walker, L. M., Nelson, L. J., \& Carroll, J. S. (2012). Affording emerging adulthood: Parental Financial Assistance of their college-aged children. Journal of Adult Development, 19(1), 50-58. doi:10.1007/s10804-011-9134-y

Pascarella, E. T., Salisbury, M. H., \& Blaich, C. (2011). Exposure to effective instruction and college student persistence: A multi-institutional replication and extension. Journal of College Student Development, 52(1), 4-19.

Patrick, B. C., Skinner, E. A., \& Connell, J. P. (1993). What motivates children's behavior and emotion? Joint effects of perceived control and autonomy in the academic domain. Journal of Personality and Social Psychology, 65(4), 781-791.

Pekrun, R., Elliot, A. J., \& Markus, M. A. (2009). Achievement goals and achievement emotions: Testing a model of their joint relaitons with academic performance. Journal of Educational Psychology, 101(1), 115-135. doi:10.1037/a0013383 
College success and student engagement / 241

Pelletier, L. G., \& Sharp, E. C. (2009). Administrative pressure and teachers interpersonal behaviour in the classroom. Theory and Research in Education, 7(2), 174-183. doi:10.1177/1477878509104322

Pierson, L. H., \& Connell, J. P. (1992). Effect of grade retention on self-system processes, school engagement, and academic performance. Journal of Educational Psychology, 84(3), 300-307.

Pintrich, P. R. (2003). A motivational science perspective on the role of student motivation in learning and teaching contexts. Journal of Educational Psychology, 95(4), 667-686. doi:10.1037/0022-0663.95.4.667

Portland State University. (2013). Engagement. Retrieved 2013, from Center for Academic Excellence: http://www.pdx.edu/cae/engagement

Preacher, K. J., \& Hayes, A. F. (2004). SPSS and SAS procedures for estimating indirect effects in simple mediation models. Behavior Research Methods, Instruments, \& Computers, 36(4), 717-731.

Preacher, K. J., \& Hayes, A. F. (2008). Asymptotic and resampling strategies for assessing and comparing indirect effects in multiple mediator models. Behavior Research Methods, 40(3), 879-891.

Quimby, J. L., \& O'Brien, K. M. (2006). Predictors of well-being among nontraditional female students with children. Journal of Couseling \& Development, 84(Fall), 451-460.

Raine, D., \& Symons, S. (2012). Problem-based learning: undergraduate physics by research. Contemporary Physics, 53(1), 39-51.

Rampey, B. D., Dion, G. S., \& Donahue, P. L. (2009). NAEP 2008 trends in academic progress (NCES 2009-479). Institute of Education Sciences, U.S. Department of Education. Washington, D.C.: National Center for Education Statistics. Retrieved from http://nationsreportcard.gov

Ratelle, C. F., Guay, F., Vallerand, R. J., Larose, S., \& Senecal, C. (2007). Autonomous, controlled, and amotivated types of academic motivation: A person-oriented analysis. Journal of Educational Psychology, 99(4), 734-746. doi:10.1037/00220663.99.4.734

Reay, D. (2008). Class, authenticity and the transition to higher education for mature students. The Sociological Revies, 50(3), 398-418. doi:10.1111/1467-954X.00389

Reeve, J., \& Jang, H. (2006). What teachers say and do to support students' autonomy during a learning activity. Journal of Educational Psychology, 98(1), 209-218. 
Reeve, J., Jang, H., Carrell, D., Jeon, S., \& Barch, J. (2004). Enhancing students' engagement by increasing teachers autonomy support. Motivation and Emotion, 28(2), 147-169.

Reschly, A. L., Huebner, E. S., Appleton, J. J., \& Antaramian, S. (2008). Engagement as flourishing: The contribution of positive emotions and coping to adolescents' engagement at school and with learning. Psychology in the Schools, 45(5), 419431.

Robbins, S. B., Allen, J., Casillas, A., Peterson, C. H., \& Le, H. (2006). Unravelling the differential effects of motivational and skills, social, and self-management measures from traditional predictiors of college outcomes. Journal of Educational Psychology, 98(3), 598-616. doi:10.1037/0022-0663.98.3.598

Rodgers, K. A., \& Summers, J. J. (2008). African American students at predominantly White institutions: A motivational and self-systems approach to understanding retention. Educational Psychology Review, 20, 171-190.

Roeser, R. W., \& Peck, S. C. (2009). An education in awareness: Self, motivation, and self-regulated learning in contemplative perspective. Educational Psychologist, 44(2), 119-136.

Rosenbaum, E., \& Rochford, J. A. (2008). Generational patterns in academic performance: The variable effects of attitudes and social capital. Social Science Research, 37, 350-372.

Roth, G., Assor, A., Kanat-Maymon, Y., \& Kaplan, H. (2007). Autonomous motivation for teaching: How self-determined teaching may lead to self-determined learning. Journal of Educational Psychology, 99(4), 761-774.

Ryan, R. M., \& Connell, J. P. (1989). Perceived locus of causality and internalization: Examining reasons for acting in two domains. Journal of Personality and Social Psychology, 57(5), 749-761.

Ryan, R. M., \& Deci, E. L. (2000). Self-Determinaion Theory and the facilitation of intrinsic motivation, social development, and well-being. American Psychologist, $55(1), 68-78$.

Salmela-Aro, K., Kiuru, N., Leskinen, E., \& Nurmi, J. (2009). School Burnout Inventory (SBI): Reliability and Validity. European Journal of Psychological Assessment, 25(1), 48-57. doi:10.1027/1015-5759.25.1.48

Salmela-Aro, K., Kiuru, N., Leskinen, E., \& Nurmi, J.-E. (2009). School Burnout Inventory (SBI): Reliability and validity. European Journal of Psychological Assessment, 25(1), 48-57. 
Schaufeli, W. B., Martinez, I. M., Pinto, A. M., Salanova, M., \& Bakker, A. B. (2002). Burnout and engagement in university students: A cross-national study. Journal of Cross-Cultural Psychology, 33(5), 464-481.

Schwartz, D., Gorman, A. H., Nakmoto, J., \& McKay, T. (2006). Popularity, social acceptance, and aggresion in adolescent peer groups: Links with academic performance and school attendance. Developmental Psychology, 42(6), 11161127.

Sengupta, S. S. (2011). Growth in Human Motivation: Beyond Maslow. The Indian Journal of Industrial Relations, 47(1), 102-105.

Shell, D. F., \& Husman, J. (2008). Control, motivation, affect, and strategic selfregulation in the college classroom: A multidimensional phenomenon. Journal of Educational Psychology, 100(2), 443-459. doi:10.1037/0022-0663.100.2.443

Shernoff, D. J., \& Schmidt, J. A. (2008). Further evidence of an engagement-achievement paradox among U.S. high school students. Journal of Youth and Adolescence, 37(5), 564-580.

Shim, S. S., Ryan, A. M., \& Anderson, C. J. (2008). Achievement goals and achievement during early adolescence: Examining time-varyin predictor and outcome variables in growth-curve analysis. Journal of Educational Psychology, 100(3), 655-671. doi:10.1037/0022-0663.100.3.655

Sinclair, M. F., Christenson, S. L., Lehr, C. A., \& Anderson, A. R. (2003). Facilitating student engagement: Lessons learned from check and connect longitudinal studies. The California School Psychologist, 8, 29-41.

Skinner, E. A., \& Belmont, M. J. (1993). Motivation in the classroom: Reciprocal effects of teacher behavior and student engagement across the school year. Journal of Educational Psychology, 85(4), 571-581.

Skinner, E. A., Marchand, G. F., \& Kindermann, T. (2008). Engagement and disaffection in the classroom: Part of a larger motivational dynamic? Educational Psychology, 100(4), 765-781.

Skinner, E. A., Wellborn, J. G., \& Connell, J. P. (1990, Mar). What it takes to do well in school and whether I've got it: A process model of perceived control and children's engagement and achievement in school. Journal of Educational Psychology, 82(1), 22-32.

Smallwood, R. A., \& Ouimet, J. A. (2009). CLASSE: Measuring student engagement at the classroom level. In T. W. Banta, E. A. Jones, \& K. E. Black (Eds.), Designing Effective Assessment: Principles and Profiles of Good Practice. San Francisco: Jossey-Bass. 
College success and student engagement / 244

Smart, J. C., Ethington, C. A., \& Umbach, P. D. (2009). Pedagogical approaches used by faculty in Holland's Model Environments: Role of environmental consistency. Journal of Career Assessment, 17(1), 69-85. doi:10.1177/1069072708325742

Smith, K. A., Sheppard, S. D., Johnson, D. W., \& Johnson, R. T. (2005). Pedagogies of Engagement: Classroom-Based Practices. Journal of Engineering Education, 94(1), 87-101.

Snijders, T., \& Bosker, R. J. (1999). Multilevel ananlysis. An introduction to basic and advanced multilevel modeling. London: Sage Publications.

Sobel, M. E. (1982). Asynptotic confidence intervals for indirect effects in structural equation models. Sociological Methodology, 13, 290-312. doi:10.2307/270723

Steele, J. P., \& Fullagar, C. J. (2009). Facilitators and outcomes of student engagement in a college setting. The Journal of Psychology, 143(1), 5-27.

Stuart, M., Lido, C., Morgan, J., Solomon, L., \& May, S. (2011). The impact of engagement with extracurricular activities on the student experience and graduate outcomes for widening participation populations. Active Learning in Higher Education, 12(3), 203-215. doi:10.1177/1469787411415081

Svanum, S., \& Bigatti, S. M. (2009). Academic course engagement during one semester forcasts college success: Engaged students are more likely to earn a degree, do it faster, and do it better. Journal of College Student Development, 50(1), 120-132.

Swanson, V., Broadbridge, A., \& Karatzias, A. (2006). Earning and learning: Role congruence, state/trait factors and adjustment to university life. British Journal of Educational Psychology, 76, 895-914. doi:10.1348/000709905X65009

Sweet, S., \& Moen, P. (2007). Integrating educational careers in work and family: Women's return to school and family life quality. Community, Work and Family, 10(2), 231-250.

Symonds, W. C., Schwartz, R. B., \& Ferguson, R. (2011). Pathways to prosperity: Meeting the challenge of preparing young americans for the 21st century. Harvard, Graduate School of Education. Pathways to Prosperity Project.

Tabachnick, B. G., \& Fidell, L. S. (2007). Using multivariate statistics (5th ed.). San Francisco: Pearson Education, Inc.

Tabachnick, S. E., Miller, R. B., \& Relyea, G. E. (2008). The relationships among students' future-oriented goals and subgoals, perceived task instrumentality, and task-oriented self-regulation strategies in an academic environment. Journal of Educational Psychology, 100(3), 629-642. doi:10.1037/0022-0663.100.3.629 
Tanaka, J. S. (1993). Multifaceted conceptions of fit in structural equation models. In K. A. Bollen, \& J. S. Long (Eds.), Testing Structural Equation Models (pp. 10-39). Sage.

Taniguchi, H., \& Kaufman, G. (2005). Degree completion among nontraditional college students. Social Science Quarterly, 86(4), 912-927.

Tapola, A., \& Niemivirta, M. (2008). The role of achievement goal orientations in students' perceptions of and preferences for classroom environment. British Journal od Educational Psychology, 78, 291-312.

Task Force on Latina/o Student Success. (2010). Exito: A path to Latino student sucess. Portland State University.

Tatar, M., \& Yahav, V. (1999). Secondary school pupils' perceptions of burnout among teachers. British Journal of Educational Psychology, 69, 457-468.

Tessier, D., Sarrazin, P., \& Ntoumanis, N. (2008). The effects of an experimental programme to support students' autonomy on the overt behaviors of physical education teachers. European Journal od Psychology of Education, 23(3), 239253.

The College Board. (2011). Higher Education Landscape. Retrieved from College Board: http://professionals.collegeboard.com/data-reports-research/trends/higher-edlandscape?vgnextfmt=default

The National Center for Public Policy and Higher Education. (2008). Measuring up 2008: The State report card on higher education - OREGON. San Jose: The National Center for Public Policy and Higher Education. Retrieved from http://measuringup2008.highereducation.org/print/state_reports/long/OR.pdf

Torres, V., Susan, J. R., \& Renn, K. A. (2009). Identity development theories in student affairs: Origins, current status, and new approaches. Journal of College Student Development, 50(6), 577-596. doi:10.1353/csd.0.0102

Trouilloud, D., Sarrazin, P., Bressoux, P., \& Bois, J. (2006). Relation between teachers' early expectations and students' later perceived competence in physical education classes: Autonomy-supportive climate as a moderator. Journal of Educational Psychology, 98(1), 75-86. doi:10.1037/0022-0663.98.1.75

Tsai, Y.-M., Kunter, M., Ludtke, O., Trautwein, U., \& Ryan, R. M. (2008). What makes lessons interesting? The role of situational and individual factors in three school subjects. Journal of Educational Psychology, 100(2), 460-472. doi:10.1037/00220663.100.2.460 
College success and student engagement / 246

US Dept. Educaton. (2011). Digest of Educational Statistics (NCES 2011-015). National Center for Education Statistics. Washington: U.S. Department of Education.

Valle, A., Nunez, J. C., Cabanach, R. G., Gonzalez-Pienda, J. A., Rodriguez, S., Rosario, P., ... Munoz-Cadavid, M. A. (2008). Self-regulated profiles and academic achievement. Psicothema, 20(4), 724-731.

Vallerand, R. J. (1997). Toward a hierarchical model of intrinsic and extrinsic motivation. In M. P. Zanna (Ed.), Advances in Experimental Social Psychology (Vol. 29, pp. 271-360). San Diego: Academic Press.

Van den Broeck, A., Vansteenkiste, M., De Witte, H., Soenens, B., \& Lens, W. (2010). Capturing autonomy, competence, and relatedness at work: Construction and initial validation of the Work-related Basic Need Satisfaction scale. Journal of Occupational Psychology, 83, 981-1002.

Van Etten, S., Pressley, M., McInerney, D. M., \& Liem, A. D. (2008). College seniors' theory of their academic motivation. Journal of Educational Psychology, 100(4), 812-828.

Vansteenkiste, M., Lens, W., \& Deci, E. L. (2006). Intrinsic versus extrinsic goal contents in self-determination theory: Another look at the quality of academic motivation. Educational Psychologist, 41(1), 19-31.

Vansteenkiste, M., Niemiec, C. P., \& Soenens, B. (2010). The Development of the Five Mini-theories of Self-determinatino Theory: An Historical Overview, Emerging Trends, and Future Directions. Advances in Motivation and Achievement, 16A(The Decade Ahead: Theoretical Perspectives on Motivation and Achievement), 105-165.

Vansteenkiste, M., Soenens, B., Verstuyf, J., \& Lens, W. (2009). 'What is the usefulness of your schoolwork?': The differential effects of intrinsic and extrinsic goal framing on optimal learning. Theory and Research in Education, 7(2), 155-163. doi: $10.1177 / 1477878509104320$

Verger, P., Combes, J.-B., Kovess-Masfety, V., Choquet, M., Guagliardo, V., Rouillon, F., \& Peretti-Wattel, P. (2009). Psychological distress in first year university students: socioeconomic and academic stressors, mastery and social support in young men and women. Social Psychiatry Psychiatric Epidemiology, 44, 643650 .

Vignoles, V. L., Camilo, R., Manzi, C., Golledge, J., \& Scabini, E. (2006). Beyond selfesteem: Influence of multiple motives on identity construction. Journal of Personality and Social Psychology, 90(2), 308-333. 
Vogt, W. P. (2011). The general linear model as structural equation modelling. In Quantitative Research Methods (pp. 486-505). Sage. doi:10.4135/9780857028228

Wang, F. (2008). Motivation and english achievement: An exploratory and confirmatory factor analysis of a new measure for Chinese students of English learning. North American Journal of Psychology, 10(3), 633-646.

Wang, M., \& Eccles, J. S. (2011). Adolescent Behavioral, Emotional, and Cognitive Engagement Trajectories in School and Their Differential Relations to Educational Success. Journal of Research on Adolescence, 22(1), 31-39.

Wang, S., \& Reeves, T. C. (2007). The effects of a web-based learning envirnoment on student motivation in a high school earth science course. Educational Technology Research \& Development, 55, 169-192.

Wapner, S., \& Demick, J. (2005). Critical person-in-environment transitions across the life span. In J. Valsiner (Ed.), Heinz Werner and developmental science (pp. 285305). New York: Kluwer Academic/Plenum Publishers.

Weaver, R. R., \& Qi, J. (2005). Classroom organization and participation: College students' perceptions. The Journal of Higher Education, 76(5), 570-601.

Wellborn, J. G., \& Connell, J. P. (1991). Student's Achievement Relevant Action in the Classroom: A Self-report Measure of Student Motivation in School. Graduate School of Education and Human Development. Rochester: University of Rochester.

Welman, J., \& Basson, P. (1995). The interrelationship between the work experience of distance education students, job satisfaction, and academic achievement. Journal of Industrial Psychology, 21(1), 14-17.

White, R. W. (1959). Motivation reconsidered: The concept of competence. Psychological Review, 66(5), 297-333.

White, R. W. (1974). Strategies of adaptation: An attempt at systematic description. In G. V. Coelho, D. A. Hamburg, \& J. E. Adams (Eds.), Coping and Adaptation (pp. 47-68). New York, NY: Basic Books, Inc.

Wigfield, A., Eccles, J. S., Schiefele, U., Roeser, R. W., \& Davis-Kean, P. (2006). Development of achievement motivation. In N. Eisenberg, W. Damon, \& R. M. Lerner (Eds.), Handbook of Child Psychology (6th ed., Vols. 3: Social, emotional, and personality development, pp. 933-1002). Hoboken, NJ: John Wiley \& Sons, Inc.

Wolf-Wendel, L., Ward, K., \& Kinzie, J. (2009). A tangled web of terms: The overlap and unique contribution of involvement, engagement, and integration to 
understanding college student success. Journal of College Student Development, 50(4), 407-428. doi:10.1353/csd.0.0077

Woolley, M. E., \& Bowen, G. L. (2007). In the context of risk: Supportive adults and the school engagment of middle school students. Family Relations, 56, 92-104.

Zepke, N., \& Leach, L. (2005). Integration and adaptation: Approaches to the student retention and achievement puzzle. Active Learning in Higher Education, 6(1), 4659.

Zhang, Y., Gan, Y., \& Cham, H. (2007). Perfectionism, academic burnout and engagement among Chinese college students: A structural equation modeling analysis. Personality and Individual Differences., 43, 1529-1540.

Zimmer-Gembeck, M. J., Chipuer, H. M., Hanisch, M., Creed, P. A., \& McGregor, L. (2006). Relationships at school and stage-environment fit as resources for adolescent engagement and achievement. Journal of Adolescence, 26, 911-933.

Zimmerman, B., \& Kitsantas, A. (2007). Reliability and validity of Self-Efficacy for Learning Form (SELF) scores of college students. Journal of Psychology, 215(3), 157-163.

Zinbarg, R. E., Revelle, W., Yovel, I., \& Li, W. (2005). Cronbach's alpha, Revelle's Beta, and McDonald's Omega(h): Their relations with each other and two alternative conceptualizations of reliability. Psychometrika, 70(1), pp. 123-133. 


\title{
Appendix A. IRB submission and approval
}

\author{
Human Subjects Research Review Committee \\ Research and Strategle Partnerships \\ $\begin{array}{ll}\text { Post Omce Bex } 751 \text { (RSP) } & 503-725-3423 \text { tel } \\ \text { Portland, Oregon } 97207-0751 & 503-725-8170 \text { far }\end{array}$ \\ nsrreopetrosis
}

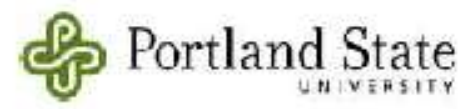

\section{Portland State University HSRRC Memorandum}

To: Ellen Skinner/ Una Chi

From: Melissa Thompson, Chair, HSRRC 2013

Date: March 6, 2013

Re: Your HSRRC application titled, "Classroom Engagement as a Proximal Lever for Student Success in Higher Edrcation: What a Self-Determination Framework Within a Molti-Level Developmental System Tells Us" (HSRRC Proposal \#132528)

\begin{abstract}
In accordance with your request, the Human Subjects Research Review Committee has reviewed your proposal for compliance with DHHS policies and regulations covering the protection of human subjects. The committee is satisfied that your provisions for protecting the rights and welfare of all subjects participating in the research are adequate, and yons project is approved.
\end{abstract}

Please note the following requirements:

Changes to Protocol: Any changes in the proposed study, whether to procedures, survey instruments, consent forms or cover letters, must be outlined and submitted to the Chair of the HSRRC immediately. The proposed changes cannot be implemented before they have been revieured and approved by the Committee.

Continuing Review: Ibis approval will expire Marcb 6,2014, ome year from the agproval date. It is the investigator's responsibility to ensure that a Continning Revien Repart (available in RSP) of the status of the project is submitted to the HSRRC approximately two months before the expiration date, and that approval of the study is kept current.

Adverse Reactions: If any adverse reactions occur as a result of this study, you are required to notify the Chair of the HSRRC immediately. If the problem is serious, approval may be withdrawn pending an investigation by the Committee.

Completion of Study. Please notify the Chair of the Human Subjects Research Review Committee (campus mail code RSP) as soon as your research has been completed. Study records, including protocols and signed consent forms for each participant, must be kept by the investigator in a secure location for three years following completion of the stridy.

If you have questions or concerns, please contact the HSRRC at hsmc@pdx.edn or (503)725-2243.

ce:

Gradnate Studies 


\section{f Portland State}

Human Subjects Research Review Committee

$\begin{array}{ll}\text { Post Office Box } 751 & 503-725-4288 \text { tel } \\ \text { Portland, Oregon 97207-0751 } & 503-725-3416 \text { fax } \\ & \text { hsrremilists.pdic.edu }\end{array}$

September 16,2010

To: $\quad \mathrm{UnaChi}$

From: Nancy Koroloff, HSRRC Chair

Re: $\quad$ HSRRC renewal of approval for your project titled, "Engagement versus Disaffection in the College Classroom: Construction of a Measurement 'Tool to Assess Students' Motivation to Learn" (HSRRC Proposal \# 091053).

As part of the Committee's continning review, the Human Subjects Research Review Committee has reviewred your above referenced project for compliance with Department of Health and Human Services policies and regulations on the protection of human subjects.

The Committee is satisfied that your provisions for protecting the rights and welfare of all subjects participating in the research are adequate. Your project is renewed and this approval will expire on September 21, 2011 Please note the following policies:

1. If the project continnes beyond the expiration date, the investigator needs to submit a Continuing Review Report form two months before the expiration date. The form is available at www rsp.pdx.edu/compliance_hnman php and in the Office of Research \& Strategic Partnerships.

2. To add this project's continning review to the HSRRC/IRB meeting agenda, please refer to the HSRRC/IRB meeting schedule. Submit the report, and the required number of copies, by the submission deadline that is approximately two months before the project's expiration date. The HSRRC/IRB needs two months to do a continning review of the project, so it is extremely important that you meet the committee's submission deadline.

3. If this project finishes before the expiration date, please contact the HSRRC administrator so that the file can be closed and records opdated. It is the investigator's responsibility to keep the approval status current. If the project's approval expires while the project is active, the investigator must complete a new application and submit it for a new HSRRC review. In addition, any data collected after the expiration date cannot be nsed in the research. Please don't let this happen!

If you have questions or concerns, please contact the HSRRC in the Office of Research and Strategic Partnerships (ORSP), 503-725-4288, Unitus Bnilding, 6th Floor, 4th and Lincoln Streets.

Ce: Thomas Kindermann 


\section{Human Subjects Research Review Committee Continuation Report for Research Involving Human Subjects Portland State University}

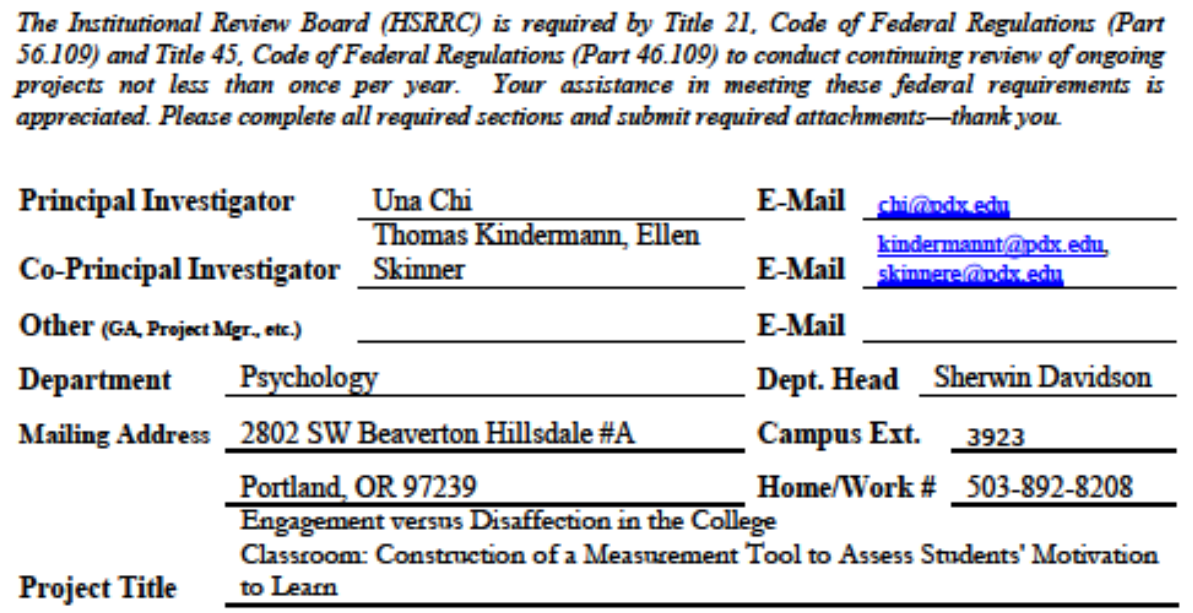

I certify that this report is accurate and that the research activities involving human subjects were conducted as stated in the approved protocol. I will abide by the Federal and University policies related to research involving human subjects.

\section{STEP 1:}

Project Funded?

Federal/Federal Pass-Through?

Funding Agency Name:

\begin{tabular}{|l|l|l}
\hline & $\begin{array}{l}\text { Yes } \\
\mathbf{X}\end{array}$ & No \\
& Pending
\end{tabular}
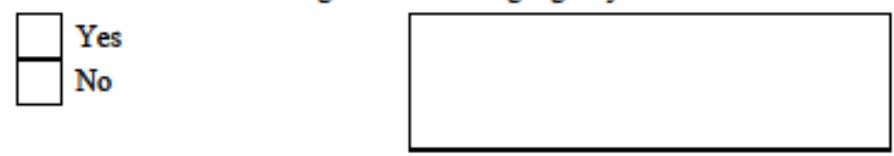

STEP 2: Are all activities involving human subjects, data collection and analysis complete?

Yes Data analysis was completed as of [Click to enter date]. Do not proceed to Step 3. Submit only this page to the HSRRC.

X No Proceed to Step 3. 


\section{Consent Form}

69082

\section{BE PART OF STUDY ON COLLEGE STUDENT LEARNING}

\section{Consent Form}

You are invited to participate in a research study conducted by Una Chi from Portland State University, Department of Psychology. Based on findings from prior groups of students at PSU, the purpose of this study is to investigate college classroom engagement, the relation of engagement to academic performance, and the role classroom engagement plays in fostering persistence and graduation - over and above university provided supports and in light of student multiple commitments.

\section{What Willu Haxe To Do?}

If you decide to participate, you will be asked to fill out a few questionnaires that take about 20 minutes to complete. These questionnaires include items about you, about the class you are in, about the instructor of the class, and about the University in general. Answering these questions will allow the researcher to test a motivational model of classroom engagement, create a short classroom survey, and examine relationships to overall student success.

\section{Are there Anv Risks?}

You may become concerned that the instructor you are answering questions about may see your answers. The distribution, collection, and storage of the surveys are designed to prevent this. At no time will any instructors have access to the actual surveys or the data files, your name is only attached to the survey if you choose to allow the researcher access to your class grade(s), and all discussion of the data will be in aggregates only. After the surveys are converted to a data file, all physical surveys will be destroyed. While it is not likely, it is possible that you may become uncomfortable or upset filling out the surveys. You may take a break from the study at any time and can refuse to participate at any time without consequence. Again, participation is entirely voluntary.

\section{What Will I Get In Return?}

You may not expenience any direct benefit from taking part in this study, other than getting an extra credit point(s) for participating in this study. To award extra credit, we will write your name and course number on a separate piece of paper. This information will be stored separately from the surveys and will be given to your instructor only for the purpose of assigning extra credit. After that, this information will be destroyed appropriately.

\section{What Are You Doing To Protect Me?}

- Participation is voluntary and you may stop doing the study at any time.

- No one will have access to the information collected from this study except for research staff that work on this project.

- Any information will be kept confidential by assigning you a unique number that will be used on all your electronic information.

- Confidentiality will be achieved by keeping information in a safe location at Portland State University, and results of the study will only be reported in averages making the identification of individuals not possible.

Any Questions?

If you have concerns or problems about your participation in this study please contact Una Chi by e-mail at: chi@pdx edu. If you have any questions about your nights as a research subject, please contact the Human Subjects Research Review Committee, Office of Research and Strategic Partnerships, 1600 SW Fourth Ave., Portland, OR 97201, (503) 725-3423, research@pdx.edu.

\section{If I Sign, What Does It Mean?}

- You have read and understand what this form says.

- You are willing to take part in the study.

- You know that you do not have to take part in the study. And, even if you agree, you can change your mind and stop at any time. No problem.

- You will get a copy of this form to keep for yourself.

- This signed copy will be removed from the actual survey and cannot be used to identify your responses. 
College success and student engagement / 253

\section{Appendix B: Partial 2009 study results.}

Table A.1. Descriptive and model fit statistics for Final Thesis (Chi, 2009) scales.

\begin{tabular}{|c|c|c|c|c|c|}
\hline \multicolumn{2}{|l|}{$\underline{\text { Scale }}$} & \multicolumn{2}{|r|}{ CFI } & $\underline{\mathrm{Cmin} / \mathrm{DF}}$ & \multirow[t]{2}{*}{ RMSEA } \\
\hline Behavi & $\begin{array}{l}\text { ral Engagement (6 Item): } \\
\text { Cronbach's ALPHA }=.862 \\
\chi^{2}(6,405)=20.969, p=.002\end{array}$ & & 0.986 & 3.495 & \\
\hline ID & Item & $\mathbf{M}$ & SD & $\begin{array}{l}\text { Factor } \\
\text { Loading }\end{array}$ & SMC \\
\hline BE1 & I try hard to do well in this class. & 3.696 & 1.057 & 0.827 & 0.683 \\
\hline BE2 & I pay attention in class. & 4.010 & 0.982 & 0.812 & 0.659 \\
\hline BE5 & $\begin{array}{l}\text { When the instructor explains new } \\
\text { material, I take careful notes. }\end{array}$ & 3.837 & 1.094 & 0.751 & 0.564 \\
\hline BE7 & I stay current with the readings. & 2.975 & 1.218 & 0.720 & 0.519 \\
\hline BE9 & I study for this class. & 3.395 & 1.109 & 0.821 & 0.675 \\
\hline BE11 & $\begin{array}{l}\text { I try to get the most I can out of this } \\
\text { class. }\end{array}$ & 3.684 & 1.096 & 0.755 & 0.570 \\
\hline Scale & & & CFI & $\mathrm{Cmin} / \mathrm{DF}$ & RMSEA \\
\hline$\overline{\text { Behavi }}$ & $\begin{array}{l}\text { ral Disaffection (6 Item): } \\
\text { Cronbach's ALPHA =.800 } \\
\chi^{2}(6,405)=25.932, p=.000\end{array}$ & & 0.972 & 4.322 & 0.091 \\
\hline ID & Item & M & SD & $\begin{array}{l}\text { Factor } \\
\text { Loading } \\
\end{array}$ & SMC \\
\hline $\mathrm{BD} 2$ & I don't try very hard in this class. & 1.696 & 0.901 & 0.828 & 0.685 \\
\hline BD3 & $\begin{array}{l}\text { In this class, I do just enough to get } \\
\text { by. }\end{array}$ & 1.958 & 0.990 & 0.780 & 0.609 \\
\hline BD4 & $\begin{array}{l}\text { When I'm in this class, my mind } \\
\text { wanders. }\end{array}$ & 2.296 & 0.882 & 0.679 & 0.461 \\
\hline BD7 & $\begin{array}{l}\text { I don't try to take good notes in this } \\
\text { class. }\end{array}$ & 1.361 & 0.779 & 0.524 & 0.274 \\
\hline $\mathrm{BD} 10$ & $\begin{array}{l}\text { I don't even try to keep up with the } \\
\text { homework. }\end{array}$ & 1.353 & 0.752 & 0.603 & 0.363 \\
\hline BD11 & I don't really study for the class. & 1.654 & 0.881 & 0.753 & 0.566 \\
\hline
\end{tabular}

(continued) 
Table A.1. Descriptive and model fit statistics (continued).

\begin{tabular}{|c|c|c|c|c|c|}
\hline \multicolumn{2}{|c|}{$\underline{\text { Scale }}$} & \multicolumn{2}{|r|}{$\underline{\text { CFI }}$} & $\underline{\mathrm{Cmin} / \mathrm{DF}}$ & RMSEA \\
\hline \multicolumn{6}{|c|}{$\begin{array}{c}\text { Emotional Engagement }(4 \text { Item }): \\
\text { Cronbach's ALPHA }=.924\end{array}$} \\
\hline ID & 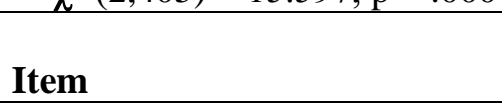 & $\mathbf{M}$ & SD & $\begin{array}{l}\text { Factor } \\
\text { Loading }\end{array}$ & SMC \\
\hline EE1 & $\begin{array}{l}\text { The material we cover is } \\
\text { interesting. }\end{array}$ & 3.679 & 1.072 & 0.744 & 0.554 \\
\hline EE2 & This class is fun. & 3.247 & 1.091 & 0.917 & 0.841 \\
\hline EE3 & $\begin{array}{l}\text { I enjoy the time I spend in this } \\
\text { class. }\end{array}$ & 3.210 & 1.116 & 0.961 & 0.924 \\
\hline EE5 & I look forward to this class. & 2.790 & 1.185 & 0.850 & 0.723 \\
\hline Scale & & & CFI & $\mathrm{Cmin} / \mathrm{DF}$ & RMSEA \\
\hline$\overline{\text { Emotic }}$ & $\begin{array}{l}\text { nal Disaffection (4 Item): } \\
\quad \text { Cronbach's ALPHA }=.860 \\
\chi^{2}(2,405)=5.785, p=.055\end{array}$ & & 0.995 & 2.893 & 0.068 \\
\hline ID & Item & $\mathbf{M}$ & SD & $\begin{array}{l}\text { Factor } \\
\text { Loading }\end{array}$ & SMC \\
\hline ED1 & This class is no fun. & 1.684 & 0.917 & 0.736 & 0.542 \\
\hline $\mathrm{ED} 2$ & When in class, I feel bored. & 1.983 & 0.924 & 0.870 & 0.756 \\
\hline ED3 & $\begin{array}{l}\text { When I am in this class, I can't } \\
\text { wait for it to be over. }\end{array}$ & 2.133 & 0.981 & 0.836 & 0.700 \\
\hline ED8 & I dread going to this class. & 1.435 & 0.740 & 0.673 & 0.452 \\
\hline
\end{tabular}

Note: Means could range from 1 (Never) to 5 (Always).

$\mathrm{N}=405$ 
College success and student engagement / 255

Table A.2: Psychometrics for context and SSP scales (Chi, 2009)

\begin{tabular}{|c|c|c|c|}
\hline Context Scales & $\begin{array}{l}\text { \# of } \\
\text { Items }\end{array}$ & $\begin{array}{l}\text { Cronbach's } \\
\text { alpha }\end{array}$ & Mean \\
\hline Instructor Autonomy Support & 6 & 0.62 & 4.18 \\
\hline Instructor Structure & 6 & 0.73 & 4.34 \\
\hline Instructor Involvement/Warmth & 6 & 0.73 & 3.53 \\
\hline SSP Scales & $\begin{array}{l}\text { \# of } \\
\text { Items }\end{array}$ & $\begin{array}{l}\text { Cronbach's } \\
\text { alpha }\end{array}$ & Mean \\
\hline $\begin{array}{l}\text { Student perception of }\{\text { self }\} \\
\text { Autonomy }\{\text { relevance }\} \text { towards } \\
\text { course }\end{array}$ & 4 & 0.80 & 4.44 \\
\hline $\begin{array}{l}\text { Student perception of }\{\text { self }\} \\
\text { Competence }\end{array}$ & 6 & 0.80 & 4.54 \\
\hline $\begin{array}{l}\text { Student perception of }\{\text { self }\} \\
\text { Relatedness towards college }\end{array}$ & 6 & 0.74 & 3.80 \\
\hline
\end{tabular}

Note: Means could range from 1 (Never) to 5 (Always).

$\mathrm{N}=405$ 


\section{Appendix C: Administered survey.}

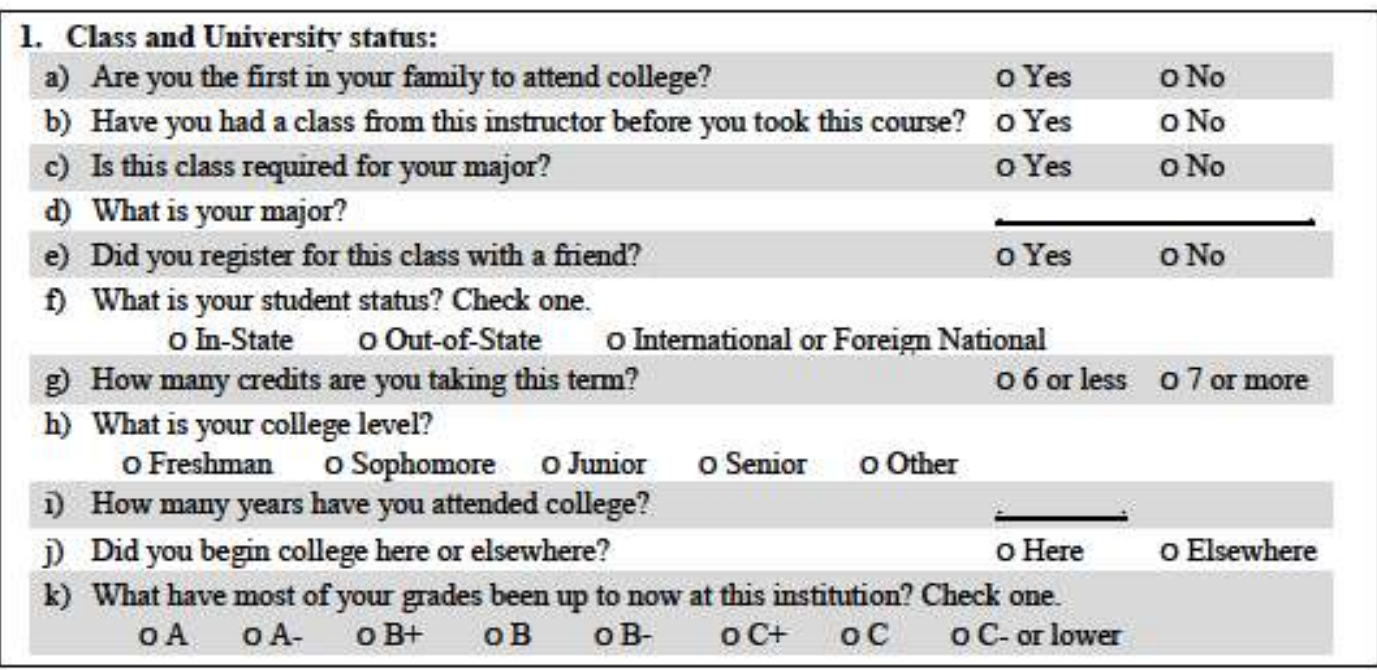

2. Thinking about your perceptions of this course:

Not True (1) A Little True (2) Somewhat True (3) Fairly True (4)

a) I try hard to do well in this class.

b) I don't care if I miss class.

c) This class is fun. $\quad$ (1) (2) (3) (4) (2)

d) It's hard to make myself come to this class.

e) This class makes me want to leam more about the topic. (1) (2) (3) (4) (2)

f) In this class, I do just enough to get by.

g) If's exciting to make connections between the ideas leamed in $\quad$ (1) (2) (3) (4) (5)

h) When in class, I feel bored. $\quad$ (1) (2) (3) (4) (5)

i) I stay current with the readings.

j) I like telling others about what Tve learned in this class.

k) When I'm in this class, my mind wanders.

1) I dread going to this class.

m) I try hard to understand the professor's lectures. (1) (2) (3) (4) (2)

n) I look forward to this class.

o) I just leamed the stuff in class to pass the test(s).

p) When I am in this class, I can't wait for it to be over.

q) This class is stressing me out.

I) I keep up with the work for this class.

s) I don't even try to keep up with the coursework. (1) (2) (3) (4) (5)

t) It's really fun to think about the material in this class.

u) The readings for this class are interesting. $\quad$ (1) (2) (3) (4) (2)

v) This class is no fun. $\quad$ (1) (2) (3) (4) (5)

w) When in class, I keep track of things I don't understand. (1) (2) (3) (4) (2)

x) I don't really study for the class.

y) I pay attention in class. $\quad$ (1) (2) (3) (4) (2)

z) I don't try very hard in this class. 


\section{About this course:}

Not True (1) A Little True (2) Somewhat True (3) Fairly True (4) Totally True (5)

a) I work hard to really understand the material covered in this class.

b) I study for this class.

c) I don't try to take good notes in this class.

d) When exams/assignments are coming up in this class, I worry a lot .

e) This instructor gives great lectures.

f) I work on other things when I'm in this class.

g) I enjoy the time I spend in this class.

h) Anything I do for this class is always last minute.

i) I try to get the most I can out of this class.

j) I don't really care about how well I do in this class.

k) The material we cover in class is challenging (in a good way).

1) When the instructor explains new material, I take careful notes.

m) This instructor's lectures are pretty dull.

n) The material we cover is interesting.

o) Outside of class, I don't put much work in on this course.

p) When $\Gamma \mathrm{m}$ in this class, my mind wanders.

q) I feel overwhelmed by this class.

r) This class gets my mind bubbling with thoughts and ideas.

s) Sitting in class is a waste of my time.

t) I set aside study time for this class.

u) If I could have gotten out of taking this class, I would have.

v) Time flies when $\mathrm{Tm}$ in this class.

(1) (2) (3) (4) (2)

(1) (2) (3) (4) (2)

(1) (2) (3) (4) (2)

(1) (2) (3) (4) (2)

(1) (2) (3) (4) (2)

(1) (2) (3) (4) (2)

(1) (2) (3) (4) (2)

(1) (2) (3) (4) (2)

(1) (2) (3) (4) (2)

(1) (2) (3) (4) (2)

(1) (2) (3) (4) (2)

(1) (2) (3) (4) (2)

(1) (2) (3) (4) (2)

(1) (2) (3) (4) (2)

(1) (2) (3) (4) (2)

(1) (2) (3) (4) (2)

(1) (2) (2) (4) (2)

(1) (2) (3) (4) (2)

(1) (2) (3) (4) (5)

(1) (2) (3) (4) (2)

(1) (2) (3) (4) (2)

(1) (2) (3) (4) (2)

\section{The following are the questions typically used in teaching evaluation of the Psychology} Department:

a) The instructor uses class time effectively.

Strongly Disagree (1)

b) The instructor answered questions in a clear and understandable way.

c) The instructor was prepared for class.

d) The instructor used examples effectively in explaining difficult concepts.

e) The instructor raised challenging questions for discussion.

f) The instructor welcomed students' questions or comments.

g) The instructor seemed to enjoy teaching.

h) The grading policies were clearly stated.

i) The course material was presented clearly.

j) Relevant information in addition to the textbook was presented.

k) I learned a lot in this course.

l) What grade do you expect to get in this course?

$$
\text { o } \mathrm{A} \text { oB oC o Below C / o Pass o No Pass }
$$

\section{$O A$ OB OC OBelow C O Pass ONo Pass}

(1) (2) (3) (4) (5) (6)

(1) (2) (3) (4) (2) (6)

(1) (2) (3) (4) (5) (6)

(1) (2) (3) (4) (2) (6)

(1) (2) (3) (4) (2) (6)

(1) (2) (3) (4) (5) (6)

(1) (2) (3) (4) (5) (6)

(1) (2) (3) (4) (2) (6)

(1) (2) (3) (4) (2) (6)

(1) (2) (3) (4) (2) (6)

(1) (2) (3) (4) (5) (6) 


\begin{tabular}{|c|c|c|c|c|c|c|c|}
\hline \multicolumn{8}{|c|}{ 5. We would like to go a bit more in-depth with regard to the teaching evaluation questions. } \\
\hline \multirow{2}{*}{ a) } & Not True (1) A Little True (2) & \multicolumn{2}{|c|}{ Somewhat True (3) Fairly True (4) } & \multicolumn{4}{|c|}{ Totally True (2) } \\
\hline & This instructor explains the relevanc & of this course to our real lives. & (1) & (2) & (3) & (4) & (5) \\
\hline & This instructor keeps changing the $n$ & les in class. & (1) & (2) & (3) & (4) & (2) \\
\hline c) & This instructor is available for stude: & & (1) & (2) & (3) & (4) & (2) \\
\hline d) & This instructor is bossy and controll & & (1) & (2) & (3) & (4) & (5) \\
\hline e) & This instructor listens to students' id & & (1) & (2) & (3) & (4) & (5) \\
\hline f) & This instructor doesn't know I exist. & & (1) & (2) & (3) & (4) & (2) \\
\hline g) & This instructor gives good feedback & about how we are doing in class. & (1) & (2) & (3) & (4) & (2) \\
\hline h) & This instructor just doesn't understa & id students. & (1) & (2) & (3) & (4) & (5) \\
\hline i) & This instructor appreciates student $\mathrm{d}$ & versity in experiences. & (1) & (2) & (3) & (4) & (5) \\
\hline j) & The exams in this class are unfair. & & (1) & (2) & (3) & (4) & (2) \\
\hline k) & The assignments in this class are cle & Ir and reason & (1) & (2) & (3) & (4) & (2) \\
\hline 1) & ctor doesn't know & & (1) & (2) & (3) & (4) & (2) \\
\hline & This instructor makes clear what he & $\mathrm{n}$ class. & (1) & (2) & (3) & (4) & (2) \\
\hline n) & derstand wha & ng about. & (1) & (2) & (3) & (4) & (5) \\
\hline o) & $\begin{array}{l}\text { Our instructor gives us some latit } \\
\text { class. }\end{array}$ & out the assignments in this & (1) & (2) & (3) & (4) & (2) \\
\hline p) & This instructor doesn't listen to stud & ents' opinions. & (1) & (2) & (3) & (4) & (2) \\
\hline q) & Instructor discourages altemative id & as from studen & (1) & (2) & (3) & (4) & (5) $10-1 \cdot 1-1$ \\
\hline r) & This instructor has time for me outsi & de of class. & (1) & (2) & (3) & (4) & (5) \\
\hline s) & $\begin{array}{l}\text { This instructor doesn't explain wh } \\
\text { this class }\end{array}$ & e have to leam certain things in & (1) & (2) & (3) & (4) & (5) \\
\hline t) & This instructor cares about how I do & in his/her class. & (1) & (2) & (3) & (4) & (5) \\
\hline
\end{tabular}

\begin{tabular}{|c|c|c|c|c|c|c|}
\hline \\
\hline \multicolumn{7}{|c|}{$\begin{array}{l}\text { 6. In this class, I think: } \\
\text { Not True (1) A Little True (2) Somewhat True (3) }\end{array}$} \\
\hline a) & I know how to do well in this class. & (1) & (2) & (3) & (4) & (5) \\
\hline b) & Most of the material we leam in this class is pointless. & (1) & (2) & (3) & (4) & (2) \\
\hline c) & This is a tough class. & (1) & (2) & (3) & (4) & (2) \\
\hline & $\begin{array}{l}\text { I don't really understand where the other students in this class are } \\
\text { coming from. }\end{array}$ & (1) & (2) & (3) & (4) & (5) \\
\hline e) & I can do well in this class if I want to. & (1) & (2) & (3) & (4) & (2) \\
\hline f) & I did not leam much from this class. & (1) & (2) & (3) & (4) & (5) \\
\hline g) & This class requires a lot of work. & (1) & (2) & (3) & (4) & (5) \\
\hline h) & I have a lot in common with the other students in this class. & (1) & (2) & (3) & (4) & (5) \\
\hline i) & I belong in this class. & (1) & (2) & (3) & (4) & (2) \\
\hline j) & I can't get a good grade in this class no matter what I do. & (1) & (2) & (3) & (4) & (5) \\
\hline & Anyone can do well in this class without much effort. & (1) & (2) & (3) & (4) & (2) \\
\hline & This class requires a lot of effort. & (1) & (2) & (3) & (4) & (2) \\
\hline & It is important to me to do well in this class. & (1) & (2) & (3) & (4) & (5) \\
\hline & This class is over my head. & (1) & (2) & (3) & (4) & (5) \\
\hline & I can relate to the other students in this class. & (1) & (2) & (3) & (4) & (2) \\
\hline & I don't have the brains to do well in this class. & (1) & (2) & (3) & (4) & (2) \\
\hline & The things we are learning in this class are important to me. & (1) & (2) & (3) & (4) & (2) \\
\hline
\end{tabular}




\begin{tabular}{|l}
\hline 7. I think that: \\
\begin{tabular}{|llllll|}
\hline Not True (1) A Little True (2) & Somewhat True (3) & Fairly True (4) & Totally True (2) \\
\hline a) In this class, my only goal is to get a passing grade. & (1) & (2) & (3) & (4) & (2) \\
b) In this class I feel like an outsider. & (1) & (2) & (3) & (4) & (2) \\
c) This is an easy class. & (1) & (2) & (3) & (4) & (2) \\
d) I can apply what we are learning in class to my real life. & (1) & (2) & (3) & (4) & (2) \\
e) I don't fit in with the students in this class. & (1) & (2) & (3) & (4) & (2) \\
f) If I decide to ace this class, I can. & (1) & (2) & (3) & (4) & (2)
\end{tabular}
\end{tabular}

8. What really gets you interested and thinking about the material of a class?

9. I agree to allow the researcher access to my class grade(s). Note: Individual survey data will NOT be seen by anyone but the primary researcher. Once the grade is recorded on the survay, your name \& signature will be blacked out.

o Yes: (Sign Name)

Print Name:

10. Please tell us a bit about yourself. $\begin{array}{lllll}\text { Not True (1) A Little True (2) } & \text { Somewhat True (3) } & \text { Fairly True (4) } & \text { Totally True (2) }\end{array}$

a) Tve got what it takes to do well here at PSU.

b) If I have trouble with a class, I usually do well in the end.

c) College is just one more thing in my life I have to deal with.

(1) (2) (3) (4) (2)

d) College is where I belong right now.

e) I don't know how to do well in college.

f) I feel at home here at PSU.

g) Im not smart enough to make it through college.

h) If I do badly on a test or quiz, I just give up.

i) If something bad happens in school, I don't let it get me down.

j) If it was up to me, I wouldn't be in college right now.

k) What $\mathrm{Tm}$ learning here at university maps onto my career goals.

l) I don't really belong in college.

m) If I do badly on my coursework, I just put in more time and effort.

n) There is no place I'd rather be right now than at college.

o) If a class is really hard, I'll probably do badly in it.

p) I am capable of being a good student here at college.

q) College doesn't relate to me or my life at all.

r) I understand what it takes to do well in college.

s) When I get behind in my coursework, I just don't do it.

t) I don't fit in here at PSU.

u) Finishing college is personally important to me.

v) I am different from the other students at PSU.

w) I can't make it here no matter what I do.

x) PSU offers me options that align with my life and interests.

\begin{tabular}{|c|c|c|c|}
\hline (1) & & (3) & (4) \\
\hline (1) & (2) & (3) & (4) \\
\hline (1) & (2) & (3) & (4) \\
\hline 1) & (2) & (3) & (4) \\
\hline (1) & (2) & (3) & (4) \\
\hline (1) & (2) & (3) & (4) \\
\hline (1) & (2) & (3) & (4) \\
\hline (1) & (2) & (3) & (4) \\
\hline (1) & (2) & (3) & (4) \\
\hline (1) & (2) & (3) & (4) \\
\hline (1) & (2) & (3) & (4) \\
\hline (1) & (2) & (3) & (4) \\
\hline (1) & (2) & (3) & (4) \\
\hline (1) & (2) & (3) & (4) \\
\hline (1) & (2) & (3) & (4) \\
\hline (1) & (2) & (3) & (4) \\
\hline (1) & (2) & (3) & (4) \\
\hline (1) & (2) & (3) & (4) \\
\hline (1) & (2) & (3) & (4) \\
\hline (1) & (2) & (3) & (4) \\
\hline (1) & (2) & (3) & (4) \\
\hline (1) & (2) & (3) & (4) \\
\hline (1) & (2) & (3) & (4) \\
\hline
\end{tabular}

63125 


\begin{tabular}{|c|c|c|c|c|}
\hline \multicolumn{5}{|c|}{ 11. Work and Family: } \\
\hline a) & $\begin{array}{l}\text { This term, in an average week I work: } \\
\text { (Hours) o None o 1-14 }\end{array}$ & 0 26-32 & $032+$ & \\
\hline b) & I have a lot of responsibility in my work. & oYes & o No & oN/A \\
\hline & My job demands interfere with my schoolwork. & oYes & o No & oN/A \\
\hline & $\begin{array}{l}\text { Does your job relate to your major or areas of study here at } \\
\text { college? }\end{array}$ & o Yes & o No & oN/A \\
\hline \multirow{2}{*}{$\begin{array}{l}\text { e) } \\
\text { f) }\end{array}$} & I have a lot of responsibility in my family. & o Yes & o No & oN/A \\
\hline & $\begin{array}{l}\text { Who do you live with? (Check all that apply) } \\
\text { o Alone o w/Partner o w/Parent(s) o w/Child(ren) o }\end{array}$ & o w/Roommate & o Other & \\
\hline g) & If you have children, what are their ages? (fill in blank) & & & \\
\hline h) & If you live with parents, do you provide care for them? & \multicolumn{2}{|c|}{ o Yes } & No \\
\hline \multicolumn{5}{|c|}{$\begin{array}{l}\text { Definition. A dissbility is a permanent physical or mental inpaimment that substantially limits one or more major life } \\
\text { activities. Examples include: chronic illness (eg. diabetes), hearing or vision loss, learning disability, cognitive } \\
\text { impairment (e.g. difficulty reading or writing), physical disablity, psychiatric disability. }\end{array}$} \\
\hline \multicolumn{2}{|r|}{ i) Based on disability def, are you a person with a disability? } & & oYes & o No \\
\hline j) & \multicolumn{2}{|c|}{ Based on disability def, do you care for a person with a disability? } & oYes & o No \\
\hline \multicolumn{2}{|r|}{ k) Are you using college loans to fund your schooling? } & & oYes & o No \\
\hline 1) & Did you apply for scholarship or grant money to fund your s & schooling? & o Yes & o No \\
\hline m) & $\begin{array}{l}\text { Do you receive any scholarship or grant money for schoolin } \\
\text { on academic performance? }\end{array}$ & ng that depend & oYes & o No \\
\hline n) & $\begin{array}{l}\text { Do you receive money from other sources (like parents) that } \\
\text { academic performance? }\end{array}$ & it depends on & oYes & o No \\
\hline
\end{tabular}

12. What, if anything, interferes with your schoolwork or academic success?

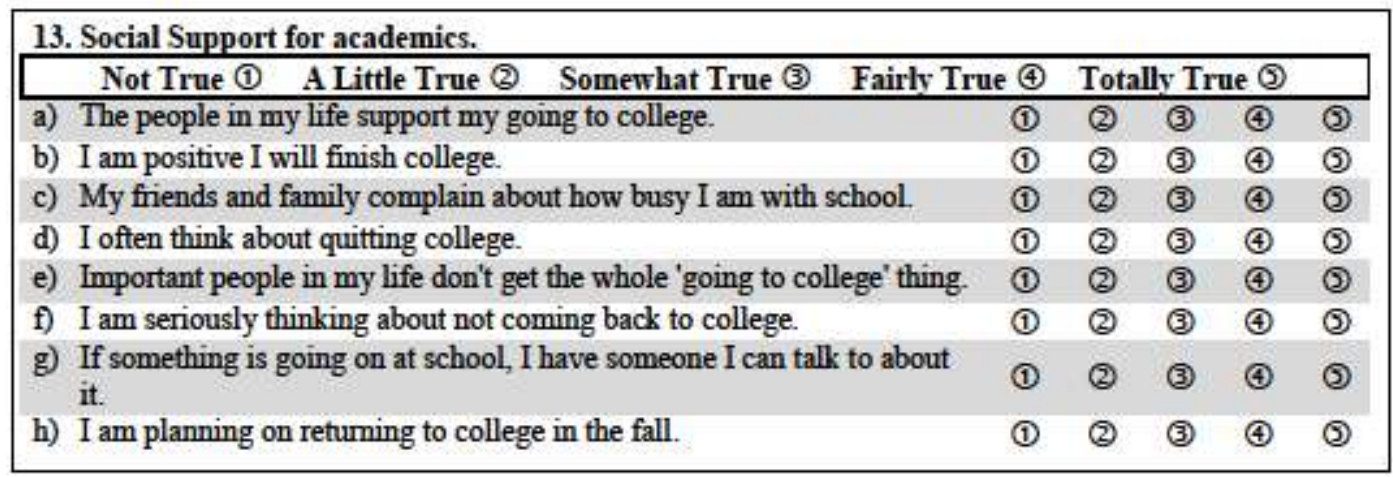




\begin{tabular}{|c|c|c|c|c|c|}
\hline \multicolumn{6}{|c|}{ 14. To what extent does your institution emphasize the following? } \\
\hline & Some (2) Quite a bit (3) & h (4) & & & \\
\hline a) & Providing the support you need to help you succeed academically. & (1) & (2) & (3) & (4) \\
\hline & $\begin{array}{l}\text { Encouraging contact among students from different economic, social, } \\
\text { and racial or ethnic backgrounds. }\end{array}$ & (1) & (2) & (3) & (4) \\
\hline & Helping you cope with your responsibilities (work, family, etc.). & (1) & (2) & (3) & (4) \\
\hline & Providing the support you need to thrive socially. & (1) & (2) & (3) & (4) \\
\hline
\end{tabular}

15. To what extent has your experience at this institution contributed to your knowledge, skilk, and personal development in the following areas?

\begin{tabular}{|c|c|c|c|}
\hline Very Little (1) Some (2) $\quad$ Quite a bit (3) & Very Much (4) & & \\
\hline a) Acquiring a broad general education. & (2) & (3) & (4) \\
\hline b) Acquiring job or work-related knowledge and skills. & (2) & (3) & (4) \\
\hline c) Writing clearly and effectively. & (2) & (3) & (4) \\
\hline d) Speaking clearly and effectively. & (2) & (3) & (4) \\
\hline e) Thinking critically and analytically. & (2) & (3) & (4) \\
\hline f) Analyzing quantitative problems. & (2) & (3) & (4) \\
\hline g) Using computing and information technology. & (2) & (3) & (4) \\
\hline h) Working effectively with others. & (2) & (3) & (4) \\
\hline i) Learning effectively on your own. & (2) & (3) & (4) \\
\hline j) Understanding yourself. & (2) & (3) & (4) \\
\hline k) Understanding people of other racial and ethnic backgrounds. & (2) & (3) & (4) \\
\hline 1) Solving complex real-world problems. & (2) & (3) & (4) \\
\hline m) Developing a personal code of values and ethics. & (2) & (3) & (4) \\
\hline n) Contributing to the welfare of your community & (2) & (3) & (4) \\
\hline
\end{tabular}

\section{Basic Information:}

a) How old are you? (fill in blank)

b) What is your biological sex? o Female o Male

c) What is your racial or ethnic identification? Check all that apply.
o Latino/Hispanic
o Native American/Alaskan Native
o White (non-Hispanic)
o African American o Asian/Pacific Islander
o Other
o Prefer not to answer

d) Which of the following best describes where you are living now while attending college?

o Dormitory or other campus housing (not fraternity/sorority house)

o Residence (house, apartment, etc.) within walking distance of the institution

o Residence (house, apartment, etc.) within driving distance of the institution

o None of the above

\section{Thank you for sharing your sharing your responses!}


Appendix D. All items, all measures, by model/construct codebook.

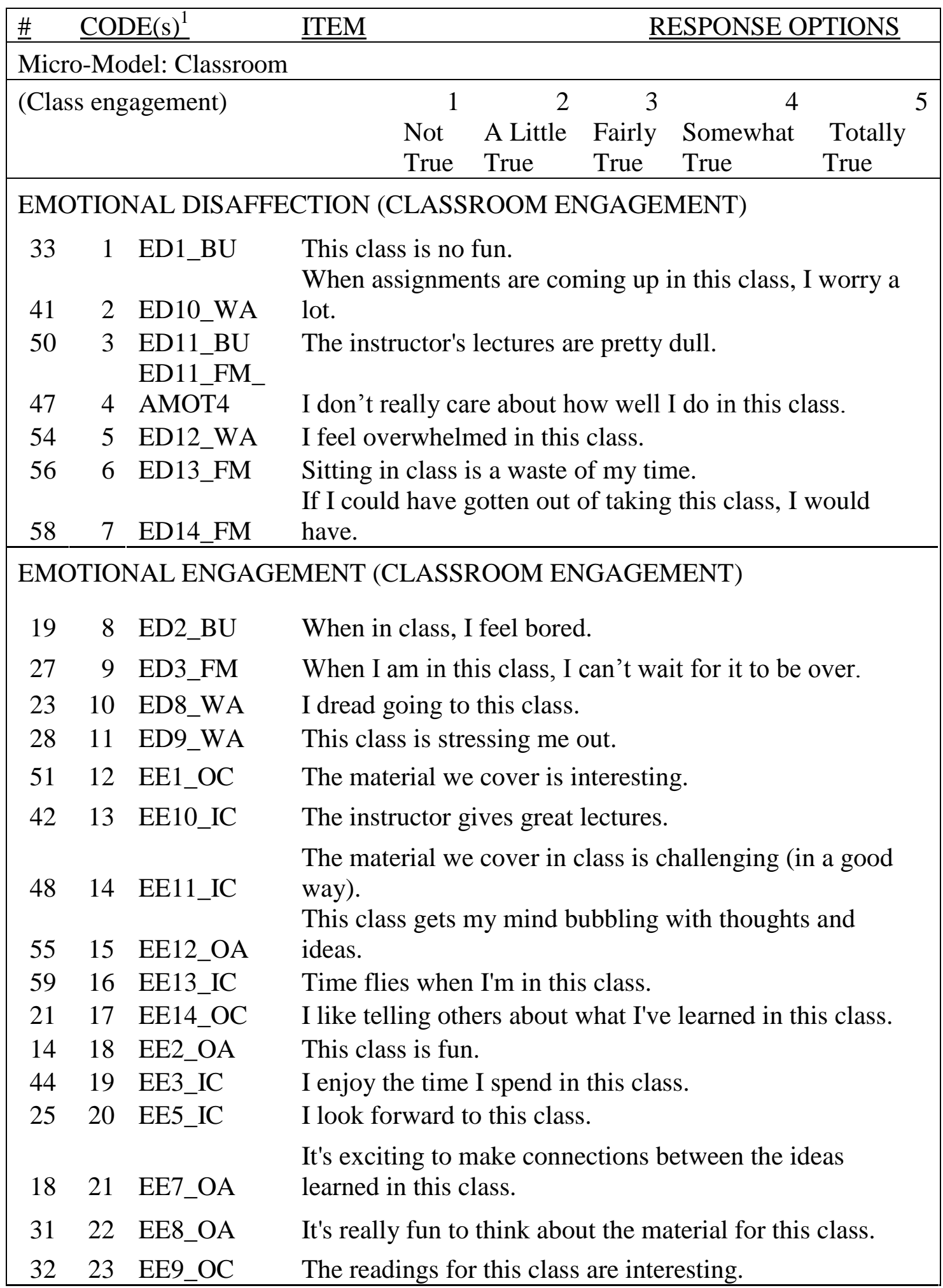


College success and student engagement / 263

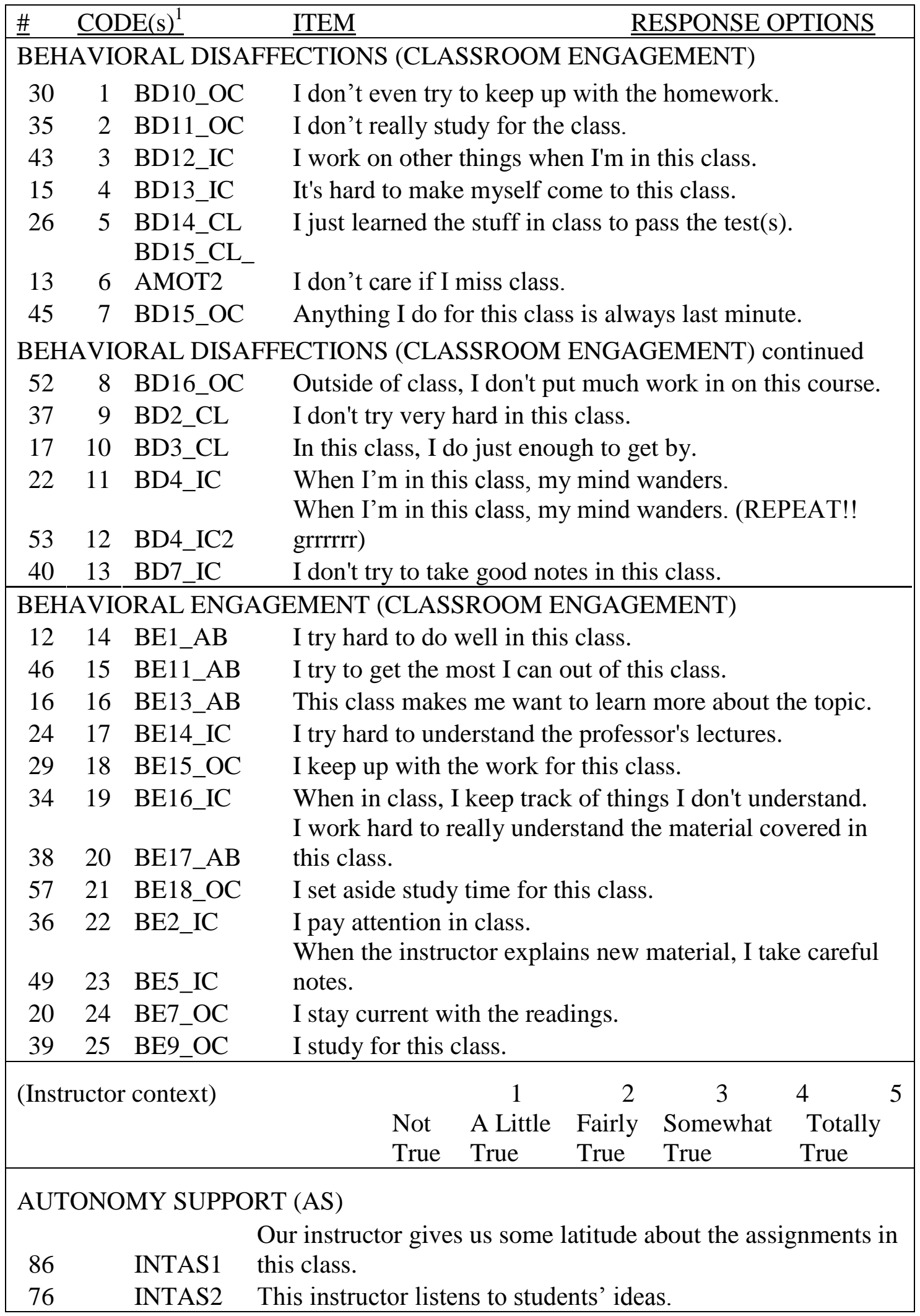


College success and student engagement / 264

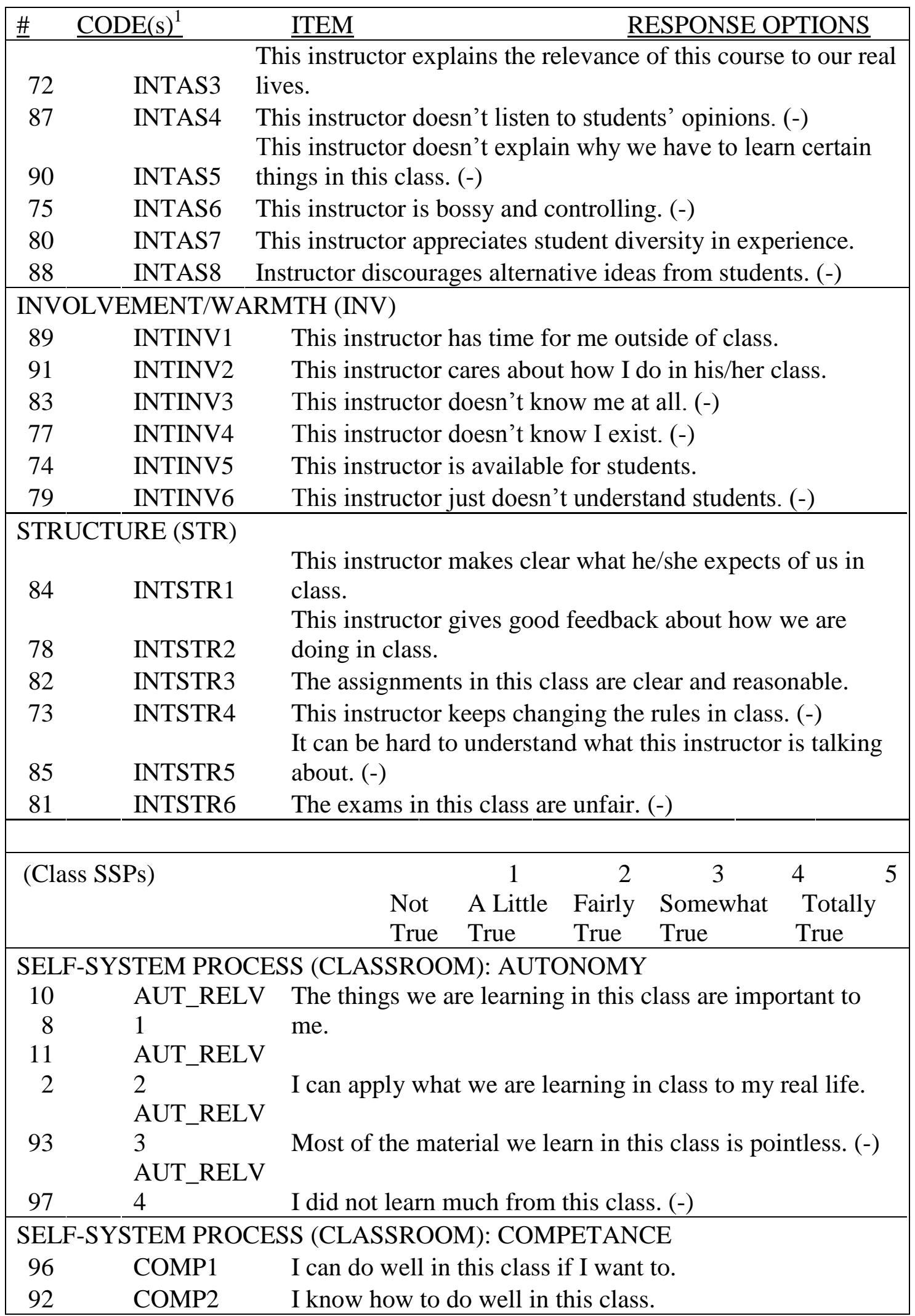


College success and student engagement / 265

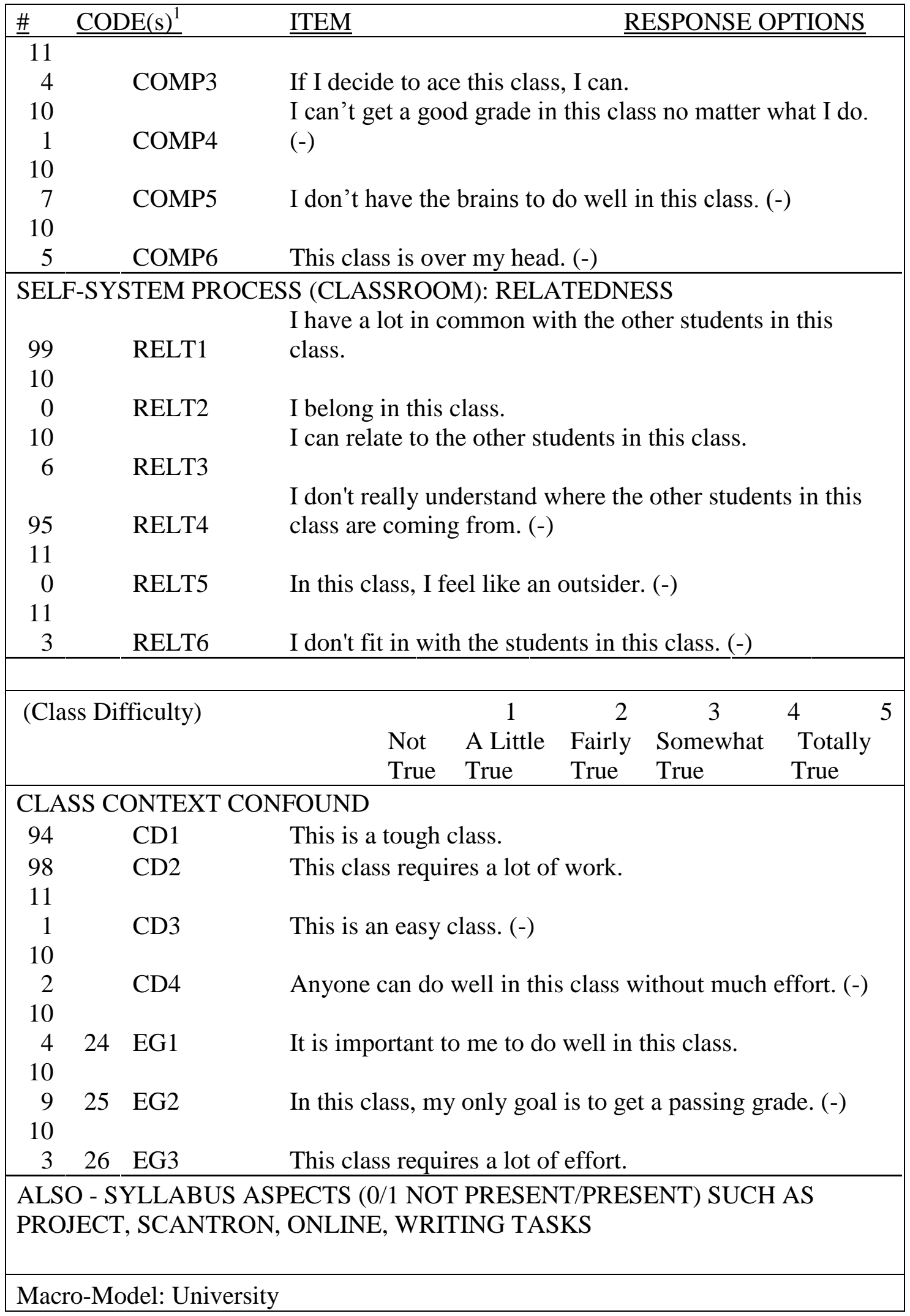


College success and student engagement / 266

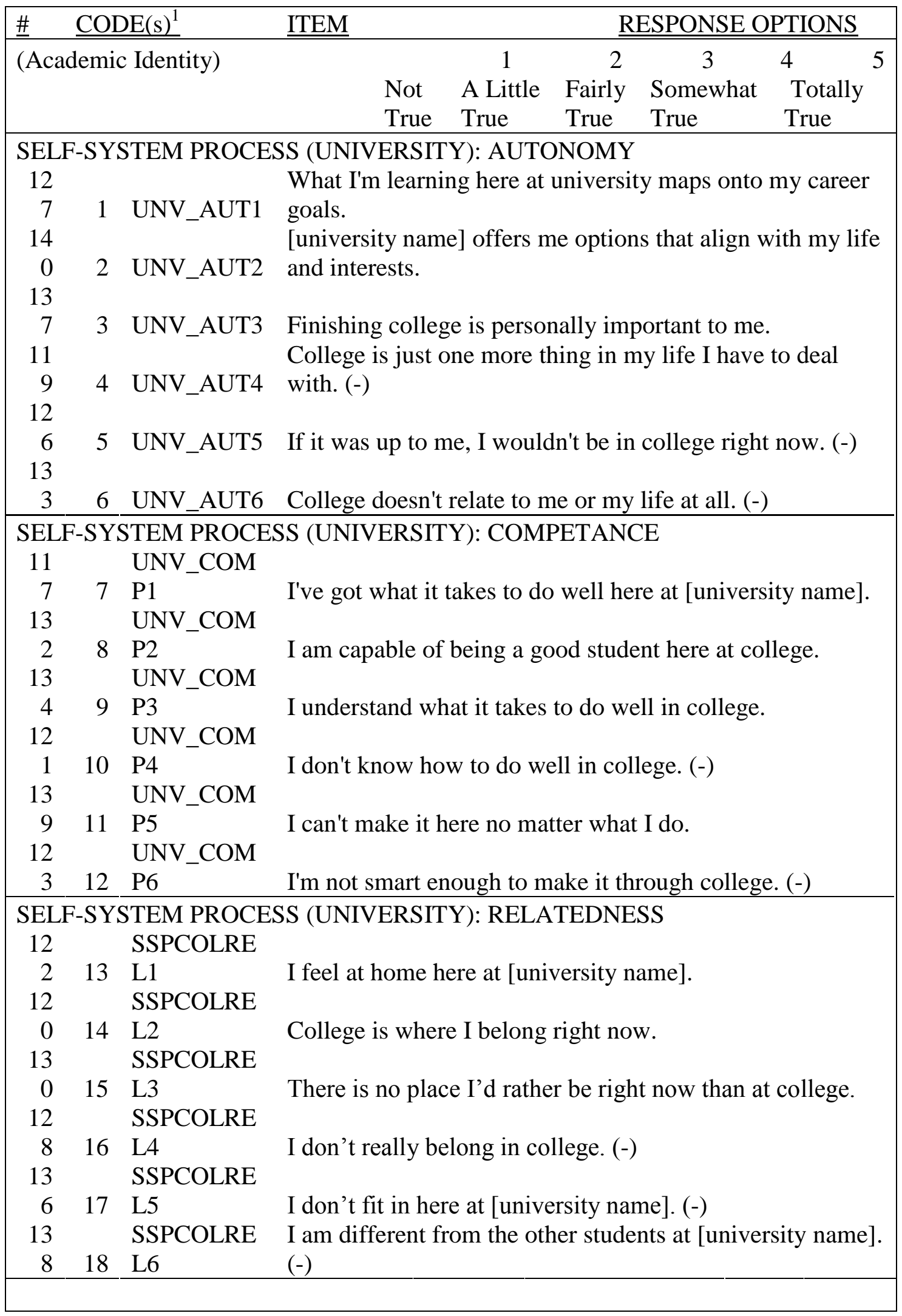


College success and student engagement / 267

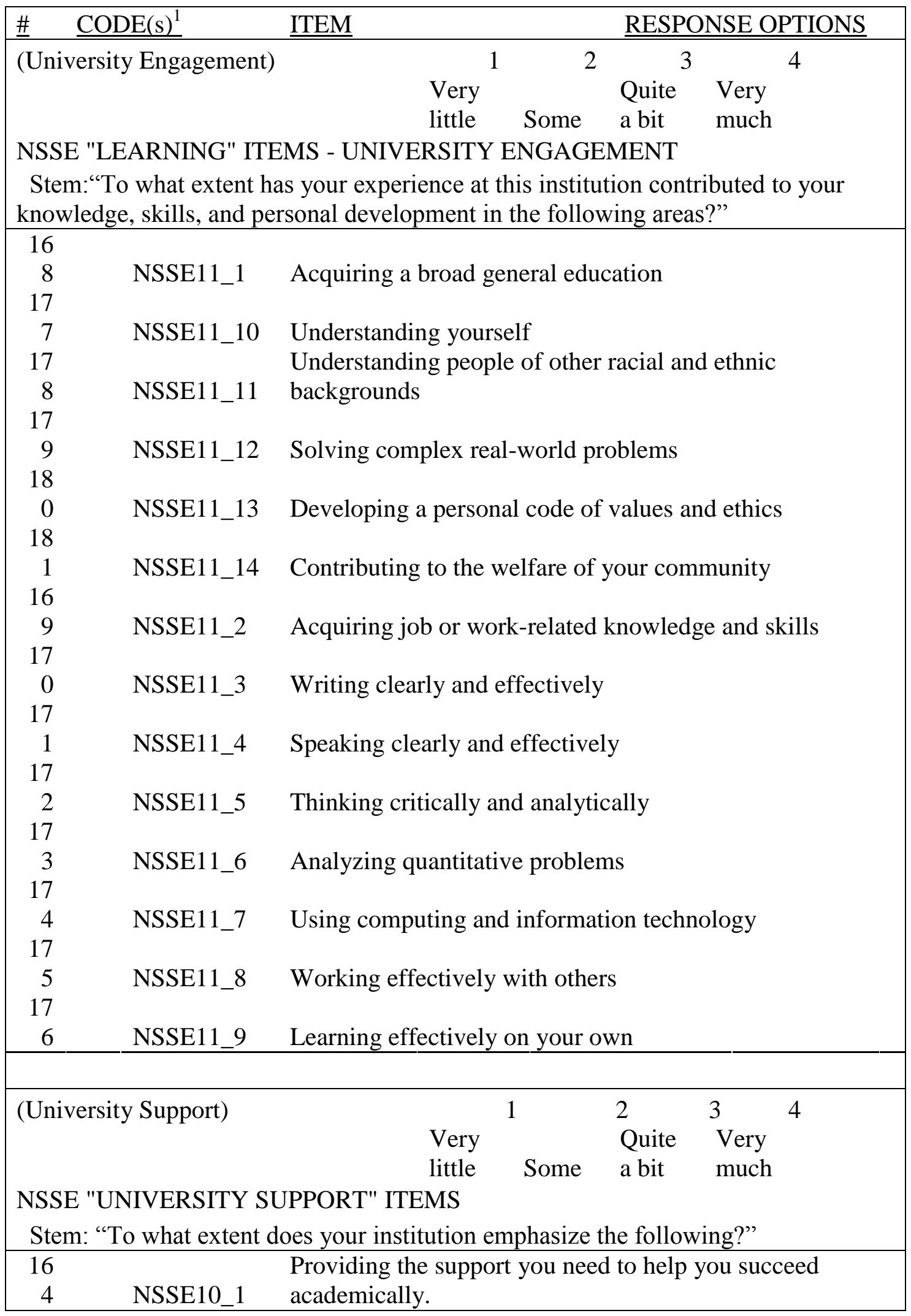


College success and student engagement / 268

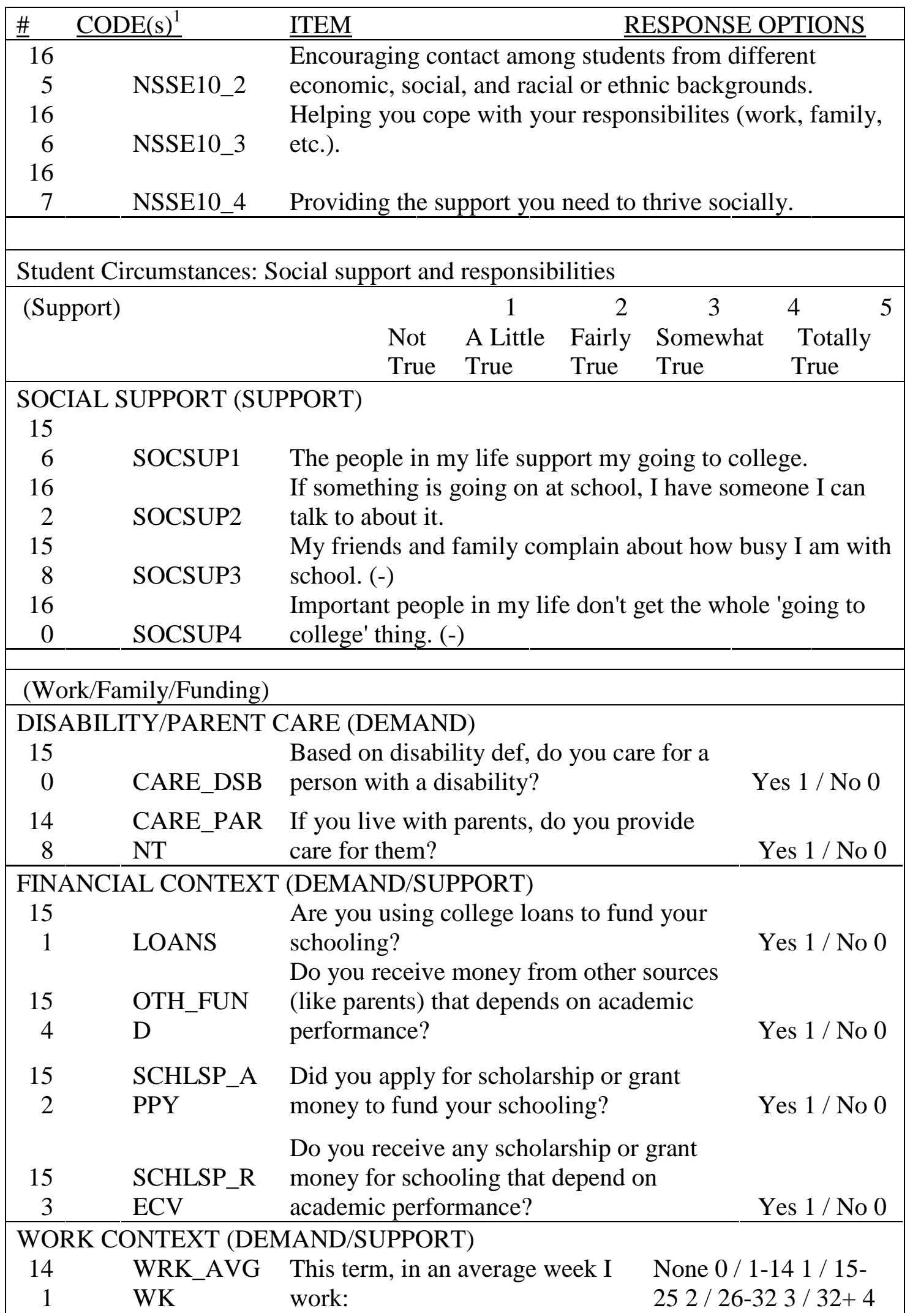


College success and student engagement / 269

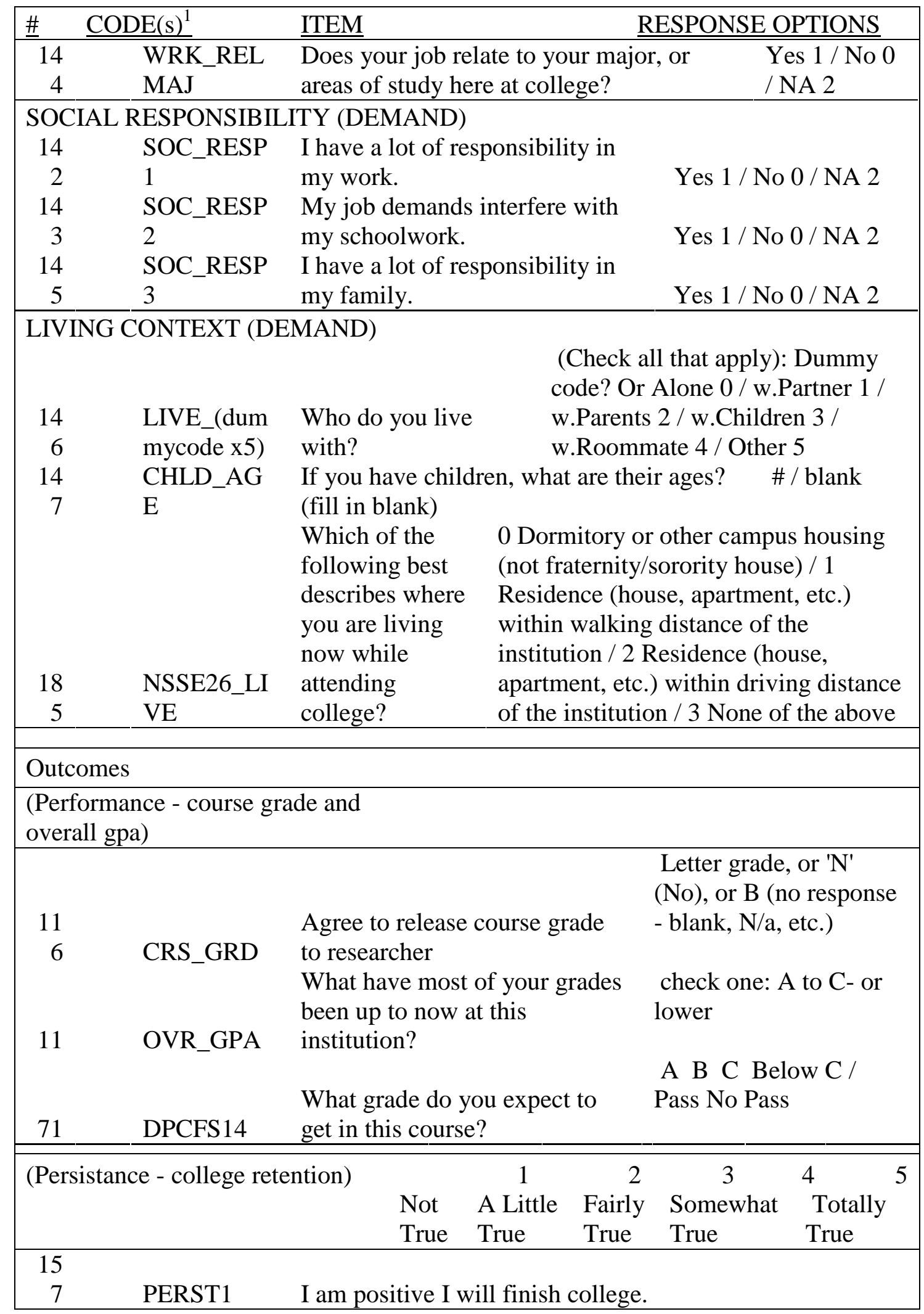


College success and student engagement / 270

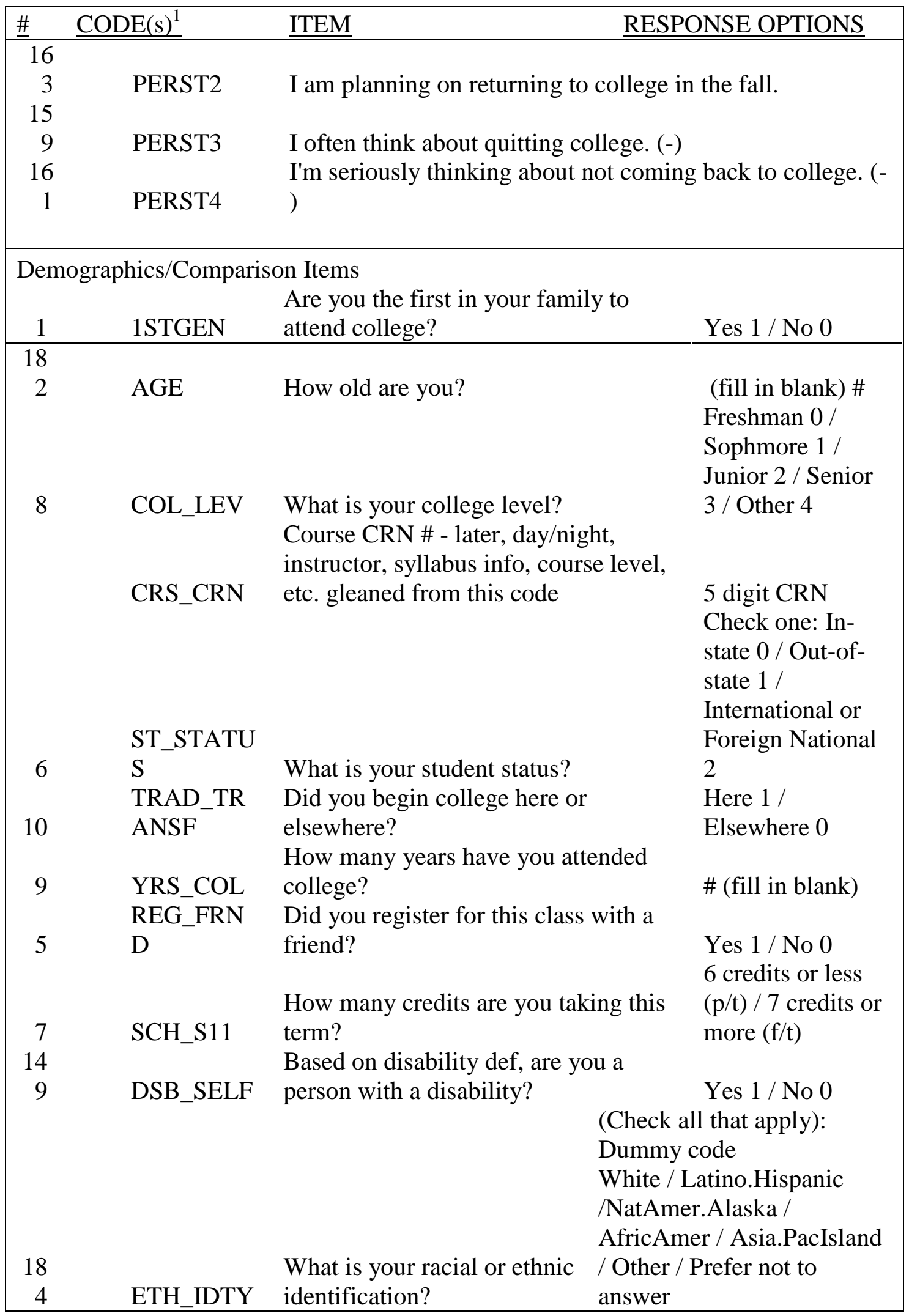


College success and student engagement / 271

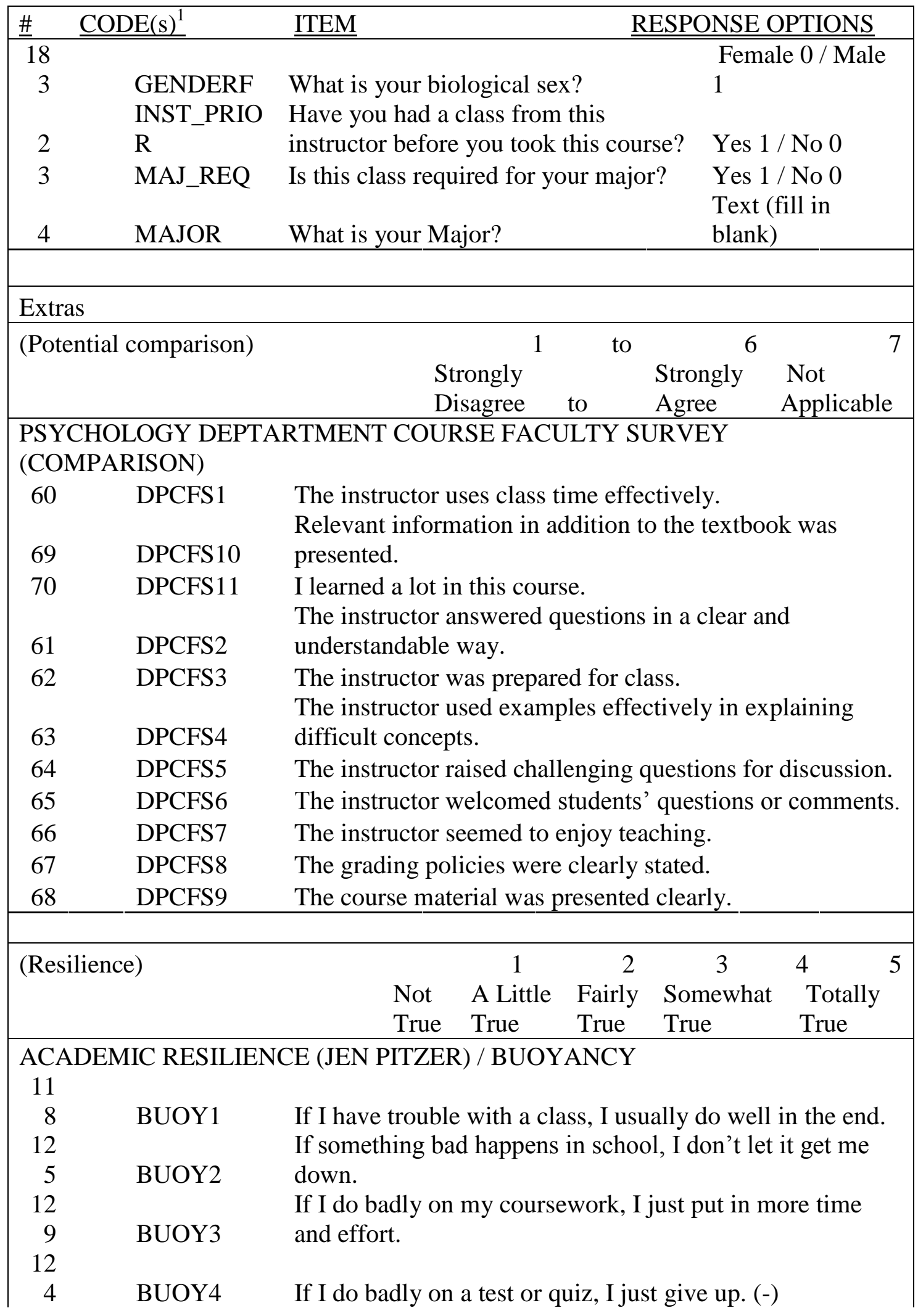


College success and student engagement / 272

\begin{tabular}{|c|c|c|}
\hline \multirow{2}{*}{\multicolumn{3}{|c|}{ RESPONSE OPTIONS }} \\
\hline & \\
\hline 1 & BUOY5 & \multirow{2}{*}{ If a class is really hard, I'll probably do badly in it. (-) } \\
\hline \multicolumn{2}{|l|}{13} & \\
\hline \multicolumn{3}{|r|}{ When I get behind in my coursework, I just don't do it. (-) } \\
\hline \multicolumn{3}{|c|}{ OPEN ENDED (OWN INTERST) } \\
\hline 15 & & What, if anything, interferes with your schoolwork or \\
\hline 5 & OE12 & academic success? \\
\hline 11 & & What really gets you interested and thinking about the \\
\hline 5 & OE8 & material of a class? \\
\hline
\end{tabular}




\section{Appendix E. Scales used in current study.}

Summary of measures/constructs by model.

\begin{tabular}{|c|c|c|c|c|}
\hline Type & Code & Construct & Items & $\begin{array}{l}\text { Sample item / } \\
\text { Responses }\end{array}$ \\
\hline \multicolumn{5}{|c|}{ Micro-Model: Classroom } \\
\hline Scale & $\mathrm{BE}$ & $\begin{array}{l}\text { Behavior } \\
\text { Engagement }\end{array}$ & $\begin{array}{l}12 \text { items, down to } \\
-\end{array}$ & $\begin{array}{l}\text { "I stay current } \\
\text { with the } \\
\text { readings"; "I try } \\
\text { hard to understand } \\
\text { the professor's } \\
\text { lectures" }\end{array}$ \\
\hline Scale & $\mathrm{BD}$ & $\begin{array}{l}\text { Behavior } \\
\text { Disaffection }\end{array}$ & $\begin{array}{l}13 \text { items, down to } \\
-\end{array}$ & $\begin{array}{l}\text { "I don't try very } \\
\text { hard in this class"; } \\
\text { "Anything I do for } \\
\text { this class is } \\
\text { always last } \\
\text { minute" }\end{array}$ \\
\hline Scale & $\mathrm{EE}$ & $\begin{array}{l}\text { Emotional } \\
\text { Engagement }\end{array}$ & $\begin{array}{l}14 \text { items, down to } \\
-\end{array}$ & $\begin{array}{l}\text { "I enjoy the time I } \\
\text { spend in this } \\
\text { class"; "The } \\
\text { material we cover } \\
\text { in class is } \\
\text { challenging (in a } \\
\text { good way)" }\end{array}$ \\
\hline Scale & ED & $\begin{array}{l}\text { Emotional } \\
\text { Disaffection }\end{array}$ & $\begin{array}{l}11 \text { items, down to } \\
-\end{array}$ & $\begin{array}{l}\text { "When in class, I } \\
\text { feel bored"; } \\
\text { "Sitting in class is } \\
\text { a waste of my } \\
\text { time" }\end{array}$ \\
\hline $\begin{array}{l}\text { Constructed } \\
\text { Scale }\end{array}$ & $\mathrm{CE}$ & $\begin{array}{l}\text { Classroom } \\
\text { Engagement }\end{array}$ & \multicolumn{2}{|c|}{$\begin{array}{l}\text { 16-18 items representing full factorial } \\
\text { configuration from the class } \\
\text { engagement scales. }\end{array}$} \\
\hline Scale & $\mathrm{COM}$ & Competence & $\begin{array}{l}6 \text { items }(2009: \mathrm{M} \\
=4.54, \mathrm{SD}=.60 \\
\mathrm{a}=.80)\end{array}$ & $\begin{array}{l}\text { "If I decide to ace } \\
\text { this class, I can"; } \\
\text { "This course is } \\
\text { over my head" }\end{array}$ \\
\hline Scale & AUT & Autonomy & $\begin{array}{l}4 \text { items }(2009: \mathrm{M} \\
=4.44, \mathrm{SD}= \\
.66, \mathrm{a}=.80)\end{array}$ & $\begin{array}{l}\text { "I can apply what } \\
\text { we are learning in } \\
\text { this class to real } \\
\text { life"; "Most of the } \\
\text { material we learn } \\
\text { in this class is }\end{array}$ \\
\hline
\end{tabular}


College success and student engagement / 274

\begin{tabular}{|c|c|c|c|c|}
\hline Type & Code & Construct & Items & $\begin{array}{l}\text { Sample item / } \\
\text { Responses }\end{array}$ \\
\hline & & & & pointless" \\
\hline Scale & REL & Relatedness & 6 items (new) & $\begin{array}{l}\text { "I have a lot in } \\
\text { common with the } \\
\text { other students in } \\
\text { this class"; ("I } \\
\text { don't really } \\
\text { understand where } \\
\text { the other students } \\
\text { in this class are } \\
\text { coming from" }\end{array}$ \\
\hline $\begin{array}{l}\text { Scale / } \\
\text { Higher } \\
\text { order } \\
\text { Factor }{ }^{1}\end{array}$ & CSSP & Classroom SSP's & 3 Scales & COM, AUT, REL \\
\hline Scale & INV & $\begin{array}{l}\text { Instructor } \\
\text { Involvement/Warmt } \\
\mathrm{h}\end{array}$ & $\begin{array}{l}6 \text { items }(2009: \mathrm{M} \\
=3.53, \mathrm{SD}=.71, \\
\mathrm{a}=.73)\end{array}$ & $\begin{array}{l}\text { "This instructor } \\
\text { cares about how I } \\
\text { do in his/her } \\
\text { class"; "This } \\
\text { instructor doesn't } \\
\text { know I exist" }\end{array}$ \\
\hline Scale & STR & Instructor Structure & $\begin{array}{l}6 \text { items }(2009: \mathrm{M} \\
=4.34, \mathrm{SD}=.57, \\
\mathrm{a}=.73)\end{array}$ & $\begin{array}{l}\text { "The assignments } \\
\text { in this class are } \\
\text { clear and } \\
\text { reasonable"; "This } \\
\text { instructor keeps } \\
\text { changing the rules } \\
\text { in class" }\end{array}$ \\
\hline \multicolumn{5}{|c|}{ Micro-Model: Classroom (continued) } \\
\hline Scale & AS & $\begin{array}{l}\text { Instructor Autonomy } \\
\text { Support }\end{array}$ & $\begin{array}{l}6 \text { items }(2009: \mathrm{M} \\
=4.18, \mathrm{SD}=.52, \\
\mathrm{a}=.62)\end{array}$ & $\begin{array}{l}\text { "This instructor } \\
\text { listens to student } \\
\text { ideas"; "This } \\
\text { instructor is bossy } \\
\text { and controlling" }\end{array}$ \\
\hline $\begin{array}{l}\text { Scale / } \\
\text { Higher } \\
\text { order } \\
\text { Factor }^{1}\end{array}$ & CCTX & Classroom Context & 3 Scales & INV, STR, AS \\
\hline
\end{tabular}


College success and student engagement / 275

\begin{tabular}{|c|c|c|c|c|}
\hline Type & Code & Construct & Items & $\begin{array}{l}\text { Sample item / } \\
\text { Responses }\end{array}$ \\
\hline $\begin{array}{l}\text { Confound } \\
\text { Scale }\end{array}$ & $\mathrm{CD}$ & Class Difficulty & 4 items & $\begin{array}{l}\text { "This class } \\
\text { requires a lot of } \\
\text { work"; "This is an } \\
\text { easy class" }\end{array}$ \\
\hline \multicolumn{5}{|c|}{ Macro-Model: University } \\
\hline Scale & UCOM & $\begin{array}{l}\text { University } \\
\text { Competence }\end{array}$ & 6 items (new) & $\begin{array}{l}\text { "I am capable of } \\
\text { being a good } \\
\text { student here at } \\
\text { college"; "I don't } \\
\text { know how to do } \\
\text { well in college" }\end{array}$ \\
\hline Scale & UAUT & $\begin{array}{l}\text { University } \\
\text { Autonomy }\end{array}$ & 6 items (new) & $\begin{array}{l}\text { "What I'm } \\
\text { learning here at } \\
\text { university maps } \\
\text { onto my career } \\
\text { goals" }\end{array}$ \\
\hline Scale & UREL & $\begin{array}{l}\text { University } \\
\text { Relatedness }\end{array}$ & $\begin{array}{l}6 \text { items }(2009: \mathrm{M} \\
=3.80, \mathrm{SD}=.79, \\
\mathrm{a}=.74)\end{array}$ & $\begin{array}{l}\text { "I feel at home } \\
\text { here at (college } \\
\text { name)"; "I don't } \\
\text { really belong in } \\
\text { college" }\end{array}$ \\
\hline $\begin{array}{l}\text { Scale / } \\
\text { Higher } \\
\text { order } \\
\text { Factor }^{1}\end{array}$ & $\mathrm{AI}$ & Academic Identity & 3 Scales & $\begin{array}{l}\text { UCOM, UAUT, } \\
\text { UREL }\end{array}$ \\
\hline \multirow[t]{2}{*}{ Scale } & \multirow[t]{2}{*}{ UE } & $\begin{array}{l}\text { University } \\
\text { Engagement }\end{array}$ & $\begin{array}{l}14 \text { items (NSSE, } \\
\text { Q\#11) (can I } \\
\text { access data \& run } \\
\text { these items for } \\
\text { psychometrics!?! } \\
\text { ) }\end{array}$ & $\begin{array}{l}\text { "Acquiring a } \\
\text { broad general } \\
\text { education"; } \\
\text { "Writing clearly } \\
\text { and effectively" }\end{array}$ \\
\hline & & UE Rescale & $\begin{array}{l}\text { Convert response } \\
\text { scale from } 4 \\
\text { point to } 5 \text { point. }\end{array}$ & \\
\hline Scale & US & University Support & $\begin{array}{l}4 \text { items (NSSE, } \\
\text { Q\#10) }\end{array}$ & $\begin{array}{l}\text { "Helping you } \\
\text { cope with your } \\
\text { responsibilities } \\
\text { (work, family, } \\
\text { etc.)"; "Providing } \\
\text { the support you } \\
\text { need to help you }\end{array}$ \\
\hline
\end{tabular}


College success and student engagement / 276

\begin{tabular}{|c|c|c|c|c|}
\hline Type & Code & Construct & Items & $\begin{array}{l}\text { Sample item / } \\
\text { Responses }\end{array}$ \\
\hline & & & & $\begin{array}{l}\text { succeed } \\
\text { academically" }\end{array}$ \\
\hline \multicolumn{5}{|c|}{ Student Circumstances: Social support \& demands } \\
\hline \multirow[t]{2}{*}{ Scale } & GSSA & $\begin{array}{l}\text { Global Social } \\
\text { Support for } \\
\text { Academics }\end{array}$ & 4 items (new) & $\begin{array}{l}\text { "If something is } \\
\text { going on at } \\
\text { school, I have } \\
\text { someone I can } \\
\text { talk to about it"; } \\
\text { "Important people } \\
\text { in my life don't } \\
\text { get the whole } \\
\text { 'going to college' } \\
\text { thing" }\end{array}$ \\
\hline & & US Rescale & $\begin{array}{l}\text { Convert response } \\
\text { scale from } 4 \\
\text { point to } 5 \text { point. }\end{array}$ & \\
\hline Item & $\mathrm{DSCH}$ & School Demand & $\begin{array}{l}1 \text { item, } 2 \text { levels: } \\
\text { Credit Hours }\end{array}$ & $\begin{array}{l}6 \text { or less, } 7+(\mathrm{PT}, \\
\text { FT) }\end{array}$ \\
\hline \multirow[b]{2}{*}{ Item } & WRK & Work Demand & $\begin{array}{l}1 \text { item, } 5 \text { levels: } \\
\text { Avg. Work Hours } \\
\text { per Week }\end{array}$ & $\begin{array}{l}\text { Demand: Avg wk } \\
\text { hrs worked =0, 1- } \\
14,15-25,26-32 \text {, } \\
32+\end{array}$ \\
\hline & DWRK & WRK Rescale & $\begin{array}{l}\text { Convert to } 3 \\
\text { levels }\end{array}$ & $\begin{array}{l}\text { None }(0), \text { part- } \\
\text { time }(1, \mathrm{PT}=1-25 \\
\text { hours), and full- } \\
\text { time ( } 2, \mathrm{FT}=26+ \\
\text { hours) }\end{array}$ \\
\hline \multirow[t]{2}{*}{ Item } & $\begin{array}{l}\text { DFAM } \\
\mathrm{o}\end{array}$ & Family Demand & $\begin{array}{l}1 \text { item: Who do } \\
\text { yo live with? }\end{array}$ & $\begin{array}{l}\text { Check all that } \\
\text { apply: Alone } 0 \text { / } \\
\text { w.Partner 1 / } \\
\text { w.Parents 2 / } \\
\text { w.Children } 3 \text { / } \\
\text { w.Roommate } 4 \text { / } \\
\text { Other } 5\end{array}$ \\
\hline & DFAM & DFAM Rescale & $\begin{array}{l}\text { Convert to } 3 \\
\text { levels }\end{array}$ & $\begin{array}{l}\text { None (0), part- } \\
\text { time ( } 1, \mathrm{PT}=1-25 \\
\text { hours), and full- }\end{array}$ \\
\hline
\end{tabular}


College success and student engagement / 277

\begin{tabular}{|c|c|c|c|c|}
\hline Type & Code & Construct & Items & $\begin{array}{l}\text { Sample item / } \\
\text { Responses }\end{array}$ \\
\hline & & & & $\begin{array}{l}\text { time }(2, \mathrm{FT}=26+ \\
\text { hours })\end{array}$ \\
\hline \multirow[t]{2}{*}{ Item } & DFINo & Financial Demand & $\begin{array}{l}4 \text { items, } 2 \text { levels: } \\
\text { Yes, No }\end{array}$ & $\begin{array}{l}\text { loans, other } \\
\text { (parents), } \\
\text { grant/scholarship } \\
\text { application, and } \\
\text { grant/scholarship } \\
\text { receipt }\end{array}$ \\
\hline & DFIN & DFINo Recode & 1 item: Yes, No & Receive \$, No \\
\hline Scale & DSRo & Social Responsibility & 3 items (new) & $\begin{array}{l}\text { "I have a lot of } \\
\text { responsibility in } \\
\text { my family[work]" } \\
\text {; "My job } \\
\text { demands interfere } \\
\text { with my } \\
\text { schoolwork" }\end{array}$ \\
\hline Item & DSR & DSRo Recode & $\begin{array}{l}1 \text { item, } 3 \text { levels: } \\
\text { Social } \\
\text { Responsibility }\end{array}$ & $\begin{array}{l}\text { none, one of two } \\
\text { areas, } 2 \text { of } 2 \text {, all }\end{array}$ \\
\hline Item & CDMD & Cumulative Demand & $\begin{array}{l}1 \text { item } \\
\text { constructed from } \\
5 \text { demands }\end{array}$ & $\begin{array}{l}\text { Level range from } \\
2 \text { (very low) to } 18 \\
\text { (very high) } \\
\text { demand }\end{array}$ \\
\hline \multicolumn{5}{|l|}{ Outcomes } \\
\hline Outcome & GPA & Overall GPA & \multicolumn{2}{|c|}{1 item: Overall GPA as of survey date } \\
\hline Outcome & ECG & $\begin{array}{l}\text { Expected Course } \\
\text { Grade }\end{array}$ & \multicolumn{2}{|c|}{1 item: Expected Grade } \\
\hline $\begin{array}{l}\text { Outcome } \\
\text { Subset }\end{array}$ & CG & $\begin{array}{l}\text { ACTUAL Course } \\
\text { Grade }\end{array}$ & $\begin{array}{l}1 \text { item: Actual } \\
\text { Grade }\end{array}$ & $\begin{array}{l}\text { (subset - could } \\
\text { estimate) }\end{array}$ \\
\hline \multirow{2}{*}{$\begin{array}{l}\text { Outcome - } \\
\text { Scale }\end{array}$} & PRS & Persistence & 4 items (new) & $\begin{array}{l}\text { "I am positive I } \\
\text { will finish } \\
\text { college"; "I often } \\
\text { think about } \\
\text { quitting college" }\end{array}$ \\
\hline & & Outcome Scale fix & \multicolumn{2}{|c|}{$\begin{array}{l}\text { Match 'return next term' item to } \\
\text { 'seniors', remove item from their } \\
\text { 'persistence' score, rescale to reflect } \\
\text { one less item. }\end{array}$} \\
\hline
\end{tabular}


College success and student engagement / 278

\begin{tabular}{|c|c|c|c|c|c|}
\hline Type & Code & Construct & & Items & $\begin{array}{l}\text { Sample item / } \\
\text { Responses }\end{array}$ \\
\hline $\begin{array}{l}\text { Compariso } \\
\text { n Item }\end{array}$ & SEX & \multicolumn{3}{|c|}{$\begin{array}{ll}\text { Demographics } & \begin{array}{l}1 \text { item, } 2 \text { levels: } \\
\text { Gender }\end{array} \\
\end{array}$} & Female, Male \\
\hline $\begin{array}{l}\text { Compariso } \\
\text { n Item }\end{array}$ & $\begin{array}{l}\text { DIS_S } \\
\mathrm{O}\end{array}$ & \multicolumn{2}{|c|}{ Demographics } & $\begin{array}{l}1 \text { item, } 2 \text { levels: } \\
\text { Disability (Self, } \\
\text { Other) }\end{array}$ & Yes, No \\
\hline \multicolumn{6}{|c|}{ Demographics, categories, and possible comparison groups (continued) } \\
\hline $\begin{array}{l}\text { Compariso } \\
\text { n Item }\end{array}$ & $\mathrm{PC}$ & Demographics & \multicolumn{2}{|c|}{$\begin{array}{l}1 \text { item, } 2 \text { levels: } \\
\text { Parental Care }\end{array}$} & Yes, No \\
\hline \multirow{2}{*}{$\begin{array}{l}\text { Compariso } \\
\text { n Item }\end{array}$} & CHDo & Demographics & \multicolumn{2}{|c|}{$\begin{array}{l}\text { Number Child(ren) } \\
\text { living with }\end{array}$} & Open ended, numeric \\
\hline & $\mathrm{CHD}$ & CHDo Recode & \multicolumn{3}{|c|}{1 item: Yes, No $\quad$ Yes, No } \\
\hline $\begin{array}{l}\text { Compariso } \\
\text { n Item }\end{array}$ & CONG & Demographics & \multicolumn{2}{|c|}{$\begin{array}{l}1 \text { item, } 2 \text { levels: } \\
\text { Job related to } \\
\text { course of Study }\end{array}$} & Yes, No \\
\hline $\begin{array}{l}\text { Compariso } \\
\text { n Item }\end{array}$ & AGE & Demographics & \multicolumn{2}{|c|}{1 item: Age } & Open ended, numeric \\
\hline $\begin{array}{l}\text { Compariso } \\
\text { n Item }\end{array}$ & REQ & Demographics & \multicolumn{2}{|c|}{$\begin{array}{l}1 \text { item, } 2 \text { levels: } \\
\text { Course Required } \\
\text { for Major } \\
\end{array}$} & Yes, No \\
\hline $\begin{array}{l}\text { Comparison } \\
\text { Item }\end{array}$ & CL & Course Level & \multicolumn{2}{|c|}{1 item, 3 levels } & $200,300,400$ \\
\hline $\begin{array}{l}\text { Comparison } \\
\text { Item }\end{array}$ & CT & Course Time & \multicolumn{2}{|c|}{1 item, 2 levels } & lay, night \\
\hline $\begin{array}{l}\text { Comparison } \\
\text { Item }\end{array}$ & SS1 & Student Status & \multicolumn{2}{|c|}{$\begin{array}{l}1 \text { item, } 2 \text { levels: } \\
\text { Generational }\end{array}$} & $\begin{array}{l}\text { irst-generation student: } \\
\text { Yes, No }\end{array}$ \\
\hline $\begin{array}{l}\text { Comparison } \\
\text { Item }\end{array}$ & SS2 & Student Status & \multicolumn{2}{|c|}{$\begin{array}{l}1 \text { item, } 2 \text { levels: } \\
\text { International }\end{array}$} & $\begin{array}{l}\text { nternational Student: } \\
\text { Yes, No }\end{array}$ \\
\hline $\begin{array}{l}\text { Comparison } \\
\text { Item }\end{array}$ & SS3 & Student Status & \multicolumn{2}{|c|}{$\begin{array}{l}1 \text { item, } 2 \text { levels: } \\
\text { Returning }\end{array}$} & $\begin{array}{l}\text { Returning Student: Yes, } \\
\text { No }\end{array}$ \\
\hline \multirow[t]{2}{*}{$\begin{array}{l}\text { Comparison } \\
\text { Item }\end{array}$} & SS4o & Student Status & \multicolumn{2}{|c|}{$\begin{array}{l}1 \text { item,Ethnic } \\
\text { Identification }\end{array}$} & $\begin{array}{l}\text { All that apply: } \\
\text { Latino/Hispanic, Native } \\
\text { American/Alaskan } \\
\text { Native, White, African } \\
\text { American, Asian, Pacific } \\
\text { slander, Other, Prefer } \\
\text { oot to answer }\end{array}$ \\
\hline & SS4 & SS4o Recode & & Race/ & e/Ethnicity: Yes, No \\
\hline
\end{tabular}

